\title{
Variabilidade populacional em manguezais: análises moleculares e morfológicas em caranguejos Brachyura (Crustacea: Decapoda)
}

\section{Raquel Corrêa Buranelli}
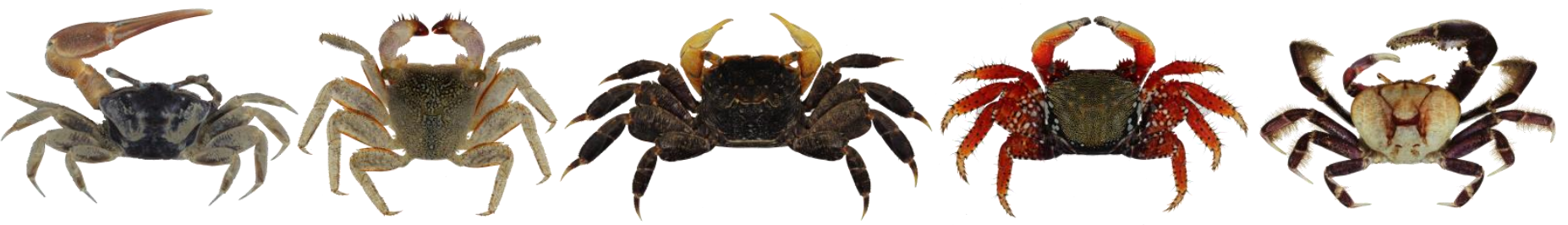

Tese apresentada à Faculdade de Filosofia, Ciências e Letras de Ribeirão Preto - USP, como parte das exigências para a obtenção do título de Doutor em Ciências, Área: Biologia Comparada 


\title{
Variabilidade populacional em manguezais: análises moleculares e morfológicas em caranguejos Brachyura (Crustacea: Decapoda)
}

\author{
Raquel Corrêa Buranelli
}

Orientador: Prof. Dr. Fernando L. M. Mantelatto

Tese apresentada à Faculdade de Filosofia, Ciências e Letras de Ribeirão Preto - USP, como parte das exigências para a obtenção do título de Doutor em Ciências, Área: Biologia Comparada 
Autorizo a reprodução e divulgação total ou parcial deste trabalho, por qualquer meio convencional ou eletrônico, para fins de estudo e pesquisa, desde que citada a fonte.

Buranelli, Raquel Corrêa

Variabilidade populacional em manguezais: análises moleculares e morfológicas em caranguejos Brachyura (Crustacea: Decapoda).

Ribeirão Preto, 2016.

$$
\mathrm{v}+188 \mathrm{p}
$$

Tese (Doutorado - Programa de Pós-Graduação em Ciências. Área de concentração: Biologia Comparada) - Faculdade de Filosofia, Ciências e Letras de Ribeirão Preto da Universidade de São Paulo.

Orientador: Fernando Luis Medina Mantelatto

$\begin{array}{llll}\text { 1. Estrutura populacional } & \text { 2. Citocromo Oxidase I } & 3 \text {. Diversidade genética } & 4 \text {. Conservação }\end{array}$ 
"That day, I learned life and death are always so mixed up together, in the same way some beginnings are endings, and some endings become beginnings."

- Capheus "Van Damme"

(Sense8) 
Agradeço imensamente ao meu orientador, Prof. Dr. Fernando L. M. Mantelatto, pela oportunidade concedida em integrar o Laboratório de Bioecologia e Sistemática de Crustáceos (LBSC) há quase sete anos e por todos esses anos de orientação, confiança, incentivo, auxílios, inúmeras oportunidades, apoio e amizade. Agradeço, inclusive, pelo oferecimento da ideia precursora deste projeto e de todas as facilidades e condições para o seu pleno desenvolvimento.

Agradeço à Fundação de Amparo à Pesquisa do Estado de São Paulo (FAPESP) pelo suporte financeiro concedido durante todo o desenvolvimento desse trabalho, por meio da concessão de bolsa de Doutorado Direto (Processo 2012/06299-5) e bolsa BEPE (Bolsa de Estágio e Pesquisa no Exterior) (Processo 2014/11659-6). Agradeço ainda aos Projetos concedidos ao Laboratório de Bioecologia e Sistemática de Crustáceos (LBSC), sob a coordenação do Prof. Dr. Fernando Mantelatto, e que proporcionaram os suportes logístico e financeiro para a execução deste trabalho: Temático BIOTA - FAPESP (processo 2010/50188-8), CNPQ (processos 301359/2007-5; 473050/2007-2; 471011/2011-8), CAPES Edital Ciências do Mar II - (processo 2005/2014 - 23038.004308/2014-14).

Ao Dr. Darryl L. Felder pela recepção em seu laboratório durante o período de doutorado sanduíche e pelo auxílio na visita às coleções durante o período e ao Departamento de Biologia da University of Louisiana at Lafayette, por toda infraestrutura concedida durante o estágio. Agradeço ainda aos colegas do Laboratory for Crustacean Research, Brent Thoma, Simon Pecnik, Claire Steward, Justin Scioli, Alexandra Olivier, Andy Savage e, principalmente, a Catherine Craig, pela recepção, ajuda e amizade.

Agradeço a Universidade de São Paulo e à Faculdade de Filosofia, Ciências e Letras de Ribeirão Preto e ao Departamento de Biologia e todos os funcionários pelo apoio prestado, pela infra-estrutura e auxílio durante todo o desenvolvimento desse projeto. Ao Programa de 
Pós-graduação em Biologia Comparada pela infra-estrutura acadêmica e à secretária Vera Cassia Cicilini de Lucca pela solicitude e paciência durante esses anos.

Agradeço a todos aqueles que auxiliaram na obtenção de toda a coleção de espécimes, imprescindível para execução desse projeto, seja por meio de coletas ou doação de animais e também pelo auxílio na devolução dos espécimes: Abner Carvalho, Adriana Rebolledo, Edvanda Souza Carvalho, Fabrício Carvalho, Felipe Ribeiro Bezerra, Fernando Mantelatto, Leonardo Pileggi, Luigi Pavoni Cerantola, Mariana Negri, Mariana Terossi, Mateus Lopes, Murilo Zanetti Marochi, Paula Chaves e Rafael Robles. Agradeço ao técnico Álvaro da Silva Costa pelo apoio nas atividades de campo.

Agradeço aos curadores e pesquisadores que contribuíram com empréstimos e/ou doações de espécimes: Alexandre Almeida (UFPE), Darryl L. Felder (ULLZ), Fernando Alvarez (CNCR), Fernando Abrunhosa (UFPA), Fernando Mantelatto (CCDB), Gustav Paulay (FMNH - UF), Irene Cardoso (MNRJ), Ingo Wehrtmann (UCR), Jose Luis Villalobos (CNCR), Luis Ernesto Bezerra (UFERSA), Marcos Tavares (MZUSP), Paul Callomon (ANSP) e Rafael Lemaitre (USNM). Agradeço, ainda, a todos os técnicos pela ajuda prestada durante as visitas às coleções: John Splapcinsky (FMNH - UF), Joana Darc (MZUSP), Karen Reed (USNM), Mauro Cardoso (MZUSP) e Rita Vargas (UCR).

Agradeço ao Centro de Recursos Biológicos e Biologia Genômica (CREBIO) do Departamento de Tecnologia da Faculdade de Ciências Agrárias e Veterinárias (FCAV) de Jaboticabal, da Universidade Estadual Paulista (UNESP), pelos serviços prestados com as etapas de sequenciamento.

Agradeço a todos àqueles que contribuíram para o desenvolvimento desse projeto, com sugestões de ideias e trabalhos e auxílios na obtenção dos dados e análises: Ana Luiza Vera, Ana Francisca Tamburus Gomes, Caio Cruz de Oliveira, Edvanda Souza Carvalho, Luis Ernesto Bezerra, Fabrício Carvalho, Mariana Negri, Mariana Terossi, Rafael Robles, Sabrina 
Simões, Silvia Mandai e Tatiana Magalhães. Agradeço a Mayara Miyazaki por todo suporte técnico na molecular.

Agradeço imensamente a todos os ex colegas do LBSC, por toda ajuda prestada e por todos esses anos de convivência e companheirismo. Agradeço aos atuais membros, pelos auxílios e amizade: Ana, Caio, Jéferson, Kana, Keity, Kelps, Kim, Mayara, Meri, Natália, Rafa, Silvia, Susana, Tati e Vanda. Agradeço, também, aos membros esporádicos, mas que sempre retornam: Abner, Sabrina e Sarah.

Às queridas Meri e Kana, em especial, não somente por toda ajuda durante a execução desse projeto em uma extensa lista de dúvidas e auxílios, mas, principalmente, pela amizade, apoio, desabafos, comilanças e alegrias fundamentais durante todos esses anos.

Agradeço à minha família, especialmente a meus pais, pelo apoio e por estarem sempre presentes durante esses anos. Agradeço, principalmente, por não terem simplesmente desistido neste último ano, encontrando força e esperança nas coisas mais simples da vida, sendo, para mim, exemplos de superação. Ainda, agradeço ao meu irmão Vinícius, por ter tido orgulho de mim e por ter deixado em mim muito mais do que saudades.

Agradeço ao meu amor e companheiro Luigi, não somente pelo seu carinho, mas também pelo seu apoio incondicional e fundamental, independentemente de quais fossem minhas escolhas. Agradeço, inclusive pela ajuda direta na execução desse projeto, mas, principalmente, pela atenção, preocupação, paciência, compreensão e pelo seu otimismo e alegria contagiantes, mesmo nos piores momentos.

A todos que de forma direta ou indireta contribuíram para a concretização deste trabalho. 


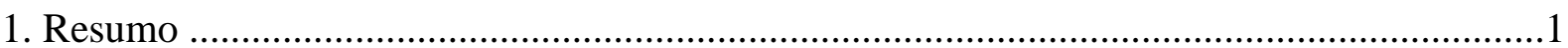

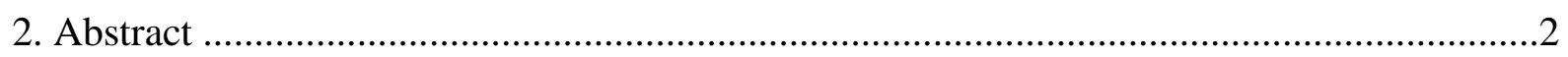

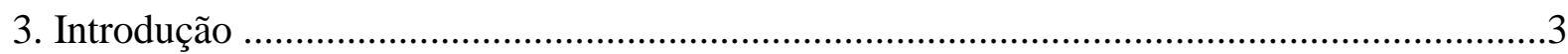

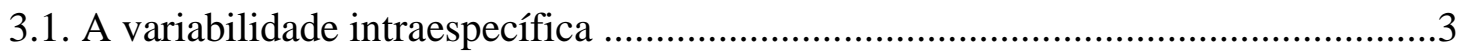

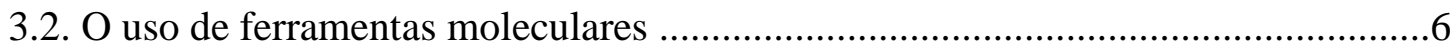

3.3. A dispersão larval e o fluxo gênico ................................................................

3.4. O ecossistema de manguezais e os caranguejos ................................................11

3.5. Caracterização das espécies alvo ................................................................. 15

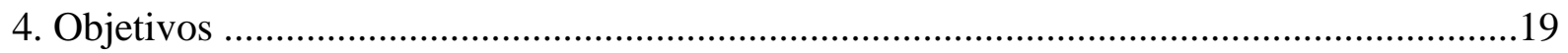

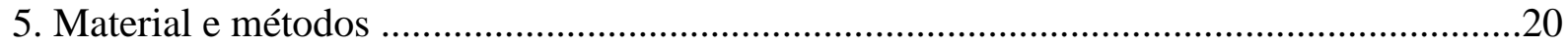

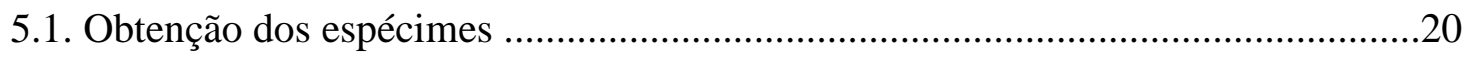

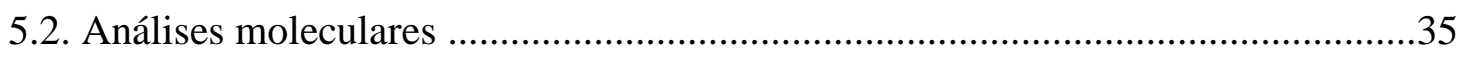

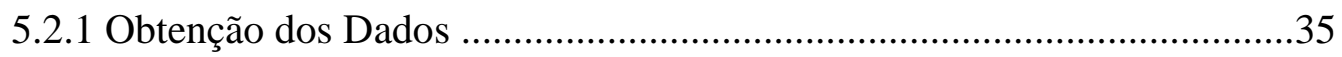

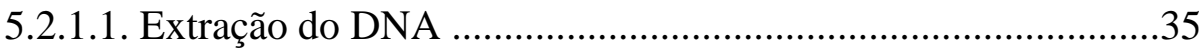

5.2.1.2. Amplificação dos genes .........................................................36

5.2.1.3. Purificação e amplificação dos produtos da PCR ....................39

5.2.1.4. Precipitação e sequenciamento do DNA .................................40

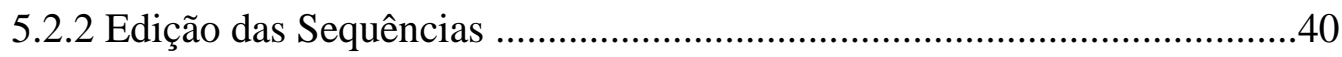

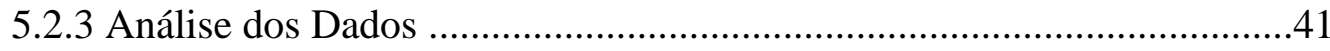

5.2.3.1. Análises de variação genética ................................................41

5.2.3.2. Análises filogenéticas .............................................................42

5.2.3.3. Análises de distância genética .............................................43

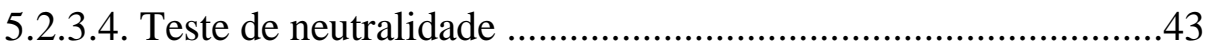




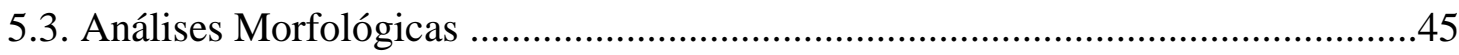

5.3.1 Variabilidade Morfológica Comparativa .............................................45

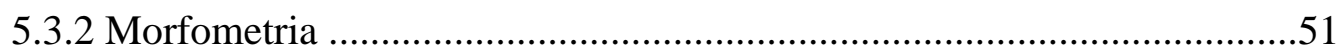

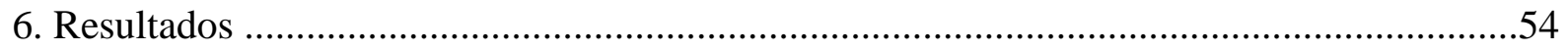

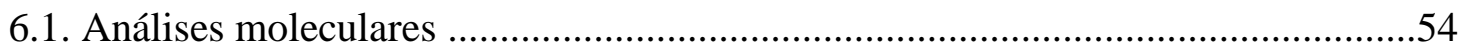

6.1.1. Espécies com Elevada Estruturação Populacional .................................55

6.1.2. Espécies com Ausência de Estruturação Populacional ..........................76

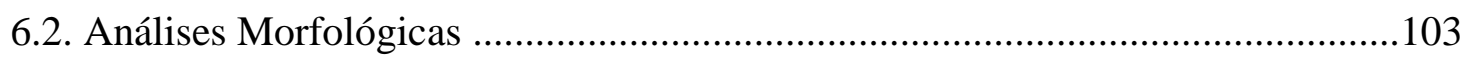

6.2.1. Variabilidade Morfológica Comparativa ...........................................103

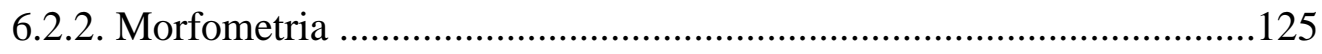

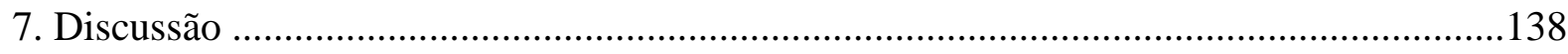

7.1. Os diferentes padrões de estruturação populacional .......................................140

7.2. Fatores bióticos e abióticos associados à estruturação populacional ...................145

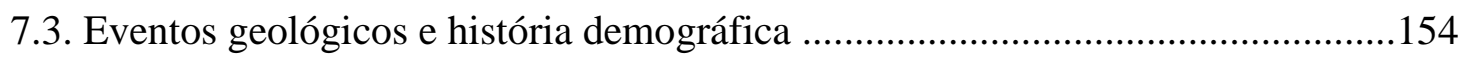

7.4. A biologia molecular na genética da conservação .............................................160

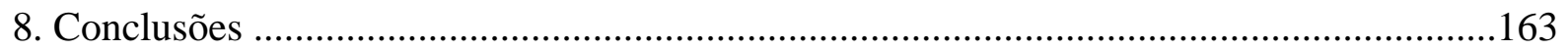

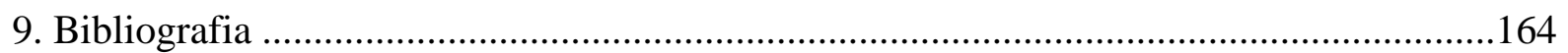




\section{RESUMO}




\section{RESUMO}

A análise da estruturação populacional de espécies codistribuídas permite a comparação de padrões de estruturação, fornecendo informações acerca dos fatores que influenciam a diferenciação em espécies pertencentes ao mesmo ecossistema. Este projeto teve como objetivo principal analisar a variabilidade intraespecífica em caranguejos habitantes de manguezais, codistribuídos ao longo do Oceano Atlântico Ocidental, por meio de ferramentas moleculares e morfológicas, visando testar a hipótese de elevada estruturação populacional em manguezais. Para este fim, cinco espécies foram utilizadas como modelo (Aratus pisonii, Goniopsis cruentata, Sesarma rectum, Uca thayeri e Ucides cordatus) e avaliadas por meio de marcadores mitocondriais COI e 16S e nuclear H3 e análises morfológicas comparativas e de morfometria. Os dados moleculares revelaram dois padrões, indicando elevada estruturação populacional para as espécies A. pisonii e U. thayeri e ausência de estruturação para G. cruentata, S. rectum e U. cordatus. Os dados morfológicos, no entanto, não acompanham esses padrões, já que não foram encontradas diferenças morfológicas ou morfométricas associadas aos grupos evidenciados pelas análises moleculares. A ausência de fluxo gênico entre regiões para algumas espécies deve-se, muito provavelmente, à existência de fatores que não se limitam ao isolamento por distância, mas também devido a diferenças na duração do estágio larval e a diferenças bruscas em alguns fatores abióticos, como a salinidade, por exemplo, que, associados às diferentes características do desenvolvimento larval de cada espécie, culminam na existência de estruturas populacionais diferentes. Além disso, os padrões de diferenciação genética observados concordam com os cenários biogeográficos propostos para o Atlântico Ocidental, no qual mudanças e flutuações geológicas, climáticas e oceanográficas, resultantes do fechamento do Istmo do Panamá e de ciclos glaciais na América do Norte, promoveram divergência genética. 
ABSTRACT 


\section{AbSTRACT}

The analysis of population structure of codistributed species allows the comparison of patterns of population structuring, providing information on the factors that influence the differentiation in species belonging to the same ecosystem. This project aimed to analyze the intraspecific variability of crabs inhabiting mangroves, codistributed along the western Atlantic Ocean, by means of molecular and morphological tools, in order to test the hypothesis of high populational structure in mangroves. The genetic variability of five species used as models (Aratus pisonii, Goniopsis cruentata, Sesarma rectum, Uca thayeri and Ucides cordatus) was assessed using the mitochondrial genes COI and 16S and the nuclear H3 and comparative morphological analysis and morphometry were performed. The molecular data revealed two patterns, indicating high population structure for the species $A$. pisonii and $U$. thayeri and absence of structure for G. cruentata, S. rectum and U. cordatus. The morphological data, however, do not follow these patterns, because there were no morphological or morphometric differences associated with the groups evidenced by the molecular analyzes. Possibly the absence of gene flow between regions for some species is due to factors not limited to isolation by distance, but also because of differences in the larval stage duration and in withstanding some abiotic factors, such as salinity. These factors associated with different characteristics of larval development can culminate in differences on population structure. In addition, the genetic differentiation patterns observed agree with biogeographical scenarios proposed for the western Atlantic, where geological, climate and oceanographic fluctuations, resulting from the Isthmus of Panama closure and cyclical glaciation in North America, promoted genetic divergence. 


\section{INTRODUCCÃO}




\section{INTRODUÇÃO}

\subsection{A VARIABILIDADE INTRAESPECÍFICA}

Sabe-se que a grande diversidade de espécies existentes constitui o resultado de processos evolutivos que levaram à diferenciação populacional e à especiação (Wilson, 1988). A diferenciação populacional, por sua vez, está intimamente relacionada à existência de impedimentos extrínsecos de fluxo gênico dentro de uma espécie, o que constitui prérequisitos para a ocorrência de divergência genética e para a eventual evolução de barreiras intrínsecas de isolamento (Avise, 2000).

A importância do fluxo gênico como um fator de prevenção de processos de especiação relaciona-se à faculdade de endocruzamento (Slatkin, 1987). Considerando que a seleção natural tende a adaptar a população às condições ambientais locais, a introdução de genes adaptados a outras condições por meio do fluxo de migrantes impede a evolução independente das populações e, eventualmente, a formação de espécies distintas (Slatkin, 1987). No entanto, o fluxo gênico não depende somente da troca de migrantes, mas, talvez, o sucesso de sua ocorrência esteja também intimamente relacionado ao fitness do migrante e se ele sobrevive à reprodução, fatos que, por sua vez, dependem da variabilidade espacial e temporal do ambiente (Scheltema, 1975; Burton, 1983; Hegdcock, 1986). Assim, a formação de uma espécie ou, ao menos, a diferenciação entre suas populações, está associada à interrupção do fluxo gênico, integrado também a outros processos, tais como a evolução de mecanismos de isolamento reprodutivo e, consequentemente, ao acúmulo de diferenças morfológicas e comportamentais (Oliveira, 2014).

A interrupção do fluxo gênico está normalmente associada à existência de barreiras geográficas ou fisiológicas que favorecem, então, a diferenciação e estruturação de populações, bem como o isolamento das mesmas e, consequentemente, a formação de raças e 
os processos de especiação (Kimura \& Weiss, 1964; Avise, 2000). No entanto, mesmo quando essas barreiras não existem, o tamanho da área habitada por uma espécie, em comparação com a distância de migração dos indivíduos, pode prever que as espécies não formem uma unidade panmítica única, produzindo um tipo de isolamento denominado isolamento por distância ou geográfico (Wright, 1943). Nesse modelo, a população é distribuída uniformemente em um vasto território, mas a geração parental de qualquer indivíduo dessa população é originária de uma área muito próxima (Wright, 1943; Kimura \& Weiss, 1964).

O isolamento por distância pode interferir significativamente na diferenciação genética, uma vez que os padrões de diferenciação baseiam-se na magnitude da taxa de migração entre as populações (Hellberg et al., 2002). Considerando a área habitada por uma espécie, suas populações podem apresentar uma redução gradual na similaridade genética com o aumento da distância geográfica, devido a uma restrição significativa da dispersão, caracterizando um fluxo gênico do tipo stepping-stone (Kimura \& Weiss, 1964; Hellberg et al., 2002). A situação mais simples para esse modelo de fluxo gênico indica que, em cada geração, um indivíduo pode migrar no máximo um passo em ambas as direções entre as populações (Kimura \& Weiss, 1964). Em outras palavras, a migração e, portanto, o fluxo gênico ocorrem primariamente entre populações vizinhas, de forma que as populações distantes sejam conectadas por populações intermediárias, ou stepping-stones (Kimura \& Weiss, 1964; Hellberg et al., 2002; Ituarte et al., 2012). Assim, as estimativas de fluxo gênico para populações sofrendo processos de stepping-stone são altas entre populações mais próximas e reduzidas entre populações distantes (Hellberg et al., 2002).

Considerando que o grau de diferenciação genética entre as populações pode ser utilizado como um índice da quantidade de migração (Waples, 1987), o modelo steppingstones de fluxo gênico pode ser relevante na compreensão e avaliação da divergência genética 
em espécies que apresentem distribuições amplas e contínuas e, concomitantemente, daquelas típicas de hábitats discretos e isolados uns dos outros por barreiras à dispersão principalmente estabelecidas por tolerância fisiológica, como manguezais, estuários e rios (Keenan, 1994; Bilton et al., 2002). Ao longo de extensas áreas geográficas, além da distância propriamente dita, variações climáticas e ambientais e a presença de barreiras geográficas e/ou fisológicas são inevitáveis (Gopurenko \& Hughes, 2002; Laurenzano et al., 2012), portanto o isolamento por distância e, consequentemente, a redução do fluxo gênico entre áreas mais distantes tornam-se significativamente prováveis. Assim, a avaliação do distanciamento genético e, por conseguinte, da magnitude do fluxo gênico entre populações pode ser, então, realizada por meio de estudos sobre variabilidade intraespecífica.

No entanto, a interpretação da variação deve ser associada a outros processos evolutivos, uma vez que a divergência genética constitui o resultado de processos intricados, não sendo somente explicada por dispersão e fluxo gênico. A quantidade de variação depende da intensidade da seleção natural e do fluxo gênico como fatores adicionador e redutor de variabilidade, respectivamente (Scheltema, 1975). Assim, as populações que tendem a divergir geneticamente, por meio de processos como seleção ou deriva, sofrem oposição de efeitos homogeneizadores por meio do fluxo gênico (Scheltema, 1975; Waples, 1987). Dessa forma, a diferenciação genética entre populações reflete um balanço dinâmico entre as forças de deriva genética, fluxo gênico, seleção e mutação (Bohonak, 1999; Bilodeau et al., 2005), que devem ser igualmente considerados na interpretação das análises de variabilidade intraespecífica, contribuindo para uma maior compreensão acerca dos modelos de processos de especiação e de diferenciação populacional (Bohonak, 1999).

A investigação sobre a variabilidade intraespecífica permite inferir a existência de fluxo gênico entre populações em diferentes escalas de distância geográfica e que seja interpretado o grau de diferenças entre populações e a descontinuidade ou não entre elas, 
demonstrando se as populações de uma espécie estão organizadas estruturalmente (Mayr, 1977; Benzie, 1998). Adicionalmente, como as diferenças genéticas fornecem material para a seleção natural, análises de diferenciação genética podem indicar o potencial para adaptação local de uma população ou uma futura especiação, além de contribuir para uma maior compreensão acerca dos modelos de processos de especiação e de diferenciação populacional (Bohonak, 1999).

\subsection{O USO DE FERRAMENTAS MOLECULARES}

Atualmente, o aumento do número de ferramentas para o estudo sobre variabilidade genética tem revelado uma grande variedade de padrões de fluxo gênico (Oliveira-Neto et al., 2007b) e estudos sobre variabilidade intraespecífica têm permitido o refinamento do status taxonômico de algumas espécies (e.g., McLay et al., 2011; Negri et al., 2012; Tourinho et al., 2012), redefinições da distribuição geográfica de outras (e.g., Vergamini et al., 2011; Rossi \& Mantelatto, 2013), a quantificação da diversidade genética (e.g., Santos et al., 2003; Terossi \& Mantelatto, 2012; Oliveira, 2014) e têm proporcionado o planejamento de estratégias de conservação (e.g., Schubart \& Huber, 2006; Weese et al., 2012).

Dentro de um contexto conservacionista, técnicas moleculares têm sido aplicadas com sucesso em estudos sobre diferenciação genética populacional no apoio às questões de manejo (Begg et al., 1999; Benzie, 2000). Avaliações da estrutura e diversidade genética intraespecífica fornecem informações de estoque genético, medida essencial para o estabelecimento de estratégias de manejo, propósitos de aquicultura e no sucesso na conservação de espécies exploradas (Begg et al., 1999; McMillen-Jackson \& Bert, 2004; Schubart \& Huber, 2006). Além disso, esses modelos de estudo revelam quais áreas geográficas abrigam a maior diversidade genética dentro da população de uma determinada espécie, permitindo que sejam designados centros de prioridade de conservação de espécies 
(Schubart \& Huber, 2006). Estratégias de manejo e de gestão são frequentemente concebidas para que níveis máximos de diversidade genética sejam mantidos entre as populações, já que se é possível assumir que populações com estoque de variação genética possuem maiores probabilidades de incluir genótipos capazes de suportar mudanças ambientais extremas (Mayr, 1977; Schubart \& Huber, 2006).

A perda da variabilidade genética pode ser considerada com um tópico central da genética da conservação (Avise, 1994) que prevê, ainda, a preservação das espécies como entidades dinâmicas capazes de se adaptarem as mudanças ambientais (Frankham et al., 2008). Áreas fragmentadas e, portanto, submetidas a efeitos negativos, tais como o gargalo populacional, abrigam populações pequenas, propensas à depressão endogâmica e à consequente prevalência de alelos deletérios recessivos, diminuindo o valor adaptativo da população em um curto espaço de tempo (Frankham, 1995; Frankham et al., 2008; Zucchi, 2002). O declínio da variação genética pode inibir a adaptação do organismo às mudanças ambientais e consequentemente limitar seu potencial evolutivo, podendo levar essas populações a um possível risco de extinção (Schubart \& Huber 2006; Frankham et al., 2008). Assim, a importância do fluxo gênico principalmente em populações naturais está na homogeneização das frequências alélicas entre as populações pequenas e na manutenção da diversidade genética e do polimorfismo (Zucchi, 2002), uma das razões pelas quais o estudo da variabilidade intraespecífica e suas consequentes interpretações de fluxo gênico e diferenciação populacional são essenciais no estabelecimento futuro de medidas de conservação.

Atualmente, diversas ferramentas têm sido utilizadas em análises de variabilidade intraespecífica, incluindo o uso concomitante de ferramentas moleculares e de análises morfológicas, com a utilização de caracteres morfológicos clássicos de forma comparada, bem como aplicações da morfometria tradicional e geométrica, na tentativa de se melhor 
compreender a conformação dos estoques de algumas espécies, uma vez que a variabilidade morfométrica entre diferentes populações pode ser atribuída a estruturas genéticas distintas e a diferentes condições ambientais (Waldman et al., 1988; Tzeng et al., 2004).

Considerando a biologia molecular, diversos genes têm sido utilizados em análises de variabilidade intraespecífica, principalmente genes provenientes de genomas de organelas. Os genes nucleares são extremamente conservados, sendo mais utilizados em estudos filogenéticos como, por exemplo, o gene codificador da proteína H3, cujos fragmentos parciais foram primeiramente utilizados em estudos evolutivos em artrópodes (Maxson et al., 1983; Colgan et al., 1998). Já os genes mitocondriais são os mais comumente utilizados, uma vez que o DNA mitocondrial apresenta características peculiares, tais como herança uniparental, taxas evolutivas rápidas, em comparação com o genoma nuclear e ausência de recombinação, mas também inclui algumas sequências bastante conservadas (Moritz et al., 1987; Schubart et al., 2000b; Calcagnotto, 2001). Essas características permitiram que seus genes fossem utilizados como uma importante ferramenta no estudo das relações evolutivas entre os organismos, sendo utilizados como marcadores genéticos em inferências filogenéticas, na busca pela história evolutiva das espécies e também em análises de variabilidade populacional, na investigação de diferenciação populacional e fluxo gênico (Moritz et al., 1987; Calcagnotto, 2001; Mantelatto et al., 2006, 2007, 2009a e b; Schubart \& Huber, 2006; Pileggi \& Mantelatto, 2010; Vergamini et al., 2011).

O gene mitocondrial $16 \mathrm{~S}$ é um gene estrutural não codificador usado com frequência em sistemática molecular para muitos táxons animais, incluindo os crustáceos decápodes (Schubart et al., 2000b; Bracken-Grissom et al., 2013). O gene Citocromo Oxidase I (COI) compreende sequências codificantes, apresenta grande variabilidade de taxas evolutivas e também tem sido muito utilizado em variados estudos evolutivos (Moritz et al., 1987; Schubart et al., 2000b), além de incluir sequências suficientemente variáveis para detectar 
variação intraespecífica (Laurenzano et al., 2012). O uso desses genes tem se demonstrado eficiente em estudos sobre relações filogenéticas, filogeográficas e variações interpopulacionais em crustáceos decápodes (e.g., Schubart et al., 2000a; Mantelatto et al., 2006; Schubart \& Huber, 2006; Mantelatto et al., 2007, 2009a e b; Pileggi \& Mantelatto, 2010; Vergamini et al., 2011, Laurenzano et al., 2012; Negri et al., 2012; Laurenzano et al., 2013; Terossi \& Mantelatto, 2012; Rossi \& Mantelatto, 2013; Timm \& Bracken-Grissom, 2015) e, além disso, haplótipos obtidos a partir de dados de DNA mitocondrial podem e tem sido muito utilizados na inferência de níveis de fluxo gênico entre populações (Gopurenko, 2002).

\subsection{A DISPERSÃO LARVAL E O FLUXO GÊNICO}

Considerando a importância dos fatores evolutivos da determinação da diferenciação genética, tanto o fluxo gênico quanto a seleção natural são essenciais na conformação da estruturação populacional de organismos marinhos, uma vez que, para a maioria das espécies marinhas costeiras e bentônicas, o fluxo gênico é limitado à dispersão durante o estágio larval (Scheltema, 1975). Se as larvas são capazes de se dispersar por longas distâncias, espera-se que elas não somente sejam agentes de colonização e recolonização, mas também de fluxo gênico entre populações amplamente separadas, de forma que esse fluxo seja amplamente controlado durante a fase larval planctônica por meio da interação da habilidade de dispersão larval e das correntes oceânicas (Scheltema, 1971; Hamasaki et al., 2015). Assim, a estruturação e conectividade populacional podem ser amplamente determinadas pela dispersão dos indivíduos (Rodríguez-Rey et al., 2014).

Algumas teorias têm correlacionado estrutura populacional e dispersão larval em ecossistemas marinhos e vários estudos têm demonstrado que a homogeneidade genética tende a aumentar com o aumento da capacidade de dispersão larval, de forma que um elevado 
potencial dispersivo é constantemente associado com diferenciação genética em larga escala (Palumbi, 1992; Ituarte et al., 2012). Assim, esses dados sugerem que existam elevados níveis de fluxo gênico entre as populações com elevadas capacidades dispersivas e espécies que apresentem estratégias de história de vida distintas possivelmente estão sujeitas à diferenciação em muitas formas e caminhos diferentes (Scheltema, 1986; Palumbi, 1992; Palumbi, 1994).

No entanto, algumas espécies que apresentam estágios larvais com maior duração e, portanto, elevadas capacidades de dispersão, desafiam essa proposta, apresentando níveis de estruturação populacional elevados e inesperados (e.g., Shulman \& Bermingham, 1995; Barber et al., 2000; Bowen et al., 2006; Kelly \& Palumbi, 2010). Assim, aparentemente, não há uma predição para a correlação entre homogeneidade genética e duração do estágio larval em espécies habitantes de sistemas marinhos e costeiros e, assim, a estruturação genética das populações não pode ser inferida necessariamente a partir das capacidades de dispersão (Burton, 1983; Ituarte et al., 2012; Wieman et al., 2014).

$\mathrm{Na}$ realidade, organismos com elevados potenciais para dispersão podem apresentar diferentes níveis de estruturação populacional devido à associação de uma variedade de fatores, tais como: presença de barreiras históricas ao fluxo gênico, barreiras ecológicas (disponibilidade de alimento, predação e interação entre espécies) ou físicas (correntes, temperatura, salinidade), ou ainda comportamento larval (retenção, respostas à luz, salinidade, temperatura) e a interação das larvas com processos ecológicos e físicos (Burton, 1983; Barber et al., 2000; Hellberg et al., 2002; Palumbi, 2003; Shanks et al., 2003). Assim, há muitas evidências que indicam que processos oceanográficos e/ou biológicos podem limitar a dispersão planctônica, resultando em níveis de estruturação populacional similares àqueles esperados em modelos de stepping-stone ou de isolamento por distância (Hellberg, 1994). Então, na tentativa de se compreender o nível de interferência da capacidade de dispersão nos 
processos de fluxo gênico de cada espécie, é preciso obter informações acerca do comportamento das larvas e sua distribuição geográfica, além do conhecimento sobre a circulação estuarina e costeira (Scheltema, 1975) e sobre processos históricos.

No entanto, apesar da tendência em não se associar elevados potenciais dispersivos e variação genética em larga escala, comparar padrões de diferenciação genética ao longo de uma mesma área geográfica para muitas espécies, analisando, portanto, a estruturação populacional de espécies codistribuídas, permite a comparação de padrões de estruturação e filogeografia, fornecendo informações acerca dos fatores que influenciam a variação e a estruturação populacional em espécies pertencentes ao mesmo ecossistema (Avise, 1998; McMillen-Jackson \& Bert, 2003; Kelly \& Palumbi, 2010). As avaliações comparativas podem fornecer dados para o avanço na compreensão de como os padrões filogeográficos intraespecíficos podem ser influenciados por fatores intrínsecos e, portanto, inerentes às espécies, tais como comportamento, fisiologia, ecologia, ou por fatores extrínsecos, tais como história demográfica, geografia, condições abióticas e, inclusive, impactos ambientais decorrentes de ações antrópicas (Avise, 1998).

\subsection{O ECOSSISTEMA DE MANGUEZAIS E OS CARANGUEJOS}

Dentre os ecossistemas aquáticos mais ameaçados do mundo, encontram-se os manguezais, que constituem um ecossistema costeiro, com distribuição tropical e subtropical, situado na confluência entre os ambientes terrestre e marinho e sujeito ao regime de marés (Schaeffer-Novelli, 1991). Os manguezais ocupam uma área estimada de $181.000 \mathrm{~km}^{2}$ (Spalding et al., 1997) e as regiões biogeográficas mais diversas incluem o Indo-Oeste Pacífico, Indonésia, Austrália, Brasil e Nigéria, que compreendem cerca de $43 \%$ das florestas de manguezais do mundo (Alongi, 2002). 
As florestas de manguezais são arquitetonicamente simples em comparação às florestas tropicais e apresentam menor riqueza de espécies (Alongi, 2002). No entanto, a constituição de uma fauna e flora com características morfológicas e fisiológicas ímpares torna esse sistema único, estrutura e funcionalmente (Alongi, 2002). Além disso, a produção em biomassa dos manguezais é, em média, maior do que qualquer outro ecossistema aquático, sendo possível equiparar os valores de biomassa dos manguezais de regiões equatoriais aos de qualquer floresta tropical (Clough, 1992).

As características desse ecossistema incluem cadeias tróficas não tão complexas, mas que compreendem componentes marinhos e terrestres (Alongi, 2002), constituindo um hábitat de variada fauna residente e migratória. Ademais, os manguezais apresentam condições propícias de alimentação, proteção e reprodução de muitas espécies, constituindo berçários de muitas espécies de peixes e crustáceos e refúgios de espécies de aves, répteis, mamíferos e outros organismos marinhos (Schaeffer-Novelli, 1991; Robertson \& Blaber, 1992; Amaral et al., 2010). Além disso, os ecossistemas de manguezais protegem a costa mecanicamente, funcionando como uma barreira à ação erosiva das ondas e marés, retendo os sedimentos carreados pelos rios e atuam como um verdadeiro filtro biológico da matéria orgânica, concentrando nutrientes e retendo metais pesados (Alongi, 2002).

Assim, os manguezais constituem um ecossistema insubstituível e único, sendo considerado uma das unidades ecológicas mais produtivas do mundo. Muitas destas áreas na América Latina e no Caribe estão compreendidas dentro de eco-regiões criadas por estudos desenvolvidos pelo Banco Mundial, com apoio do Fundo Mundial para a Natureza (World Wildlife Fund - WWF) (Olson et al., 2001), facilitando a avaliação do estado de conservação dessas unidades e a identificação de prioridades de conservação e estratégias, sendo considerados importantes santuários na manutenção de algumas espécies ameaçadas de extinção (Dinerstein et al., 1995; Olson et al., 2001). 
Adicionalmente, os manguezais, além de seu alto valor ecológico, constituem verdadeiros hotspots de diferenciação populacional, uma vez que esses sistemas constituem hábitats discretos e isolados uns dos outros por barreiras à dispersão, distância geográfica ou tolerância fisiológica (Keenan, 1994; Bilton et al., 2002). Isso indica uma maior taxa de variabilidade entre as populações das espécies habitantes desses sistemas, promovendo diferenciação genética e populacional (Keenan, 1994).

Dentre as espécies habitantes da epifauna dos manguezais, os caranguejos constituem um dos grupos mais representativos em termos de abundância e diversidade, incluindo espécies das famílias Sesarmidae Dana 1851, Grapsidae MacLeay 1838, Gecarcinidae MacLeay 1838, Ocypodidae Rafinesque 1815 e Ucididae Stevcic 2005. O reconhecimento sobre a importância desses organismos nos manguezais surgiu a partir de pesquisas conduzidas na Austrália, na década de 80 , que modificaram a antiga visão de que os manguezais exportariam grandes quantidades de detritos à costa adjacente, subsidiando as cadeias tróficas e o fluxo de energia e nutrientes (Lee, 1999; Alongi, 2002, 2009). As pesquisas encontraram que os caranguejos consomem uma fração significante da serrapilheira (Robertson, 1986), reduzindo os detritos disponíveis para a costa, garantindo a reciclagem de nutrientes e matéria orgânica (Alongi, 2009).

Além disso, a bioturbação do solo pelos caranguejos pode resultar em mudanças na textura e química do solo, topografia superficial, redução de anoxia e abundância da meiofauna com estimulação da produção microbiana (Alongi, 2009). A presença das tocas garante o fluxo da água de marés no solo, acelerando o fluxo de água e do material particulado e dissolvido associado entre a floresta e as vias adjacentes (Ridd, 1996). A presença dos caranguejos facilita também o crescimento das plantas, devido à aeração dos solos, limitando o acúmulo de metabólitos tóxicos (Alongi, 2009). Pode-se, portanto, constatar que, muito provavelmente, a ameaça aos manguezais mundiais e a consequente 
perda desses organismos, afetaria negativamente a sucessão e o crescimento natural das florestas de manguezais (Alongi, 2002).

O crescimento rápido das populações humanas e os muitos impactos derivados desse crescimento têm afetado os ambientes naturais em todo o mundo, principalmente os ecossistemas de zonas costeiras, mais sensíveis e com menor capacidade de recuperação (Almeida et al., 2001). Os impactos ambientais em áreas costeiras, atingindo, principalmente, os ecossistemas de mangue, incluem desmatamento e aterro visando construção civil, industrial e portuária, lançamento de resíduos sólidos e esgotos industriais e, portanto, descarga de materiais tóxicos (Cintrón \& Schaeffer-Novelli; 1983; Varjabedian, 1995). A poluição decorrente de todo esse impacto atua como tensora crônica e pode, a longo prazo, provocar a morte do manguezal, pois cria condições quase sempre impróprias ao seu desenvolvimento, impossibilitando sobremaneira a sua capacidade de recuperação (Varjabedian, 1995).

Recentemente, alterações no tamanho das populações de caranguejos amplamente consumidos no Brasil, como Cardisoma ganhumi Latreille 1828 e Ucides cordatus (Linnaeus 1763), têm sido atribuídas à sobrepesca, à captura seletiva e a doenças infecciosas e têm sido acentuadas em função da destruição das áreas de manguezais (Feliciano, 1962; Taissoun, 1974; Foale, 1999; Boeger et al., 2005; Amaral \& Jablonski, 2005; Diele et al., 2005; Oliveira-Neto et al., 2007a e b). Esses fatores contribuem conjuntamente para a não recuperação dos estoques genéticos não somente de espécies de interesse econômico, mas também daquelas coabitantes, diretamente afetadas pela destruição do hábitat (Amaral \& Jablonski, 2005). Apesar da importância socioeconômica de muitas espécies, o status populacional e o estoque genético de muitos caranguejos semiterrestres habitantes de manguezais são geralmente desconhecidos, o que frequentemente dificulta o estabelecimento de estratégias de manejo (Diele et al., 2005). Esse histórico reforça a importância da 
conservação de unidades, na tentativa de se fornecer melhores condições de sobrevivência dos sistemas e da biota mais sensível às ações humanas (Kramer et al., 1997), como é o caso de muitas espécies de caranguejos semiterrestres habitantes de áreas de manguezais.

Assim, a necessidade imediata e futura de se traçar planos e gestões de conservação e sustentabilidade de espécies de caranguejos habitantes de manguezais torna imprescindível a obtenção do conhecimento sobre a variabilidade intraespecífica, bem como dos estoques e a análise da diferenciação genética e estruturação populacional de espécies codistribuídas. Esses estudos podem revelar as áreas que abrigam maior diversidade genética dentro da população de uma determinada espécie, bem como quais fatores (íntrinsecos ou extrínsecos) estariam agindo no estabelecimento de determinadas estruturas populacionais. Para tal, cinco espécies frequentemente encontradas e amplamente relacionadas aos ambientes de manguezais e codistribuídas, apresentando a mesma ampla área de distribuição geográfica, foram selecionadas para este estudo: Aratus pisonii (H. Milne Edwards 1837), Goniopsis cruentata (Latreille 1803), Sesarma rectum Randall 1840, Uca thayeri Rathbun 1900 e Ucides cordatus.

\subsection{CARACTERIZAĊ̃̃o DAS ESPÉCIES ALVO}

Os crustáceos compreendem um dos maiores, mais diversos e mais bem-sucedidos grupos de invertebrados, constituindo o quarto maior clado de animais e aos quais têm sido atribuídos papéis vitais em níveis tróficos e ciclos energéticos nas comunidades (McLaughlin, 1980; Martin et al., 2009). Dentre os Crustacea, a ordem Decapoda compreende o grupo com espécies mais conhecidas, incluindo uma grande diversidade de táxons marinhos, de água doce e semiterrestres (McLaughlin, 1980), compreendendo uma das mais diversas ordens de crustáceos em termos de plano corporal (Martin et al., 2009). A ordem inclui os caranguejos (Brachyura), ermitões e espécies relacionadas (Anomura), camarões (Dendobranchiata, 
Caridea e Stenopodidea), lagostas (Palinura), dentre outros grupos menos conhecidos (Martin et al., 2009).

As espécies selecionadas para esse estudo estão incluídas na infraordem Brachyura e, dentre elas, buscou-se incluir representantes de grande parte das famílias constituintes das faunas de manguezais, incluindo representantes das famílias Grapsidae (Goniopsis cruentata), Ocypodidae (Uca thayeri), Sesarmidae (Aratus pisonii e Sesarma rectum) e Ucididae (Ucides cordatus).

A espécie Aratus pisonii (Fig. 1A) apresenta hábito arborícola, sendo encontrado em ramos e troncos das árvores de manguezal (Warner, 1967) e representa uma espécie muito abundante, habitando principalmente a borda e o meio do manguezal (Oshiro et al., 1998). Goniopsis cruentata (Fig. 1B) é uma espécie encontrada em manguezais do supra ao médiolitoral, habitando substratos consolidados, inconsolidados e sendo comumente encontrada junto às raízes das árvores (Coelho, 1965). A espécie Sesarma rectum (Fig. 1C) apresenta hábito escavador, construindo tocas sob as sombras das árvores do mangue (Melo, 1996) e junto a gramíneas em solo arenoso. A espécie Uca thayeri (Fig. 1D) habita regiões lamacentas das bordas dos manguezais (Melo, 1996) e a espécie Ucides cordatus (Fig. 1E) escava tocas individuais de até $1.6 \mathrm{~m}$ de profundidade e é intensamente consumida e considerada uma importante fonte de renda para populações ao longo da costa brasileira (Glaser, 2003).

Todas as espécies utilizadas nesse estudo apresentam distribuição geográfica limitada à costa do Oceano Atlântico Ocidental, com registros desde a Península da Flórida, nos Estados Unidos, até o Estado de Santa Catarina, no Brasil, com alguns hiatos de ocorrência em suas distribuições, com exceção da espécie Sesarma rectum, com registros da Colômbia até o Brasil (Chace \& Hobbs, 1969; Abele, 1992; Melo, 1996; von Sternberg, 1994; PradoRatti, 2004; Bezerra, 2012) (Tabela 1). 
A

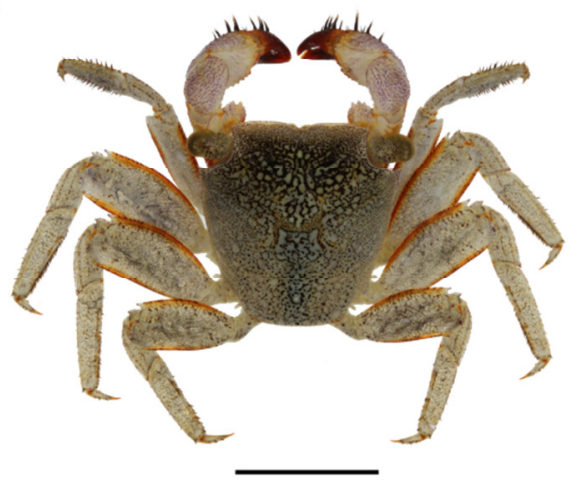

$\mathrm{C}$

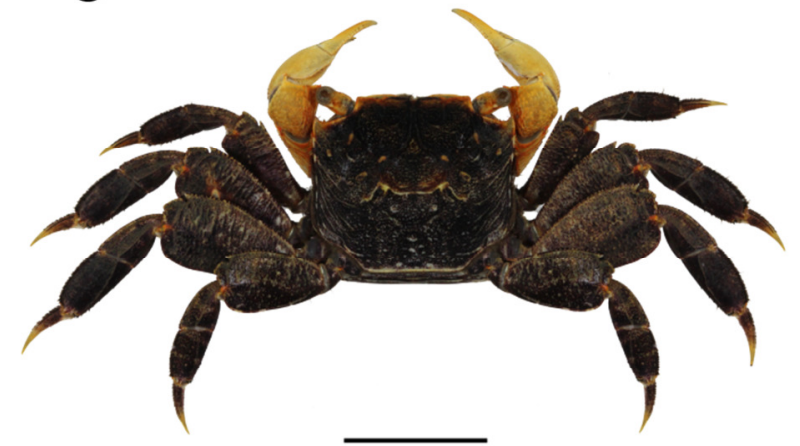

B

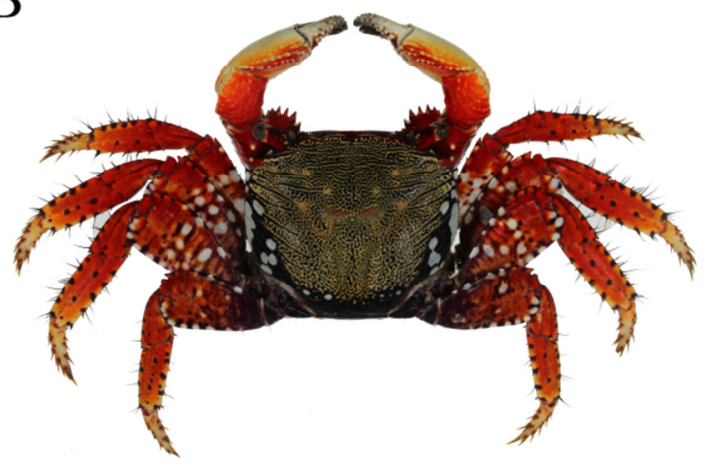

D

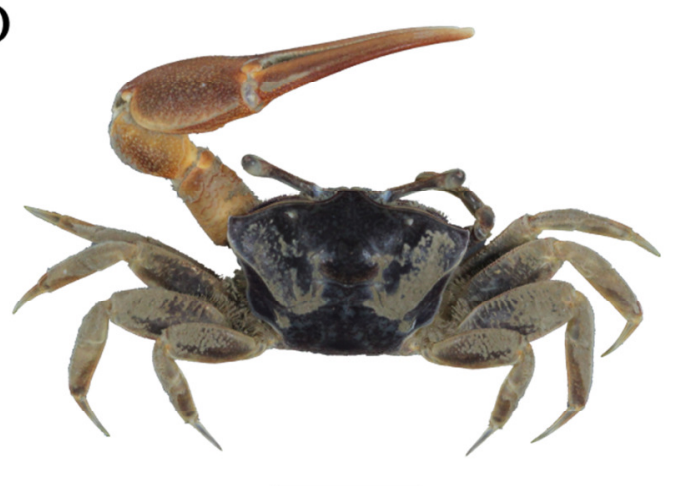

E

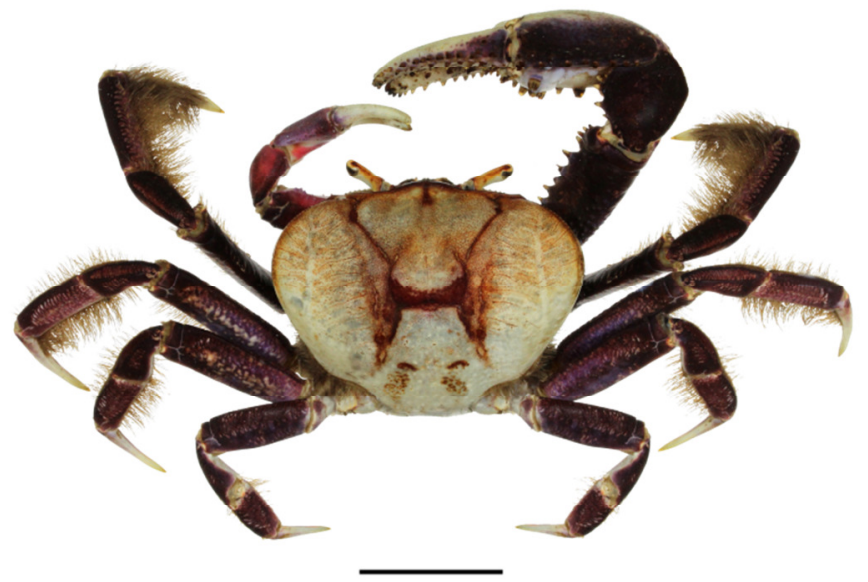

Figura 1. A. Aratus pisonii (macho; CCDB 4890). B. Goniopsis cruentata (macho; CCDB 5053). C. Sesarma rectum (fêmea; CCDB 5081). D. Uca thayeri (macho; CCDB 2540). E. Ucides cordatus (macho; CCDB 5059). Barras de escala: A: $12 \mathrm{~mm}$; B: $30 \mathrm{~mm}$; C: $18 \mathrm{~mm}$; D: $10 \mathrm{~mm}$; E: $32 \mathrm{~mm}$. 
Tabela 1. Distribuição geográfica das espécies em estudo (Chace \& Hobbs, 1969; Abele, 1992; Melo, 1996; von Sternberg, 1994; Prado-Ratti, 2004; Bezerra, 2012; observações pessoais).

\begin{tabular}{|c|c|}
\hline Espécie & Distribuição \\
\hline Aratus pisonii & $\begin{array}{c}\text { Flórida, Golfo do México, Antilhas, Costa Rica, Panamá, } \\
\text { Colômbia, Venezuela, Guiana, Suriname, Guiana Francesa, } \\
\text { Brasil (PA, PI a PR) }\end{array}$ \\
\hline Goniopsis cruentata & $\begin{array}{l}\text { Bermudas, Flórida, Golfo do México, Antilhas, Costa Rica, } \\
\text { Guiana, Suriname, Guiana Francesa, Brasil (PA a SC) }\end{array}$ \\
\hline Sesarma rectum & $\begin{array}{c}\text { Colômbia, Venezuela, Guiana, Suriname, Guiana Francesa, } \\
\text { Brasil (AP a SC) }\end{array}$ \\
\hline Uca thayeri & $\begin{array}{c}\text { Flórida, Golfo do México, Antilhas, Guatemala, Panamá, } \\
\text { Venezuela, Brasil (PA a SC) }\end{array}$ \\
\hline Ucides cordatus & $\begin{array}{l}\text { Flórida, Golfo do México, Antilhas, Belize, Guatemala, } \\
\text { Honduras, Nicarágua, Costa Rica, Panamá, Colômbia, } \\
\text { Venezuela, Guiana, Suriname, Guiana Francesa, Brasil (PA a } \\
\text { SC) }\end{array}$ \\
\hline
\end{tabular}


OBJETIVOS 


\section{ObJetivos}

Com base no cenário relatado anteriormente, este projeto teve como objetivo principal analisar a variabilidade populacional de cinco espécies de caranguejos habitantes de manguezais, distribuídos ao longo da mesma área geográfica, por meio de ferramentas moleculares e morfológicas, buscando reunir dados para futuros projetos de manejo e avaliar quais fatores podem estar interferindo na determinação da estruturação populacional.

Uma vez que as espécies estão continuamente distribuídas ao longo de uma extensa área geográfica e habitam um ecossistema com áreas isoladas, estando, portanto, sujeitas à existência de barreiras à dispersão causadas por distância geográfica ou tolerância fisiológica e todas apresentam dispersão via estágio larval planctônico, visou-se testar duas hipóteses:

1) todas as espécies alvo apresentam o mesmo padrão em relação à diferenciação genética e estruturação populacional

2) há elevada diferenciação genética e estruturação populacional entre as populações das espécies alvo 
MATERIAL E MÉTOdOS 


\section{Material e Métodos}

\subsection{OBTENĊ̃̃O DOS ESPÉCIMES}

Durante a execução desse projeto, esforços foram reunidos na tentativa de se obter uma coleção de indivíduos das espécies alvo que abrangesse toda a extensão ou, ao menos, os limites latitudinais da área de ocorrência de cada uma delas, ao longo do Atlântico Ocidental, incluindo, inclusive, exemplares da localidade tipo para algumas delas (Tabelas 2 a 6). A coleção de indivíduos das espécies de interesse, bem como das espécies utilizadas como grupos externos, se deu por meio de coleta dos espécimes nos manguezais de ocorrência das espécies alvo, previamente reportados na literatura (Abele, 1992; von Sternberg, 1994; Melo, 1996; Prado-Ratti, 2004; Bezerra, 2012), além de reunião de lotes previamente catalogados na Coleção de Crustáceos do Departamento de Biologia da Faculdade de Filosofia, Ciências e Letras de Ribeirão Preto da Universidade de São Paulo (CCDB/FFCLRP/USP) e empréstimos e análises de material presente nas coleções carcinológicas do Brasil: Museu de Oceanografia da Universidade Federal de Pernambuco (MOUFPE), Museu Nacional do Rio de Janeiro (MNRJ/UFRJ) e Museu de Zoologia da Universidade de São Paulo (MZUSP); e do Exterior: United States National Museum (USNM) - Smithsoniam Institution [National Museum of Natural History (NMNH)], University of Louisiana at Lafayette Zoological Collection (ULLZ), Florida Museum of Natural History (UF) - University of Florida, Academy of Natural Sciences of Drexel University - Filadélfia, Colección Nacional de Crustaceos (CNCR) - Universidad Autonoma de México (UNAM), Museo de Zoología - Universidad de Costa Rica (MZUCR), e Australian Museum (AMS). Os indivíduos coletados foram fixados em etanol $80 \%$ e posteriormente depositados na CCDB/FFCLRP/USP. 
Previamente às análises, confirmou-se a identificação dos exemplares, com base nas características morfológicas diagnósticas das espécies (Chace \& Hobbs, 1969; Abele, 1992; Melo, 1996; Prado-Ratti, 2004; Bezerra, 2012). 
Tabela 2. Aratus pisonii. Continua. Espécimes utilizados nas análises, com número de catálogo (Coleção), local de amostragem, número de acesso no GenBank das sequências geradas para cada gene (COI, 16S e H3), espécimes analisados morfologicamente $(\checkmark)$ (Morfologia) e localidade designada. AMS: Australian Museum; CCDB: Coleção de Crustáceos do Departamento de Biologia da Faculdade de Filosofia, Ciências e Letras de Ribeirão Preto da Universidade de São Paulo; CNCR: Colección Nacional de Crustaceos, Universidad Autonoma de México; MOUFPE: Museu de Oceanografia, Universidade Federal de Pernambuco; MZUSP: Museu de Zoologia da Universidade de São Paulo; ULLZ: University of Louisiana at Lafayette Zoological Collection; USNM: United States National Museum do Smithsoniam Institution - National Museum of Natural History; UF: Florida

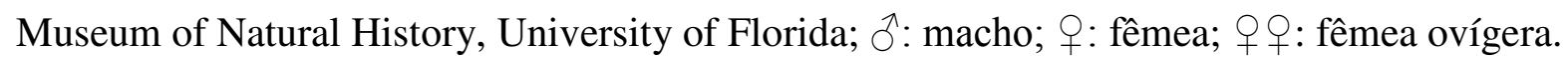

\begin{tabular}{|c|c|c|c|c|c|c|}
\hline \multirow{2}{*}{ Coleção } & \multirow{2}{*}{ Local de Amostragem } & \multicolumn{3}{|c|}{ GenBank } & \multirow{2}{*}{ Morfologia } & \multirow{2}{*}{ Localidade } \\
\hline & & COI & $16 \mathrm{~S}$ & H3 & & \\
\hline UF 26189 & Elliot Key, Flórida, Estados Unidos & - & - & - & $\checkmark$ & EUA \\
\hline UF 32620 & Daytona Beach, Flórida, Estados Unidos & KU313023 & - & - & $\checkmark$ & EUA \\
\hline ULLZ 5459 & Fort Pierce, Flórida, Estados Unidos & KU313019, KU313020 & KU313094 & KU313200 & $\checkmark$ & EUA \\
\hline ULLZ 9430 & Fort Pierce, Flórida, Estados Unidos & KU313021 & - & - & $\checkmark$ & EUA \\
\hline ULLZ 9467 & Fort Pierce, Flórida, Estados Unidos & KU313022 & - & - & $\checkmark$ & EUA \\
\hline UF 11375 & Hollywood, Flórida, Estados Unidos & KU313024, KU313025 & - & - & $\checkmark$ & EUA \\
\hline UF 32623 & Hollywood, Flórida, Estados Unidos & - & - & - & $\checkmark$ & EUA \\
\hline UF 11453 & Key West, Flórida, Estados Unidos & KU313027 & - & - & $\checkmark$ & EUA \\
\hline UF 8255 & Pigeon Key, Flórida, Estados Unidos & - & - & - & $\checkmark$ & EUA \\
\hline UF 32621 & Pigeon Key, Flórida, Estados Unidos & - & - & - & $\checkmark$ & EUA \\
\hline UF 32622 & Pigeon Key, Flórida, Estados Unidos & KU313026 & KU313095 & - & $\checkmark$ & EUA \\
\hline USNM 170175 & Palm Beach, Flórida, Estados Unidos & - & - & - & $\checkmark$ & EUA \\
\hline ULLZ 3838 & Tampa Bay, Flórida, Estados Unidos & - & - & - & $\checkmark$ & EUA \\
\hline ULLZ 6646 & Tampa Bay, Flórida, Estados Unidos & - & - & - & $\checkmark$ & EUA \\
\hline CNCR 4732 & Catemaco, Veracruz, México & - & - & - & $\checkmark$ & México \\
\hline CNCR 20717 & Catemaco, Veracruz, México & KU313028 & - & - & $\checkmark$ & México \\
\hline CNCR 4417 & San Andrés Tuxtla, Veracruz, México & KU313029 & - & - & $\checkmark$ & México \\
\hline CNCR 17126 & Huimanguillo, Tabasco, México & - & - & - & $\checkmark$ & México \\
\hline CNCR 17217 & Huimanguillo, Tabasco, México & - & - & - & $\checkmark$ & México \\
\hline CNCR 5620 & Carmen, Campeche, México & KU313032 & - & - & $\checkmark$ & México \\
\hline CNCR 18562 & Carmen, Campeche, México & - & - & - & $\checkmark$ & México \\
\hline CNCR 20806 & Champotón, Campeche, México & KU313031 & - & - & $\checkmark$ & México \\
\hline CNCR 8624 & Campeche, Campeche, México & KU313030 & - & - & $\checkmark$ & México \\
\hline USNM 1136811 & Twin Cays, Belize & - & - & - & $\checkmark$ & Belize \\
\hline CCDB 875 & Laguna de Gandoca, Costa Rica & KU313033 a KU313035 & KU313096 & KU313201 & $\checkmark$ & Costa Rica \\
\hline CCDB 4685 & Laguna de Gandoca, Costa Rica & KU313036, KU313037 & - & - & $\checkmark$ & Costa Rica \\
\hline CCDB 1533 & Bocas del Toro, Panamá & KU313038 a KU313042 & KU313097 & KU313202 & $\checkmark$ & Panamá \\
\hline
\end{tabular}


Tabela 2. Aratus pisonii. Continua.

\begin{tabular}{|c|c|c|c|c|c|c|}
\hline \multirow{2}{*}{ Coleção } & \multirow{2}{*}{ Local de Amostragem } & \multicolumn{3}{|c|}{ GenBank } & \multirow{2}{*}{ Morfologia } & \multirow{2}{*}{ Localidade } \\
\hline & & COI & $16 S$ & H3 & & \\
\hline USNM 143592 & Riddell's Bay, Bermuda & - & - & - & $\checkmark$ & Bermuda \\
\hline AMS P.45132 & Cardenas, Cuba & - & - & - & $\checkmark$ & Cuba \\
\hline USNM 4857 & Los Arroyos, Cuba & - & - & - & $\checkmark$ & Cuba \\
\hline USNM 18557 & Jamaica & - & - & - & $\checkmark$ & Jamaica \\
\hline USNM 24051 & Porto Rico & - & - & - & $\checkmark$ & Porto Rico \\
\hline USNM 154561 & St Thomas, Ilhas Virgens & - & - & - & $\checkmark$ & Ilhas Virgens \\
\hline USNM 95715 & Los Roques, Venezuela & - & - & - & $\checkmark$ & Venezuela \\
\hline CCDB 1823 & Margarita, Venezuela & KU313043 & KU313098 & KU313203 & $\checkmark$ & Venezuela \\
\hline USNM 91241 & Margarita, Venezuela & - & - & - & $\checkmark$ & Venezuela \\
\hline USNM 76472 & Rio San Grass, Venezuela & - & - & - & $\checkmark$ & Venezuela \\
\hline USNM 139282 & Trinidad, Trinidad \& Tobago & - & - & - & $\checkmark$ & Trinidad \& Tobago \\
\hline UF 8860 & Trinidad, Trinidad \& Tobago & KU313047, KU313048 & - & - & $\checkmark$ & Trinidad \& Tobago \\
\hline UF 32614 & Trinidad, Trinidad \& Tobago & KU313044 & KU313099 & KU313204 & $\checkmark$ & Trinidad \& Tobago \\
\hline UF 32616 & Trinidad, Trinidad \& Tobago & KU313045 & - & - & $\checkmark$ & Trinidad \& Tobago \\
\hline UF 32615 & Trinidad, Trinidad \& Tobago & KU313046 & - & - & $\checkmark$ & Trinidad \& Tobago \\
\hline UF 11280 & Trinidad \& Tobago & - & - & - & $\checkmark$ & Trinidad \& Tobago \\
\hline CCDB 5414 & Calçoene, AP, Brasil & KU313049, KU313050 & & & $\checkmark$ & Brasil (AP) \\
\hline CCDB 4447 & Salinópolis, PA, Brasil & KU313051 a KU313055 & KU313100 & KU313205 & $\checkmark$ & Brasil (PA) \\
\hline CCDB 4366 & Cascavel, CE, Brasil & - & KU313101 & KU313206 & $\checkmark$ & Brasil (CE) \\
\hline CCDB 3365 & Natal, RN, Brasil & KU313057 & KU313102 & KU313207 & $\checkmark$ & Brasil (RN) \\
\hline CCDB 5260 & Nísia Floresta, RN, Brasil & KU313056 & & & - & Brasil (RN) \\
\hline MZUSP 29920 & Estuário Ceará-Mirim, RN, Brasil & - & - & - & $\checkmark$ & Brasil (RN) \\
\hline MZUSP 29921 & Estuário Ceará-Mirim, RN, Brasil & - & - & - & $\checkmark$ & Brasil (RN) \\
\hline MZUSP 29922 & Estuário Ceará-Mirim, RN, Brasil & - & - & - & $\checkmark$ & Brasil (RN) \\
\hline MZUSP 29923 & Estuário Ceará-Mirim, RN, Brasil & - & - & - & $\checkmark$ & Brasil (RN) \\
\hline MZUSP 13263 & Mamanguape, PB, Brasil & - & - & - & $\checkmark$ & Brasil (PB) \\
\hline MZUSP 29907 & Mamanguape, PB, Brasil & - & - & - & $\checkmark$ & Brasil (PB) \\
\hline MOUFPE 13536 & Sirinhaém, PE, Brasil & - & - & - & $\checkmark$ & Brasil (PE) \\
\hline MZUSP 29915 & Passo do Camaragibe, AL, Brasil & KU313058 & KU313103 & KU313208 & $\checkmark$ & Brasil (AL) \\
\hline MZUSP 29916 & Passo do Camaragibe, AL, Brasil & - & - & - & $\checkmark$ & Brasil (AL) \\
\hline MZUSP 29917 & Passo do Camaragibe, AL, Brasil & KU313060 & - & - & $\checkmark$ & Brasil (AL) \\
\hline MZUSP 29918 & Passo do Camaragibe, AL, Brasil & KU313059 & - & - & $\checkmark$ & Brasil (AL) \\
\hline MZUSP 29919 & Passo do Camaragibe, AL, Brasil & - & - & - & $\checkmark$ & Brasil (AL) \\
\hline CCDB 181 & Porto do Sauípe, BA, Brasil & KU313061 a KU313063 & KU313104 & - & $\checkmark$ & Brasil (BA) \\
\hline CCDB 1448 & Porto Seguro, BA, Brasil & KU313064, KU313065 & - & - & $\checkmark$ & Brasil (BA) \\
\hline CCDB 4267 & Porto Seguro, BA, Brasil & - & - & - & $\checkmark$ & Brasil (BA) \\
\hline CCDB 3968 & Guarapari, ES, Brasil & KU313068, KU313069 & - & - & $\checkmark$ & Brasil (ES) \\
\hline CCDB 3967 & Marataízes, ES, Brasil & KU313066, KU313067 & KU313105 & KU313209 & $\checkmark$ & Brasil (ES) \\
\hline CCDB 4113 & Niterói, RJ, Brasil & KU313073, KU313074 & KU313106 & - & $\checkmark$ & Brasil (RJ) \\
\hline CCDB 3466 & Paraty, RJ, Brasil & KU313070 a KU313072 & - & KU313210 & $\checkmark$ & Brasil (RJ) \\
\hline CCDB 1857 & Ubatuba, SP, Brasil & KU313075 a KU313077 & KU313107 & KU313211 & $\checkmark$ & Brasil (SP) \\
\hline CCDB 3880 & Ubatuba, SP, Brasil & KU313078, KU313079 & - & - & $\checkmark$ & Brasil (SP) \\
\hline
\end{tabular}


Tabela 2. Aratus pisonii. Conclusão.

\begin{tabular}{|c|c|c|c|c|c|c|}
\hline \multirow{2}{*}{ Coleção } & \multirow{2}{*}{ Local de Amostragem } & \multicolumn{3}{|c|}{ GenBank } & \multirow{2}{*}{ Morfologia } & \multirow{2}{*}{ Localidade } \\
\hline & & COI & $16 S$ & H3 & & \\
\hline CCDB 3598 & Guarujá, SP, Brasil & KU313080 a KU313083 & KU313108 & KU313212 & $\checkmark$ & Brasil (SP) \\
\hline CCDB 957 & Cananéia, SP, Brasil & - & - & - & $\checkmark$ & Brasil (SP) \\
\hline CCDB 3264 & Cananéia, SP, Brasil & KU313085 & - & - & $\checkmark$ & Brasil (SP) \\
\hline CCDB 3770 & Cananéia, SP, Brasil & KU313087 & - & - & $\checkmark$ & Brasil (SP) \\
\hline CCDB 3661 & Ilha Comprida, SP, Brasil & KU313086 & - & - & $\checkmark$ & Brasil (SP) \\
\hline CCDB 3765 & Ilha Comprida, SP, Brasil & KU313084 & KU313109 & KU313213 & $\checkmark$ & Brasil (SP) \\
\hline CCDB 4885 & Ilha da Sepultura, PR, Brasil & KU313090, KU313091 & KU313110 & - & $\checkmark$ & Brasil (PR) \\
\hline CCDB 4884 & Paranaguá, PR, Brasil & KU313088, KU313089 & - & - & $\checkmark$ & Brasil (PR) \\
\hline CCDB 4886 & Joinville, SC, Brasil & KU313092, KU313093 & - & - & $\checkmark$ & Brasil (SC) \\
\hline
\end{tabular}


Tabela 3. Goniopsis cruentata. Continua. Espécimes utilizados nas análises, com número de catálogo (Coleção), local de amostragem, número de acesso no GenBank das sequências geradas para cada gene (COI, 16S e H3), espécimes analisados morfologicamente $(\checkmark)$ (Morfologia) e localidade designada. AMS: Australian Museum; CCDB: Coleção de Crustáceos do Departamento de Biologia da Faculdade de Filosofia, Ciências e Letras de Ribeirão Preto da Universidade de São Paulo; CNCR: Colección Nacional de Crustaceos, Universidad Autonoma de México; MOUFPE: Museu de Oceanografia, Universidade Federal de Pernambuco; MZUCR: Museo de Zoología da Universidad de Costa Rica; MZUSP: Museu de Zoologia da Universidade de São Paulo; ULLZ: University of Louisiana at Lafayette Zoological Collection; USNM: United States National Museum do Smithsoniam Institution - National Museum of Natural History; UF: Florida Museum of Natural History, University of Florida. $\bigcirc$ : macho; $q$ : fêmea; $q$ + : fêmea ovígera.

\begin{tabular}{|c|c|c|c|c|c|c|}
\hline \multirow{2}{*}{ Coleção } & \multirow{2}{*}{ Local de Amostragem } & \multicolumn{3}{|c|}{ GenBank } & \multirow{2}{*}{ Morfologia } & \multirow{2}{*}{ Localidade } \\
\hline & & COI & $16 S$ & H3 & & \\
\hline USNM 151478 & Del Ray Beach, Flórida, Estados Unidos & - & - & - & $\checkmark$ & EUA \\
\hline UF 9132 & Flagler County, Flórida, Estados Unidos & KU313264 & - & - & $\checkmark$ & EUA \\
\hline ULLZ 9487 & Fort Pierce, Flórida, Estados Unidos & KU313261 & - & - & $\checkmark$ & EUA \\
\hline ULLZ 9658 & Fort Pierce, Flórida, Estados Unidos & KU313262 & - & - & $\checkmark$ & EUA \\
\hline ULLZ 3750 & Indian River Lagoon, Flórida, Estados Unidos & KU313260 & KU313111 & KU313214 & $\checkmark$ & EUA \\
\hline UF 3734 & Key Largo, Flórida, Estados Unidos & KU313263 & - & - & $\checkmark$ & EUA \\
\hline CNCR 10508 & Altamira, Tamaulipas, México & - & - & - & $\checkmark$ & México \\
\hline ULLZ 3712 & Barra del Toro, Taumalipas, México & KU313269 & - & - & $\checkmark$ & México \\
\hline CNCR 17517 & Água Dulce, Veracruz, México & KU313268 & - & - & $\checkmark$ & México \\
\hline CNCR 10495 & Alvarado, Veracruz, México & - & - & - & $\checkmark$ & México \\
\hline CNCR 20715 & Catemaco, Veracruz, México & KU313265 & KU313112 & KU313215 & $\checkmark$ & México \\
\hline ULLZ 4007 & Laguna San Agustin, Veracruz, México & KU313271 & - & - & $\checkmark$ & México \\
\hline ULLZ 3713 & Palma Sola, Veracruz, México & KU313270 & - & - & $\checkmark$ & México \\
\hline CNCR 4757 & San Andrés Tuxtla, Veracruz, México & KU313266 & - & - & $\checkmark$ & México \\
\hline CNCR 4951 & Río Lagartos, Yucatán, México & KU313267 & - & - & $\checkmark$ & México \\
\hline CNCR 3721 & Felipe Carrillo Puerto, Quintana Roo, México & - & - & - & $\checkmark$ & México \\
\hline CNCR 3643 & Solidaridad, Quintana Roo, México & - & - & - & $\checkmark$ & México \\
\hline ULLZ 11205 & Twin Cays, Belize & KU313272 & - & - & $\checkmark$ & Belize \\
\hline ULLZ 12533 & Twin Cays, Belize & KU313273 & KU313113 & KU313216 & $\checkmark$ & Belize \\
\hline CCDB 4686 & Laguna de Gandoca, Costa Rica & KU313276 a KU313278 & KU313114 & KU313217 & $\checkmark$ & Costa Rica \\
\hline CCDB 4687 & Laguna de Gandoca, Costa Rica & KU313279 & - & - & - & Costa Rica \\
\hline CCDB 4688 & Laguna de Gandoca, Costa Rica & KU313280 & - & - & - & Costa Rica \\
\hline MZUCR 1335 & Laguna de Gandoca, Costa Rica & KU313274, KU313275 & - & - & - & Costa Rica \\
\hline USNM 94236 & Ferry Reach, Bermuda & - & - & - & $\checkmark$ & Bermuda \\
\hline USNM 1188927 & Ferry Reach, Bermuda & - & - & - & $\checkmark$ & Bermuda \\
\hline USNM 1188928 & Ferry Reach, Bermuda & - & - & - & $\checkmark$ & Bermuda \\
\hline
\end{tabular}


Tabela 3. Goniopsis cruentata. Continua.

\begin{tabular}{|c|c|c|c|c|c|c|}
\hline \multirow{2}{*}{ Coleção } & \multirow{2}{*}{ Local de Amostragem } & \multicolumn{3}{|c|}{ GenBank } & \multirow{2}{*}{ Morfologia } & \multirow{2}{*}{ Localidade } \\
\hline & & COI & $16 S$ & H3 & & \\
\hline USNM 59895 & Guantamano Bay, Cuba & - & - & - & $\checkmark$ & Cuba \\
\hline USNM 1188921 & Guantamano Bay, Cuba & - & - & - & $\checkmark$ & Cuba \\
\hline USNM 1188922 & Guantamano Bay, Cuba & - & - & - & $\checkmark$ & Cuba \\
\hline AM P.44532 & Marianao, Havana, Cuba & - & - & - & $\checkmark$ & Cuba \\
\hline AM P.46262 & Marianao, Havana, Cuba & - & - & - & $\checkmark$ & Cuba \\
\hline USNM 65862 & Port Moa, Cuba & - & - & - & $\checkmark$ & Cuba \\
\hline USNM 41749 & Montego Bay, Jamaica & - & - & - & $\checkmark$ & Jamaica \\
\hline USNM 72787 & Montego Bay, Jamaica & - & - & - & $\checkmark$ & Jamaica \\
\hline USNM 1188929 & Montego Bay, Jamaica & - & - & - & $\checkmark$ & Jamaica \\
\hline UF 8865 & Jamaica & KU313283 & - & - & $\checkmark$ & Jamaica \\
\hline USNM 22793 & San Juan Bay, Porto Rico & - & - & - & $\checkmark$ & Porto Rico \\
\hline UF 32137 & San Martin & KU313282 & - & - & $\checkmark$ & San Martin \\
\hline UF 32164 & San Martin & KU313281 & KU313115 & KU313218 & $\checkmark$ & San Martin \\
\hline USNM 126864 & Portsmouth, Dominica & - & - & - & $\checkmark$ & Dominica \\
\hline USNM 1188923 & Portsmouth, Dominica & - & - & - & $\checkmark$ & Dominica \\
\hline USNM 1188924 & Portsmouth, Dominica & - & - & - & $\checkmark$ & Dominica \\
\hline USNM 1188925 & Portsmouth, Dominica & - & - & - & $\checkmark$ & Dominica \\
\hline USNM 91239 & Miranda, Venezuela & - & - & - & $\checkmark$ & Venezuela \\
\hline USNM 1188926 & Miranda, Venezuela & - & - & - & $\checkmark$ & Venezuela \\
\hline USNM 139285 & Trinidad, Trinidad \& Tobago & - & - & - & $\checkmark$ & Trinidad \& Tobago \\
\hline UF 8819 & Trinidad, Trinidad \& Tobago & KU313285, KU313286 & - & - & $\checkmark$ & Trinidad \& Tobago \\
\hline UF 8837 & Tobago, Trinidad \& Tobago & KU313284 & KU313116 & KU313219 & $\checkmark$ & Trinidad \& Tobago \\
\hline MZUSP 16152 & De Barcadaire du Mahury, Guiana Francesa & KU313290 & - & - & $\checkmark$ & Guiana Francesa \\
\hline MZUSP 16157 & Guiana Francesa & - & - & - & $\checkmark$ & Guiana Francesa \\
\hline MZUSP21406 & Guiana Francesa & - & - & - & $\checkmark$ & Guiana Francesa \\
\hline MZUSP29908 & Plage de Rénuré, Guiana Francesa & KU313287 & KU313117 & - & $\checkmark$ & Guiana Francesa \\
\hline MZUSP29909 & Plage de Rénuré, Guiana Francesa & KU313288 & - & - & $\checkmark$ & Guiana Francesa \\
\hline MZUSP29910 & Plage de Rénuré, Guiana Francesa & KU313289 & - & - & $\checkmark$ & Guiana Francesa \\
\hline CCDB 5408 & Calçoene, AP, Brasil & KU313291 a KU313293 & - & - & $\checkmark$ & Brasil (AP) \\
\hline MZUSP 29931 & Jipioca, AP, Brasil & - & - & - & $\checkmark$ & Brasil (AP) \\
\hline MZUSP 29932 & Jipioca, AP, Brasil & - & - & - & $\checkmark$ & Brasil (AP) \\
\hline MZUSP 29933 & Jipioca, AP, Brasil & - & - & - & $\checkmark$ & Brasil (AP) \\
\hline MZUSP 29934 & Jipioca, AP, Brasil & - & - & - & $\checkmark$ & Brasil (AP) \\
\hline CCDB 4612 & Bragança, PA, Brasil & KU313294 a KU313296 & KU313118 & KU313220 & $\checkmark$ & Brasil (PA) \\
\hline MZUSP 6229 & São Luís do Maranhão, MA, Brasil & - & - & - & $\checkmark$ & Brasil (MA) \\
\hline MZUSP 6238 & São Luís do Maranhão, MA, Brasil & - & - & - & $\checkmark$ & Brasil (MA) \\
\hline MZUSP 29930 & São Luís do Maranhão, MA, Brasil & - & - & - & $\checkmark$ & Brasil (MA) \\
\hline CCDB 4498 & Caucaia, CE, Brasil & KU313297, KU313298 & - & - & $\checkmark$ & Brasil (CE) \\
\hline CCDB 3389 & Natal, RN, Brasil & KU313299 a KU313301 & KU313119 & KU313221 & $\checkmark$ & Brasil (RN) \\
\hline MZUSP 13254 & Mamanguape, PB, Brasil & - & - & - & $\checkmark$ & Brasil (PB) \\
\hline MZUSP 29935 & Mamanguape, PB, Brasil & - & - & - & $\checkmark$ & Brasil (PB) \\
\hline MZUSP 29936 & Mamanguape, PB, Brasil & - & - & - & $\checkmark$ & Brasil (PB) \\
\hline
\end{tabular}


Tabela 3. Goniopsis cruentata. Conclusão.

\begin{tabular}{|c|c|c|c|c|c|c|}
\hline \multirow{2}{*}{ Coleção } & \multirow{2}{*}{ Local de Amostragem } & \multicolumn{3}{|c|}{ GenBank } & \multirow{2}{*}{ Morfologia } & \multirow{2}{*}{ Localidade } \\
\hline & & COI & $16 S$ & H3 & & \\
\hline MOUFPE 13689 & Estuário Rio Goiana, PE, Brasil & - & - & - & $\checkmark$ & Brasil (PE) \\
\hline MZUSP 25228 & Tamandaré, PE, Brasil & KU313304 & - & - & $\checkmark$ & Brasil (PE) \\
\hline MZUSP 29928 & Tamandaré, PE, Brasil & KU313302 & KT279696 & KU313222 & $\checkmark$ & Brasil (PE) \\
\hline MZUSP 29929 & Tamandaré, PE, Brasil & KU313303 & - & - & $\checkmark$ & Brasil (PE) \\
\hline MZUSP 29937 & Passo do Camaragibe, AL, Brasil & KU313305 & KU313120 & KU313223 & $\checkmark$ & Brasil (AL) \\
\hline MZUSP 29938 & Passo do Camaragibe, AL, Brasil & - & - & - & $\checkmark$ & Brasil (AL) \\
\hline MZUSP 29939 & Passo do Camaragibe, AL, Brasil & KU313306 & - & - & $\checkmark$ & Brasil (AL) \\
\hline MZUSP 29940 & Passo do Camaragibe, AL, Brasil & KU313307 & - & - & $\checkmark$ & Brasil (AL) \\
\hline CCDB 187 & Porto do Sauípe, BA, Brasil & KU313312, KU313313 & - & - & $\checkmark$ & Brasil (BA) \\
\hline CCDB 317 & Porto Seguro, BA, Brasil & KU313308 a KU313310 & KU313121 & KU313224 & $\checkmark$ & Brasil (BA) \\
\hline CCDB 3786 & Porto Seguro, BA, Brasil & KU313311 & - & - & $\checkmark$ & Brasil (BA) \\
\hline CCDB 2247 & Guarapari, ES, Brasil & KU313314 & KU313122 & KU313225 & $\checkmark$ & Brasil (ES) \\
\hline CCDB 3975 & Guarapari, ES, Brasil & KU313315 a KU31331517 & - & - & $\checkmark$ & Brasil (ES) \\
\hline CCDB 3970 & Marataízes, ES, Brasil & - & - & - & $\checkmark$ & Brasil (ES) \\
\hline CCDB 4110 & Niterói, RJ, Brasil & KU313321 & KU313123 & - & $\checkmark$ & Brasil (RJ) \\
\hline CCDB 3460 & Paraty, RJ, Brasil & KU313318 a KU313320 & - & KU313226 & $\checkmark$ & Brasil (RJ) \\
\hline CCDB 1860 & Ubatuba, SP, Brasil & KU313323 & - & - & $\checkmark$ & Brasil (SP) \\
\hline CCDB 3913 & Ubatuba, SP, Brasil & KU313322 & - & - & $\checkmark$ & Brasil (SP) \\
\hline CCDB 3916 & Ubatuba, SP, Brasil & KU313324, KU313325 & KU313124 & KU313227 & $\checkmark$ & Brasil (SP) \\
\hline CCDB 4966 & Bertioga, SP, Brasil & KU313328 & - & - & $\checkmark$ & Brasil (SP) \\
\hline CCDB 4968 & Bertioga, SP, Brasil & KU313329 & - & - & - & Brasil (SP) \\
\hline MZUSP 12241 & Cubatão, SP, Brasil & - & - & - & $\checkmark$ & Brasil (SP) \\
\hline CCDB 2962 & Guarujá, SP, Brasil & KU313326, KU313327 & KU313125 & KU313228 & $\checkmark$ & Brasil (SP) \\
\hline CCDB 746 & Cananéia, SP, Brasil & KU313330 & KU313126 & - & $\checkmark$ & Brasil (SP) \\
\hline CCDB 3217 & Cananéia, SP, Brasil & KU313331 & - & - & $\checkmark$ & Brasil (SP) \\
\hline CCDB 3777 & Cananéia, SP, Brasil & KU313332 & - & KU313229 & $\checkmark$ & Brasil (SP) \\
\hline CCDB 785 & Ilha Comprida, SP, Brasil & KU313333 & - & - & $\checkmark$ & Brasil (SP) \\
\hline CCDB 3778 & Ilha Comprida, SP, Brasil & KU313334 & - & - & $\checkmark$ & Brasil (SP) \\
\hline CCDB 4399 & Camboriú, SC, Brasil & KU313335 & KU313127 & KU313230 & $\checkmark$ & Brasil (SC) \\
\hline
\end{tabular}


Tabela 4. Sesarma rectum. Continua. Espécimes utilizados nas análises, com número de catálogo (Coleção), local de amostragem, número de acesso no GenBank das sequências geradas para cada gene (COI, 16S e H3), espécimes analisados morfologicamente $(\checkmark)$ (Morfologia) e localidade designada. CA: Academy of Natural Sciences of Drexel University, Filadélfia CCDB: Coleção de Crustáceos do Departamento de Biologia da Faculdade de Filosofia, Ciências e Letras de Ribeirão Preto da Universidade de São Paulo; MOUFPE: Museu de Oceanografia, Universidade Federal de Pernambuco; MZUSP: Museu de Zoologia da Universidade de São Paulo; USNM: United States National Museum do Smithsoniam Institution - National Museum of Natural History; UF: Florida Museum of Natural History,

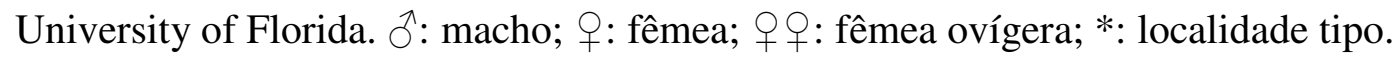

\begin{tabular}{|c|c|c|c|c|c|c|}
\hline \multirow{2}{*}{ Coleção } & \multirow{2}{*}{ Local de Amostragem } & \multicolumn{3}{|c|}{ GenBank } & \multirow{2}{*}{ Morfologia } & \multirow{2}{*}{ Localidade } \\
\hline & & COI & $16 S$ & H3 & & \\
\hline USNM 139299 & Trinidad, Trinidad \& Tobago & - & - & - & $\checkmark$ & Trinidad \& Tobago \\
\hline USNM 1188936 & Trinidad, Trinidad \& Tobago & - & - & - & $\checkmark$ & Trinidad \& Tobago \\
\hline USNM 1188937 & Trinidad, Trinidad \& Tobago & - & - & - & $\checkmark$ & Trinidad \& Tobago \\
\hline UF 8817 & Trinidad, Trinidad \& Tobago & KU313336 a KU313339 & KU313128 & - & $\checkmark$ & Trinidad \& Tobago \\
\hline UF 8827 & Trinidad, Trinidad \& Tobago & KU313340 & - & - & $\checkmark$ & Trinidad \& Tobago \\
\hline UF 8830 & Tobago, Trinidad \& Tobago & - & - & - & $\checkmark$ & Trinidad \& Tobago \\
\hline CA 3976 & Suriname* & - & - & - & $\checkmark$ & Suriname \\
\hline CCDB 4469 & Bragança, PA, Brasil & KU313342, KU313343 & KU313129 & KU313231 & $\checkmark$ & Brasil (PA) \\
\hline CCDB 4613 & Bragança, PA, Brasil & KU313344, KU313345 & - & - & $\checkmark$ & Brasil (PA) \\
\hline CCDB 4440 & Salinópolis, PA, Brasil & KU313341 & - & - & $\checkmark$ & Brasil (PA) \\
\hline MZUSP 29903 & São Luís do Maranhão, MA, Brasil & - & - & - & $\checkmark$ & Brasil (MA) \\
\hline MZUSP 29904 & São Luís do Maranhão, MA, Brasil & - & - & - & $\checkmark$ & Brasil (MA) \\
\hline CCDB 4369 & Fortaleza, CE, Brasil & KU313346 a KU313349 & KU313130 & - & $\checkmark$ & Brasil (CE) \\
\hline MZUSP 22926 & Estuário Rio das Conchas, RN, Brasil & KU313354 & - & - & $\checkmark$ & Brasil (RN) \\
\hline MZUSP 29924 & Estuário Rio das Conchas, RN, Brasil & KU313352 & - & - & $\checkmark$ & Brasil (RN) \\
\hline MZUSP 29925 & Estuário Rio das Conchas, RN, Brasil & KU313353 & - & - & $\checkmark$ & Brasil (RN) \\
\hline CCDB 3477 & Natal, RN, Brasil & KU313350, KU313351 & KU313131 & KU313232 & $\checkmark$ & Brasil (RN) \\
\hline MZUSP 3885 & Ponta de Pedras, PE, Brasil & - & - & - & $\checkmark$ & Brasil (PE) \\
\hline MZUSP 29900 & Ponta de Pedras, PE, Brasil & - & - & - & $\checkmark$ & Brasil (PE) \\
\hline MZUSP 29901 & Ponta de Pedras, PE, Brasil & - & - & - & $\checkmark$ & Brasil (PE) \\
\hline MZUSP 29902 & Ponta de Pedras, PE, Brasil & - & - & - & $\checkmark$ & Brasil (PE) \\
\hline MOUFPE 13723 & Rio Goiana, PE, Brasil & - & - & - & $\checkmark$ & Brasil (PE) \\
\hline MZUSP 24878 & Passo do Camaragibe, AL, Brasil & KU313356 & - & - & $\sqrt{ }$ & Brasil (AL) \\
\hline MZUSP 29914 & Passo do Camaragibe, AL, Brasil & KU313355 & KU313132 & KU313233 & $\checkmark$ & Brasil (AL) \\
\hline MZUSP 29927 & Passo do Camaragibe, AL, Brasil & KU313357 & - & - & $\checkmark$ & Brasil (AL) \\
\hline CCDB 700 & Porto Seguro, BA, Brasil & KU31335 a KU313362 & KU313133 & KU313234 & $\checkmark$ & Brasil (BA) \\
\hline MZUSP 29911 & Anchieta, ES, Brasil & KU313364 & - & - & $\checkmark$ & Brasil (ES) \\
\hline MZUSP 29912 & Anchieta, ES, Brasil & KU313365 & - & - & $\checkmark$ & Brasil (ES) \\
\hline MZUSP 29913 & Itapemirim, ES, Brasil & - & - & - & $\checkmark$ & Brasil (ES) \\
\hline
\end{tabular}


Tabela 4. Sesarma rectum. Conclusão.

\begin{tabular}{|c|c|c|c|c|c|c|}
\hline \multirow{2}{*}{ Coleção } & \multirow{2}{*}{ Local de Amostragem } & \multicolumn{3}{|c|}{ GenBank } & \multirow{2}{*}{ Morfologia } & \multirow{2}{*}{ Localidade } \\
\hline & & COI & $16 S$ & H3 & & \\
\hline CCDB 4005 & Marataízes, ES, Brasil & KU313363 & KU313134 & KU313235 & $\checkmark$ & Brasil (ES) \\
\hline MZUSP 1862 & Angra dos Reis, RJ, Brasil & - & - & - & $\checkmark$ & Brasil (RJ) \\
\hline MZUSP 3046 & Angra dos Reis, RJ, Brasil & - & - & - & $\checkmark$ & Brasil (RJ) \\
\hline MZUSP 29899 & Angra dos Reis, RJ, Brasil & - & - & - & $\checkmark$ & Brasil (RJ) \\
\hline MZUSP 1836 & Atafona, RJ, Brasil & - & - & - & $\checkmark$ & Brasil (RJ) \\
\hline MZUSP 21425 & Niterói, RJ, Brasil & - & - & - & $\checkmark$ & Brasil (RJ) \\
\hline CCDB 158 & Ubatuba, SP, Brasil & KU313369 & - & - & $\checkmark$ & Brasil (SP) \\
\hline CCDB 159 & Ubatuba, SP, Brasil & - & - & - & $\checkmark$ & Brasil (SP) \\
\hline CCDB 2539 & Ubatuba, SP, Brasil & KU313368 & - & - & $\checkmark$ & Brasil (SP) \\
\hline CCDB 3914 & Ubatuba, SP, Brasil & KU313366, KU313367 & KU313135 & KU313236 & $\checkmark$ & Brasil (SP) \\
\hline CCDB 4970 & Bertioga, SP, Brasil & KU313370 a KU313374 & KU313136 & - & $\checkmark$ & Brasil (SP) \\
\hline MZUSP 12359 & Cubatão, SP, Brasil & - & - & - & $\checkmark$ & Brasil (SP) \\
\hline MZUSP 29906 & Cubatão, SP, Brasil & - & - & - & $\checkmark$ & Brasil (SP) \\
\hline MZUSP 16213 & Peruíbe, SP, Brasil & - & - & - & $\checkmark$ & Brasil (SP) \\
\hline CCDB 3669 & Ilha Comprida, SP, Brasil & KU31337 a KU313379 & KU313137 & KU313237 & $\checkmark$ & Brasil (SP) \\
\hline MZUSP 8340 & Florianópolis, SC, Brasil & - & - & - & $\checkmark$ & Brasil (SC) \\
\hline MZUSP 29905 & Florianópolis, SC, Brasil & - & - & - & $\checkmark$ & Brasil (SC) \\
\hline
\end{tabular}


Tabela 5. Uca thayeri. Continua. Espécimes utilizados nas análises, com número de catálogo (Coleção), local de amostragem, número de acesso no GenBank das sequências geradas para cada gene (COI, 16S e H3), espécimes analisados morfologicamente ( $\checkmark$ ) (Morfologia) e localidade designada. AMS: Australian Museum; CCDB: Coleção de Crustáceos do Departamento de Biologia da Faculdade de Filosofia, Ciências e Letras de Ribeirão Preto da Universidade de São Paulo; CNCR: Colección Nacional de Crustaceos, Universidad Autonoma de México; MZUSP: Museu de Zoologia da Universidade de São Paulo; ULLZ: University of Louisiana at Lafayette Zoological Collection; USNM: United States National Museum do Smithsoniam Institution - National Museum of Natural History; UF: Florida Museum of Natural History, University of Florida. $\delta^{\lambda}$ : macho; : fềmea; 우: fêmea ovígera; *: localidade tipo.

\begin{tabular}{|c|c|c|c|c|c|c|}
\hline \multirow{2}{*}{ Coleção } & \multirow{2}{*}{ Local de Amostragem } & \multicolumn{3}{|c|}{ GenBank } & \multirow{2}{*}{ Morfologia } & \multirow{2}{*}{ Localidade } \\
\hline & & COI & $16 S$ & H3 & & \\
\hline UF 28616 & Callalisa Park, Flórida, Estados Unidos & KU313385 & - & - & $\checkmark$ & EUA \\
\hline ULLZ 9541 & Fort Pierce, Flórida, Estados Unidos & KU313381, KU313382 & KU313138 & KU313238 & $\checkmark$ & EUA \\
\hline ULLZ 9501 & Fort Pierce, Flórida, Estados Unidos & KU313383, KU313384 & - & - & $\checkmark$ & EUA \\
\hline ULLZ 10115 & Fort Pierce, Flórida, Estados Unidos & KU313380 & - & - & $\checkmark$ & EUA \\
\hline ULLZ 15310 & Fernandina Beach, Flórida, Estados Unidos & KU313386 & - & - & $\checkmark$ & EUA \\
\hline UF 11377 & Hollywood, Flórida, Estados Unidos & KU313387 & - & - & $\checkmark$ & EUA \\
\hline CNCR 8602 & Campeche, Campeche, México & KU313388 & KU313139 & - & $\checkmark$ & México \\
\hline CNCR 8621 & Campeche, Campeche, México & KU313389 & - & - & $\checkmark$ & México \\
\hline CNCR 20811 & Champotón, Campeche, México & - & - & - & $\checkmark$ & México \\
\hline USNM 171531 & Rio Champoton, Campeche, Mexico & - & - & - & $\checkmark$ & México \\
\hline USNM 2204997 & Rio Champoton, Campeche, Mexico & - & - & - & $\checkmark$ & México \\
\hline CNCR 21365 & Felipe Carrillo Puerto, Quintana Roo, México & - & - & - & $\checkmark$ & México \\
\hline AM P.44529 & Matanzas, Cuba & - & - & - & $\checkmark$ & Cuba \\
\hline USNM 93082 & Juntia, Cuba & - & - & - & $\checkmark$ & Cuba \\
\hline USNM 96458 & La Sierra, Cardenas, Cuba & - & - & - & $\checkmark$ & Cuba \\
\hline USNM 1188938 & Jamaica & KU313390 & KU313140 & - & $\checkmark$ & Jamaica \\
\hline USNM 1188939 & Jamaica & KU313391 & - & - & $\checkmark$ & Jamaica \\
\hline USNM 210463 & Saint Catherine Parish, Jamaica & - & - & - & $\checkmark$ & Jamaica \\
\hline USNM 24541 & Rio Bayamon, Porto Rico & - & - & - & $\checkmark$ & Porto Rico \\
\hline USNM 138127 & Aragua, Venezuela & - & - & - & $\checkmark$ & Venezuela \\
\hline USNM 138128 & Pedernales, Venezuela & - & - & - & $\checkmark$ & Venezuela \\
\hline USNM 137752 & Trinidad, Trinidad \& Tobago & - & - & - & $\checkmark$ & Trinidad \& Tobago \\
\hline MZUSP 23133 & Rio Amapá, AP, Brasil & KU313392 & KU313141 & - & $\checkmark$ & Brasil (AP) \\
\hline MZUSP 33192 & Rio Amapá, AP, Brasil & KU313393 & - & - & $\checkmark$ & Brasil (AP) \\
\hline CCDB 4441 & Salinópolis, PA, Brasil & KU313394 a KU313398 & KU313142 & KU313239 & $\checkmark$ & Brasil (PA) \\
\hline MZUSP 33177 & Itacu, MA, Brasil & KU313399 & - & - & $\checkmark$ & Brasil (MA) \\
\hline MZUSP 33178 & Itacu, MA, Brasil & KU313400 & KU313143 & - & $\checkmark$ & Brasil (MA) \\
\hline MZUSP 33179 & Itacu, MA, Brasil & - & - & - & $\checkmark$ & Brasil (MA) \\
\hline
\end{tabular}


Tabela 5. Uca thayeri. Continua.

\begin{tabular}{|c|c|c|c|c|c|c|}
\hline \multirow{2}{*}{ Coleção } & \multirow{2}{*}{ Local de Amostragem } & \multicolumn{3}{|c|}{ GenBank } & \multirow{2}{*}{ Morfologia } & \multirow{2}{*}{ Localidade } \\
\hline & & COI & $16 S$ & H3 & & \\
\hline MZUSP 33180 & Itacu, MA, Brasil & KU313401 & - & - & - & Brasil (MA) \\
\hline MZUSP 33181 & Itacu, MA, Brasil & KU313402 & - & - & - & Brasil (MA) \\
\hline CCDB 4367 & Fortaleza, CE, Brasil & - & KU313144 & - & $\checkmark$ & Brasil (CE) \\
\hline MZUSP 33187 & Fortaleza, CE, Brasil & KU313403 & - & - & $\checkmark$ & Brasil (CE) \\
\hline MZUSP 33188 & Fortaleza, CE, Brasil & - & - & - & $\checkmark$ & Brasil (CE) \\
\hline MZUSP 33189 & Fortaleza, CE, Brasil & KU313404 & - & - & $\checkmark$ & Brasil (CE) \\
\hline MZUSP 33190 & Fortaleza, CE, Brasil & KU313405 & - & - & $\checkmark$ & Brasil (CE) \\
\hline MZUSP 33191 & Fortaleza, CE, Brasil & KU313406 & - & - & $\checkmark$ & Brasil (CE) \\
\hline USNM 23753 & Cabedelo, PB, Brasil & - & - & - & $\checkmark$ & Brasil (PB) \\
\hline MZUSP 33169 & Ilha de Tamaracá, PE, Brasil & - & - & - & $\checkmark$ & Brasil (PE) \\
\hline MZUSP 33170 & Ilha de Tamaracá, PE, Brasil & KU313410 & - & - & $\checkmark$ & Brasil (PE) \\
\hline MZUSP 33171 & Ilha de Tamaracá, PE, Brasil & KU313411 & - & - & $\checkmark$ & Brasil (PE) \\
\hline MZUSP 33172 & Ilha de Tamaracá, PE, Brasil & KU313412 & - & - & - & Brasil (PE) \\
\hline MZUSP 33173 & Ilha de Tamaracá, PE, Brasil & KU313413 & - & - & - & Brasil (PE) \\
\hline CCDB 2998 & Sirinhaem, PE, Brasil & KU313407 a KU313409 & KU313145 & KU313240 & $\checkmark$ & Brasil (PE) \\
\hline USNM 23753 & Cabedelo, PB, Brasil* & - & - & - & $\checkmark$ & Brasil (PB) \\
\hline MZUSP 33163 & Estuário Rio Camaragibe, AL, Brasil & KU313414 & - & - & $\checkmark$ & Brasil (AL) \\
\hline MZUSP 33194 & Estuário Rio Camaragibe, AL, Brasil & KU313415 & KU313146 & KU313241 & $\checkmark$ & Brasil (AL) \\
\hline MZUSP 33193 & Estuário Rio Camaragibe, AL, Brasil & KU313416 & - & - & $\checkmark$ & Brasil (AL) \\
\hline CCDB 3028 & Ilhéus, BA, Brasil & KU313417 & - & - & $\checkmark$ & Brasil (AL) \\
\hline CCDB 4049 & Porto do Sauípe, BA, Brasil & KU313418 & KU313147 & KU313242 & $\checkmark$ & Brasil (BA) \\
\hline CCDB 4036 & Porto Seguro, BA, Brasil & KU313419 & - & - & $\checkmark$ & Brasil (BA) \\
\hline CCDB 4088 & Porto Seguro, BA, Brasil & KU313420 & - & - & $\checkmark$ & Brasil (BA) \\
\hline CCDB 4263 & Porto Seguro, BA, Brasil & KU313421 & - & - & $\checkmark$ & Brasil (BA) \\
\hline CCDB 4002 & Guarapari, ES, Brasil & KU313422 & KU313148 & KU313243 & $\checkmark$ & Brasil (ES) \\
\hline CCDB 3996 & Marataízes, ES, Brasil & KU313423, KU313424 & - & - & $\checkmark$ & Brasil (ES) \\
\hline MZUSP 33174 & Baia de Sepetiba, RJ, Brasil & KU313425 & - & - & $\checkmark$ & Brasil (RJ) \\
\hline MZUSP 33175 & Baia de Sepetiba, RJ, Brasil & KU313426 & - & - & $\checkmark$ & Brasil (RJ) \\
\hline MZUSP 33176 & Baia de Sepetiba, RJ, Brasil & KU313427 & - & - & $\checkmark$ & Brasil (RJ) \\
\hline CCDB 3458 & Paraty, RJ, Brasil & KU313429 & - & - & $\checkmark$ & Brasil (RJ) \\
\hline CCDB 3459 & Paraty, RJ, Brasil & KU313428 & KU313149 & KU313244 & $\checkmark$ & Brasil (RJ) \\
\hline CCDB 1930 & Ubatuba, SP, Brasil & KU313431 & KU313150 & - & $\checkmark$ & Brasil (SP) \\
\hline CCDB 2364 & Ubatuba, SP, Brasil & KU313432 & - & - & $\checkmark$ & Brasil (SP) \\
\hline CCDB 2540 & Ubatuba, SP, Brasil & KU313434 & - & - & $\checkmark$ & Brasil (SP) \\
\hline CCDB 2992 & Ubatuba, SP, Brasil & KU313433 & - & - & $\checkmark$ & Brasil (SP) \\
\hline CCDB 4034 & Ubatuba, SP, Brasil & KU313430 & - & - & $\checkmark$ & Brasil (SP) \\
\hline CCDB 4997 & Bertioga, SP, Brasil & KU313435 & KU313151 & KU313245 & - & Brasil (SP) \\
\hline CCDB 784 & Cananéia, SP, Brasil & KU313439 & - & - & $\checkmark$ & Brasil (SP) \\
\hline CCDB 798 & Cananéia, SP, Brasil & KU313440 & - & - & $\checkmark$ & Brasil (SP) \\
\hline CCDB 2987 & Cananéia, SP, Brasil & KU313436 & KU313152 & KU313246 & $\checkmark$ & Brasil (SP) \\
\hline CCDB 3220 & Cananéia, SP, Brasil & KU313438 & - & - & $\checkmark$ & Brasil (SP) \\
\hline CCDB 4027 & Ilha Comprida, SP, Brasil & KU313437 & - & - & $\checkmark$ & Brasil (SP) \\
\hline
\end{tabular}


Tabela 5. Uca thayeri. Conclusão.

\begin{tabular}{c|c|c|c|c|c|c}
\hline \multirow{2}{*}{ Coleção } & \multirow{2}{*}{ Local de Amostragem } & \multicolumn{2}{|c|}{ GenBank } & \multirow{2}{*}{ Morfologia } & \multicolumn{2}{|}{ Localidade } \\
\cline { 3 - 5 } & Guaratuba, PR, Brasil & KU313441 & KU313153 & - & $\checkmark$ & Brasil (PR) \\
MZUSP 33164 & Guaratuba, PR, Brasil & - & - & - & $\checkmark$ & Brasil (PR) \\
MZUSP 33165 & Guaratuba, PR, Brasil & KU313442 & - & - & $\checkmark$ & Brasil (PR) \\
MZUSP 33166 & Guaratuba, PR, Brasil & KU313443 & - & - & $\checkmark$ & Brasil (PR) \\
MZUSP 33167 & Guaratuba, PR, Brasil & KU313444 & - & - & $\checkmark$ & Brasil (PR) \\
MZUSP 33168 & Florianópolis, SC, Brasil & KU313445 & - & - & $\checkmark$ & Brasil (SC) \\
MZUSP 33182 & Florianópolis, SC, Brasil & KU313446 & - & - & $\checkmark$ & Brasil (SC) \\
MZUSP 33183 & Florianópolis, SC, Brasil & KU313447 & - & - & $\checkmark$ & Brasil (SC) \\
MZUSP 33184 & Florianópolis, SC, Brasil & KU313448 & KU313154 & - & $\checkmark$ & Brasil (SC) \\
MZUSP 33185 & Florianópolis, SC, Brasil & - & - & - & $\checkmark$ & Brasil (SC) \\
MZUSP 33186 & & &
\end{tabular}


Tabela 6. Ucides cordatus. Continua. Espécimes utilizados nas análises, com número de catálogo (Coleção), local de amostragem, número de acesso no GenBank das sequências geradas para cada gene (COI, 16S e H3), espécimes analisados morfologicamente $(\checkmark)$ (Morfologia) e localidade designada. AMS: Australian Museum; CCDB: Coleção de Crustáceos do Departamento de Biologia da Faculdade de Filosofia, Ciências e Letras de Ribeirão Preto da Universidade de São Paulo; CNCR: Colección Nacional de Crustaceos, Universidad Autonoma de México; ULLZ: University of Louisiana at Lafayette Zoological Collection; USNM: United States National Museum do Smithsoniam Institution - National Museum of Natural History; UF: Florida Museum of Natural History, University of Florida.

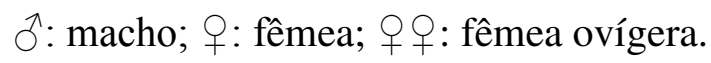

\begin{tabular}{|c|c|c|c|c|c|c|}
\hline \multirow{2}{*}{ Coleção } & \multirow{2}{*}{ Local de Amostragem } & \multicolumn{3}{|c|}{ GenBank } & \multirow{2}{*}{ Morfologia } & \multirow{2}{*}{ Localidade } \\
\hline & & COI & $16 S$ & H3 & & \\
\hline ULLZ 11988 & Fort Pierce, Flórida, Estados Unidos & KU313449 & KU313155 & KU313247 & $\checkmark$ & EUA \\
\hline USNM 171615 & Miami, Flórida, Estados Unidos & KU313450 & - & - & $\checkmark$ & EUA \\
\hline USNM 105882 & Miami, Flórida, Estados Unidos & KU313451 & - & - & $\checkmark$ & EUA \\
\hline CNCR - & Veracruz, México & KU313457 a KU313461 & KU313156 & KU313248 & $\checkmark$ & México \\
\hline CNCR 1199 & Tecolutla, Veracruz, México & - & - & - & $\checkmark$ & México \\
\hline CNCR 21034 & Río Lagartos, Yucatán, México & - & - & - & $\checkmark$ & México \\
\hline ULLZ 12263 & Bocas del Toro, Panamá & - & - & - & $\checkmark$ & Panamá \\
\hline ULLZ 11847 & Mosquito Cove, Jamaica & - & KU313157 & - & $\checkmark$ & Jamaica \\
\hline ULLZ 14236 & Mosquito Cove, Jamaica & KU313452 & - & - & $\checkmark$ & Jamaica \\
\hline USNM 240009 & Rio Bayamon, Porto Rico & - & - & - & $\checkmark$ & Porto Rico \\
\hline USNM 1188930 & Rio Bayamon, Porto Rico & - & - & - & $\checkmark$ & Porto Rico \\
\hline USNM 1188931 & Rio Bayamon, Porto Rico & - & - & - & $\checkmark$ & Porto Rico \\
\hline USNM 126965 & Estuário Rio Layou, Dominica & - & - & - & $\checkmark$ & Dominica \\
\hline USNM 1188932 & Estuário Rio Layou, Dominica & - & - & - & $\checkmark$ & Dominica \\
\hline USNM 1188933 & Estuário Rio Layou, Dominica & - & - & - & $\checkmark$ & Dominica \\
\hline USNM 1188934 & Estuário Rio Layou, Dominica & - & - & - & $\checkmark$ & Dominica \\
\hline USNM 1188935 & Estuário Rio Layou, Dominica & - & - & - & $\checkmark$ & Dominica \\
\hline USNM 139275 & Trinidad, Trinidad \& Tobago & - & - & - & $\checkmark$ & Trinidad \& Tobago \\
\hline UF 8815 & Trinidad, Trinidad \& Tobago & KU313453 a KU313456 & KU313158 & KU313249 & $\checkmark$ & Trinidad \& Tobago \\
\hline CCDB 5411 & Calçoene, AP, Brasil & KU313462, KU313463 & - & - & $\checkmark$ & Brasil (AP) \\
\hline CCDB 5412 & Calçoene, AP, Brasil & KU313464, KU313465 & - & - & $\checkmark$ & Brasil (AP) \\
\hline CCDB 4365 & Belém, PA, Brasil & KU313466, KU313467 & KU313159 & KU313250 & $\checkmark$ & Brasil (PA) \\
\hline CCDB 4468 & Bragança, PA, Brasil & KU313468 a KU313470 & - & - & $\checkmark$ & Brasil (PA) \\
\hline CCDB 4499 & Caucaia, CE, Brasil & KU313471 a KU313474 & KU313160 & - & $\checkmark$ & Brasil (CE) \\
\hline CCDB 5262 & Natal, RN, Brasil & KU313475 a KU313478 & KU313161 & KU313251 & $\checkmark$ & Brasil (RN) \\
\hline CCDB 4467 & Ipojuca, PE, Brasil & KU313479 a KU313483 & KT279700 & KU313252 & $\checkmark$ & Brasil (PE) \\
\hline CCDB 4146 & Camaragibe, AL, Brasil & KU313484 & KU313162 & KU313253 & $\checkmark$ & Brasil (AL) \\
\hline CCDB 4520 & Ilhéus, BA, Brasil & KU313488, KU313489 & - & - & $\checkmark$ & Brasil (BA) \\
\hline CCDB 3785 & Porto Seguro, BA, Brasil & KU313485, KU313487 & KU313163 & KU313254 & $\checkmark$ & Brasil (BA) \\
\hline
\end{tabular}


Tabela 6. Ucides cordatus. Conclusão.

\begin{tabular}{|c|c|c|c|c|c|c|}
\hline \multirow{2}{*}{ Coleção } & \multirow{2}{*}{ Local de Amostragem } & \multicolumn{3}{|c|}{ GenBank } & \multirow{2}{*}{ Morfologia } & \multirow{2}{*}{ Localidade } \\
\hline & & COI & $16 S$ & H3 & & \\
\hline CCDB 3976 & Marataízes, ES, Brasil & KU313490 & KU313164 & KU313255 & $\checkmark$ & Brasil (ES) \\
\hline CCDB 4951 & Duque de Caxias, RJ, Brasil & KU313492 a KU313495 & - & - & $\checkmark$ & Brasil (RJ) \\
\hline CCDB 4111 & Niterói, RJ, Brasil & KU313491 & KU313165 & KU313256 & - & Brasil (RJ) \\
\hline CCDB 2372 & Ubatuba, SP, Brasil & KU313496, KU313497 & - & - & $\checkmark$ & Brasil (SP) \\
\hline CCDB 3915 & Ubatuba, SP, Brasil & KU313498 a KU313500 & KU313166 & KU313257 & $\checkmark$ & Brasil (SP) \\
\hline CCDB 4969 & Bertioga, SP, Brasil & KU313501 a KU313504 & KU313167 & - & $\checkmark$ & Brasil (SP) \\
\hline CCDB 807 & Cananéia, SP, Brasil & - & - & - & $\checkmark$ & Brasil (SP) \\
\hline CCDB 3219 & Cananéia, SP, Brasil & KU313505 a KU313506 & KU313168 & KU313258 & $\checkmark$ & Brasil (SP) \\
\hline CCDB 3779 & Cananéia, SP, Brasil & - & - & - & $\checkmark$ & Brasil (SP) \\
\hline CCDB 3780 & Ilha Comprida, SP, Brasil & KU313507 & - & - & $\checkmark$ & Brasil (SP) \\
\hline CCDB 4397 & Camboriú, SC, Brasil & KU313508 & KU313169 & KU313259 & $\checkmark$ & Brasil (SC) \\
\hline
\end{tabular}




\subsection{ANÁLISES MOLECULARES}

Para as análises moleculares, os genes mitocondriais COI e 16S e o nuclear H3 foram utilizados como marcadores. Todas as sequências geradas durante o desenvolvimento desse projeto foram depositadas no GenBank (números de acesso KU313019 a KU313508; Tabelas 2 a 6$)$.

\subsubsection{Obtenção dos Dados}

Os procedimentos de extração, amplificação do DNA, purificação e obtenção das sequências seguiram os protocolos de metodologia de Mantelatto et al. (2006, 2007, 2009a e b), Pileggi \& Mantelatto (2010), Vergamini et al. (2011) e Thoma et al. (2014), com algumas alterações, visando adequação ao material. A obtenção de parte dos dados foi realizada no Laboratory for Crustacean Research, no Departamento de Biologia da University of Louisiana at Lafayette, em Lafayette, Estados Unidos, durante o período de Doutorado Sanduíche, realizado por meio de bolsa BEPE FAPESP (Bolsa de Estágio e Pesquisa no Exterior), no período de $1^{\circ}$ de Setembro a 30 de Novembro de 2014.

\subsubsection{Extração do DNA}

Para extração do material genômico total, uma porção de tecido muscular dos quelípodos ou dos pereópodos dos exemplares foi extraída e posteriormente incubada a $55^{\circ} \mathrm{C}$ por, aproximadamente, $24 \mathrm{~h}$ em $600 \mu \mathrm{L}$ de tampão de lise e $200 \mu \mathrm{L}$ de proteinase $\mathrm{K}$ (500 $\mu \mathrm{g} / \mathrm{ml})$. A inativação da atividade da proteinase $\mathrm{K}$ seguiu-se por meio de incubação em gelo por 10 minutos e, posteriormente, as proteínas foram separadas pela adição de $200 \mu \mathrm{L}$ de acetato de amônio (7,5 M), seguida de centrifugação a $14000 \mathrm{rpm}$ e $18^{\circ} \mathrm{C}$, por 10 minutos. Para precipitação do DNA, adicionou-se o sobrenadante a $600 \mu \mathrm{L}$ de isopropanol resfriado, seguido de centrifugação a $14000 \mathrm{rpm}$ e $18^{\circ} \mathrm{C}$, por 10 minutos e incubação a $-20^{\circ} \mathrm{C}$, por 48 
horas. Após centrifugação a $14000 \mathrm{rpm}$ e $18^{\circ} \mathrm{C}$, por 10 minutos, $15 \mu \mathrm{L}$ de etanol $70 \%$ foi adicionado ao pellet resultante, seguido de centrifugação a $14000 \mathrm{rpm}$ e $18^{\circ} \mathrm{C}$, por 10 minutos, liofilização a $45^{\circ} \mathrm{C}$ no Concentrator 5301 (Eppendorf $^{\circledR}$ ) e ressuspensão em $20 \mu \mathrm{L}$ de tampão TE. Para a extração do material genômico dos exemplares analisados durante o estágio no exterior, foi utilizado o Qiagen DNeasy Blood and Tissue Kit (Qiagen ${ }^{\circledR}$ ), seguindose o manual do fabricante.

A concentração e qualidade do DNA extraído foi avaliada utilizando-se os espectrofotômetros NanoDrop 2000 (Thermo Scientific ${ }^{\circledR}$ ) e NanoDrop Lite (Thermo Scientific $^{\circledR}$ ) possibilitando a adequação da concentração de DNA extraído à quantidade necessária para a realização da amplificação dos genes de interesse pela técnica de PCR (Polymerase Chain Reaction) (Sambrook et al., 1989).

\subsubsection{Amplificação dos genes}

Fragmentos dos genes COI, 16S e H3 foram amplificados a partir do DNA genômico extraído, por meio da técnica de PCR, utilizando-se primers universais (Tabela 7). A amplificação dos genes foi realizada por meio de uma reação em um volume total de $25 \mu \mathrm{L}$ contendo água destilada e deionizada, $3 \mu \mathrm{L}$ de tampão de PCR, $3 \mu \mathrm{L}$ de $\mathrm{MgCl}_{2}(25 \mathrm{mM}), 5 \mu \mathrm{L}$ de betaína (5M), $4 \mu \mathrm{L}$ de solução de DNTPs (10 mM cada), $1 \mu \mathrm{L}$ de cada primer $(10 \mu \mathrm{M}$ cada), $0.5 \mu \mathrm{L}$ Thermus aquaticus (Taq) polimerase $(5 \mathrm{U} / \mu \mathrm{L})$ e quantidades previamente calculadas do DNA extraído. A amplificação dos genes dos exemplares analisados durante o estágio no exterior foi realizada por meio de uma reação em um volume total de $25 \mu \mathrm{L}$ contendo água destilada e deionizada, $2.5 \mu \mathrm{L}$ de tampão de PCR 10X, $4 \mu \mathrm{L}$ de solução de DNTPs (200 $\mu \mathrm{M}$ cada), $0.5 \mu \mathrm{L}$ de cada primer $(20 \mu \mathrm{M}$ cada), $0.2 \mu \mathrm{L}$ de Thermus aquaticus (Taq) Fermentas DreamTaq Green DNA polimerase (Thermo Fisher Scientific $\left.{ }^{\circledR}\right)(5 \mathrm{U} / \mu \mathrm{L})$ e quantidades previamente calculadas do DNA extraído. 
A amplificação do DNA pela técnica de PCR foi realizada utilizando-se os termocicladores 96 Well Thermal Cycler (Applied Biosystems ${ }^{\circledR}$ ) e C1000 Touch Thermal Cycler $\left(\right.$ BioRad $\left.^{\circledR}\right)$ com adequação dos ciclos termais para cada marcador utilizado: 16S e H3 [desnaturação inicial a $95^{\circ} \mathrm{C}$, por 5 minutos, seguida de 40 ciclos de anelamento dos primers $\left(95^{\circ} \mathrm{C}\right.$, por 45 segundos; $48^{\circ} \mathrm{C}$, por 45 segundos e $72^{\circ} \mathrm{C}$, por 1 minuto) e extensão final por 3 minutos a $72^{\circ} \mathrm{C}$; COI [desnaturação inicial a $94^{\circ} \mathrm{C}$, por 2 minutos, seguida de 35 ciclos de anelamento dos primers $\left(94^{\circ} \mathrm{C}\right.$, por 30 segundos; $50^{\circ} \mathrm{C}$, por 30 segundos e $72^{\circ} \mathrm{C}$, por 1 minuto) e extensão final por 2 min a $72^{\circ} \mathrm{C}$ ]. Os resultados das PCRs foram observados em eletroforese em gel de agarose $1.4 \%$ e fotografados com câmera digital C-7070 (Olympus ${ }^{\circledR}$ ) no UV Transilluminator M20 (UVP $\left.{ }^{\circledR}\right)$ ou no Molecular Imager Gel DocTM XR System $\left(\operatorname{BioRad}^{\circledR}\right)$. 
Tabela 7. Primers utilizados na amplificação dos genes de interesse por meio da técnica de PCR (Polymerase Chain Reaction).

\begin{tabular}{|c|c|c|c|}
\hline Gene & Primer & Sequência & Referência \\
\hline \multirow{5}{*}{$16 \mathrm{~S}$} & $16 \mathrm{H} 9$ & 5'-CCGGTCTGAACTCAGATCACGT-3' & \multirow{2}{*}{ Palumbi \& Benzie, 1991} \\
\hline & $16 \mathrm{~L} 9$ & 5'-CGCCTGTTTATCAAAAACAT-3' & \\
\hline & 1472 & 5'-AGATAGAAACCAACCTGG-3' & Schubart et al., 2000b \\
\hline & 16SL2 & 5'-TGCCTGTTTATCAAAAACAT-3' & Schubart et al., 2000b \\
\hline & 1471 & 5'-CCTGTTTANCAAAAACAT-3' & Shih et al., 2010 \\
\hline \multirow{4}{*}{$\mathrm{COI}$} & COH6 & 5'-TADACTTCDGGRTGDCCAAARAAYCA-3' & \multirow{2}{*}{ Schubart \& Huber, 2006} \\
\hline & COL6b & 5'-ACAAATCATAAAGATATYGG-3' & \\
\hline & LCO1490 & 5' - GGTCAACAAATCATAAAGATATTG -3' & \multirow{2}{*}{ Folmer et al., 1994} \\
\hline & $\mathrm{HCO} 2198$ & 5' - TAAACTTCAGGGTGACCAAAAAATCA -3' & \\
\hline \multirow{2}{*}{$\mathrm{H} 3$} & H3-F & 5'-ATGGCTCGTACCAAGCAGAC(ACG)GC-3' & \multirow{2}{*}{ Colgan et al., 1998} \\
\hline & $\mathrm{H} 3-\mathrm{R}$ & 5'-ATATCCTT(AG)GGCAT(AG)AT(AG)GTGAC-3' & \\
\hline
\end{tabular}




\subsubsection{Purificação e amplificação dos produtos da PCR}

Os produtos das PCRs foram purificados utilizando-se o kit de purificação SureClean Plus (BioLine ${ }^{\circledR}$ ), seguindo-se o manual do fabricante. Para a obtenção das sequências, as amostras purificadas foram enviadas ao Departamento de Tecnologia da Faculdade de Ciências Agrárias e Veterinárias (FCAV) de Jaboticabal, da Universidade Estadual Paulista (UNESP), para a realização das reações de PCR de sequenciamento, purificação e sequenciamento.

Cada produto de PCR purificado foi submetido a uma reação de sequenciamento contendo: $3.0 \mu \mathrm{L}$ de tampão de sequenciamento (Save Money ${ }^{\circledR} 2.5 \mathrm{X}$ ), $1.0 \mu \mathrm{L}$ de BigDye Terminator Cycle Sequencing v3.1 (Applied Biosystems ${ }^{\circledR}$ ), 10 pM de primer, produto da PCR purificado em quantidade que totalize $50 \mathrm{ng}$ de DNA por reação e água ultrapura em quantidade que complete um volume total de reação de $10 \mu \mathrm{L}$. A PCR de sequenciamento foi realizada com desnaturação inicial a $96^{\circ} \mathrm{C}$, por 1 minuto, seguido de 39 ciclos de anelamento dos primers $\left(96^{\circ} \mathrm{C}\right.$, por 15 segundos; $50^{\circ} \mathrm{C}$ ou $48^{\circ} \mathrm{C}$, por 15 segundos e $60^{\circ} \mathrm{C}$, por 4 minutos).

Para as amostras processadas durante o estágio no exterior, cada produto de PCR já purificado foi submetido a uma reação de sequenciamento contendo: $1.88 \mu \mathrm{L}$ de tampão BigDye Terminator Sequencing (5x) (Applied Biosystems ${ }^{\circledR}$ ), $1.75 \mu \mathrm{L}$ de tampão BDX64 BigDye $^{\circledR}$ Enhancing Buffer $\left(\right.$ Mclab $\left.^{\circledR}\right), 0.25 \mu \mathrm{L}$ de BigDye Terminator Cycle Sequencing (Applied Biosystems $^{\circledR}$ ), $2 \mu \mathrm{L}$ de primer $(3.2 \mu \mathrm{M})$, produto da PCR purificado em quantidade que totalize $100 \mathrm{ng}$ de DNA por reação e água destilada deionizada em quantidade que complete um volume total de reação de $20 \mu \mathrm{L}$. A PCR de sequenciamento foi realizada no C1000 Touch Thermal Cycler $\left(\right.$ BioRad $\left.^{\circledR}\right)$, com desnaturação inicial a $96^{\circ} \mathrm{C}$, por 3 minutos, seguido de 30 ciclos de anelamento dos primers $\left(96^{\circ} \mathrm{C}\right.$, por 10 segundos; $50^{\circ} \mathrm{C}$, por 10 segundos e $60^{\circ} \mathrm{C}$, por 2 minutos). 


\subsubsection{Precipitação e sequenciamento do DNA}

Os produtos da PCR de sequenciamento foram precipitados por meio da adição de 80 $\mu \mathrm{L}$ de isopropanol $75 \%$ a cada amostra, incubação à temperatura ambiente por 15 minutos e centrifugação por 30 minutos, a $20^{\circ} \mathrm{C}$. Posteriormente ao descarte do sobrenadante, o precipitado foi lavado, duas vezes, com $200 \mu \mathrm{L}$ de etanol 70\%, seco à temperatura ambiente, adicionado a $200 \mu \mathrm{L}$ de etanol 70\%, seguido de centrifugação a $3040 \mathrm{G}$, por 10 minutos, a $20^{\circ} \mathrm{C}$. As amostras foram, então, secas à vácuo, ressuspendidas em $10 \mu \mathrm{L}$ de formamida, desnaturadas por 5 minutos, a $95{ }^{\circ} \mathrm{C}$ e submetidas a sequenciamento em um sequenciador automático ABI 3730xl DNA Analyzer (Applied Biosystems ${ }^{\circledR}$ ) do Departamento de Tecnologia da Faculdade de Ciências Agrárias e Veterinárias (FCAV) de Jaboticabal, da Universidade Estadual Paulista (UNESP).

Para as amostras processadas durante o estágio no exterior, os produtos da PCR de sequenciamento foram purificados utilizando-se o gel de filtração Sephadex G-50 (GE HealthCare ${ }^{\circledR}$ ), segundo manual do fabricante e submetidos a sequenciamento em um sequenciador automático ABI Prism 3130xl Genetic Analyzer (Life Technologies ${ }^{\circledR}$ ), do departamento de Biologia da University of Louisiana at Lafayette, Lafayette, Estados Unidos.

\subsubsection{Edicão das Sequências}

Todas as sequências obtidas foram confirmadas pelo sequenciamento de ambas as fitas e obtenção de uma sequência consenso por meio do programa BioEdit 7.2.0 (Hall, 1999). As regiões dos primers e regiões não-legíveis das sequências foram retiradas. A ausência de stop códons, que podem indicar a presença de pseudogenes, foi visualmente checada utilizando-se a plataforma Emboss Sixpack (http://www.ebi.ac.uk/Tools/st/emboss_sixpack/). Os fragmentos obtidos foram submetidos ao alinhamento no sistema BLAST para confirmação de suas respectivas identidades, em comparação com a assembléia do banco de dados NCBI (http://blast.ncbi.ncbi.nlm.nih.gov/blast.cgi). 


\subsubsection{Análise dos Dados}

Para as análises dos dados, todas as sequências consenso obtidas foram editadas e alinhadas utilizando-se o programa BioEdit 7.2.0, com parâmetros predefinidos no programa Clustal W (Thompson et al., 1994).

\subsubsection{Análises de variação genética}

Para a análise dos haplótipos e diferenciação genética a partir dos dados obtidos para o gene COI, foi seguida metodologia utilizada por Vergamini et al. (2011) e Terossi \& Mantelatto (2012). O número de haplótipos foi calculado no programa DnaSP 5.10.01 (Rozas \& Rozas, 1999) e redes de haplótipos foram construídas, pelo método de Median-Joining, no programa Network 4.6.1.3 (Bandelt et al., 1999), com preparação dos dados no programa DnaSP. As diversidades gênica ou haplotípica (h) e nucleotídica $(\pi)$ foram calculadas por meio do programa Arlequin 3.5.2.2 (Excoffier et al., 2005) e para se avaliar a diferenciação genética e calcular os índices de fixação foi realizada uma Análise de Variância Molecular (AMOVA) (Excoffier et al., 1992), considerando a variação em cada sítio nucleotídico separadamente, no programa Arlequin.

Considerando que a diferenciação de um único nucleotídeo indica a presença de um novo haplótipo, a informação sobre o número de diferenças entre haplótipos é essencial e, em muitos casos, pode ser considerada mais importante do que determinar se as sequências são iguais ou diferentes (Freeland, 2005). Nestes casos, utiliza-se a diversidade nucleotídica $\pi$ (Nei, 1987), baseada na divergência média entre as sequências.

A AMOVA calcula os níveis de variância molecular entre amostras de populações hierarquicamente agrupadas, produzindo estimativas dos componentes de variância análogas às estatísticas $\mathrm{F}$, refletindo, então, a correlação da diversidade dos haplótipos em diferentes níveis de subdivisão hierárquica (Excoffier et al., 2005; Gopurenko, 2002). A AMOVA 
baseia-se na análise da proporção de variância das frequências de haplótipos entre grupos amostrais e é muito eficiente no teste de modelos populacionais quando se tem um conhecimento prévio acerca da estruturação geográfica ou histórica (Excoffier et al., 2005; Gopurenko, 2002).

As estatísticas F de Wright permitem a caracterização da distribuição da variabilidade genética entre as populações e o índice de fixação (FST) reflete a diferenciação genética entre as populações (Zucchi, 2002), sendo considerado uma importante ferramenta em análises populacionais, com aplicações em diversas áreas, tais como conservação ou biologia evolutiva (Meirmans \& Hedrick, 2011). A partir da introdução das estatísticas $\Phi$ (Excoffier et al., 1992), lançou-se uma nova alternativa para a análise de sequências nucleotídicas e, consequentemente, de dados provenientes de haplótipos. Para a análise dos dados obtidos nesse trabalho, o índice FST é utilizado na identificação da estruturação populacional, a partir da diversidade genética, como indicativo de migrantes e/ou de fluxo gênico entre as populações.

$\mathrm{Na}$ intenção de se verificar se há correlação significativa entre a distância geográfica e a divergência genética nos indivíduos analisados, foi realizado o teste de Mantel (Mantel, 1967) com 1000 permutações no programa Arlequin.

\subsubsection{Análises filogenéticas}

No intuito de se verificar a relação entre os indivíduos provenientes de diferentes localidades, foram realizadas análises de máxima verossimilhança para os genes COI e 16S de forma concatenada, utilizando-se o método de busca Maximum Likelihood (Felsenstein, 1973, 1981), por meio do programa RAxML 7.2.7 (Randomized Axelerated Maximum Likelihood) (Stamatakis, 2006), implementado na plataforma CIPRES (Cyberinfrastructure for Phylogenetic Research) (http://www.phylo.org). Foi utilizado o modelo de substituição 
GTR $+\Gamma+\mathrm{I}$ - General Time Reversible (Tavaré, 1986) + Gama + sítios invariáveis-, especificado pelo RAxML. O GTR é o modelo que mais considera parâmetros, assumindo frequências de bases distintas, e taxa de variação distinta entre cada possibilidade de substituição (Pereira et al., 2001). A consistência das topologias foi avaliada pelo método de rapidbootstrap (Stamatakis et al., 2008). As topologias foram visualizadas e editadas no programa MEGA 5.1.

\subsubsection{Análises de distância genética}

Os fragmentos dos genes COI, 16S e H3 obtidos foram analisados separadamente para cada espécie e matrizes de divergência genética foram calculadas no programa MEGA 5.1, utilizando-se o modelo de substituição Kimura-2-parâmetros (Kimura, 1980), para se avaliar a taxa de variação intra e interespecífica. A matriz de divergência genética permite a visualização da diferenciação entre os grupos e das diferenças nas sequências de bases nucleotídicas, não visualizáveis nas topologias construídas. É importante mencionar que esses dados apenas indicam uma relação fenética entre os grupos, não representando relações evolutivas. Posteriormente, diante das matrizes de distância genética, histogramas foram construídos, representando as frequências de pares de localidades por intervalo de distância genética.

\subsubsection{Teste de neutralidade}

Os dados obtidos para o gene COI foram submetidos aos testes de Tajima D (Tajima, 1989) e $\mathrm{Fu} \mathrm{F}_{\mathrm{s}}(\mathrm{Fu}, 1997)$, no programa Arlequin, com o objetivo de se detectar desvios em relação à neutralidade, ou seja, se os dados indicam um modelo distinto daquele assumido por Wright-Fisher, no qual as mutações são neutras (Fisher, 1930; Wright, 1931) e a maior parte da variação genética é considerada como resultado de deriva genética (Duret, 2008). Desvios 
em relação à neutralidade podem ser interpretados como resultado de processos evolutivos e diversos tipos de seleção, tais como seleção balanceadora e efeito carona ou de mudanças na estrutura populacional, como expansões, retrações, efeito gargalo, dentre outros. Assim, uma hipótese nula de neutralidade é assumida e, se rejeitada, os dados indicariam a interferência de processos evolutivos nas populações das espécies estudadas.

\subsubsection{Datação molecular}

Utilizando-se os dados obtidos para o gene COI e com a adoção de apenas uma sequência por localidade, foi realizada uma análise de datação molecular para a avaliação do tempo de divergência entre clados apenas para as espécies que apresentaram elevada estruturação populacional (Aratus pisonii e Uca thayeri). Por meio de inferências bayesianas, foi utilizado um relógio molecular estrito no programa Mr. Bayes 3.2.2 (Ronquist et al., 2012). Para ambas as espécies analisadas, o modelo de substituição de nucleotídeos utilizado foi $\operatorname{TrN}+\mathrm{I}+\mathrm{G}$, selecionado pelo Critério de Informação Bayesiano (BIC), no software jModelTest 2.1.4 (Darriba et al., 2012). As análises foram realizadas com 5x10 gerações. Para Aratus pisonii, a calibração do relógio baseou-se no tempo de divergência de 3.1 milhões de anos das espécies A. pisonii e Aratus pacificus (Thiercelin \& Schubart 2014) (Thiercelin \& Schubart, 2014). Para Uca thayeri, a calibração foi realizada com base no tempo de divergência das espécies Uca borealis Crane 1975 e Uca crassipes (White 1847) (28.5 milhões de anos) e das espécies Uca lactea (De Haan 1835) e U. borealis + U. crassipes (33.8 milhões de anos) (Tsang et al., 2014). Para a análise de datação da espécie Uca thayeri, as sequências das espécies utilizadas nos nós de calibração foram obtidas do GenBank (números de acesso U. borealis: AB491163; U. crassipes: AB471918; U. lactea: AB471913). As topologias finais foram visualizadas e editadas no software FigTree 1.4.0. 


\subsection{ANÁLISES MORFOLÓGICAS}

\section{$\underline{\text { 5.3.1 Variabilidade Morfológica Comparativa }}$}

Para a análise da variabilidade morfológica de forma comparativa, adotou-se, para cada espécie, uma lista de caracteres morfológicos abaixo detalhados, previamente estabelecidos com base em diagnoses e descrições e na literatura para a taxonomia das famílias correspondentes. Os caracteres morfológicos propostos foram comparados entre os indivíduos de diferentes localidades. Vide Figura 2 para consulta das estruturas. 


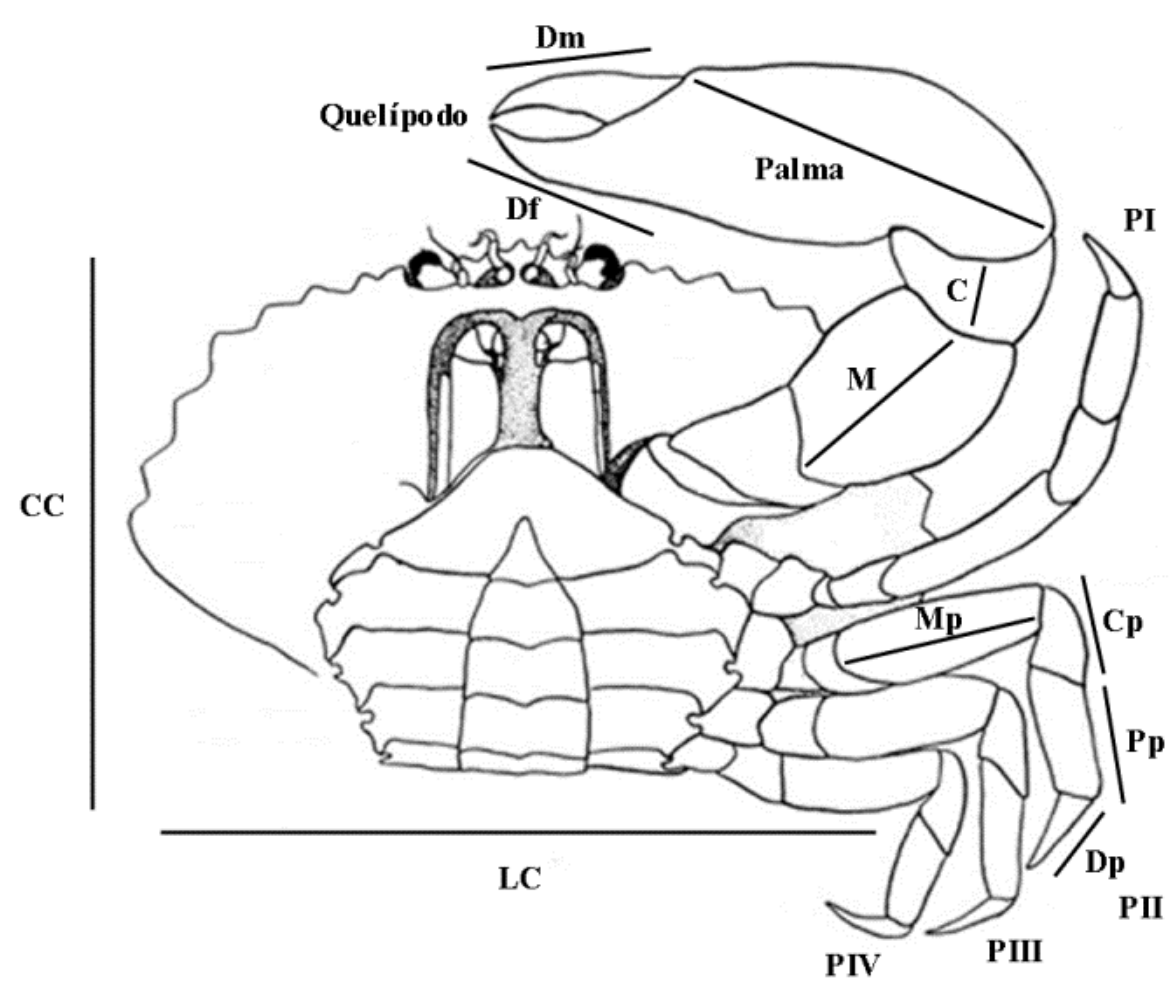

Figura 2. Desenho esquemático de um caranguejo Brachyura em vista ventral. LC: largura da carapaça; CC: comprimento da carapaça; PI a PIV: pereópodos ou pernas ambulatórias I a IV; Mp: comprimento do mero do pereópodo; $\mathrm{Cp}$ : comprimento do carpo do pereópodo; $\mathrm{Pp}$ : comprimento do própodo do pereópodo; Dp: comprimento do dátilo do peréopodo; $\mathrm{M}$ : comprimento do mero do quelípodo; C: comprimento do carpo do quelípodo; Palma: comprimento da palma; Dm: comprimento do dedo móvel do quelípodo; comprimento do Df: dedo fixo do quelípodo. Retirado e modificado de Williams (1984), fig. 3, p. 10. 


\section{Aratus pisonii}

A diagnose de Melo (1996) para a espécie foi seguida para a análise de variabilidade morfológica, adicionada aos caracteres morfológicos clássicos utilizados na literatura para a taxonomia da família (Abele \& Kim, 1986; Melo, 1996; Prado-Ratti, 2004), comparando-os e acrescentando novos caracteres, de acordo com a variabilidade encontrada. Todos os caracteres foram analisados baseando-se na morfologia de machos e de fêmeas, sendo os machos caracterizados pela presença de um abdômen subcircular com um par de gonópodos (pleópodos I e II modificados). Foram comparados e sumarizados os seguintes caracteres morfológicos:

- formato da carapaça

- presença de grânulos na porção externa da região branquial, lóbulos gástricos e face superior da fronte

- disposição e quantidade de lóbulos da fronte

- tamanho do dente orbital externo

- presença de espinho ou dente na margem interna do ísquio do quelípodo

- presença de estrias granuladas na face externa do mero e carpo dos pereópodos

- presença de margens espinulosas no mero dos pereópodos

- presença de espinhos terminal e subterminal no mero dos pereópodos

- presença de fileira de cerdas no própodo dos pereópodos PI e PII

- número de dentes da evaginação do mero do quelípodo

Foi aplicado um teste “t”, utilizando-se o programa Statistica 7.0, com o intuito de se averiguar a existência de diferenças significativa entre a largura (LC) e o comprimento (CC) da carapaça. 


\section{Goniopsis cruentata}

A descrição de Chace \& Hobbs (1969) e a diagnose de Melo (1996) para a espécie foram seguidas para as análises de variabilidade morfológica, adicionadas aos caracteres morfológicos clássicos utilizados na literatura (Chace \& Hobbs, 1969; Melo, 1996; PradoRatti, 2004) para a taxonomia da família, comparando-os e acrescentando novos caracteres, de acordo com a variabilidade encontrada. Todos os caracteres foram analisados baseando-se na morfologia de machos e de fêmeas, sendo os machos caracterizados pela presença de um abdômen subtriangular com um par de gonópodos (pleópodos I e II modificados). Foram analisados e descritos os seguintes caracteres morfológicos:

- morfologia da região branquial da carapaça

- disposição e tamanho dos lóbulos da fronte

- presença de tubérculos e margem serrilhada na fronte

- morfologia das carenas no mero do quelípodo

- número e tamanho dos dentes nas margens interna e externa no mero do quelípodo

- $\quad$ presença de dentes no ângulo interno do carpo do quelípodo

- número e disposição de linha de tubérculos na face externa da palma

- presença de dente subterminal do mero dos pereópodos

- presença de duas estrias horizontais no carpo dos pereópodos

- presença de tubérculos nas margens dos quelípodos

- número de espinhos na margem interna do ísquio do quelípodo

\section{Sesarma rectum}

A descrição de Abele (1992) e a diagnose de Melo (1996) para a espécie foram seguidas para as análises, adicionadas aos caracteres morfológicos clássicos utilizados na literatura (Abele, 1992; Melo, 1996; Prado-Ratti, 2004) para a taxonomia da família, 
comparando-os e acrescentando novos caracteres, de acordo com a variabilidade morfológica encontrada. Todos os caracteres foram analisados baseando-se na morfologia de machos e de fêmeas, sendo os machos caracterizados pela presença de um abdômen subtriangular com um par de gonópodos (pleópodos I e II modificados). Foram analisados e descritos os seguintes caracteres morfológicos:

- razão largura/comprimento do mero dos pereópodos

- morfologia da saliência da carapaça após o dente pós-orbital

- disposição e quantidade de tufos de cerdas e carenas da região dorsal da carapaça

- razão comprimento/largura e morfologia da carapaça

- morfologia da fronte

- comprimento e quantidade de dentes do serrilhado da margem dorsal do dedo móvel

- presença, quantidade e disposição de linhas transversais do mero dos pereópodos PI e PII

- presença de dente subterminal no mero dos pereópodos

- disposição e quantidade de estrias transversais no carpo e própodo dos pereópodos

- disposição e quantidade de fileiras de cerdas no própodo e dátilo dos pereópodos

- ornamentações da face externa e interna da palma

- presença de espinhos e dentes subterminais no mero e carpo do quelípodo

Foi aplicado um teste "t", utilizando-se o programa Statistica 7.0, com o intuito de se averiguar a existência de diferenças significativa entre a largura (LC) e o comprimento (CC) da carapaça. 


\section{Uca thayeri}

A diagnose de Bezerra (2012) para a espécie foi seguida para as análises de variabilidade morfológica, adicionada aos caracteres morfológicos clássicos utilizados na literatura (Crane, 1975; Melo, 1996; Bezerra, 2012) para a taxonomia da família, comparando-os e acrescentando novos caracteres, de acordo com a variabilidade encontrada. Todos os caracteres foram analisados baseando-se na morfologia de machos e de fêmeas, sendo os machos caracterizados pela presença de um abdômen subtriangular com um par de gonópodos (pleópodos I e II modificados) e pelo crescimento desigual de um dos quelípodos, que chega a atingir tamanhos superiores à largura da carapaça do animal portador (Crane, 1975). Foram analisados os seguintes caracteres morfológicos:

- pubescência na margem dorsal da carapaça em forma de $\mathrm{H}$

- forma da sobrancelha

- forma da depressão pós-margem suborbicular

- presença e distribuição de granulações suborbiculares

- presença de linha de cerdas acima e abaixo das granulações suborbiculares

- presença de tubérculos e cerdas nas estrias póstero-laterais superiores

- presença de cerdas e distribuição do serrilhado dos dedos do quelípodo menor

- presença de granulações na palma externa

- carena oblíqua da palma não atingindo o meio da cavidade carpal

- tamanho relacionado e forma dos dedos do quelípodo maior

- pubescência aveludada na superfície posterior dos pereópodos

- número e distribuição dos tubérculos na margem interna dos dedos do quelípodo maior

- presença e número de tubérculos na margem interna do carpo do quelípodo maior 


\section{Ucides cordatus}

A diagnose de Melo (1996) para a espécie foi seguida para as análises de variabilidade morfológica, adicionada aos caracteres morfológicos clássicos utilizados na literatura (Chace \& Hobbs, 1969; Melo, 1996) para a taxonomia da família, comparando-os e acrescentando novos caracteres, de acordo com a variabilidade encontrada. Todos os caracteres foram analisados baseando-se na morfologia de machos e de fêmeas, sendo os machos caracterizados pela presença de um abdômen subtriangular com um par de gonópodos (pleópodos I e II modificados). Foram analisados os seguintes caracteres morfológicos:

- forma e proporções da carapaça

- proporção da largura fronto-orbital

- forma e proporções da córnea

- presença de uma longa franja de cerdas no carpo e própodo dos pereópodos II a IV em machos

- ausência de longa franja de cerdas na superfície ventral da coxa dos pereópodos III e IV

- margem suborbital tuberculada e com franja de cerdas na região anterior

- tubérculos formando uma linha que desce até a porção final da margem suborbital e margeia o aparato bucal

- mancha pubescente no carpo e própodo dos pereópodos

\subsubsection{Morfometria}

Para a avaliação da variabilidade morfométrica, as seguintes medidas foram obtidas: largura (LC) e comprimento da carapaça (CC), comprimento dos artículos mero (Mp), carpo (Cp), própodo $(\mathrm{Pp})$ e dátilo $(\mathrm{Dp})$ do peréopodo II e comprimento dos artículos mero (M), carpo (C), palma (P), dedo móvel do quelípodo (Dm) e dedo fixo do quelípodo (Df) (Fig. 2). 
Considerando as análises morfométricas, todas as medidas obtidas foram logaritimizadas e, em seguida, padronizadas, a partir de uma equação alométrica e, posteriormente, submetidas a uma análise morfométrica clássica, com exceção da largura da carapaça que foi utilizada como variável independente na equação alométrica. A transformação dos dados por meio da logaritimização e da aplicação de uma equação alométrica tem como objetivo a remoção do efeito do tamanho nas estruturas mensuradas (Tzeng, 2004). A equação $y=a x^{b}$, obtida por meio da plotagem de gráficos de dispersão entre as medidas das variáveis independentes e cada uma das variáveis dependentes, foi utilizada para encontrar o valor de b (Tzeng, 2004). Então, todas as demais medidas foram padronizadas de acordo com a equação $\mathrm{Yi}^{*}=\mathrm{Yi}[\mathrm{X} / \mathrm{Xi}] \mathrm{b}$, no qual $\mathrm{Yi}^{*}$ corresponde ao valor padronizado final da medida; Yi corresponde ao valor da medida que será padronizada; $X$ corresponde à média do valor da variável independente (LC) de cada amostra analisado e Xi corresponde ao valor de LC do indivíduo analisado (Tzeng, 2004).

Quando vários caracteres são medidos em duas ou mais populações ou grupos distintos, funções lineares dessas medidas podem diagnosticar quais delas melhor discriminam esses grupos (Fisher, 1936). Assim, o padrão de discriminação entre indivíduos de diferentes populações pode ser examinado por meio da análise das funções discriminantes, em associação com as variáveis canônicas (Fisher, 1936; Morrison, 1976; Pimentel, 1979).

A Análise Discriminante gera funções discriminantes, ou seja, combinações lineares das variáveis, que ampliam a discriminação dos grupos descritos pelas variáveis dependentes (Fávero et al., 2009). A Análise de Discriminantes Canônicos é uma técnica que permite a redução da dimensionalidade dos dados, sendo especialmente empregada em análises realizadas a partir de amostras com observações repetidas. A análise visa obter combinações lineares, ou variáveis canônicas, das características medidas, de forma que a correlação entre essas variáveis seja nula (Khattree \& Naik, 2000). A redução dessa dimensionalidade 
proposta pela Análise de Discriminantes Canônicos constitui, então, as variáveis canônicas obtidas na análise discriminante que podem ser entendidas como o número de raízes não nulas.

Assim, diante das medidas transformadas, foi realizada uma Análise Discriminante e uma Análise de Discriminantes Canônicos, no programa Statistica 7.0, com o objetivo determinar quais variáveis mensuradas foram mais significativas e verificar a existência de diferenças morfométricas entre os indivíduos oriundos de grupos distintos. O poder de discriminação de cada variável foi analisado pelo teste de Wilks'Lambda, associado aos valores estatísticos de $\mathrm{F}$ e $\mathrm{P}$, de forma que os valores de $\mathrm{F}>1$ e significativos $(\mathrm{p}<0.05)$ foram considerados discriminantes para as amostras e os valores Wilks'Lambda, que variam de 0 a 1, mais elevados e mais próximos a 1 indicam ausência de discriminação (Lu \& Bernatchez, 1999; Anastasiadou \& Leonardos, 2008). Também, foi analisada a estatística F da distância de Mahalanobis, a fim de se demonstrar se há significância na distância entre os grupos analisados.

Adicionalmente, foi realizada uma Análise de Discriminantes Canônicos, na qual as variáveis canônicas (raízes) foram testadas quanto à sua significância pelo teste do $\chi^{2}$ e, posteriormente, os escores canônicos significativos foram plotados em um gráfico, para visualização da possível formação de grupos (Lu \& Bernatchez, 1999). 


\section{RESULTADOS}




\section{Resultados}

\subsection{ANÁLISES MOLECULARES}

Para as análises moleculares, os indivíduos de cada uma das espécies foram agrupados em diferentes localidades, de acordo com o estado de procedência (para as amostras brasileiras) ou país (para as demais amostras), conforme as indicações nas Tabelas 2 a 6 . Para o agrupamento dos indivíduos, optou-se pela adoção do termo "localidade", ao invés de "populações", uma vez que os limites aqui adotados seguem barreiras geopolíticas, simplesmente para efeito de amostragem, e não necessariamente genéticas.

De uma forma geral, os resultados obtidos permitem a divisão das espécies estudadas em dois padrões de estruturação populacional: 1) espécies com elevada estruturação populacional, com ausência de compartilhamento de haplótipos entre grupos geográficos; e 2) espécies com estruturação populacional reduzida ou ausente, com total compartilhamento de haplótipos em sua maioria. Assim, optou-se por apresentar os resultados das análises moleculares de acordo com os padrões encontrados. 


\subsubsection{Espécies com Elevada Estruturação Populacional}

\section{Aratus pisonii}

\section{$\underline{\text { Análise de variação genética }}$}

As análises de variação genética foram baseadas em um alinhamento final de 629 pares de bases, contendo fragmentos parciais do gene COI de 75 espécimes de A. pisonii provenientes de 16 localidades distintas (Tabela 2). Foram encontrados 30 sítios polimórficos e 19 haplótipos (H) distintos foram definidos e estão distribuídos na rede de haplótipos apresentada (Fig. 3). A diversidade haplotípica total encontrada foi de 0.8641. Dentre os haplótipos definidos, 10 representaram haplótipos individuais e, considerando os haplótipos compartilhados por mais de um indivíduo, o H15 foi o mais frequente, sendo compartilhado por 24 indivíduos provenientes de sete localidades. As diversidades gênicas (h), ou haplotípicas, calculadas para as populações de A. pisonii variaram de 0 a 1 e as diversidades nucleotídicas $(\pi)$ variaram de 0 a 0.00286 (Tabela 8). Dentre as localidades com números amostrais mais elevados, a que apresentou maiores valores de diversidades gênica e nucleotídica corresponde à Costa Rica $(\mathrm{h}=0.9000 \pm 0.1610 ; \pi=0.00286 \pm 0.00229)$ (Tabela $8)$.

A rede de haplótipos evidenciou divisão em três grandes grupos que não compartilham haplótipos entre si, sendo eles: 1) EUA + México; 2) Costa Rica + Panamá + Venezuela; e 3) Trinidad \& Tobago + localidades brasileiras (Fig. 3). Dentre cada um dos grupos, os haplótipos encontram-se a, no máximo, três passos mutacionais dos haplótipos principais (Fig. 3). Um total de oito passos mutacionais separam o grupo 1 do grupo 2; sete passos separam os grupos 1 e 3; e nove passos separam os haplótipos dos grupos 2 e 3 (Fig. 3). Considerando o grupo 1, apesar da mínima distância mutacional, em comparação com a 
distância entre os grupos, não há compartilhamento de haplótipos entre as localidades EUA e México (Fig. 3). Da mesma forma, considerando o grupo 3, não há compartilhamento de haplótipos entre as localidades Trinidad \& Tobago + Brasil (AP) + Brasil (PA) e as demais localidades (Fig. 3).

A análise de variância molecular (AMOVA) com estrutura hierárquica simples, ou seja, sem estruturação entre grupos, mostrou que a maior porcentagem de variação $(87.02 \%)$ encontra-se entre as populações de A. pisonii analisadas (Tabela 9). A aplicação da AMOVA com estruturação das populações de acordo com os grupos evidenciados pela rede de haplótipos detectou que a maior parte da variação genética (84.52\%) encontra-se entre os grupos analisados, com reduzida porcentagem de variação entre as populações (Tabela 9). Os valores dos índices de fixação obtidos para cada uma das análises e seus correspondentes valores de $p$ sugerem alto grau de diferenciação genética e restrição de fluxo gênico significativa entre os grupos (Tabela 9). 


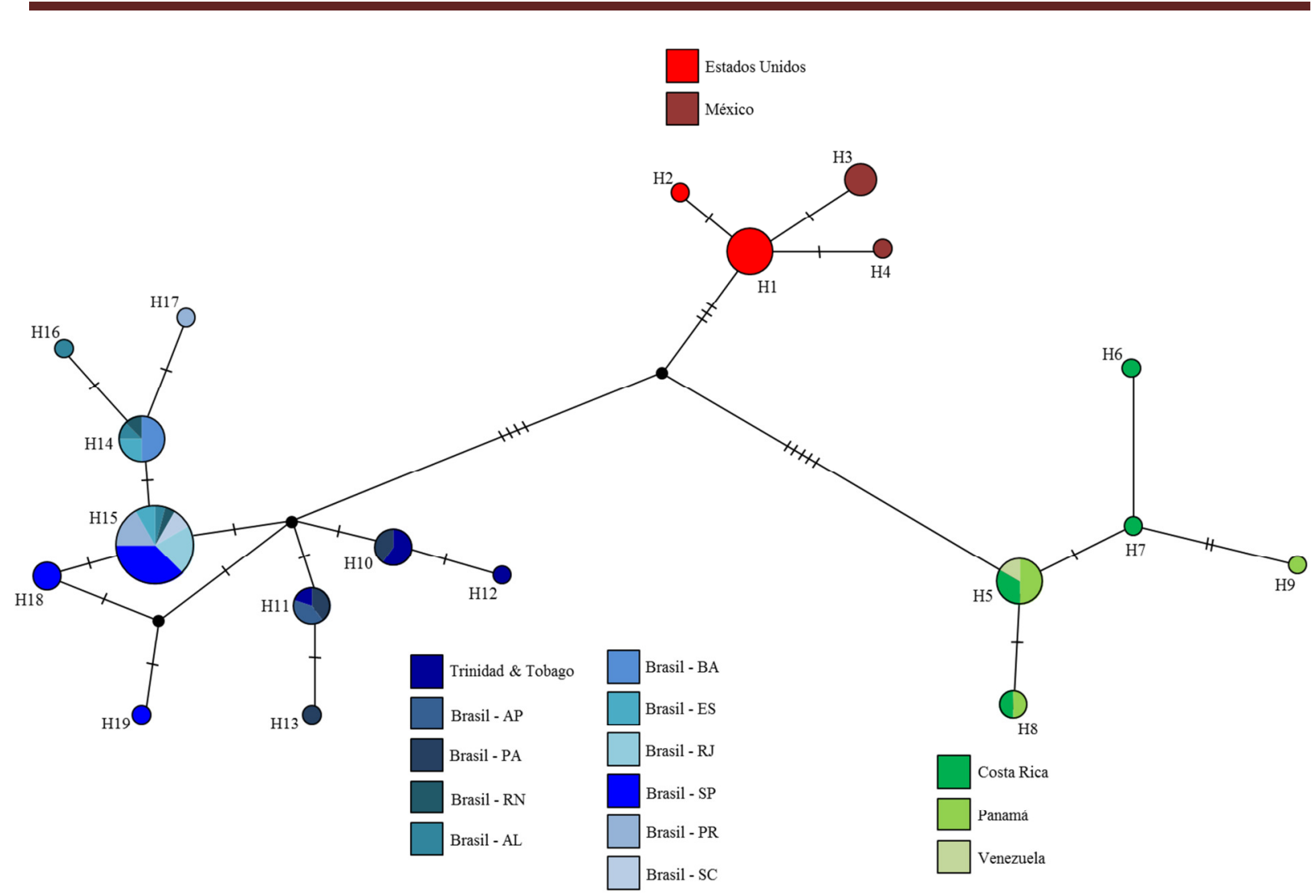

Figura 3. Aratus pisonii. Rede de haplótipos construída pelo método de Median-Joining, indicando a distribuição dos 19 haplótipos (H) identificados. O tamanho do círculo é proporcional à frequência do haplótipo. Os traços em preto indicam passos mutacionais. Para designação das localidades, consultar Tabela 2. 
Tabela 8. Aratus pisonii. Número de indivíduos, de haplótipos e índices de diversidade haplotípica ou gênica $(h)$ e nucleotídica $(\pi)$, por localidade. Para designação das localidades, consultar Tabela 2.

\begin{tabular}{l|c|c|c|c}
\hline \multicolumn{1}{c|}{ Localidade } & $\begin{array}{c}\text { Número } \\
\text { de } \\
\text { Indivíduos }\end{array}$ & $\begin{array}{c}\text { Número } \\
\text { de } \\
\text { Haplótipos }\end{array}$ & $\begin{array}{c}\text { Diversidade } \\
\text { Gênica (h) }\end{array}$ & $\begin{array}{c}\text { Diversidade } \\
\text { Nucleotídica ( } \boldsymbol{\pi})\end{array}$ \\
\hline EUA & 9 & 2 & $0.2222 \pm 0.1662$ & $0.00035 \pm 0.00051$ \\
México & 5 & 2 & $0.4000 \pm 0.2373$ & $0.00127 \pm 0.00126$ \\
Costa Rica & 5 & 4 & $0.9000 \pm 0.1610$ & $0.00286 \pm 0.00229$ \\
Panamá & 5 & 3 & $0.7000 \pm 0.2184$ & $0.00254 \pm 0.00209$ \\
Venezuela & 1 & 1 & $1.0000 \pm 0.0000$ & $0.00000 \pm 0.00000$ \\
Trinidad \& Tobago & 5 & 3 & $0.7000 \pm 0.2184$ & $0.00190 \pm 0.00168$ \\
Brasil - AP & 2 & 1 & $0.0000 \pm 0.0000$ & $0.00000 \pm 0.00000$ \\
Brasil - PA & 5 & 3 & $0.8000 \pm 0.1640$ & $0.00254 \pm 0.00209$ \\
Brasil - RN & 2 & 2 & $1.0000 \pm 0.5000$ & $0.00159 \pm 0.00224$ \\
Brasil - AL & 3 & 3 & $1.0000 \pm 0.2722$ & $0.00212 \pm 0.00217$ \\
Brasil - BA & 5 & 2 & $0.4000 \pm 0.2373$ & $0.00063 \pm 0.00080$ \\
Brasil - ES & 4 & 2 & $0.6667 \pm 0.2041$ & $0.00106 \pm 0.00118$ \\
Brasil - RJ & 5 & 1 & $0.0000 \pm 0.0000$ & $0.00000 \pm 0.00000$ \\
Brasil - SP & 13 & 3 & $0.5000 \pm 0.1364$ & $0.00122 \pm 0.00107$ \\
Brasil - PR & 4 & 1 & $0.0000 \pm 0.0000$ & $0.00000 \pm 0.00000$ \\
Brasil - SC & 2 & 1 & $0.0000 \pm 0.0000$ & $0.00000 \pm 0.00000$ \\
\hline
\end{tabular}


Tabela 9. Resultados das análises de variância molecular $(\mathrm{AMOVA}){ }^{*}=$ valores significativos: $\mathrm{p}<0.05$

\begin{tabular}{|c|c|c|c|c|c|}
\hline Espécie & Estruturação & Fonte de Variação & $\begin{array}{l}\text { Porcentagem } \\
\text { de Variação }\end{array}$ & $\begin{array}{l}\text { Índices de } \\
\text { Fixação }\end{array}$ & $\mathbf{p}$ \\
\hline \multirow[b]{2}{*}{ Aratus pisonii } & $\varnothing$ & $\begin{array}{c}\text { entre populações } \\
\text { dentro das populações }\end{array}$ & $\begin{array}{l}87.02 \% \\
12.97 \%\end{array}$ & $\mathrm{FST}=0.87023$ & $0.00000^{*}$ \\
\hline & $\begin{array}{c}(\text { EUA + México }) \text { x }(\text { Costa } \\
\text { Rica + Panamá }+ \\
\text { Venezuela) x (Trinidad \& } \\
\text { Tobago + Brasil }) \\
\end{array}$ & $\begin{array}{c}\text { entre grupos } \\
\text { entre populações (dentro dos grupos) } \\
\text { dentro das populações }\end{array}$ & $\begin{array}{l}84.52 \% \\
7.48 \% \\
7.99 \% \\
\end{array}$ & $\begin{aligned} \mathrm{FCT} & =0.84521 \\
\mathrm{FSC} & =0.48357 \\
\mathrm{FST} & =0.92006\end{aligned}$ & $\begin{array}{l}0.00000^{*} \\
0.00000^{*} \\
0.00000^{*}\end{array}$ \\
\hline Goniopsis cruentata & $\varnothing$ & $\begin{array}{c}\text { entre populações } \\
\text { dentro das populações }\end{array}$ & $\begin{array}{l}-6.40 \% \\
106.40 \%\end{array}$ & $\mathrm{FST}=-0.06405$ & 0.99804 \\
\hline \multirow{4}{*}{ Sesarma rectum } & $\varnothing$ & $\begin{array}{c}\text { entre populações } \\
\text { dentro das populações }\end{array}$ & $\begin{array}{l}73.43 \% \\
26.56 \% \\
\end{array}$ & $\mathrm{FST}=0.26563$ & $0.00000 *$ \\
\hline & \multirow{3}{*}{$\begin{array}{l}\text { Brasil (CE) X demais } \\
\text { localidades }\end{array}$} & entre grupos & $14.32 \%$ & $\mathrm{FCT}=0.14327$ & 0.30694 \\
\hline & & entre populações (dentro dos grupos) & $32.69 \%$ & $\mathrm{FSC}=0.38158$ & $0.00000 *$ \\
\hline & & dentro das populações & $52.98 \%$ & $\mathrm{FST}=0.47018$ & $0.00000^{*}$ \\
\hline \multirow[b]{2}{*}{ Uca thayeri } & $\varnothing$ & $\begin{array}{c}\text { entre populações } \\
\text { dentro das populações }\end{array}$ & $\begin{array}{l}66.55 \% \\
33.44 \% \\
\end{array}$ & $\mathrm{FST}=0.66558$ & $0.00000 *$ \\
\hline & $\begin{array}{c}(\text { EUA + Jamaica }+ \text { México }) \\
\text { x Brasil }\end{array}$ & $\begin{array}{c}\text { entre grupos } \\
\text { entre populações (dentro dos grupos) } \\
\text { dentro das populações }\end{array}$ & $\begin{array}{l}85.93 \% \\
0.33 \% \\
13.73 \% \\
\end{array}$ & $\begin{array}{l}\mathrm{FCT}=0.85936 \\
\mathrm{FSC}=0.02325 \\
\mathrm{FST}=0.86263\end{array}$ & $\begin{array}{c}0.00000^{*} \\
0.25024 \\
0.00000^{*}\end{array}$ \\
\hline Ucides cordatus & $\varnothing$ & $\begin{array}{c}\text { entre populações } \\
\text { dentro das populações }\end{array}$ & $\begin{array}{l}0.66 \% \\
99.33 \%\end{array}$ & $\mathrm{FST}=0.00662$ & 0.40176 \\
\hline
\end{tabular}


$\underline{\text { Análise filogenética }}$

A análise filogenética concatenada para os genes COI e $16 \mathrm{~S}$ foi baseada nos alinhamentos para cada um dos genes, contendo, respectivamente, 669 e 590 pares de bases. A análise final baseou-se no alinhamento de 1259 pares de bases, contendo fragmentos parciais dos genes de 18 espécimes de A. pisonii provenientes de 15 localidades distintas (Tabela 2). Ademais, foram adicionadas à análise duas sequências da espécie congenérica Aratus pacificus (GenBank COI: KU313185, KU313186; 16S: KU313170, KU313171) e, para enraizamento da topologia, foram utilizadas sequências das espécies Armases rubripes (Rathbun 1897) (GenBank COI: KU313187; 16S: KU313172) e Sesarma curacaoense De Man 1892 (GenBank COI: KU313188; 16S: KU313173). A escolha desses representantes baseou-se em resultados de análises filogenéticas prévias estabelecidas para a família Sesarmidae (Niem, 1993; Niem, 1996; Schubart et al., 2000a; Thiercelin \& Schubart, 2014), bem como na alternativa de se incluir representantes pertencentes à mesma família na qual a espécie Aratus pisonii encontra-se inserida (Schubart et al., 2000a; Ng et al., 2008).

O dendrograma obtido evidenciou os mesmos três grandes grupos encontrados na rede de haplótipos, por meio da formação de três clados bem suportados, exibindo elevados valores de bootstrap, dentro do clado de indivíduos pertencentes à A. pisonii, concentrando, então, indivíduos pertencentes às localidades 1) EUA + México, 2) Costa Rica + Panamá + Venezuela e 3) Trinidad \& Tobago + localidades brasileiras em seus respectivos clados (Fig. 4). Ademais, a análise demonstrou a formação de um clado bem suportado contendo ambas as espécies do gênero Aratus, clado-irmão aquele formado pelas espécies pertencentes ao grupo externo (Fig. 4). 


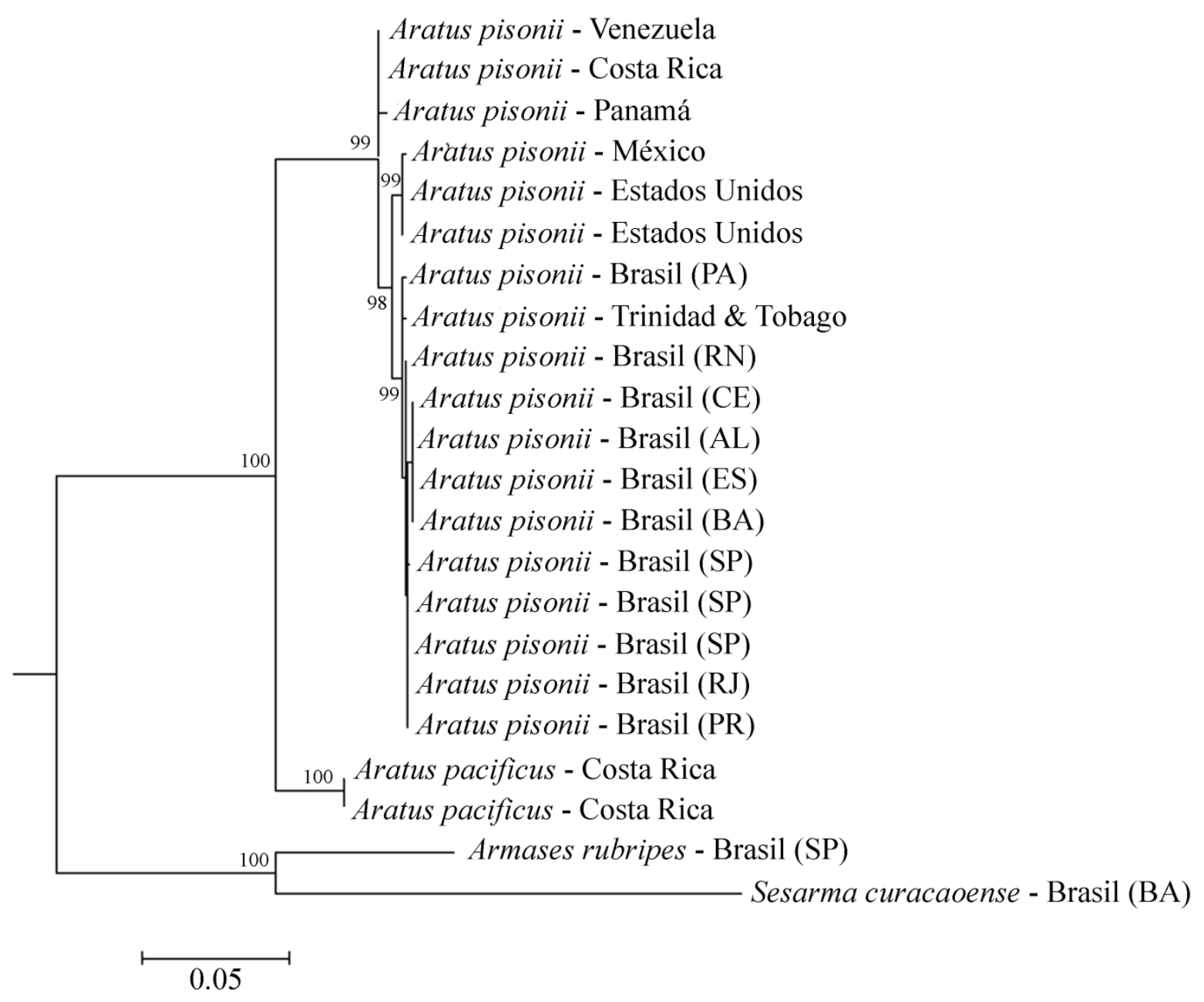

Figura 4. Aratus pisonii. Dendrograma construído pelo método de busca por "Maximum Likelihood" para os genes COI e 16S concatenados. Os números apresentados correspondem aos valores de significância para 1000 réplicas de bootstrap. Para designação das localidades, consultar Tabela 2. 
$\underline{\text { Análise de distância genética }}$

Os alinhamentos finais para as análises de distância genética correspondem aos mesmos alinhamentos utilizados para a análise filogenética dos genes COI e 16S, separadamente.

Para o gene COI, observou-se distância genética para os espécimes de Aratus pisonii analisados variando de 0 a 2.6\%, sendo que a divergência entre os indivíduos dentro de cada um dos grupos evidenciados pelas redes de haplótipos e dendrograma variou de 0 a $0.8 \%$, enquanto que a distância entre os grupos variou de 1.4 a $2.6 \%$ (Fig. 5A), evidenciando a presença de um pequeno gap entre as distâncias intra e intergrupos. A taxa de divergência interespecífica mostrou-se superior à intraespecífica, uma vez que a distância entre as espécies congenéricas variou de 4.8 a $6.7 \%$ e a distância interespecífica, incluindo as espécies utilizadas como grupos externos, variou de 9.2 a $11.15 \%$ (Fig. 5A).

No entanto, para o gene $16 \mathrm{~S}$, houve sobreposição das taxas de distância intra-grupo e entre os indivíduos pertencentes a grupos distintos: a divergência dentro dos grupos variou de 0 a $0.4 \%$, enquanto que a entre os grupos variou de 0.2 a $0.6 \%$ (Fig. 5B). A taxa de divergência interespecífica mostrou-se superior à intraespecífica, uma vez que a distância entre as espécies congenéricas variou de 2.8 a 3.4\% e a distância interespecífica, incluindo as espécies utilizadas como grupos externos, variou de 3.6 a $7.9 \%$ (Fig. 5B).

Para o gene H3, a análise de distância genética baseou-se no alinhamento de 341 pares de bases, contendo fragmentos parciais dos genes de 14 espécimes de A. pisonii provenientes de 12 localidades distintas (Tabela 2). Para esse gene, observou-se distância genética de 0\% entre todos os espécimes.

O teste de Mantel indicou uma correlação significativa entre a distância genética para o gene COI e a distância geográfica dos indivíduos analisados (coeficiente de correlação = 0.5207; $\mathrm{p}=0$ ). 

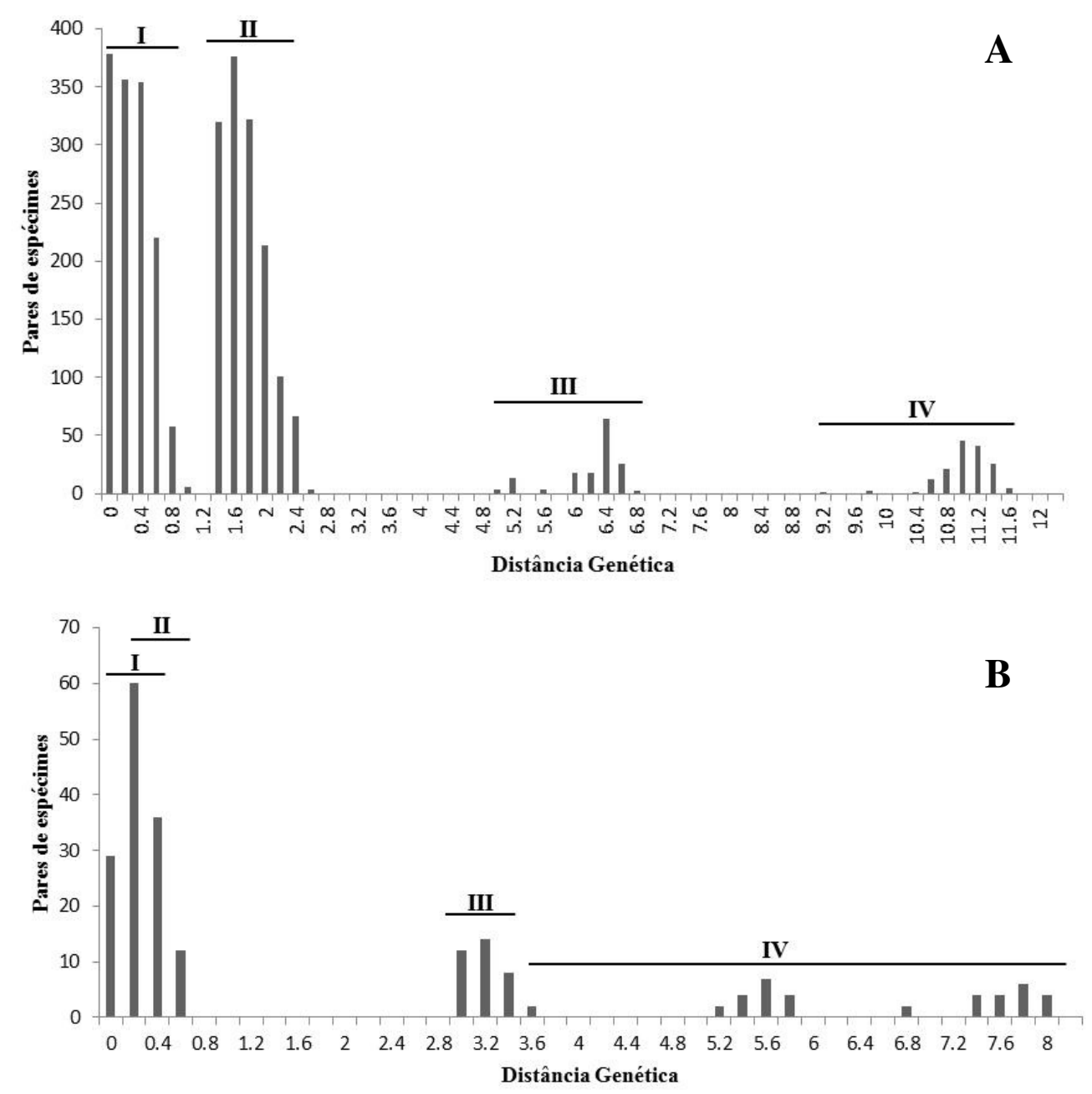

Figura 5. Aratus pisonii. Histogramas com as frequências de distâncias genéticas entre os pares de localidades analisadas para os genes COI (A) e 16S (B); I: variação intraespecífica dentro dos grupos; II: variação intraespecífica entre os grupos; III: variação interespecífica congenérica; IV: variação intergenérica. 
$\underline{\text { Teste de neutralidade }}$

Os testes de Tajima $\mathrm{D}$ e Fu $\mathrm{F}_{\mathrm{s}}$ para as amostras de cada um dos três grupos não foram significativos: grupo $1: \mathrm{D}=-0.70, \mathrm{p}>0.05 ; \mathrm{F}_{\mathrm{s}}=-1.11, \mathrm{p}>0.05$; grupo $2: \mathrm{D}=-1.07, \mathrm{p}>0.05$; $\mathrm{F}_{\mathrm{s}}=-1.08, \mathrm{p}>0.05 ;$ grupo 3: $\mathrm{D}=-0.93, \mathrm{p}>0.05 ; \mathrm{F}_{\mathrm{s}}=-3.24, \mathrm{p}>0.05$. Assim, o teste de neutralidade não apontou valores significativamente diferentes de zero para todos os grupos, indicando que a hipótese nula de neutralidade das populações não pode ser rejeitada.

\section{$\underline{\text { Datação Molecular }}$}

Com base no gene COI e utilizando-se um relógio estrito, estimou-se o tempo de divergência entre os clados que incluem os indivíduos dos três grupos distintos, evidenciados pelas análises de variação genética e de máxima verossimilhança (Fig 6). O tempo de divergência entre os grupos 1 (EUA + México $)+3($ Trinidad \& Tobago + localidades brasileiras) e 2 (Costa Rica + Panamá + Venezuela) foi estimado como tendo ocorrido há, aproximadamente, 1.07 milhões de anos (Ma) (Fig 6) e o intervalo de 95\% de credibilidade foi de 0.61 a 1.64 Ma. O tempo de divergência entre os grupos 1 e 3 foi estimado como tendo ocorrido há, aproximadamente, 0.78 Ma e o intervalo de $95 \%$ de credibilidade foi de 0.44 a 1.19 Ma (Fig 6). Assim, os dados obtidos sugerem que a divergência entre todos os grupos tenha ocorrido no Pleistoceno. 


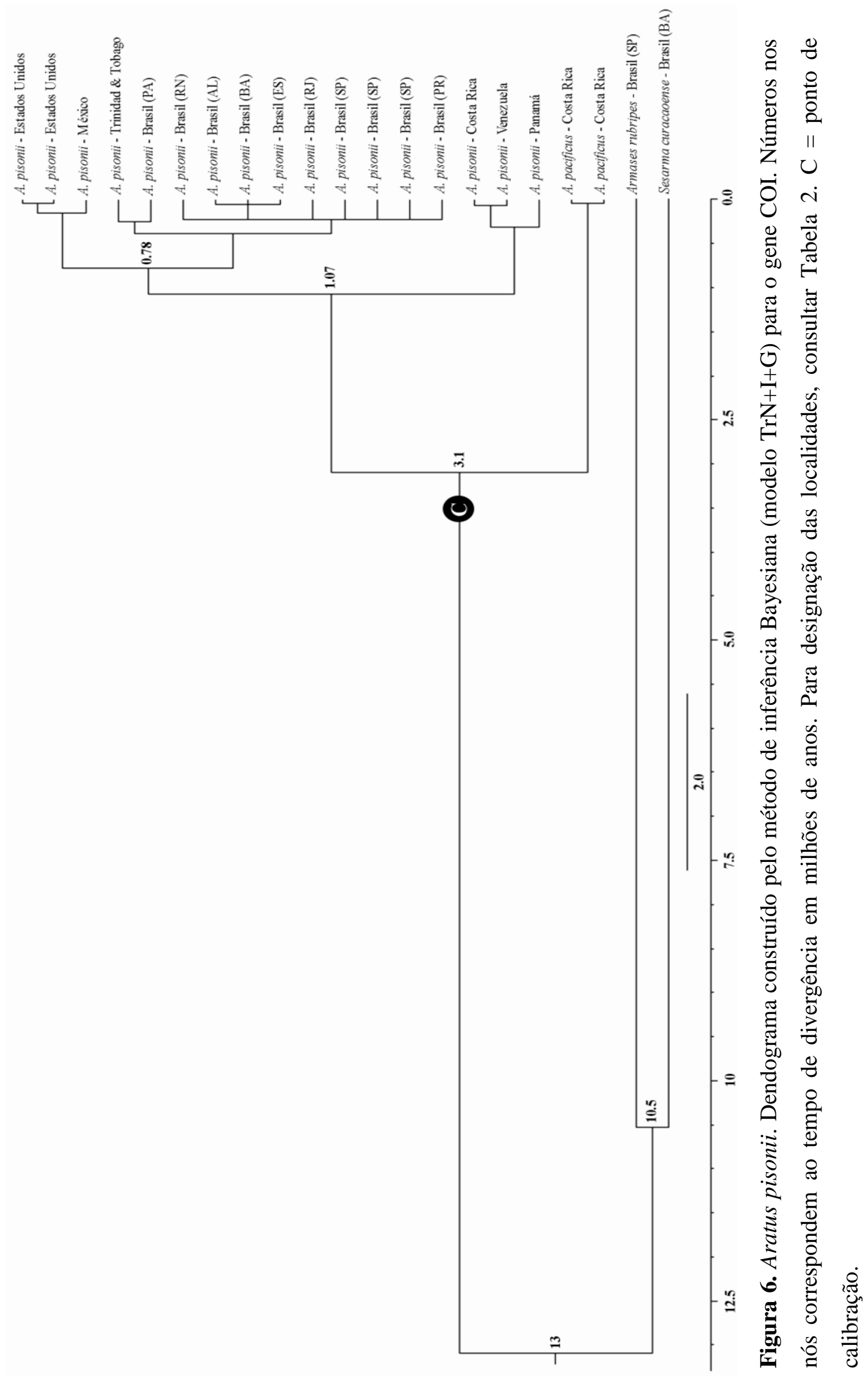




\section{Uca thayeri}

\section{Análise de variação genética}

As análises de variação genética foram baseadas em um alinhamento final de 614 pares de bases, contendo fragmentos parciais do gene COI de 69 espécimes de $U$. thayeri provenientes de 15 localidades distintas (Tabela 5). Foram encontrados 44 sítios polimórficos e 35 haplótipos $(\mathrm{H})$ distintos foram definidos e estão distribuídos na rede de haplótipos apresentada (Fig. 7). A diversidade haplotípica total encontrada foi de 0.9207. Dentre os haplótipos definidos, 30 representaram haplótipos individuais e, considerando os haplótipos compartilhados por mais de um indivíduo, o H10 foi o mais frequente, sendo compartilhado por 15 indivíduos provenientes de oito localidades. As diversidades gênicas (h), ou haplotípicas, calculadas para as populações de $U$. thayeri variaram de 0.6 a 1 e as diversidades nucleotídicas $(\pi)$ variaram de 0.00162 a 0.00814 (Tabela 10). Dentre as localidades com números amostrais mais elevados, a que apresentou maiores valores de diversidades gênica e nucleotídica corresponde à Brasil $(\mathrm{PE})(\mathrm{h}=0.9524 \pm 0.0955 ; \pi=0.00449 \pm 0.00309)$ (Tabela $10)$.

A rede de haplótipos evidenciou divisão em dois grandes grupos que não compartilham haplótipos entre si, sendo eles: 1) EUA + México + Jamaica; e 2) Brasil (Fig. 7). Dentre cada um dos grupos, os haplótipos encontram-se a, no máximo, quatro passos mutacionais dos haplótipos principais (Fig. 7). Um total de 11 passos mutacionais separam os dois grupos (Fig. 7).

A análise de variância molecular (AMOVA) com estrutura hierárquica simples, ou seja, sem estruturação entre grupos, mostrou que a maior porcentagem de variação $(66.55 \%)$ encontra-se entre as populações de $U$. thayeri analisadas (Tabela 9). A aplicação da AMOVA com estruturação das populações de acordo com os grupos evidenciados pela rede de 
haplótipos detectou que a maior parte da variação genética $(85.93 \%)$ encontra-se entre os grupos analisados, com reduzida porcentagem de variação entre as populações (Tabela 9). Os valores dos índices de fixação obtidos para cada uma das análises e seus correspondentes valores de $p$ sugerem alto grau de diferenciação genética e restrição de fluxo gênico significativa entre os grupos (Tabela 9). 


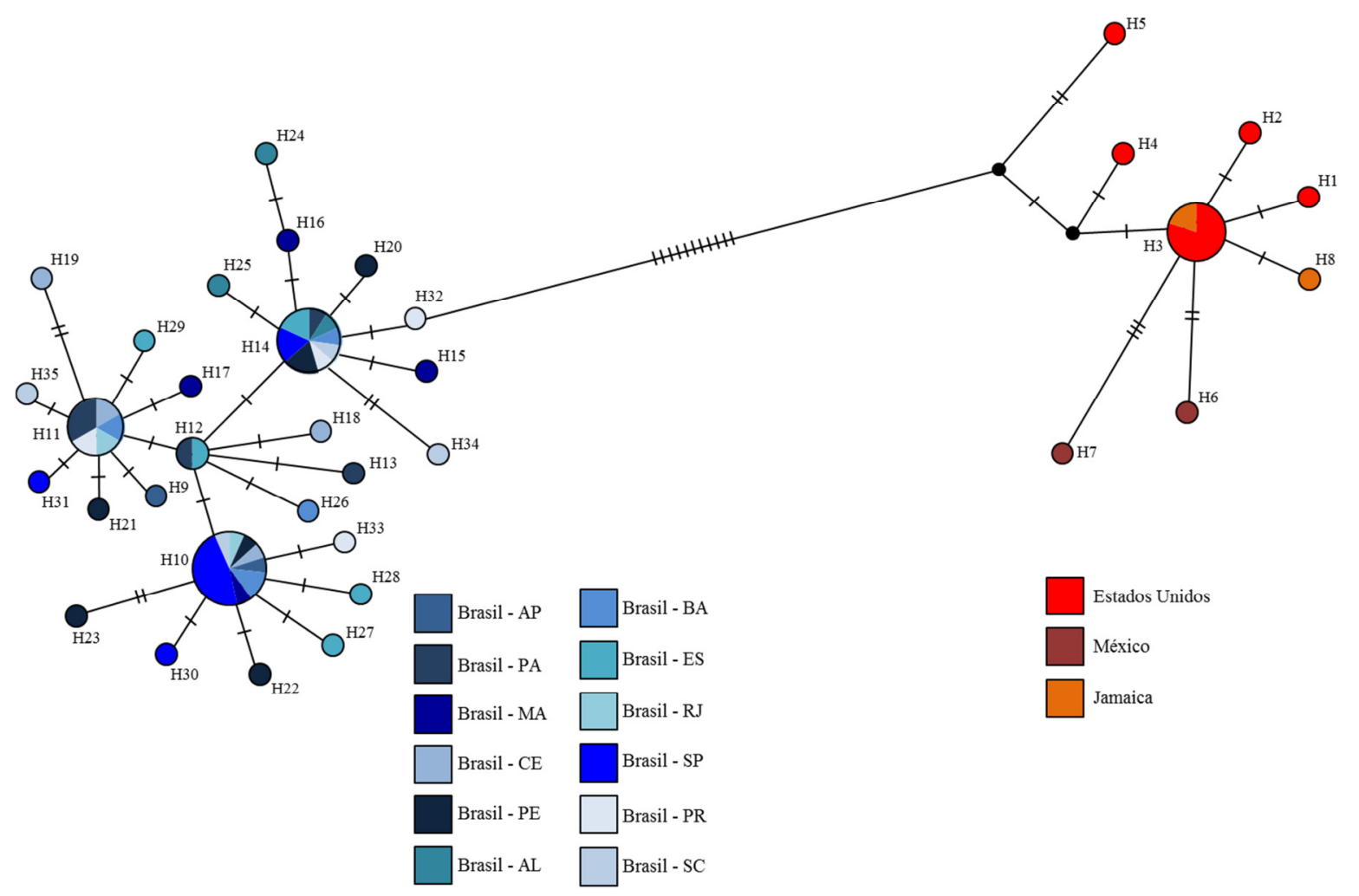

Figura 7. Uca thayeri. Rede de haplótipos construída pelo método de Median-Joining, indicando a distribuição dos 35 haplótipos (H) identificados. O tamanho do círculo é proporcional à frequência do haplótipo. Os traços em preto indicam passos mutacionais. Para designação das localidades, consultar Tabela 5. 
Tabela 10. Uca thayeri. Número de indivíduos, de haplótipos e índices de diversidade haplotípica ou gênica $(h)$ e nucleotídica $(\pi)$, por localidade. Para designação das localidades, consultar Tabela 5.

\begin{tabular}{l|c|c|c|c}
\hline Localidade & $\begin{array}{c}\text { Número } \\
\text { de } \\
\text { Indivíduos }\end{array}$ & $\begin{array}{c}\text { Número } \\
\text { de } \\
\text { Haplótipos }\end{array}$ & $\begin{array}{c}\text { Diversidade } \\
\text { Gênica (h) }\end{array}$ & $\begin{array}{c}\text { Diversidade } \\
\text { Nucleotídica }(\boldsymbol{\pi})\end{array}$ \\
\hline EUA & 8 & 5 & $0.7857 \pm 0.1508$ & $0.00314 \pm 0.00226$ \\
México & 2 & 2 & $1.0000 \pm 0.5000$ & $0.00814 \pm 0.00892$ \\
Jamaica & 2 & 2 & $1.0000 \pm 0.5000$ & $0.00162 \pm 0.00230$ \\
Brasil - AP & 2 & 2 & $1.0000 \pm 0.5000$ & $0.00488 \pm 0.00564$ \\
Brasil - PA & 5 & 4 & $0.9000 \pm 0.1610$ & $0.00228 \pm 0.00194$ \\
Brasil - MA & 4 & 4 & $1.0000 \pm 0.1768$ & $0.00597 \pm 0.00453$ \\
Brasil - CE & 4 & 4 & $1.0000 \pm 0.1768$ & $0.00434 \pm 0.00345$ \\
Brasil - PE & 7 & 6 & $0.9524 \pm 0.0955$ & $0.00449 \pm 0.00309$ \\
Brasil - AL & 3 & 3 & $1.0000 \pm 0.2722$ & $0.00325 \pm 0.00307$ \\
Brasil - BA & 5 & 4 & $0.9000 \pm 0.1610$ & $0.00293 \pm 0.00235$ \\
Brasil - ES & 3 & 5 & $0.9333 \pm 0.1217$ & $0.00390 \pm 0.00284$ \\
Brasil - RJ & 5 & 2 & $1.0000 \pm 0.5000$ & $0.00325 \pm 0.00398$ \\
Brasil - SP & 11 & 4 & $0.6000 \pm 0.1539$ & $0.00213 \pm 0.00162$ \\
Brasil - PR & 4 & 4 & $1.0000 \pm 0.1768$ & $0.00434 \pm 0.00345$ \\
Brasil - SC & 4 & 4 & $1.0000 \pm 0.1768$ & $0.00515 \pm 0.00399$ \\
\hline
\end{tabular}


$\underline{\text { Análise filogenética }}$

A análise filogenética concatenada para os genes COI e $16 \mathrm{~S}$ foi baseada nos alinhamentos para cada um dos genes, contendo, respectivamente, 695 e 603 pares de bases. A análise final baseou-se no alinhamento de 1298 pares de bases, contendo fragmentos parciais dos genes de 17 espécimes de $U$. thayeri provenientes de 15 localidades distintas (Tabela 5). Ademais, foram adicionadas à análise sequências das espécies congenéricas Uca leptodactyla Rathbun 1898 (Genbank COI: KU313195; 16S: KU313180) e Uca mordax (Smith 1870) (Genbank COI: KU313196; 16S: KU313181) e, para enraizamento da topologia, foram utilizadas sequências das espécies Ocypode quadrata (Fabricius 1787) (Genbank COI: KU313197; 16S: KU313182) e Ucides occidentalis (Ortmann 1897) (Genbank COI: KU313199; 16S: KU313184). A escolha desses representantes baseou-se na taxonomia do grupo e em resultados de análises filogenéticas prévias (Rosenberg, 2001; Bezerra, 2012), bem como na alternativa de se incluir representantes pertencentes às mesmas família e superfamília na qual a espécie Uca thayeri encontra-se inserida (Ng et al., 2008).

O dendrograma obtido evidenciou os mesmos dois grandes grupos encontrados na rede de haplótipos, por meio da formação de dois clados bem suportados, exibindo elevados valores de bootstrap, dentro do clado de indivíduos pertencentes a U. thayeri, concentrando, então, indivíduos pertencentes às localidades EUA + México + Jamaica e Brasil em seus respectivos clados (Fig. 8). Ademais, a análise demonstrou a formação de um clado bem suportado contendo as espécies do gênero $U c a$, clado-irmão aquele formado pelas espécies pertencentes ao grupo externo (Fig. 8). 


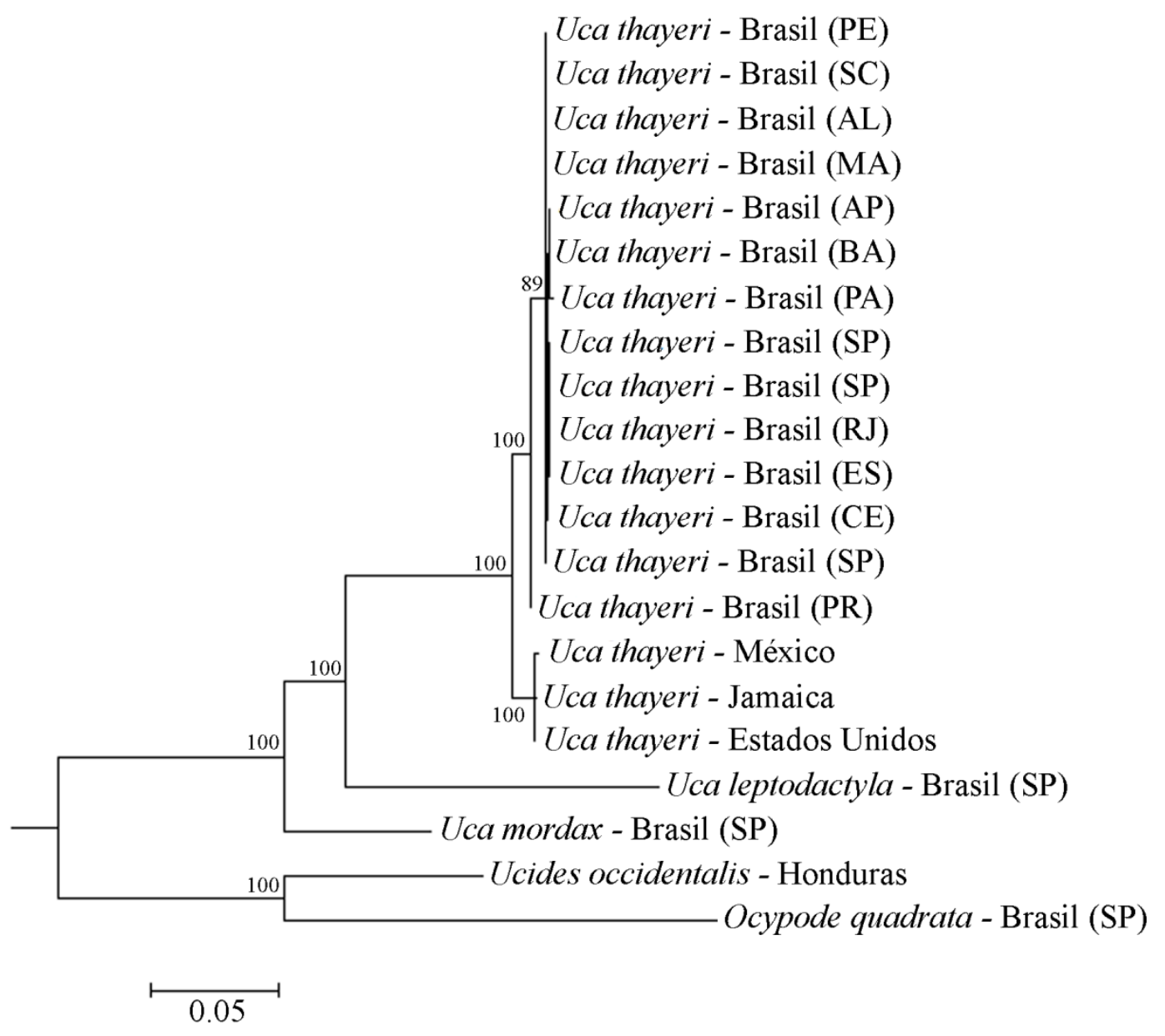

Figura 8. Uca thayeri. Dendrograma construído pelo método de busca por "Maximum Likelihood" para os genes COI e 16S concatenados. Os números apresentados correspondem aos valores de significância para 1000 réplicas de bootstrap. Para designação das localidades, consultar Tabela 5. 
$\underline{\text { Análise de distância genética }}$

Os alinhamentos finais para as análises de distância genética correspondem aos mesmos alinhamentos utilizados para a análise filogenética dos genes COI e 16S, separadamente.

Para o gene COI, observou-se distância genética para os espécimes de Uca thayeri analisados variando de 0 a 3.2\%, sendo que a divergência entre os indivíduos dentro de cada um dos grupos evidenciados pelas redes de haplótipos e dendrograma variou de 0 a $1.2 \%$, enquanto que a distância entre os grupos variou de 2.2 a 3.2\% (Fig. 9A), evidenciando a presença de um pequeno gap entre as distâncias intra e intergrupos. A taxa de divergência interespecífica mostrou-se superior à intraespecífica, uma vez que a distância entre as espécies congenéricas variou de 12.7 a $15.7 \%$ e a distância interespecífica, incluindo as espécies utilizadas como grupos externos, variou de 16 a 22.9\% (Fig. 9A).

Para o gene $16 \mathrm{~S}$, a distância genética intraespecífica variou de 0 a $0.8 \%$, sendo que a divergência intra-grupo variou de 0 a $0.2 \%$, enquanto que a distância entre os grupos variou de 0.6 a $0.8 \%$ (Fig. 9B), evidenciando a presença de um gap entre as distâncias intra e intergrupos, assim como para o gene COI. A taxa de divergência interespecífica mostrou-se superior à intraespecífica, uma vez que a distância entre as espécies congenéricas variou de 9 a $12.5 \%$ e a distância interespecífica, incluindo as espécies utilizadas como grupos externos, variou de 10.6 a $20.2 \%$ (Fig. 9B).

Para o gene H3, a análise de distância genética baseou-se no alinhamento de 314 pares de bases, contendo fragmentos parciais dos genes de nove espécimes de $U$. thayeri provenientes de oito localidades distintas (Tabela 5). Para esse gene, observou-se distância genética de $0 \%$ entre todos os espécimes.

O teste de Mantel indicou uma correlação significativa entre a distância genética e a distância geográfica dos indivíduos analisados (coeficiente de correlação $=0.4139 ; \mathrm{p}=0.01$ ). 

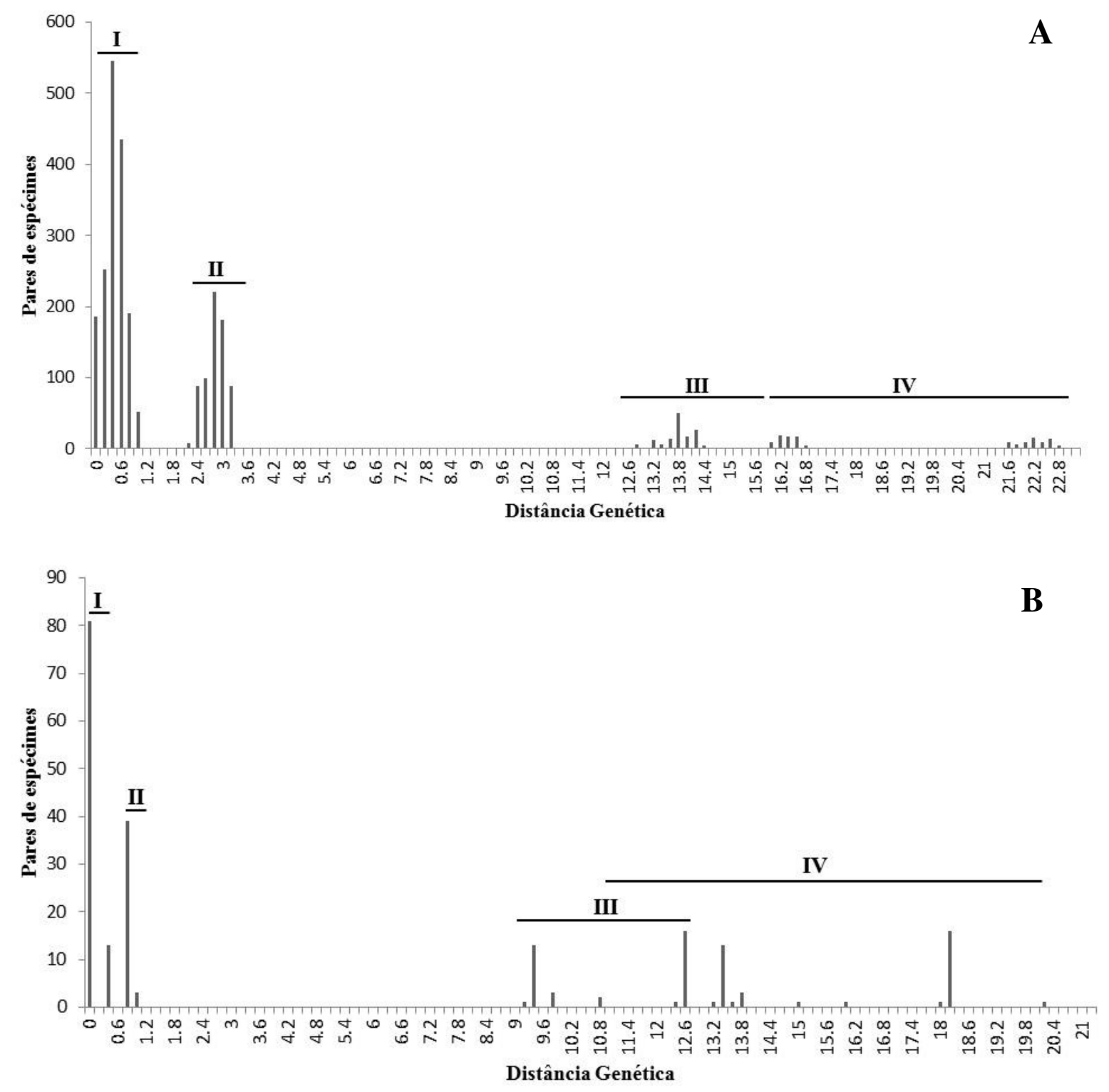

Figura 9. Uca thayeri. Histogramas com as frequências de distâncias genéticas entre os pares de localidades analisadas para os genes COI (A) e 16S (B); I: variação intraespecífica dentro dos grupos; II: variação intraespecífica entre os grupos; III: variação interespecífica congenérica; IV: variação intergenérica. 
$\underline{\text { Teste de neutralidade }}$

Os testes de Tajima $\mathrm{D}$ e $\mathrm{Fu} \mathrm{F}_{\mathrm{s}}$ para as amostras de cada um dos grupos apontaram valores significativamente negativos: grupo $1: \mathrm{D}=-1.96, \mathrm{p}>0.05 ; \mathrm{F}_{\mathrm{s}}=-3.48, \mathrm{p}>0.05$; grupo 2: $\mathrm{D}=-1.95, \mathrm{p}>0.05 ; \mathrm{F}_{\mathrm{s}}=-25.31, \mathrm{p}>0.05$. Assim, o teste de neutralidade indica a rejeição da hipótese nula de neutralidade das populações e a interferência de processos como expansão demográfica recente na população.

\section{$\underline{\text { Datação Molecular }}$}

Com base no gene COI e utilizando-se um relógio estrito, estimou-se o tempo de divergência entre os clados que incluem os indivíduos dos dois grupos distintos, evidenciados pelas análises de variação genética e de máxima verossimilhança (Fig 10). O tempo de divergência entre os grupos foi estimado como tendo ocorrido há, aproximadamente, 3.7 milhões de anos (Ma) (Fig 10) e o intervalo de 95\% de credibilidade foi de 2.3 a 5.4 Ma. Assim, os dados obtidos sugerem que a divergência entre os grupos tenha ocorrido no Pleistoceno. 


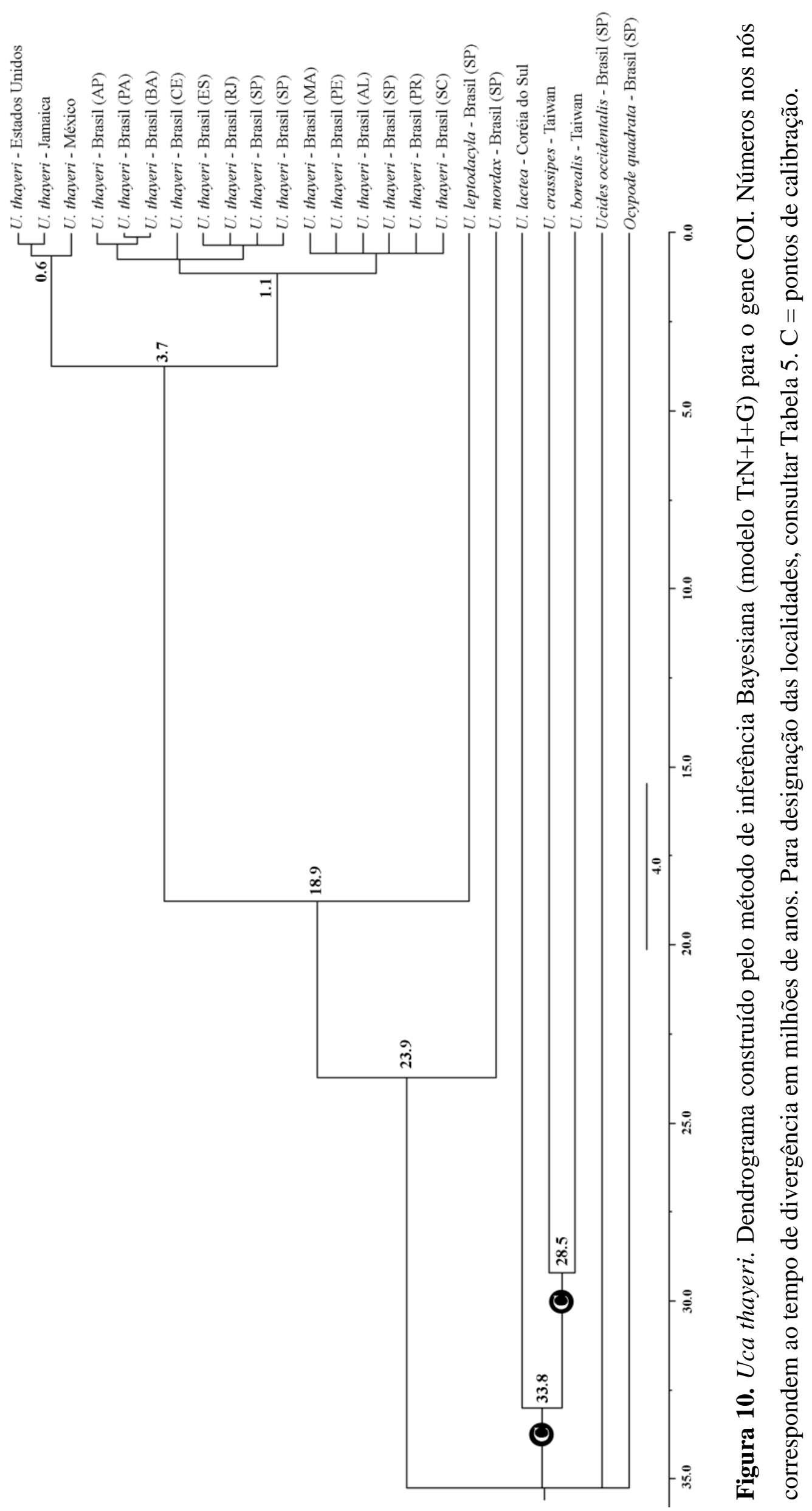




\subsubsection{Espécies com Ausência de Estruturacão Populacional}

\section{Goniopsis cruentata}

\section{$\underline{\text { Análise de variação genética }}$}

As análises de variação genética foram baseadas em um alinhamento final de 623 pares de bases, contendo fragmentos parciais do gene COI de 76 espécimes de G. cruentata provenientes de 19 localidades distintas, conforme distribuição na Tabela 3. Foram encontrados 49 sítios polimórficos e 50 haplótipos $(\mathrm{H})$ distintos foram definidos e estão distribuídos na rede de haplótipos apresentada (Fig. 11). A diversidade haplotípica total encontrada foi de 0.9505 . Dos haplótipos definidos, 42 representaram haplótipos individuais e, considerando os haplótipos compartilhados por mais de um indivíduo, o H1 foi o mais frequente, sendo compartilhado por 16 indivíduos provenientes de dez localidades. As diversidades gênicas (h) ou haplotípicas calculadas para as populações de G. cruentata variaram de 0.6667 a 1 e as diversidades nucleotídicas $(\pi)$ variaram de 0 a 0.01364 (Tabela 11). Dentre as localidades com números amostrais mais elevados, as que apresentaram maiores valores de diversidades gênica e nucleotídica correspondem à EUA $(h=1.0000 \pm$ 0.1265) e Costa Rica $(\pi=0.01161 \pm 0.00710)$, respectivamente (Tabela 11).

A rede de haplótipos apresentou, aparentemente, divisão dos haplótipos em dois grupos geneticamente próximos, separados por apenas três passos mutacionais, mas que incluem, cada um deles, indivíduos de localidades distintas, não havendo padronização com relação às localidades ou de acordo com regiões geográficas (Fig. 11). Também, pode ser observado que a maioria dos haplótipos individuais está, diretamente ou não, relacionada com o haplótipo mais comum, aproximando-se de uma rede haplotípica em forma de estrela, sem estrutura genealógica (Fig. 11). Assim, a rede de haplótipos evidenciou ausência de 
estruturação geográfica dos haplótipos, não havendo relação aparente entre a origem geográfica de um haplótipo e a relação genética com os demais, sendo total o compartilhamento entre eles (Fig. 11).

A análise de variância molecular (AMOVA) com estrutura hierárquica simples, ou seja, sem estruturação, mostrou que a maior porcentagem de variação (106.4\%) encontra-se dentro das populações de $G$. cruentata analisadas e não entre elas (Tabela 9). O valor negativo do índice de fixação obtido e seu correspondente valor de $p$ também sugerem baixo grau ou ausência de diferenciação genética entre as populações (Tabela 9). Como os valores de FST correspondem à razão da variação de frequências gênicas, as taxas desses índices devem ser, necessariamente, positivas (Wright, 1965). No entanto, valores negativos de FST estão usualmente associados com a imprecisão dos algoritmos usados nas análises e podem ser interpretados como zero, no caso de espécies com alta variação genética e poucos haplótipos compartilhados (Winkelmann et al., 2013). Assim, nesse caso, o valor de FST encontrado para G. cruentata aponta ausência de estruturação populacional. 


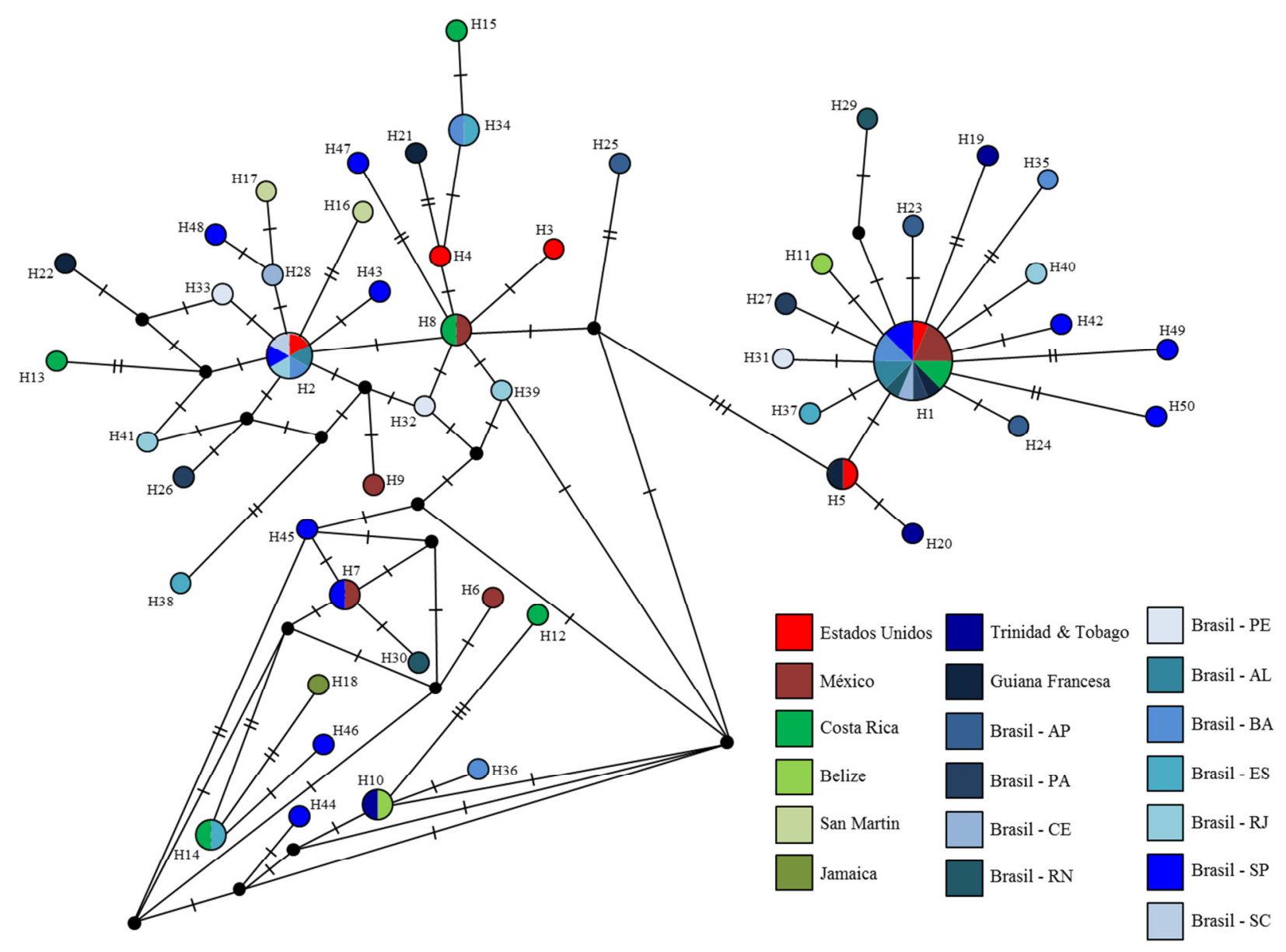

Figura 11. Goniopsis cruentata. Rede de haplótipos construída pelo método de MedianJoining, indicando a distribuição dos 50 haplótipos (H) identificados. O tamanho do círculo é proporcional à frequência do haplótipo. Os traços em preto indicam passos mutacionais. Para designação das localidades, consultar Tabela 3. 
Tabela 11. Goniopsis cruentata. Número de indivíduos, de haplótipos e índices de diversidade haplotípica ou gênica $(\mathrm{h})$ e nucleotídica $(\pi)$, por localidade. Para designação das localidades, consultar Tabela 3.

\begin{tabular}{l|c|c|c|c}
\hline \multicolumn{1}{c|}{ Localidade } & $\begin{array}{c}\text { Número } \\
\text { de } \\
\text { Indivíduos }\end{array}$ & $\begin{array}{c}\text { Número } \\
\text { de } \\
\text { Haplótipos }\end{array}$ & $\begin{array}{c}\text { Diversidade } \\
\text { Gênica (h) }\end{array}$ & $\begin{array}{c}\text { Diversidade } \\
\text { Nucleotídica }(\boldsymbol{\pi})\end{array}$ \\
\hline EUA & 5 & 5 & $1.0000 \pm 0.1265$ & $0.00642 \pm 0.00450$ \\
México & 7 & 5 & $0.8571 \pm 0.1371$ & $0.00871 \pm 0.00547$ \\
Belize & 2 & 2 & $1.0000 \pm 0.5000$ & $0.01123 \pm 0.01201$ \\
Costa Rica & 7 & 6 & $0.9524 \pm 0.0955$ & $0.01161 \pm 0.00710$ \\
San Martin & 2 & 2 & $1.0000 \pm 0.5000$ & $0.00642 \pm 0.00717$ \\
Jamaica & 1 & 1 & $1.0000 \pm 0.0000$ & $0.00000 \pm 0.00000$ \\
Trinidad \& Tobago & 3 & 3 & $1.0000 \pm 0.2722$ & $0.00856 \pm 0.00706$ \\
Guiana Francesa & 4 & 4 & $1.0000 \pm 0.1768$ & $0.01070 \pm 0.00763$ \\
Brasil - AP & 3 & 3 & $1.0000 \pm 0.2722$ & $0.00856 \pm 0.00706$ \\
Brasil - PA & 3 & 3 & $1.0000 \pm 0.2722$ & $0.00963 \pm 0.00786$ \\
Brasil - CE & 2 & 2 & $1.0000 \pm 0.5000$ & $0.00802 \pm 0.00879$ \\
Brasil - RN & 3 & 3 & $1.0000 \pm 0.2722$ & $0.01123 \pm 0.00906$ \\
Brasil - PE & 3 & 3 & $1.0000 \pm 0.2722$ & $0.00963 \pm 0.00786$ \\
Brasil - AL & 3 & 2 & $0.6667 \pm 0.3143$ & $0.00642 \pm 0.00545$ \\
Brasil - BA & 6 & 5 & $0.9333 \pm 0.1217$ & $0.00834 \pm 0.00542$ \\
Brasil - ES & 4 & 4 & $1.0000 \pm 0.1768$ & $0.01364 \pm 0.00956$ \\
Brasil - RJ & 4 & 4 & $1.0000 \pm 0.1768$ & $0.00829 \pm 0.00605$ \\
Brasil - SP & 13 & 12 & $0.9872 \pm 0.0354$ & $0.01039 \pm 0.00591$ \\
Brasil - SC & 1 & 1 & $1.0000 \pm 0.0000$ & $0.00000 \pm 0.00000$ \\
\hline
\end{tabular}


$\underline{\text { Análise filogenética }}$

A análise filogenética concatenada para os genes COI e $16 \mathrm{~S}$ foi baseada nos alinhamentos para cada um dos genes, contendo, respectivamente, 669 e 586 pares de bases. A análise final baseou-se no alinhamento de 1255 pares de bases, contendo fragmentos parciais dos genes de 21 espécimes de G. cruentata provenientes de 19 localidades distintas, conforme distribuição na Tabela 3. Ademais, foram adicionadas à análise sequências das espécies congenéricas Goniopsis pelii (Herklots 1851) (Genbank COI: KU313190; 16S: KU313175) e Goniopsis pulchra (Lockington 1877) (Genbank COI: KU313191; 16S: KU313176) e, para enraizamento da topologia, foram utilizadas sequências das espécies Pachygrapsus transversus (Gibbes 1850) (Genbank COI: KU313192; 16S: KU313177) e Geograpsus lividus (H. Milne Edwards 1837) (Genbank COI: KU313194; 16S: KU313179). A escolha dos representantes como grupo externo baseou-se na taxonomia e em resultados de análises filogenéticas prévias para a família Grapsidae (von Sternberg, 1994; Schubart, 2011), bem como na alternativa de se incluir representantes pertencentes à mesma família na qual a espécie Goniopsis cruentata encontra-se inserida ( $\mathrm{Ng}$ et al., 2008).

O dendrograma obtido evidenciou a ausência de estruturação geográfica observada na rede de haplótipos, por meio da formação de um único clado bem suportado incluindo todos os indivíduos pertencentes a G. cruentata, contendo, ainda, subclados com indivíduos de origens geográficas distintas, não havendo padronização com relação às localidades ou regiões (Fig. 12). Ademais, a análise demonstrou a formação de um clado bem suportado contendo todas as espécies do gênero Goniopsis, grupo-irmão do clado formado pelas espécies pertencentes ao grupo externo (Fig. 12). 


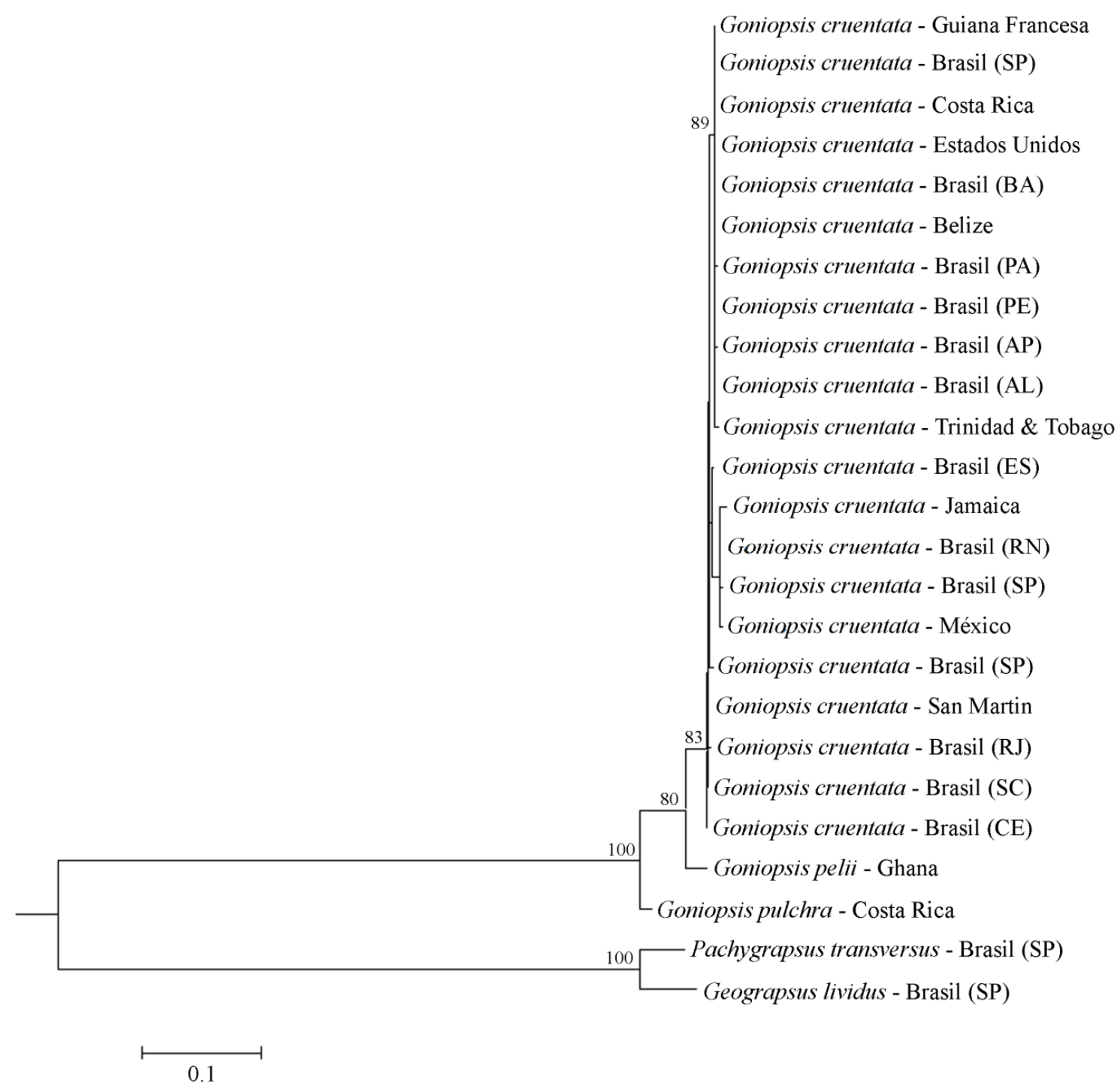

Figura 12. Goniopsis cruentata. Dendrograma construído pelo método de busca por "Maximum Likelihood" para os genes COI e 16S concatenados. Os números apresentados correspondem aos valores de significância para 1000 réplicas de bootstrap. Para designação das localidades, consultar Tabela 3. 
$\underline{\text { Análise de distância genética }}$

Os alinhamentos finais para as análises de distância genética correspondem aos mesmos alinhamentos utilizados para a análise filogenética dos genes COI e 16S, separadamente.

Para o gene COI, observou-se distância genética para os espécimes de Goniopsis cruentata analisados variando de 0 a $2 \%$ (Fig. 13A). A taxa de divergência interespecífica mostrou-se superior à intraespecífica, uma vez que a distância entre as espécies congenéricas variou de 4 a $7.1 \%$ e a distância interespecífica, incluindo as espécies utilizadas como grupos externos, variou de 21.8 a $24.1 \%$ (Fig. 13A).

No entanto, para o gene $16 \mathrm{~S}$, houve sobreposição das taxas de distância intra e interespecífica, sendo que a divergência dentro de G. cruentata variou de 0 a $1.3 \%$, enquanto que a entre as espécies congenéricas variou de 0.3 a 3.3\% (Fig. 13B). A taxa de divergência interespecífica, incluindo as espécies utilizadas como grupos externos, variou de 13 a $15.9 \%$ (Fig. 13B).

Para o gene H3, a análise de distância genética baseou-se no alinhamento de 334 pares de bases, contendo fragmentos parciais dos genes de 17 espécimes de G. cruentata provenientes de 15 localidades distintas (Tabela 3). Para esse gene, observou-se distância genética de $0 \%$ entre todos os espécimes.

Apesar da ausência de estruturação geográfica e populacional, apontada pelas análises de variação genética e de máxima verossimilhança, o teste de Mantel indicou uma correlação significativa entre a distância genética para o gene COI e a distância geográfica dos indivíduos analisados (coeficiente de correlação $=0.1643 ; \mathrm{p}=0.027$ ). 

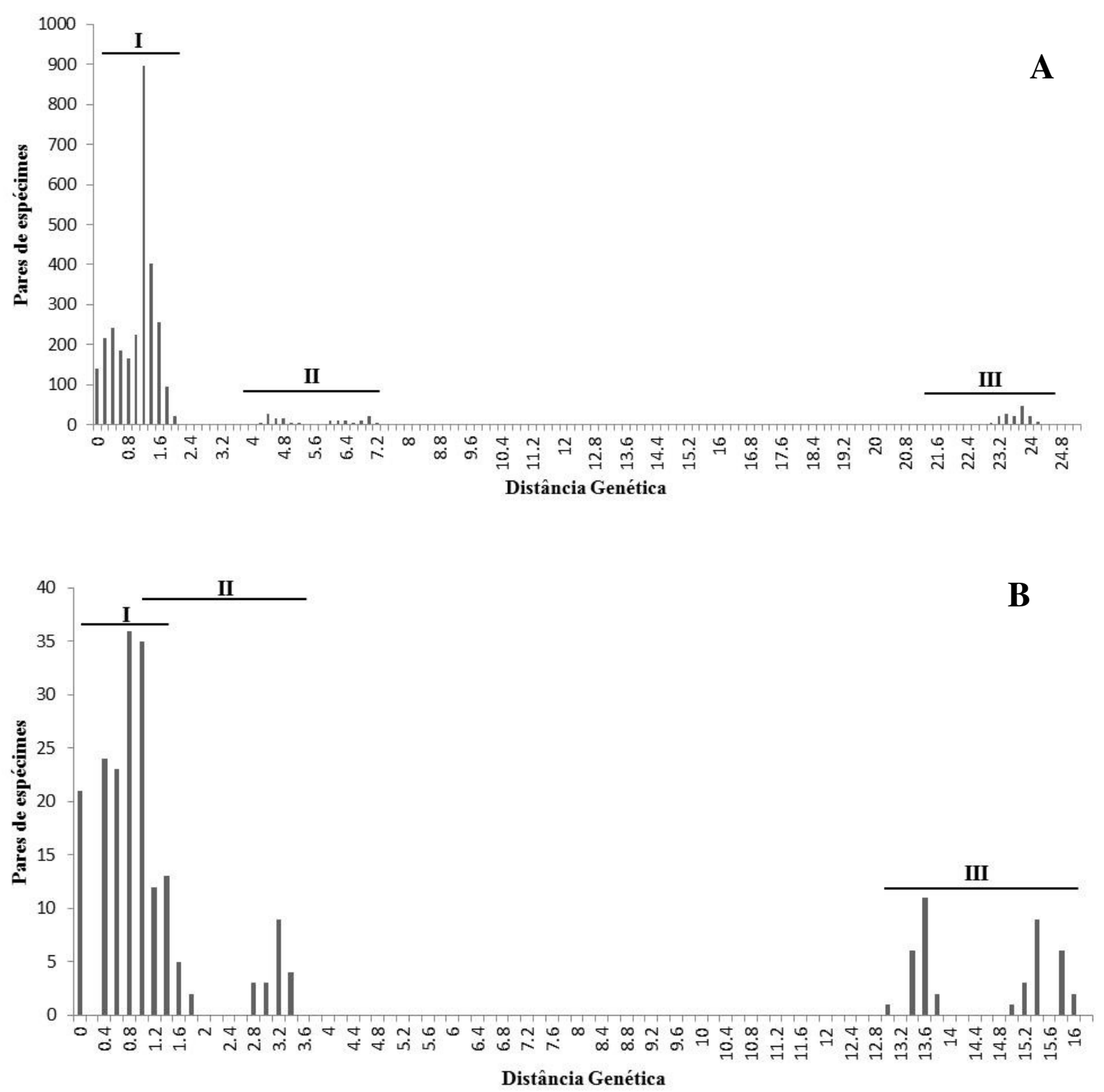

Figura 13. Goniopsis cruentata. Histogramas com as frequências de distâncias genéticas entre os pares de localidades analisadas para os genes COI (A) e 16S (B); I: variação intraespecífica; II: variação interespecífica congenérica; III: variação intergenérica. 


\section{$\underline{\text { Teste de neutralidade }}$}

Os testes de Tajima $\mathrm{D}$ e $\mathrm{Fu} \mathrm{F}_{\mathrm{s}}$ apontaram valores significativamente negativos $(\mathrm{D}=$ $\left.1.42, \mathrm{p}<0.05 ; \mathrm{F}_{\mathrm{s}}=-25.34, \mathrm{p}<0.05\right)$, indicando a rejeição da hipótese nula de neutralidade das populações e a interferência de processos como expansão demográfica recente na população. 


\section{Sesarma rectum}

\section{Análise de variação genética}

As análises de variação genética foram baseadas em um alinhamento final de 637 pares de bases, contendo fragmentos parciais do gene COI de 44 espécimes de $S$. rectum provenientes de 8 localidades distintas, conforme distribuição na Tabela 4. Foram encontrados 13 sítios polimórficos e 13 haplótipos (H) distintos foram definidos e estão distribuídos na rede de haplótipos apresentada (Fig. 14). A diversidade haplotípica total encontrada foi de 0.7357 . Dos haplótipos definidos, 10 representaram haplótipos individuais e, considerando os haplótipos compartilhados por mais de um indivíduo, o H1 foi o mais frequente, sendo compartilhado por 19 indivíduos provenientes de seis localidades. As diversidades gênicas (h) ou haplotípicas calculadas para as populações de S. rectum variaram de 0 a 1 e as diversidades nucleotídicas $(\pi)$ variaram de 0 a 0.00471 (Tabela 12). Dentre as localidades com números amostrais mais elevados, a que apresentou maiores valores de diversidades gênica e nucleotídica corresponde à Brasil $(\mathrm{CE})(\mathrm{h}=1.0000 \pm 0.1768 ; \pi=$ $0.00471 \pm 0.00368)$ (Tabela 12)

A rede de haplótipos evidenciou a ausência de estruturação geográfica dos haplótipos, não havendo relação, em sua maioria, entre a origem geográfica de um haplótipo e a relação genética com os demais (Fig. 14). Todos os haplótipos encontram-se a, no máximo, três passos mutacionais do haplótipo principal, aproximando-se de uma rede haplotípica em forma de estrela, sem estrutura genealógica (Fig. 14). No entanto, apesar da mínima distância mutacional, a população Brasil (CE) não compartilha haplótipos com as demais populações (Fig. 14).

No entanto, apesar da ausência de estruturação geográfica evidenciada pela rede de haplótipos, a análise de variância molecular (AMOVA) com estrutura hierárquica simples, ou 
seja, sem estruturação, mostrou que a maior porcentagem de variação (73.43\%) encontra-se entre as populações de S. rectum analisadas (Tabela 9). Ademais, o valor do índice de fixação obtido e seu correspondente valor de $p$ sugerem alto grau de diferenciação genética entre as populações (Tabela 9). No entanto, a aplicação da AMOVA com estruturação das populações, detectou que a maior parte da variação genética (52.98\%) encontra-se dentro das populações e não entre os grupos sugeridos (Tabela 9). Os valores dos índices de fixação obtidos para cada uma das hierarquias, com exceção dos grupos, e seus correspondentes valores de $p$ sugerem alto grau de diferenciação genética (Tabela 9). Assim, embora exista uma marcante estruturação genética, essa não é necessariamente congruente com as localidades geográficas. 


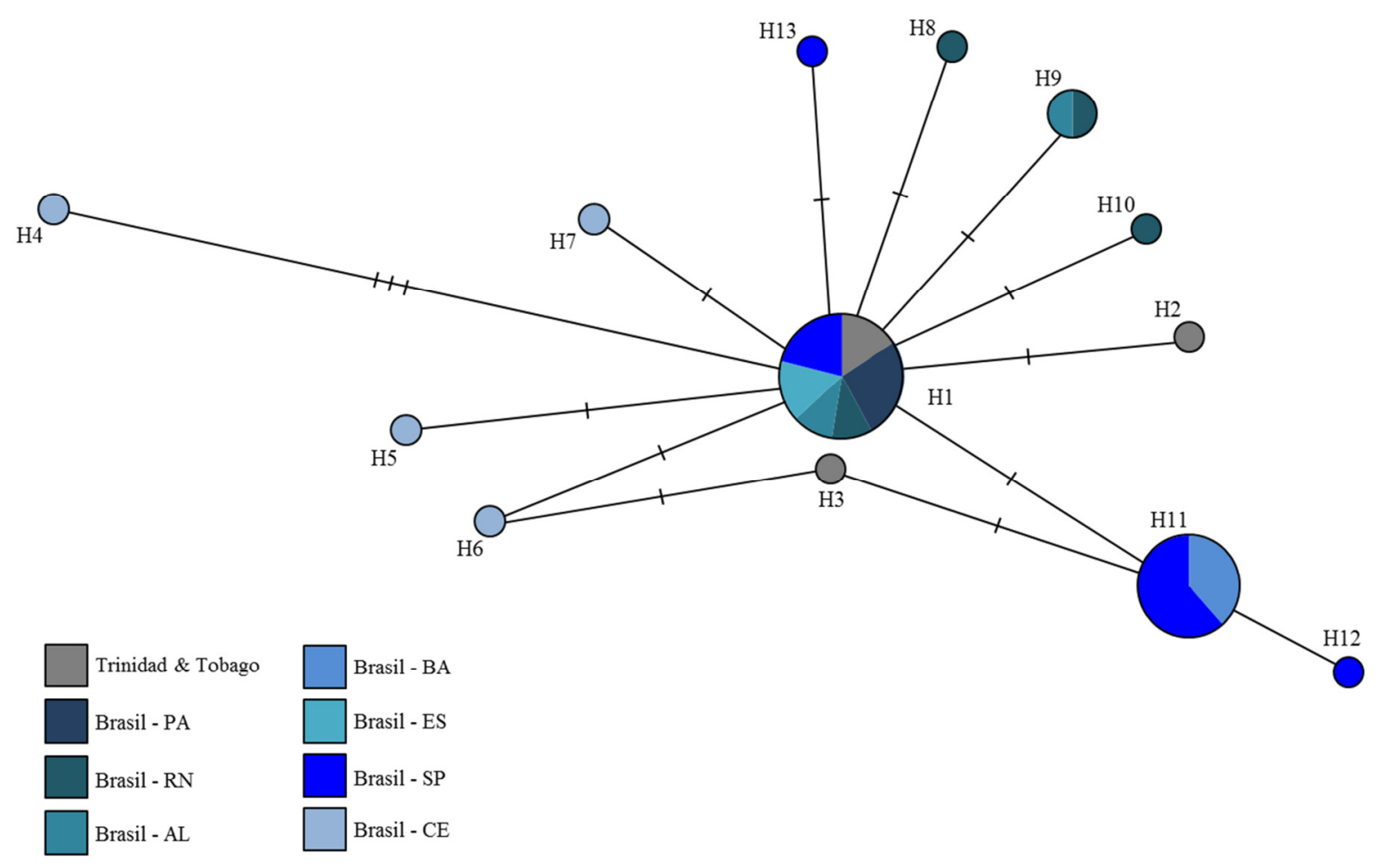

Figura 14. Sesarma rectum. Rede de haplótipos construída pelo método de Median-Joining, indicando a distribuição dos 13 haplótipos (H) identificados. O tamanho do círculo é proporcional à frequência do haplótipo. Os traços em preto indicam passos mutacionais. Para designação das localidades, consultar Tabela 4. 
Tabela 12. Sesarma rectum. Número de indivíduos, de haplótipos e índices de diversidade haplotípica ou gênica (h) e nucleotídica $(\pi)$, por localidade. Para designação das localidades, consultar Tabela 4.

\begin{tabular}{l|c|c|c|c}
\hline \multicolumn{1}{c|}{ Localidade } & $\begin{array}{c}\text { Número } \\
\text { de } \\
\text { Indivíduos }\end{array}$ & $\begin{array}{c}\text { Número } \\
\text { de } \\
\text { Haplótipos }\end{array}$ & $\begin{array}{c}\text { Diversidade } \\
\text { Gênica (h) }\end{array}$ & $\begin{array}{c}\text { Diversidade } \\
\text { Nucleotídica }(\boldsymbol{\pi})\end{array}$ \\
\hline Trinidad \& Tobago & 5 & 3 & $0.7000 \pm 0.2184$ & $0.00188 \pm 0.00166$ \\
Brasil - PA & 5 & 1 & $0.0000 \pm 0.0000$ & $0.00000 \pm 0.00000$ \\
Brasil - CE & 4 & 4 & $1.0000 \pm 0.1768$ & $0.00471 \pm 0.00368$ \\
Brasil - RN & 5 & 4 & $0.9000 \pm 0.1610$ & $0.00188 \pm 0.00166$ \\
Brasil - AL & 3 & 2 & $0.6667 \pm 0.3143$ & $0.00104 \pm 0.00130$ \\
Brasil - BA & 5 & 1 & $0.0000 \pm 0.0000$ & $0.00000 \pm 0.00000$ \\
Brasil - ES & 3 & 1 & $0.0000 \pm 0.0000$ & $0.00000 \pm 0.00000$ \\
Brasil - SP & 14 & 4 & $0.6264 \pm 0.1098$ & $0.00122 \pm 0.00106$ \\
\hline
\end{tabular}


$\underline{\text { Análise filogenética }}$

A análise filogenética concatenada para os genes COI e $16 \mathrm{~S}$ foi baseada nos alinhamentos para cada um dos genes, contendo, respectivamente, 684 e 605 pares de bases. A análise final baseou-se no alinhamento de 1289 pares de bases, contendo fragmentos parciais dos genes de 10 espécimes de $S$. rectum provenientes de 8 localidades distintas, conforme distribuição na Tabela 4. Ademais, foram adicionadas à análise sequências das espécies congenéricas Sesarma curacaoense (GenBank COI: KU313188; 16S: KU313173) e Sesarma sulcatum Smith 1870 (GenBank COI: KU313189; 16S: KU313174) e, para enraizamento da topologia, foram utilizadas sequências das espécies Armases rubripes (GenBank COI: KU313187; 16S: KU313172) e Neohelice granulata (Dana 1851) (GenBank COI: KU313193; 16S: KU313178). A escolha dos representantes como grupo externo baseou-se na taxonomia do grupo e em resultados de análises filogenéticas prévias para a família Sesarmidae (Abele, 1992; Schubart et al., 2000a), bem como na alternativa de se incluir representantes pertencentes à mesma família na qual a espécie Sesarma rectum encontra-se inserida (Schubart et al., 2000a; Ng et al., 2008).

O dendrograma obtido evidenciou a ausência de estruturação geográfica por meio da formação de um único clado bem suportado incluindo todos os indivíduos pertencentes a $S$. rectum, contendo, ainda, subclados com indivíduos de origens geográficas distintas, não havendo padronização com relação às localidades ou regiões (Fig. 15). Ademais, a análise demonstrou a formação de um clado bem suportado contendo todas as espécies do gênero Sesarma, grupo-irmão do clado formado pelas espécies pertencentes ao grupo externo (Fig. $15)$. 


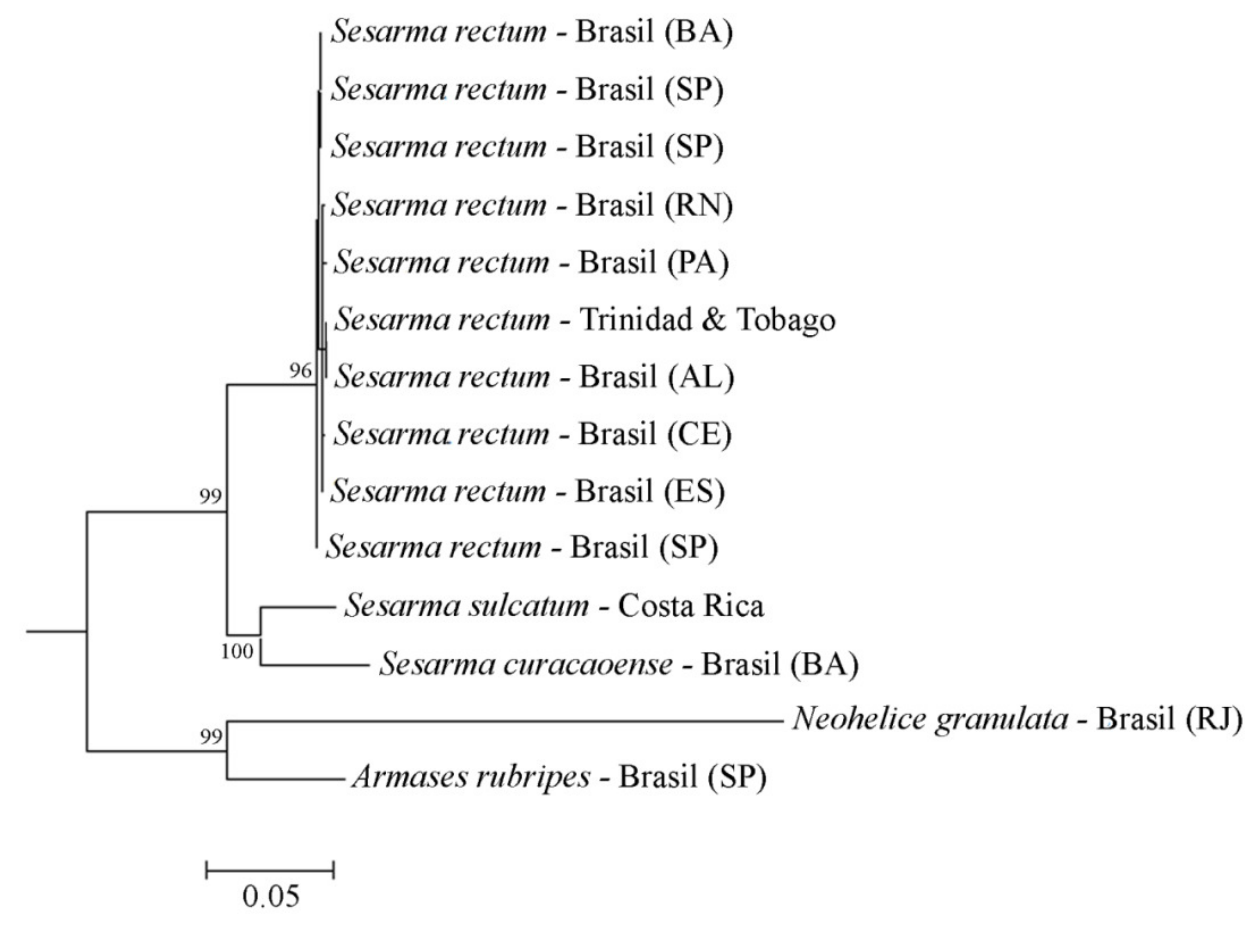

Figura 15. Sesarma rectum. Dendrograma construído pelo método de busca por "Maximum Likelihood" para os genes COI e 16S concatenados. Os números apresentados correspondem aos valores de significância para 1000 réplicas de bootstrap. Para designação das localidades, consultar Tabela 4. 
$\underline{\text { Análise de distância genética }}$

Os alinhamentos finais para as análises de distância genética correspondem aos mesmos alinhamentos utilizados para a análise filogenética dos genes COI e 16S, separadamente.

Para o gene COI, observou-se distância genética entre os espécimes de Sesarma rectum analisados variando de 0 a $0.6 \%$ (Fig. 16A). A taxa de divergência interespecífica mostrou-se superior à intraespecífica, uma vez que a distância entre as espécies congenéricas variou de 6.5 a $7.1 \%$ e a distância interespecífica, incluindo as espécies utilizadas como grupos externos, variou de 9.2 a $21 \%$ (Fig. 16A).

Para o gene $16 \mathrm{~S}$, a distância genética entre os espécimes de $S$. rectum variou de 0 a 0.4\% (Fig. 16B). Da mesma forma que observado para o gene COI, a taxa de divergência interespecífica mostrou-se superior à intraespecífica, sendo que a distância entre as espécies congenéricas variou de 2.3 a $3.8 \%$ e a distância interespecífica, incluindo as espécies utilizadas como grupos externos, variou de 5.2 a $13.4 \%$ (Fig. 16B).

Para o gene H3, a análise de distância genética baseou-se no alinhamento de 336 pares de bases, contendo fragmentos parciais dos genes de sete espécimes de S. rectum provenientes de seis localidades distintas (Tabela 4). Para esse gene, observou-se distância genética de 0\% entre todos os espécimes.

O teste de Mantel indicou uma correlação não significativa entre a distância genética e a distância geográfica dos indivíduos analisados (coeficiente de correlação $=-0.1896 ; \mathrm{p}=$ 0.719). Dessa forma, assim como observado nas análises de variação genética de máxima verossimilhança, embora exista uma estruturação genética entre as populações dessa espécie, essa não é necessariamente congruente com as distâncias ou localidades geográficas. 

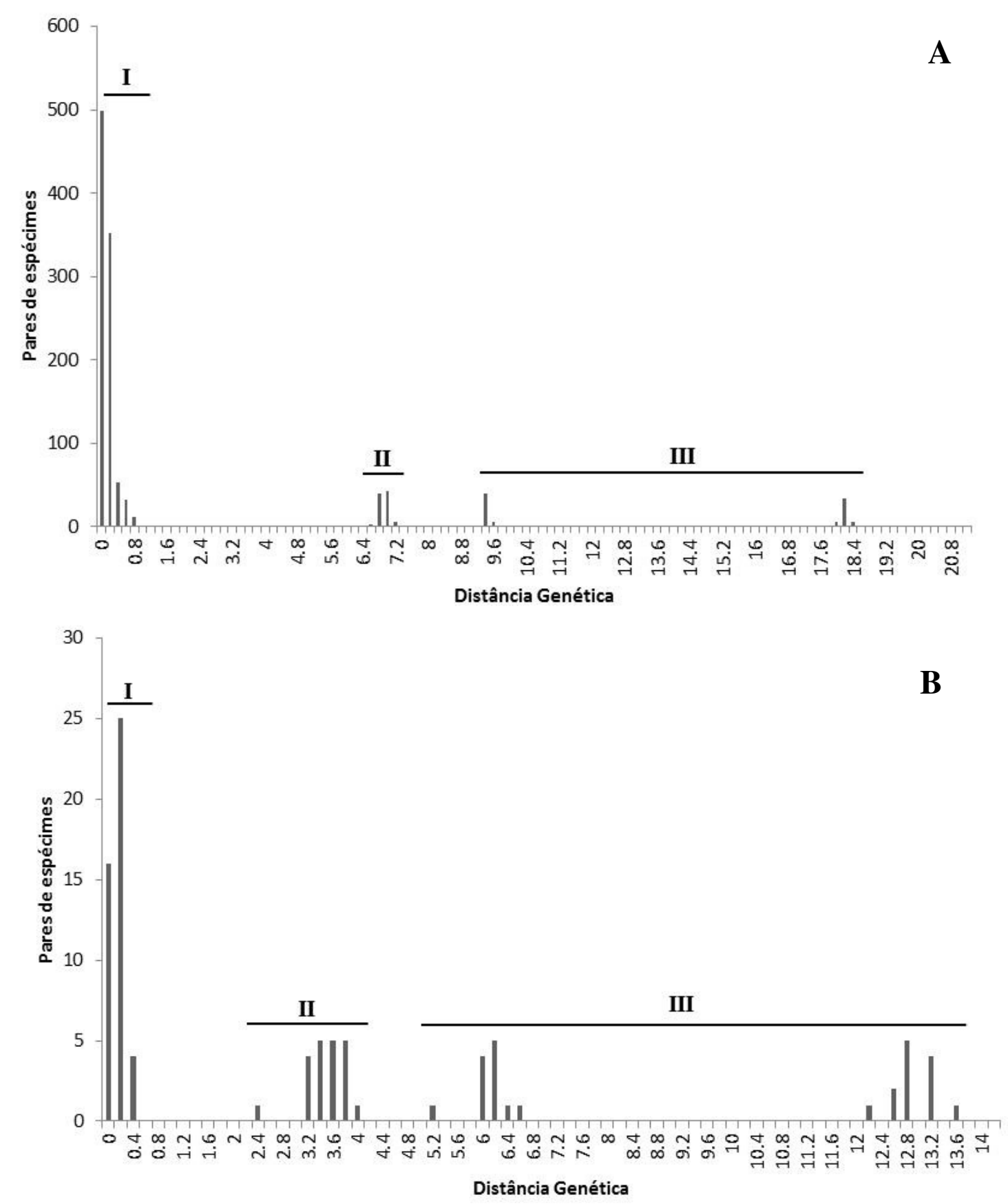

Figura 16. Sesarma rectum. Histogramas com as frequências de distâncias genéticas entre os pares de localidades analisadas para os genes COI (A) e 16S (B); I: variação intraespecífica; II: variação interespecífica congenérica; III: variação intergenérica. 


\section{$\underline{\text { Teste de neutralidade }}$}

Os testes de Tajima $\mathrm{D}$ e $\mathrm{Fu} \mathrm{F}_{\mathrm{s}}$ apontaram valores significativamente negativos $(\mathrm{D}=-$ 1.94, $\left.\mathrm{p}<0.05 ; \mathrm{F}_{\mathrm{s}}=-9.82, \mathrm{p}<0.05\right)$, indicando a rejeição da hipótese nula de neutralidade das populações e a interferência de processos como expansão demográfica recente na população. 


\section{Ucides cordatus}

\section{$\underline{\text { Análise de variação genética }}$}

As análises de variação genética foram baseadas em um alinhamento final de 619 pares de bases, contendo fragmentos parciais do gene COI de 60 espécimes de $U$. cordatus provenientes de 15 localidades distintas (Tabela 6). Foram encontrados 47 sítios polimórficos e 43 haplótipos $(\mathrm{H})$ distintos foram definidos e estão distribuídos na rede de haplótipos apresentada (Fig. 17). A diversidade haplotípica total encontrada foi de 0.9774. Dos haplótipos definidos, 34 representaram haplótipos individuais e, considerando os haplótipos compartilhados por mais de um indivíduo, o H12 foi o mais frequente, sendo compartilhado por 8 indivíduos provenientes de seis localidades. As diversidades gênicas (h) ou haplotípicas calculadas para as populações de $U$. cordatus variaram de 0.6667 a 1 e as diversidades nucleotídicas $(\pi)$ variaram de 0 a 0.00668 (Tabela 13 ). Dentre as localidades com números amostrais mais elevados, a que apresentou maiores valores de diversidades gênica e nucleotídica corresponde à Brasil $(\mathrm{PE})(\mathrm{h}=1.0000 \pm 0.1265 ; \pi=0.00646 \pm 0.00453)$ (Tabela 13).

A rede de haplótipos evidenciou a ausência de estruturação geográfica dos haplótipos, não havendo relação entre a origem geográfica de um haplótipo e a relação genética com os demais (Fig. 17). Também, pode ser observado que a maioria dos haplótipos individuais está, diretamente ou não, relacionada com o haplótipo mais comum, aproximando-se de uma rede haplotípica em forma de estrela, sem estrutura genealógica (Fig. 17).

A análise de variância molecular (AMOVA) com estrutura hierárquica simples, ou seja, sem estruturação, mostrou que a maior porcentagem de variação (99.33\%) encontra-se dentro das populações de $U$. cordatus analisadas e não entre elas (Tabela 9). O baixo valor do 
índice de fixação obtido e seu correspondente valor de $p$ também sugerem ausência de diferenciação genética entre as populações (Tabela 9). 


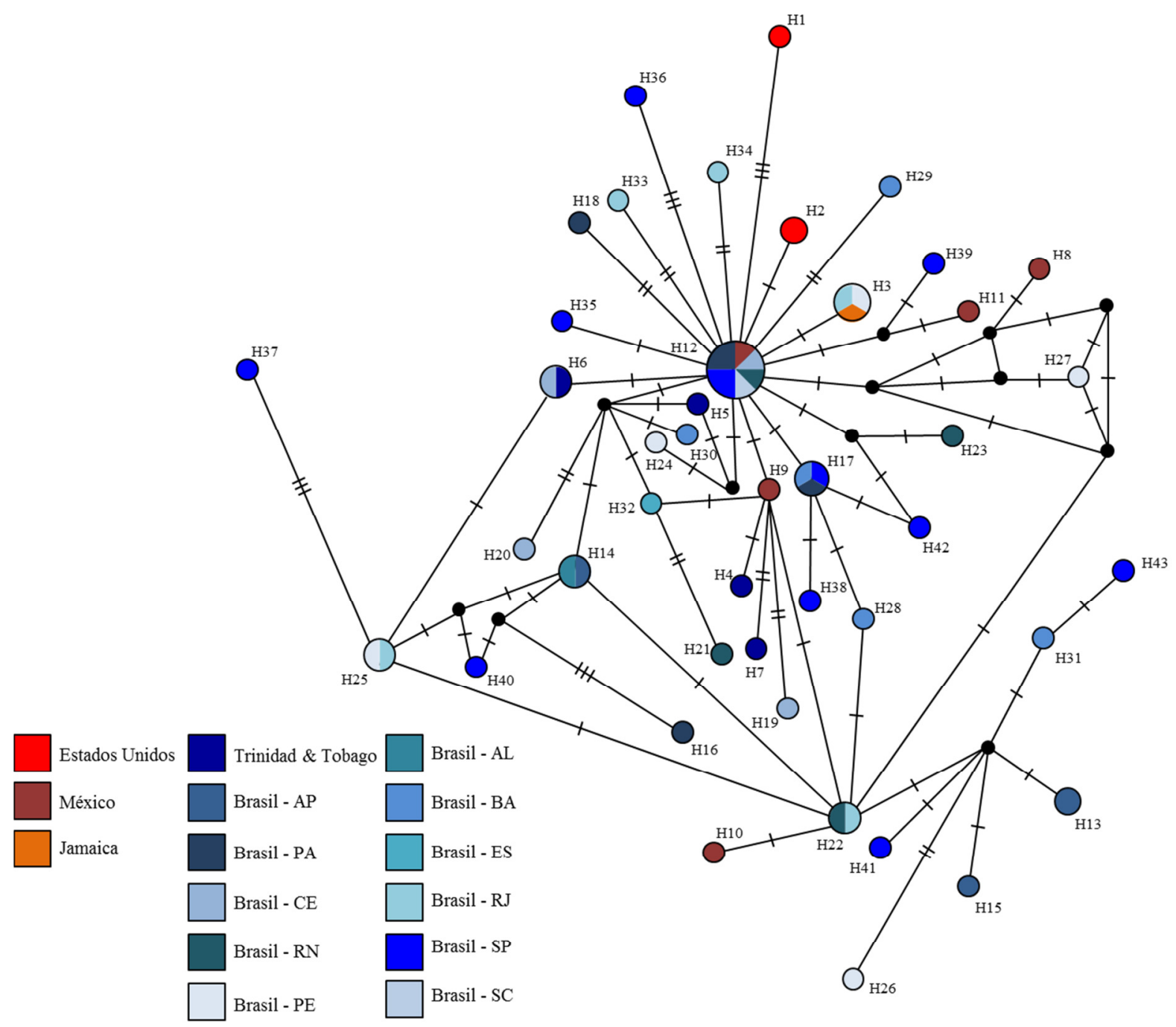

Figura 17. Ucides cordatus. Rede de haplótipos construída pelo método de Median-Joining, indicando a distribuição dos 43 haplótipos $(\mathrm{H})$ identificados. O tamanho do círculo é proporcional à frequência do haplótipo. Os traços em preto indicam passos mutacionais. Para designação das localidades, consultar Tabela 6. 
Tabela 13. Ucides cordatus. Número de indivíduos, de haplótipos e índices de diversidade haplotípica ou gênica (h) e nucleotídica $(\pi)$, por localidade. Para designação das localidades, consultar Tabela 6.

\begin{tabular}{l|c|c|c|c}
\hline \multicolumn{1}{c|}{ Localidade } & $\begin{array}{c}\text { Número } \\
\text { de } \\
\text { Indivíduos }\end{array}$ & $\begin{array}{c}\text { Número } \\
\text { de } \\
\text { Haplótipos }\end{array}$ & $\begin{array}{c}\text { Diversidade } \\
\text { Gênica (h) }\end{array}$ & $\begin{array}{c}\text { Diversidade } \\
\text { Nucleotídica }(\boldsymbol{\pi})\end{array}$ \\
\hline EUA & 3 & 2 & $0.6667 \pm 0.3143$ & $0.00430 \pm 0.00386$ \\
Jamaica & 1 & 1 & $1.0000 \pm 0.0000$ & $0.00000 \pm 0.00000$ \\
México & 5 & 5 & $1.0000 \pm 0.1265$ & $0.00517 \pm 0.00373$ \\
Trinidad \& Tobago & 4 & 4 & $1.0000 \pm 0.1768$ & $0.00592 \pm 0.00450$ \\
Brasil - AP & 4 & 3 & $0.8333 \pm 0.2224$ & $0.00350 \pm 0.00289$ \\
Brasil - PA & 5 & 4 & $0.9000 \pm 0.1610$ & $0.00581 \pm 0.00413$ \\
Brasil - CE & 4 & 4 & $1.0000 \pm 0.1768$ & $0.00565 \pm 0.00432$ \\
Brasil - RN & 4 & 4 & $1.0000 \pm 0.1768$ & $0.00565 \pm 0.00432$ \\
Brasil - PE & 5 & 5 & $1.0000 \pm 0.1265$ & $0.00646 \pm 0.00453$ \\
Brasil - AL & 1 & 1 & $1.0000 \pm 0.0000$ & $0.00000 \pm 0.00000$ \\
Brasil - BA & 5 & 5 & $1.0000 \pm 0.1265$ & $0.00646 \pm 0.00453$ \\
Brasil - ES & 1 & 1 & $1.0000 \pm 0.0000$ & $0.00000 \pm 0.00000$ \\
Brasil - RJ & 5 & 5 & $1.0000 \pm 0.1265$ & $0.00484 \pm 0.00353$ \\
Brasil - SP & 12 & 11 & $0.9848 \pm 0.0403$ & $0.00668 \pm 0.00402$ \\
Brasil - SC & 1 & 1 & $1.0000 \pm 0.0000$ & $0.00000 \pm 0.00000$ \\
\hline
\end{tabular}


$\underline{\text { Análise filogenética }}$

A análise filogenética concatenada para os genes COI e $16 \mathrm{~S}$ foi baseada nos alinhamentos para cada um dos genes, contendo, respectivamente, 690 e 584 pares de bases. A análise final baseou-se no alinhamento de 1274 pares de bases, contendo fragmentos parciais dos genes de 17 espécimes de Ucides cordatus provenientes de 15 localidades distintas (Tabela 6). Ademais, foram adicionadas à análise duas sequências da espécie congenérica Ucides occidentalis (Genbank COI: KU313199, KU313198; 16S: KU313183, KU313184) e, para enraizamento da topologia, foram utilizadas sequências das espécies Ocypode quadrata (Genbank COI: KU313197; 16S: KU313182) e Uca mordax (Genbank COI: KU313196; 16S: KU313181).

A escolha desses representantes baseou-se na taxonomia do grupo e em resultados de análises filogenéticas prévias (Türkay, 1983; Melo, 1996; Ng et al., 2008), bem como na alternativa de se incluir representantes pertencentes às mesmas família e superfamília na qual a espécie Ucides occidentalis encontra-se inserida ( $\mathrm{Ng}$ et al., 2008)

O dendrograma obtido evidenciou a ausência de estruturação geográfica observada na rede de haplótipos, por meio da formação de um único clado bem suportado incluindo todos os indivíduos pertencentes a U. cordatus, contendo, ainda, subclados com indivíduos de origens geográficas distintas, não havendo padronização com relação às localidades ou regiões (Fig. 18). Ademais, a análise demonstrou a formação de um clado bem suportado contendo ambas as espécies do gênero Ucides, grupo-irmão do clado formado pelas espécies pertencentes ao grupo externo (Fig. 18). 


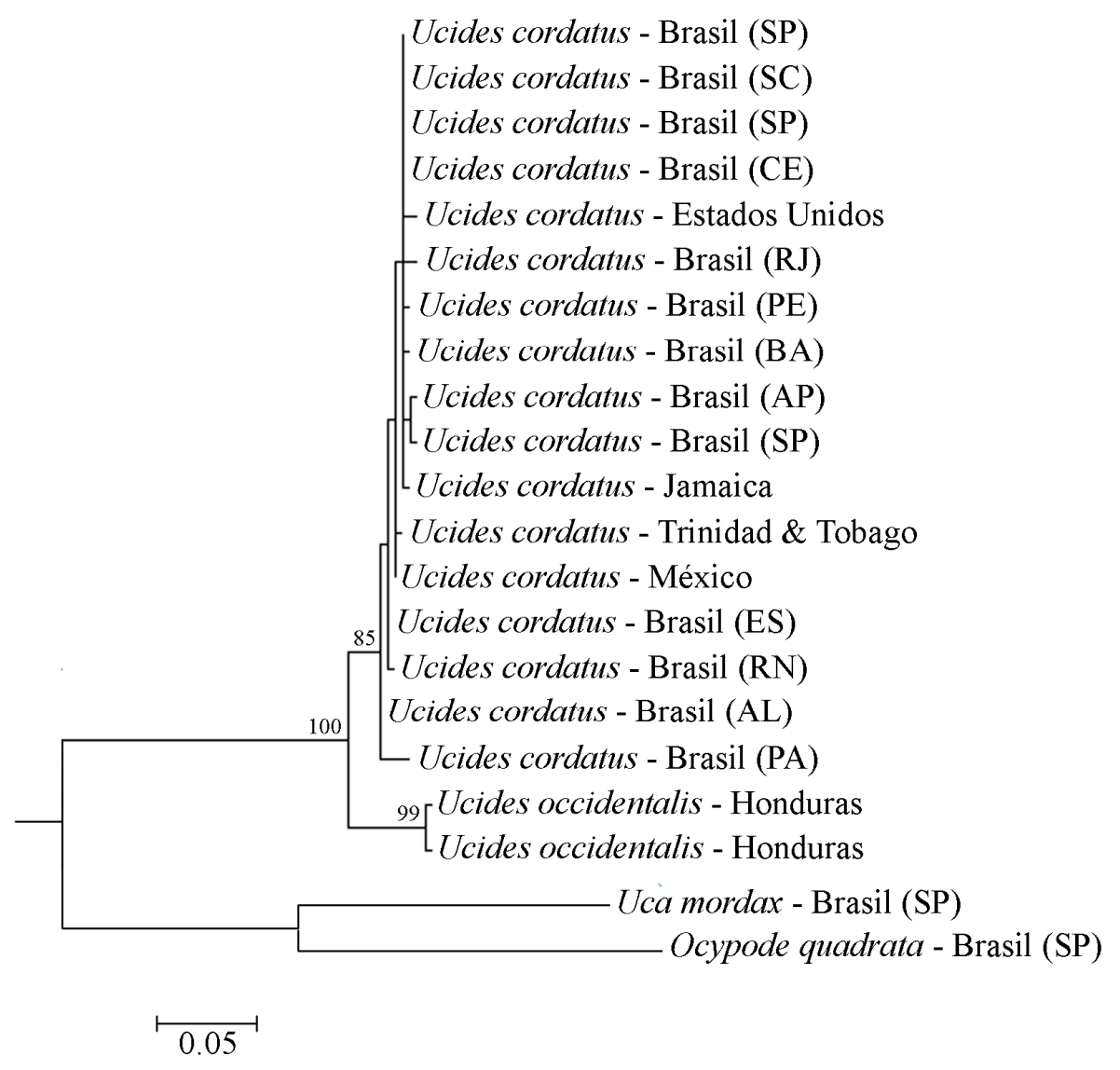

Figura 18. Ucides cordatus. Dendrograma construído pelo método de busca por "Maximum Likelihood" para os genes COI e 16S concatenados. Os números apresentados correspondem aos valores de significância para 1000 réplicas de bootstrap. Para designação das localidades, consultar Tabela 6 . 
$\underline{\text { Análise de distância genética }}$

Os alinhamentos finais para as análises de distância genética correspondem aos mesmos alinhamentos utilizados para a análise filogenética dos genes COI e 16S, separadamente.

Para o gene COI, observou-se distância genética para os espécimes de Ucides cordatus analisados variando de 0 a 1.3\% (Fig. 19A). A taxa de divergência interespecífica mostrou-se superior à intraespecífica, uma vez que a distância entre as espécies congenéricas variou de 2.4 a 3.3\% e a distância interespecífica, incluindo as espécies utilizadas como grupos externos, variou de 17.6 a $22.8 \%$ (Fig. 19A).

Para o gene $16 \mathrm{~S}$, a distância genética entre os espécimes de $U$. cordatus variou de 0 a 0.6\% (Fig. 19B). Da mesma forma que observado para o gene COI, a taxa de divergência interespecífica mostrou-se superior à intraespecífica, sendo que a distância entre as espécies congenéricas variou de 1.2 a 2\% e a distância interespecífica, incluindo as espécies utilizadas como grupos externos, variou de 10.6 a 15.4\% (Fig. 19B).

Para o gene H3, a análise de distância genética baseou-se no alinhamento de 335 pares de bases, contendo fragmentos parciais dos genes de 13 espécimes de $U$. cordatus provenientes de 12 localidades distintas (Tabela A6). Para esse gene, observou-se distância genética de $0 \%$ entre todos os espécimes.

O teste de Mantel indicou uma correlação não significativa entre a distância genética e a distância geográfica dos indivíduos analisados (coeficiente de correlação $=0.04938 ; \mathrm{p}=$ 0.373). 


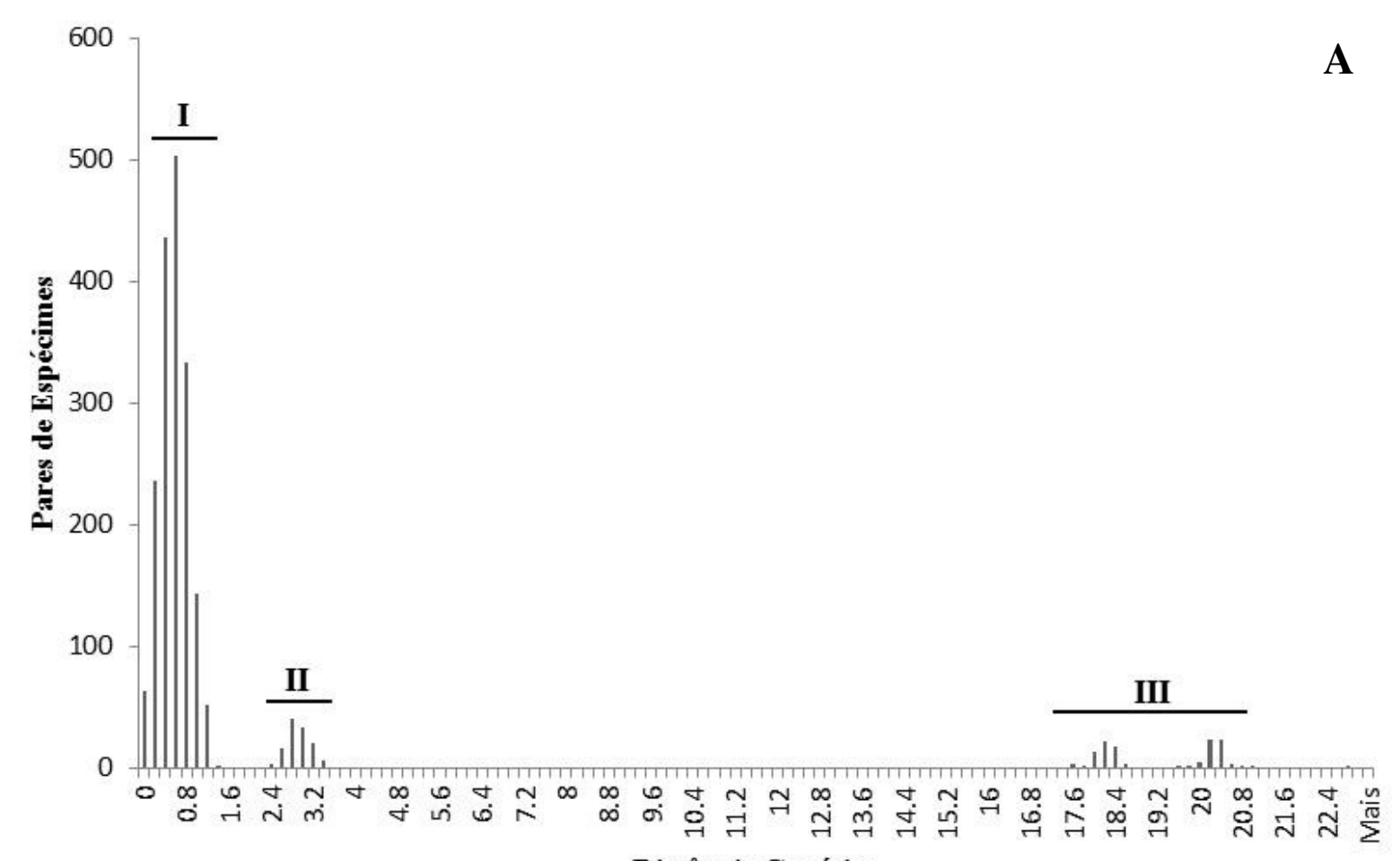

Distância Genética

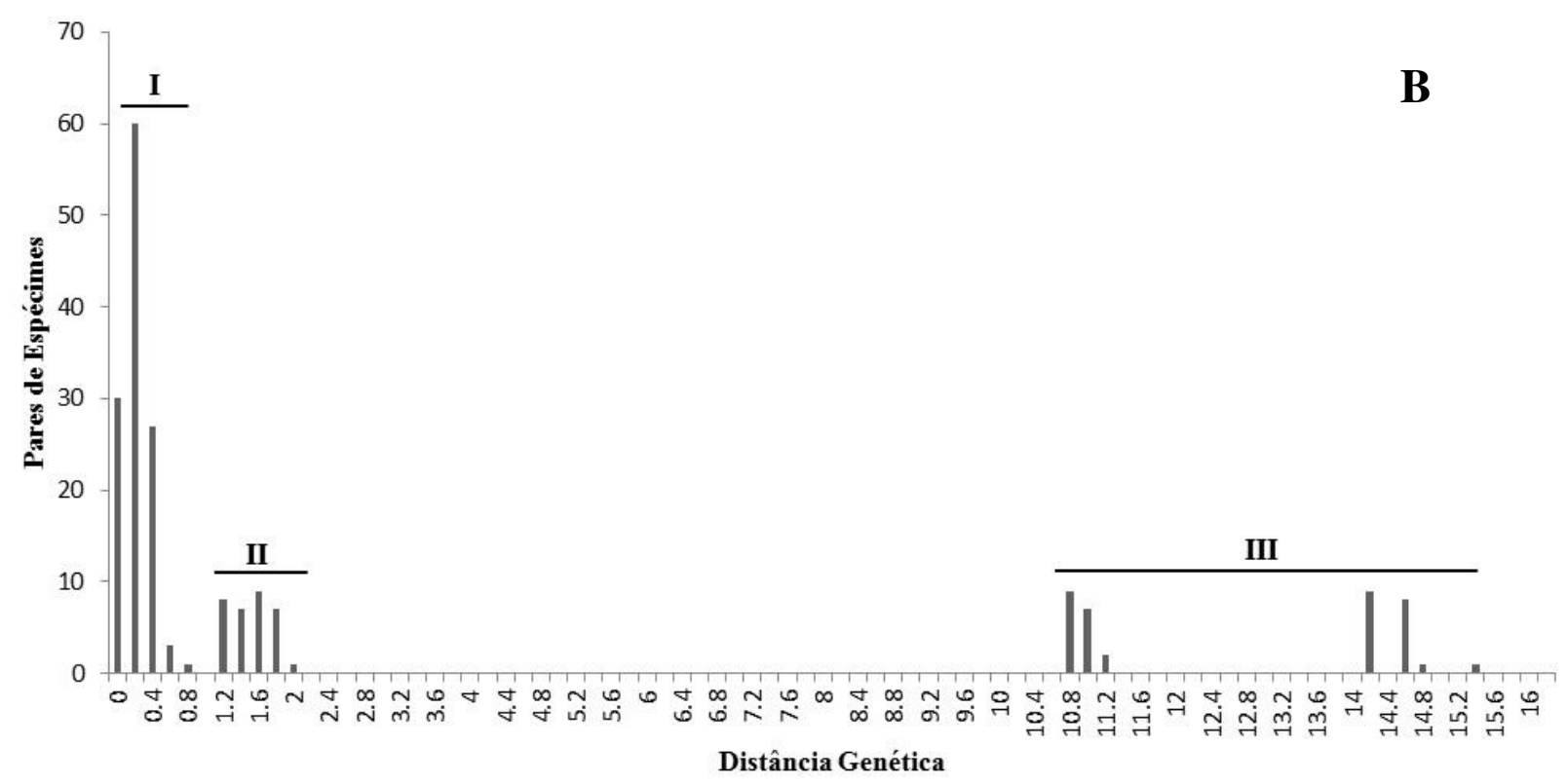

Figura 19. Ucides cordatus. Histogramas com as frequências de distâncias genéticas entre os pares de localidades analisadas para os genes COI (A) e 16S (B); I: variação intraespecífica; II: variação interespecífica congenérica; III: variação intergenérica. 


\section{$\underline{\text { Teste de neutralidade }}$}

Os testes de Tajima $\mathrm{D}$ e $\mathrm{Fu} \mathrm{F}_{\mathrm{s}}$ apontaram valores significativamente negativos $(\mathrm{D}=-$ 2.20, $\left.\mathrm{p}<0.05 ; \mathrm{F}_{\mathrm{s}}=-26.10, \mathrm{p}<0.05\right)$, indicando a rejeição da hipótese nula de neutralidade das populações e a interferência de processos como expansão demográfica recente na população. 


\subsection{ANÁLISES MORFOLÓGICAS}

Para as análises morfológicas, os indivíduos de cada uma das espécies também foram agrupados em diferentes localidades, de acordo com o local ou região de procedência. Assim, igualmente às análises moleculares, os espécimes procedentes do mesmo estado (para as amostras brasileiras) ou país foram reunidos na mesma localidade, conforme as indicações nas Tabelas 2 a 6.

Os resultados incluem, primeiramente, as análises de variabilidade morfológica comparativa, para a qual se utilizou os caracteres morfológicos propostos, comparando-os entre os indivíduos de diferentes localidades. Essa primeira análise foi realizada para todas as espécies. Posteriormente, estão expostos os resultados procedentes das análises de morfometria clássica, apresentadas apenas para as espécies Aratus pisonii e Uca thayeri, cujos dados moleculares evidenciaram elevada estruturação populacional e geográfica.

\subsubsection{Variabilidade Morfológica Comparativa}

Para todas as espécies, sem exceção, não foram encontradas variações que pudessem prever divisão dos indivíduos de diferentes localidades em grupos, de forma que todos se apresentaram semelhantes, com relação à maioria das caraterísticas propostas. Diante das características que apresentaram maior variabilidade, também não foi possível definir nenhum padrão de variação que pudesse estabelecer padrões morfológicos para cada localidade ou grupo de localidades, não sendo possível identificar variação correspondente a nenhuma dessas hierarquias, conforme descrito abaixo, para cada uma das espécies.

Abaixo, segue a lista de material examinado para cada uma das espécies, bem como uma síntese dos resultados obtidos durante a análise morfológica comparativa. Todos os indivíduos aqui sumarizados e utilizados na análise morfológica comparativa das espécies 
Aratus pisonii e Uca thayeri foram também adicionados às análises morfométricas posteriores, com exceção daqueles marcados com *.

\section{Aratus pisonii}

Foram analisados 155 exemplares, sendo 82 machos, 57 fêmeas não ovígeras e 16 fêmeas ovígeras, de A. pisonii provenientes de 27 localidades, ao longo de sua distribuição (Tabela 2).

\section{Material examinado}

Abreviações: AMS: Australian Museum; CCDB: Coleção de Crustáceos do Departamento de Biologia da Faculdade de Filosofia, Ciências e Letras de Ribeirão Preto da Universidade de São Paulo; CNCR: Colección Nacional de Crustaceos, Universidad Autonoma de México; MOUFPE: Museu de Oceanografia, Universidade Federal de Pernambuco; MZUSP: Museu de Zoologia da Universidade de São Paulo; ULLZ: University of Louisiana at Lafayette Zoological Collection; USNM: United States National Museum do Smithsoniam Institution - National Museum of Natural History; UF: Florida Museum of Natural History, University of Florida; ${ }^{\lambda}:$ macho; $q$ : fêmea; $q$ $q$ : fêmea ovígera; s/loc.: sem local de coleta; s/d.: sem data de coleta; s/col.: sem coletor.

BERMUDA: Riddell's Bay, 32¹5'45.6"N - 6449'45.8"W, vii/1972, col. J.E. Pearson, $1 \overbrace{}^{\Uparrow *(U S N M} 143592)$

ESTADOS UNIDOS: Flórida - Daytona Beach, 29¹2'18.9"N - 8059'46.9"W, 04/iii/2005, col. H.C Liu, 19 (UF 32620) - Gandy Bridge, Tampa Bay, 2752'20.9"N 82³6'39.0"W, 24/i/2004, col. D.L. Felder et al., 1 ㅇ (ULLZ 6646) - Alafia River, Tampa Bay, 2751'13.8"N - 82²4'09.7"W, 23/ii/1996, col. C.D Schubart, $1{ }^{\curvearrowright}$ (ULLZ 3838) - Little Jim 


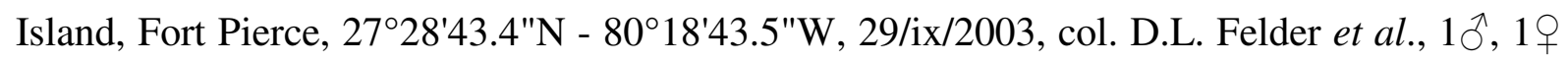
(ULLZ 5459) - Little Jim Island, Fort Pierce, 27²8'43.4"N - 80¹8'43.5"W, 26/vii/2005, col. D.L. Felder et al., $1 \widehat{O}^{\hat{O}}$ (ULLZ 9467) - Little Jim Island, Fort Pierce, 27²8'43.4"N 80¹8'43.5"W, 27/vii/2005, col. D.L. Felder et al., 1 + (ULLZ 9430) - Palm Beach, 265' $47.0^{\prime \prime} \mathrm{N}-80^{\circ} 7^{\prime} 30.4 " \mathrm{~W}, 22 / \mathrm{v} / 1974$, s/col., 2 q (USNM 170175) - Hollywood,

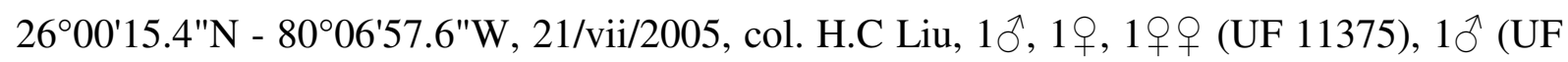
32623) - Dade County, Biscayne Bay National Park, Elliot Key, 25²6'41.6"N 80¹1'35.4"W, 30/iv/2010, col. J. Slapcinsky \& S. Schramski, $1 ð ð$ (UF 26189) - Pigeon Key,

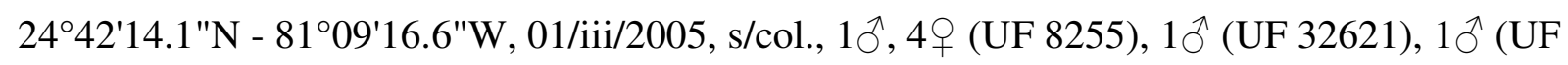

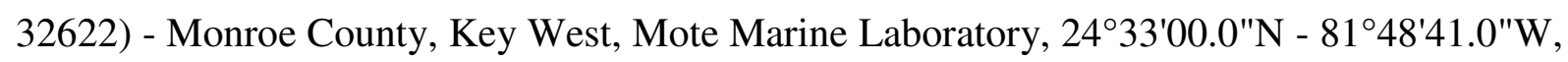
29/v/2003, col. V. Bonito, $1 ð$ (UF 11453).

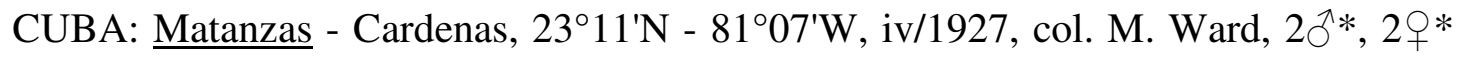
(AMS P.45132). La Habana - Los Arroyos, 22²1'07.5"N - 84²2'53.1"W, 20/v/1914, col. Henderson \& Bartsch, 4 $\overbrace{}^{\Uparrow *}$ (USNM 4857).

JAMAICA: - s/loc., iii/1884, col. Jamaica Fish Expedition, $1 \bigcirc^{\Uparrow *}, 1 \uparrow *, 3 q \circ *$ (USNM 18559).

PORTO RICO: - s/loc., 14/ii/1999, col. US Fish Commision Porto Rico Expedition, $3{ }^{\Uparrow *}, 2$ 우 (USNM 24051).

ILHAS VIRGENS: St Thomas, Benner Bay, 18¹9'01.1"N - 6451'59.6"W, 1972, col. W.E. Rainey, 1ㅇ* (USNM 154561).

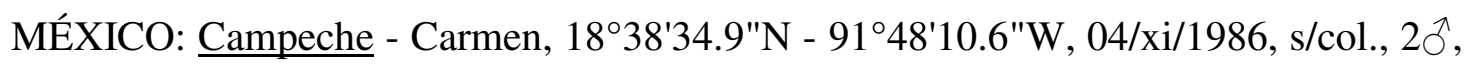

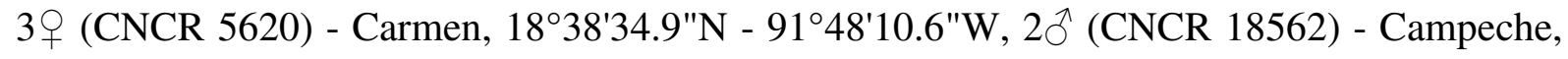
1950'12.4"N - 90³3'10.2"W, 21/viii/1987, col. M.D. Valle et al., 1ठ* (CNCR 8624) -

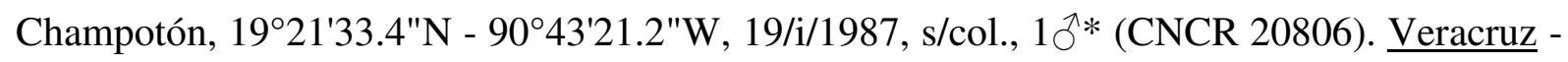

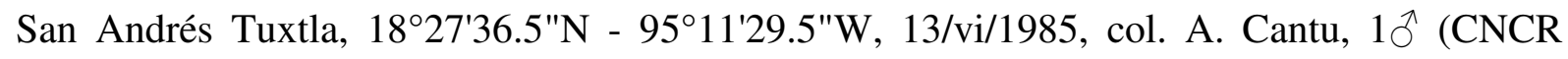


4417) - Catemaco, $18^{\circ} 25^{\prime} 00.2^{\prime \prime} \mathrm{N}-95^{\circ} 06^{\prime} 19.6^{\prime \prime} \mathrm{W}, 13 / \mathrm{vi} / 1985$, col. A. Cantu, $1 \varrho^{\Uparrow}$ (CNCR 4732) - Catemaco, 18²5'00.2"N - 9506'19.6"W, 02/viii/1985, col. M.D. Valle \& P. Schmidtsdorf, 19 (CNCR 20717). Tabasco - Huimanguillo, 1750'27.3"N - 93²2'48.4"W, 19/i/1998, col. J. Villalobos \& R. Robles, 1 (CNCR 17126) - Huimanguillo, 1750'27.3"N 93²2'48.4"W, 23/iii/1998, col. J. Villalobos \& R. Robles, 1ð̄, 1ㅇ, 1 우 (CNCR 17217).

BELIZE: Twin Cays, Main Channel, 1649'49.7"N - 8806'12.2"W, 29/v/1980, col. B. Spracklin, 1ठ*(USNM 1136811).

COSTA RICA: Limón - Manzanillo National Wildlife Refuge (Atlântico), Laguna de Gandoca, $09^{\circ} 35^{\prime} 24^{\prime \prime} \mathrm{N}-82^{\circ} 35^{\prime} 46 " \mathrm{~W}, 03 / \mathrm{vi} / 2011$, col. A. Rebolledo, $2 \bigcirc^{\Uparrow *,} 2$ 2 * (CCDB 875) Manzanillo National Wildlife Refuge (Atlântico), Laguna de Gandoca, 09³5'24"N 82³5'46"W, 12/vii/2013, col. R. Buranelli et al., 2ð, 3 ㅇ (CCDB 4685).

PANAMÁ: Bocas del Toro - Bocas del Toro, 09²1'0.62"N - 82¹5'4.2"W, 01/viii/2011, col. F.L. Mantelatto, 2ð̂, 2q, 1 qq (CCDB 1533).

VENEZUELA: Nueva Esparta - Laguna de La Restinga, Isla Margarita, 1059'14.5"N - 6409'2.0"W, 02/xi/1949, col. L. Carbonell, 1ठ, 19q (USNM 91241) - Laguna de La Restinga, Isla Margarita, $10^{\circ} 59^{\prime} 14.5^{\prime \prime} \mathrm{N}-64^{\circ} 09^{\prime} 2.0^{\prime \prime W}$, 28/vi/2006, col. F.L. Mantelatto \& L. Pileggi, 2ð (CCDB 1823). Dependencias Federales - Archipiélago de Los Roques, Playa Arenosa, $11^{\circ} 51^{\prime} 40.1^{\prime \prime} \mathrm{N}-66^{\circ} 45^{\prime} 09.4^{\prime \prime} \mathrm{W}, \mathrm{ix} / 1950$, col. W.H. Weibezahn, 1q, 19 우 (USNM 95715). Cairifoita, Rio San Grass, iii/1937, $1 \jmath^{\Uparrow}$ (USNM 76472).

TRINIDAD \& TOBAGO: - s/loc., i/2005, col. H.C. Liu, 19 (UF 11280). Trinidad -

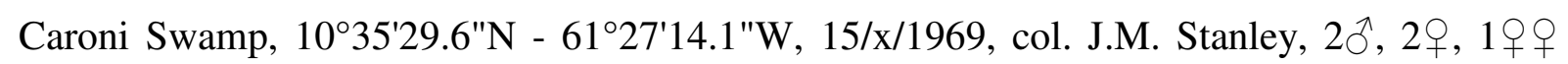
(USNM 139282) - s/loc., 11/ii/2005, col. H.C. Liu, $3 q$ (UF 8860), 1ð* (UF 32614), 1ð (UF 32615), 1 ๙ (UF 32616).

BRASIL: Amapá - Calçoene, Mangue Praia do Goiabal, 2³5'41.9"N - 5050'57.0"W, 05/ix/2014, col. M. Lopes \& A.C. Batista, 1 $\overbrace{}^{*}, 1$ 1 * (CCDB 5414). Pará - Salinópolis, Lagoa 
Praia do Maçarico, $0^{\circ} 36^{\prime} 49.2^{\prime \prime} \mathrm{S}$ - 47²0'35.3"W, 16/xi/2012, col. F.L. Carvalho et al., $2 \widehat{ }$ (CCDB 4447). Ceará - Cascavel, 4²'37.4"S - 38¹0'5.1"W, 20/vi/2005, col. L.E.A Bezerra, 1 우 (CCDB 4366). Rio Grande do Norte - Estuário Ceará - Mirim, 0540'6.5"S - 35²13'5.7"W, 18/vi/2009, col. M. Tavares et al., 1ðð (MZUSP 29920), 19 (MZUSP 29921), 1 (MZUSP 29922), $10^{\Uparrow}$ (MZUSP 29923) - Natal, 605'8.6"S - 3506'0.8"W, 09/vi/2011, col. R. Robles, $1 \overbrace{}^{\Uparrow}$ (CCDB 3365). Paraíba - Mamanguape, 644'52.0"S - 3456'51.8"W, 19/iv/2000, col. R. Leonel, $1 \delta^{\Uparrow}$ (MZUSP 13263), 19 (MZUSP 29907). Pernambuco - Ilha Santo Aleixo, Sirinhaém, 08³6'37"S - 3501'21"W, 06/ii/2007, col. A. Almeida, 10̋ (MOUFPE 13536).

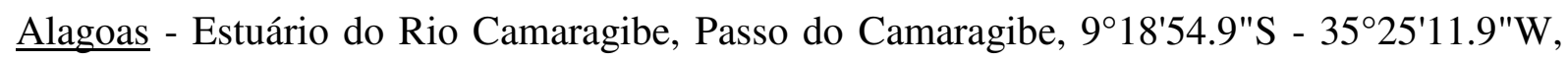

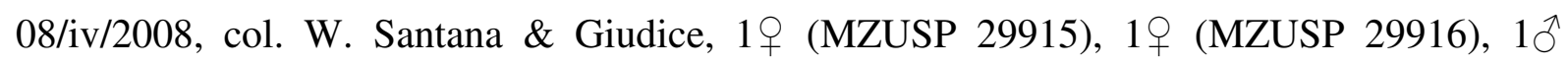
(MZUSP 29917), 19 (MZUSP 29918), 19 (MZUSP 29919). Bahia - Porto do Sauípe,

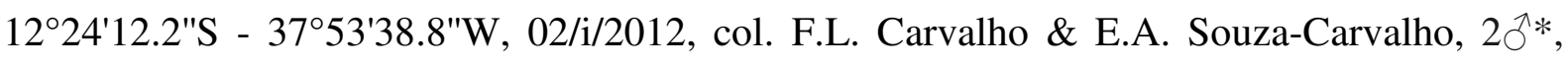
1우 (CCDB 181) - Porto Seguro, 16²7'49.2"S - 394'18.7"W, 14/viii/2011, col. F.L. Carvalho \& E.A. Souza-Carvalho, 2q, $2{ }^{\Uparrow}$ (CCDB 1448) - Porto Seguro, 16²7'49.2"S 394'18.7"W, 16/viii/2012, col. F.L. Carvalho \& E.A. Souza-Carvalho, $1 \overbrace{}^{\Uparrow}$ (CCDB 4267). Espírito Santo - Guarapari, 20³8'55.5"S - 40³0'02.0"W, 18/vi/2012, col. F.L. Carvalho et al., 1우, 2 ㅇ (CCDB 3968) - Marataízes, 2059'47.7"S - 4048'53.2"W, 26/vi/2012, col. F.L.

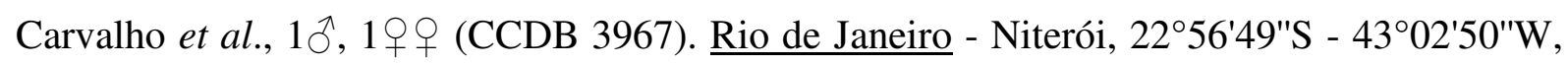

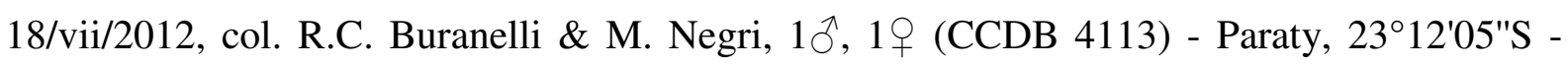

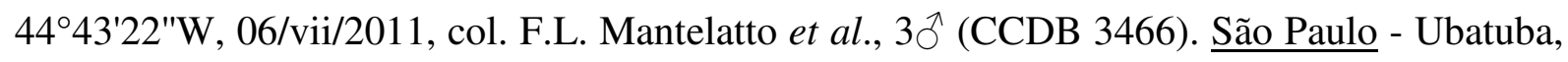

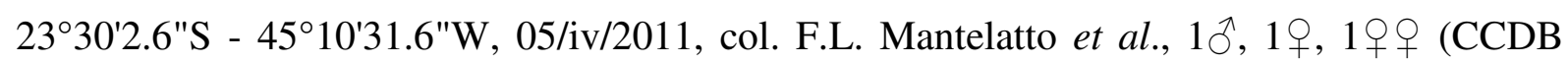

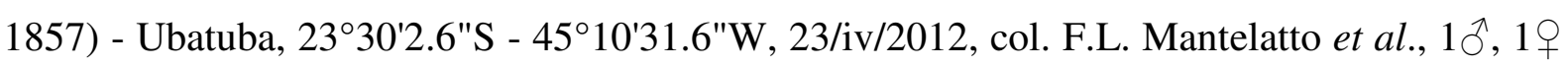

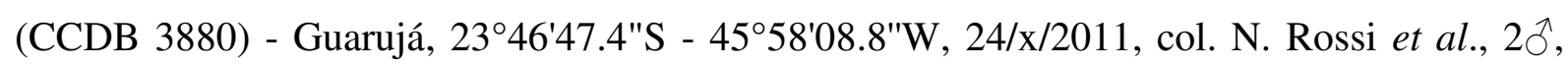
3 우 (CCDB 3598) - Cananéia, 245'ㄱ' 1 "S - 4953'24'"W, 30/viii/2011, col. R. Costa et al.,

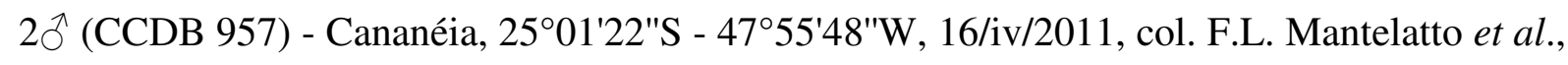


1ठ, 1 우 (CCDB 3264) - Cananéia, 2501'22"S - 4755'48"W, 10/iii/2012, col. F.L. Mantelatto, 19 (CCDB 3770) - Ilha Comprida, Praia da Balsa, 2501'2.3"S - 4755'0.7'"W, 09/xi/2011, col. F.L. Carvalho et al., 1 $\delta^{\Uparrow *}$ (CCDB 3661) - Ilha Comprida, Praia da Balsa, 2501'2.3"S - 4755'0.7"'W, 10/iii/2012, col. F.L. Mantelatto et al., 1今* (CCDB 3765). Paraná - Baía de Paranaguá, 25³0'54.7"S - 48³0'1.0"W, 28/ii/2013, col. M.Z. Marochi, 20 (CCDB 4884) - Ilha da Sepultura, Baía de Guaratuba, 2551'41.22'S - 48³5'23.5"W, 25/iii/2013, col. M.Z. Marochi, 3ð̄ (CCDB 4885). Santa Catarina - Joinville, Baía da Babitonga, 26017'57.5"S - 4847'56.8"W, 21/iii/2013, col. M.Z. Marochi, $2 \overbrace{}^{\Uparrow}$ (CCDB 4886).

O tamanho dos animais analisados variou de 8.15 a $23.49 \mathrm{~mm}$ para CC e de 8.64 a $25.14 \mathrm{~mm}$ para LC em machos; de 9.49 a $25.38 \mathrm{~mm}$ para CC e de 9.83 a $25.93 \mathrm{~mm}$ para LC em fêmeas não ovígeras e de 15.83 a 22.75 mm para CC e de 15.64 a 23.40 para LC em fêmeas ovígeras.

Dentre as características morfológicas analisadas, foram observados, sem exceção: carapaça com forma trapezoidal, com medidas de LC significativamente maiores que as de $\mathrm{CC}(\mathrm{t}=10.07 ; \mathrm{df}=138 ; \mathrm{P}<0.05)$ e com regiões profundamente marcadas; lóbulos gástricos e face superior da fronte com grânulos esparsos e região branquial com poucos grânulos esparsos; face superior da fronte com quatro lóbulos bem separados e de iguais medidas de largura; face externa do própodo dos pereópodos PI e PII com estreita fileira de cerdas; mero dos pereópodos com espinhos terminal e sub-terminal e com margens interna e externa denteadas.

Dentre os caracteres analisados que apresentaram maior variabilidade, estão: presença de dente orbital externo com base larga, mas com comprimento variável; ísquio do quelípodo ornamentado na margem interna com um dente ou às vezes um espinho; face externa do carpo e, às vezes, do própodo dos pereópodos com duas estrias granuladas ou própodo com estria 
oblíqua; mero do quelípodo com evaginação denteada interna, com dentes que variam em número (de 10 a 21), forma e distribuição.

\section{Goniopsis cruentata}

Foram analisados 144 exemplares, sendo 75 machos, 46 fêmeas não ovígeras, 21 fêmeas ovígeras e dois juvenis de G. cruentata, provenientes de 28 localidades, ao longo de sua distribuição (Tabela 3).

\section{Material examinado}

Abreviações: AMS: Australian Museum; CCDB: Coleção de Crustáceos do Departamento de Biologia da Faculdade de Filosofia, Ciências e Letras de Ribeirão Preto da Universidade de São Paulo; CNCR: Colección Nacional de Crustaceos, Universidad Autonoma de México; MOUFPE: Museu de Oceanografia, Universidade Federal de Pernambuco; MZUCR: Museo de Zoología da Universidad de Costa Rica; MZUSP: Museu de Zoologia da Universidade de São Paulo; ULLZ: University of Louisiana at Lafayette Zoological Collection; USNM: United States National Museum do Smithsoniam Institution National Museum of Natural History; UF: Florida Museum of Natural History, University of Florida. ${ }^{\Uparrow}$ : macho; $\bigcirc$ : fêmea; $\bigcirc$ : fêmea ovígera; s/loc.: sem local de coleta; s/d.: sem data de coleta; s/col.: sem coletor.

BERMUDA: Ferry Reach, Bermuda Biological Station for Research, St George's

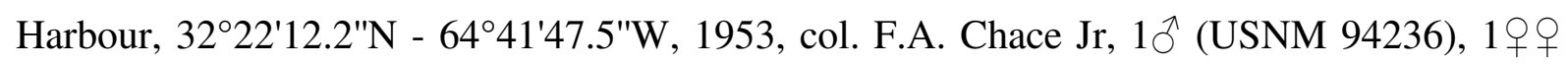
(USNM 1188927), 1 우 (USNM 1188928).

ESTADOS UNIDOS: Flórida - Flagler County, Whitney Laboratory for Marine Bioscience, $29^{\circ} 40^{\prime} 13.2^{\prime \prime} \mathrm{N}-81^{\circ} 12^{\prime} 56.9^{\prime \prime} \mathrm{W}$, ix/2006, col. J. Netherton, $1 \overbrace{}^{\Uparrow}$ (UF 9132) - Indian 
River Lagoon, 284'24.9"N - 80³5'54.1"W, 15/iii/1998, col. D.L. Felder et al., 1 ㅇ (ULLZ 3750) - Little Jim Island, Fort Pierce, $27^{\circ} 28^{\prime} 43.4^{\prime \prime} \mathrm{N}-80^{\circ} 18^{\prime} 43.5^{\prime \prime} \mathrm{W}, 04 /$ viii/2001, col. B.

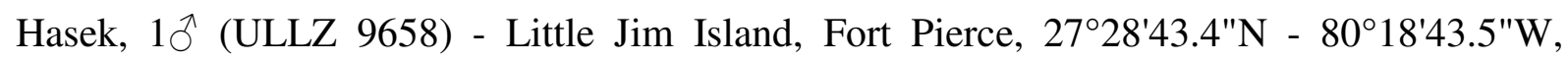
05/viii/2005, col. D.L. Felder 10َ (ULLZ 9487) - Del Ray Beach, 26²8'55.3"N 80³'17.2"W, 1953, col. C.A. Child, 1ðึ (USNM 151478) - Monroe County, Key Largo,

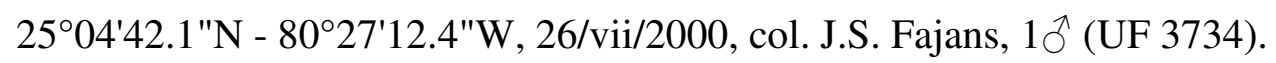

CUBA: La Habana - Havana, Marianao Beach, $23^{\circ} 05^{\prime} \mathrm{N}-82^{\circ} 26^{\prime} \mathrm{W}$, iv/1927, col. M. Ward, 2J (AM P.44532), 19 (AM P.46262). ㅂolguín - Puerto de Moa, 20³9'10.1"N 7454'39.3"W, 08/iii/1930, col. Parish Smithsonian Expedition, 1 q (USNM 65862).

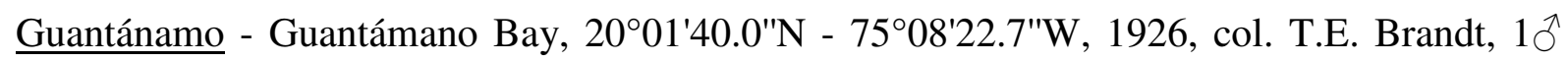
(USNM 59895), 1 (USNM 1188921), 1 (USNM 1188922).

MÉXICO: Tamaulipas - Altamira, 22²3'13.9"N - 9756'19.8"W, 02/iv/1988, col. J.

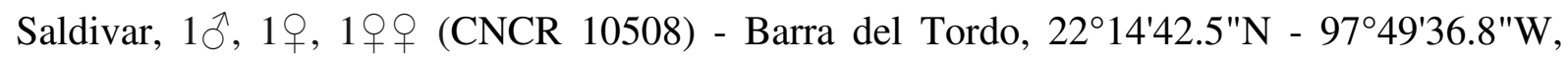
20/iv/1998, col. D.L. Felder et al., 1 q (ULLZ 3712). Yucatán - Río Lagartos, Cenote Chiquila, $21^{\circ} 35^{\prime} 47.2^{\prime \prime} \mathrm{N}-88^{\circ} 08^{\prime} 45.1^{\prime \prime} \mathrm{W}, 11 / \mathrm{v} / 1985$, s/col., $1{ }^{\Uparrow}, 19+$ (CNCR 4951). Quintana $\underline{\text { Roo }}$ - Solidaridad, Laguna de Paila, $20^{\circ} 02^{\prime} 01.5^{\prime \prime} \mathrm{N}$ - 87²28'45.0"W, 18/i/1985, col. J.C. Nates et al., 1 (CNCR 3643) - Felipe Carrillo Puerto, Vigía Chico, 1945'56.4"N - 87³5'53.6"W, 18/i/1985, col. J.C. Nates et al., 1 ( (CNCR 3721). Veracruz - Palma Sola, 1946'21.3"N -

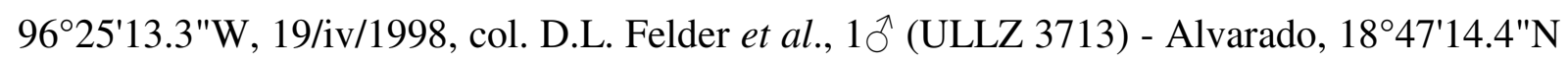
- 9545'14.3"W, 02/viii/1987, col. B. Bonilla, 1ठ (CNCR 10495) - San Andrés Tuxtla, $18^{\circ} 27^{\prime} 35.1 " \mathrm{~N}$ - 95¹1'29.0"W, 23/x/1985, col. J.L. Villalobos et al., $2 \bigcirc^{\Uparrow}$ (CNCR 4757) -

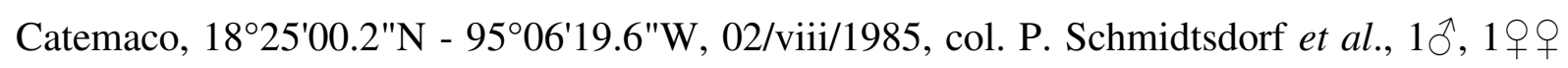

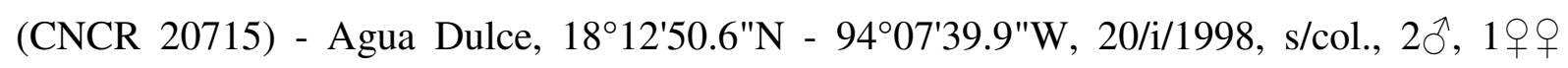
(CNCR 17157) - Laguna San Agustin, 18¹0'11.942"N - 94²4'2.455"W, 09/ii/1999, col. D.L. Felder et al., $1{ }^{\Uparrow}$ (ULLZ 4007). 
JAMAICA: Saint James - Montego Bay, 18²7'56.4"N - 7755'35.5"W, 28/vi/1910,

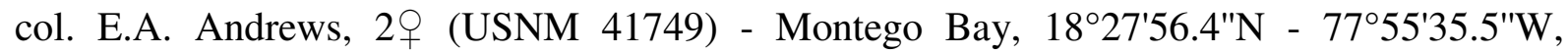
02/viii/1936, col. L. Gardner, $1 ð$ (USNM 72787), 1 (USNM 1188929). Westmoreland Negril, $18^{\circ} 16^{\prime} 45.0^{\prime \prime} \mathrm{N}-78^{\circ} 20^{\prime} 45.5^{\prime \prime} \mathrm{W}, 21 / \mathrm{x} / 2005$, col. H.C. Liu, 1 우 (UF 8865).

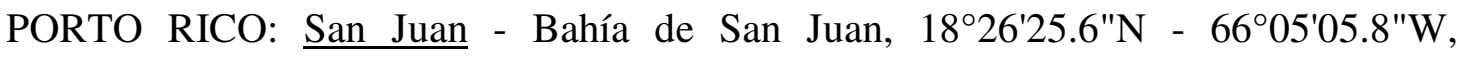
18/i/1899, col. P. Beckwirth, 1今̂, 2 우 (USNM 22793).

SAN MARTIN: - Baie de l'Embouchure, 1804'01.3"N - 6300'59.8"W, 16/iv/2012, col. G Paulay et al., 1ð (UF 32137), 1ð (UF 32164).

BELIZE: - Twin Cays, 1649'23.383"N - 886'9.889"W, 24/ii/2009, col. D.L. Felder et

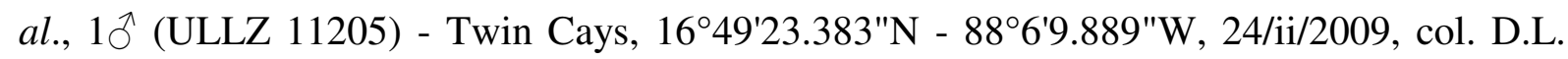
Felder et al., 1 ( (ULLZ 12553).

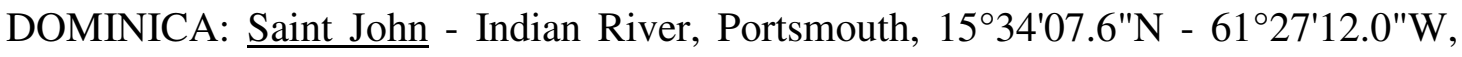

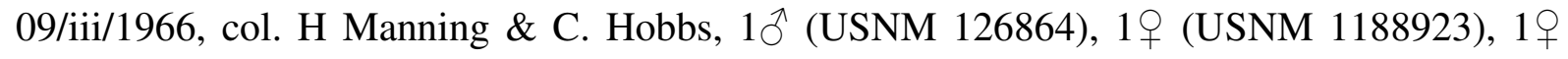
(USNM 1188924), 1ð (USNM 1188925).

COSTA RICA: Limón - Laguna de Gandoca, Manzanillo National Wildlife Refuge

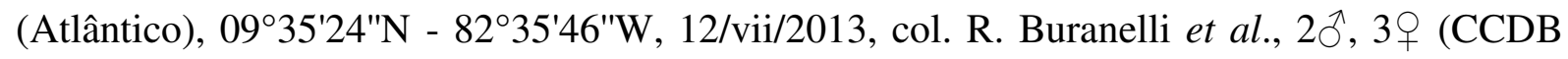
4686).

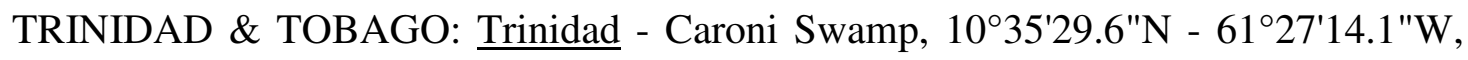
15/vii/1970, col. J.M. Stanley, 1ð, 2 (USNM 139285) - s/loc., 11/ii/2005, col. H.C. Liu, $1 \lesssim$, 1 ( (UF 8819). Tobago - Canoe Bay, $11^{\circ} 08^{\prime} 32.8^{\prime \prime} \mathrm{N}-60^{\circ} 47^{\prime} 59.4^{\prime \prime} \mathrm{W}, 31 / \mathrm{i} / 2000$, col. HC. Liu, 1 으 (UF 8837).

VENEZUELA: Miranda - Higuerote, 10²8'29.4"N - 6605'32.0"W, 21/iv/1948, col. F. Martin, 1ठ (USNM 91239), 1 ( (USNM 1188926). 
GUIANA FRANCESA: - Plage de Rénuré, 453'48.3"N - 52¹5'34.1"W, 25/ix/2000, s/col., 10ิ (MZUSP 29908), 19 (MZUSP 29909), 1ð (MZUSP29910) - De Barcadaire du Matoury, $4^{\circ} 50^{\prime} 59.9 " \mathrm{~N}-52^{\circ} 19^{\prime} 52.8^{\prime \prime W}, 25 / \mathrm{ix} / 2000$, s/col., $1{ }^{\Uparrow}, 19+$ (MZUSP 16157).

BRASIL: Amapá - Calçoene, Mangue Praia do Goiabal, 2³5'41.9"N - 5050'57.0"W, 4/ix/2014, col. M. Lopes \& A.B. Carvalho, 1q, 2 +q (CCDB 5408) - Jipioca, 153'21.5"N 50¹0'34.5"W, 19/x/1995, col. M. Fernandes, 1 우 (MZUSP 29931), 1ð (MZUSP 29932), $1{ }^{\Uparrow}$ (MZUSP 29933), 10 (MZUSP 29934). Pará - Bragança, 048'7.1"S - 46³6'57.0"W, 09/xi/2012, col. F. Abrunhosa, 1つ̂, 1q, $1 q q$ (CCDB 4612). Maranhão - São Luís, 2²9'35.1"S - 44²0'33.1"W, 19/xi/1983, col. I. Schardijn, 19 (MZUSP 6229) - São Luís,

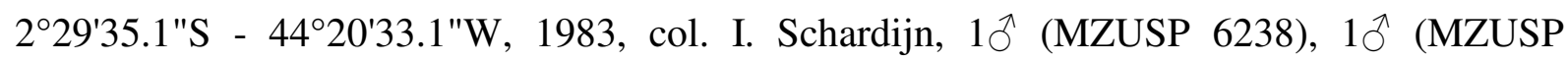

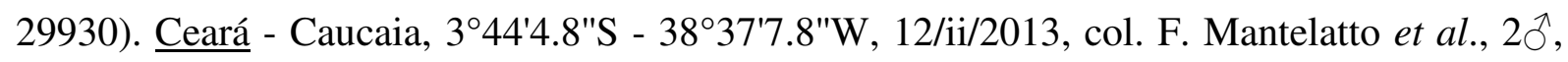
2ㅇ, 1 우 (CCDB 4498). Rio Grande do Norte - Natal, 605'8.6"S - 3506'0.8"W, 09/vi/2011, col. R. Robles, 2ð̄, 1 ( (CCDB 3389). Paraíba - Mamanguape, 644'52.0"S - 3456'51.8"W, 21/ii/2000, col. R. Leonel, $1 ð$ (MZUSP 13254), $1 q$ (MZUSP 29935), $1 q q$ (MZUSP 29936). Pernambuco - Estuário Rio Goiana, 7³3'57.7"S - 3450'14.4"W, 12/viii/2003, s/col., $1 \delta^{\Uparrow}$ (MOUFPE 13689) - Tamandaré, 08²1'28.4"S - 3506'09.3"W, i/2012, col. A. Benetti, 1 $^{\circ}$

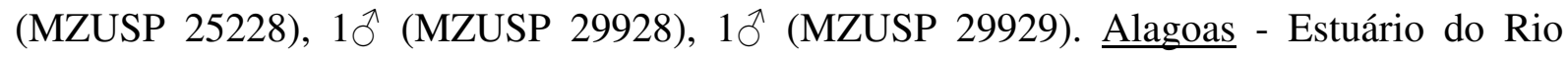
Camaragibe, Passo do Camaragibe, $9^{\circ} 18^{\prime} 54.9^{\prime \prime S}$ - 35²5'11.9"W, 02/vi/2011, col. M. Cardoso \& A. Benetti, $1 \delta^{\Uparrow}$ (MZUSP 29937), $1 ð$ (MZUSP 29938), $1 q$ (MZUSP 29939), $1 ð$ (MZUSP 29940). Bahia - Porto Seguro, 12²4'2.2"S - 3753'38.8"W, 14/viii/2011, col. F.L. Carvalho \&

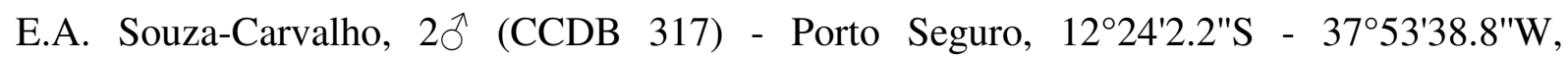
07/i/2012, col. F.L. Carvalho \& E.A. Souza-Carvalho, 1 đ̊ (CCDB 3786) - Porto do Sauípe, $16^{\circ} 27^{\prime} 28.5^{\prime \prime S}-39^{\circ} 41^{\prime} 8.8^{\prime \prime W}, 02 / \mathrm{i} / 2012$, col. F.L. Carvalho \& E.A. Souza-Carvalho, $2{ }^{\Uparrow}, 1+q$ (CCDB 187). Espírito Santo - Guarapari, 20³8'55.5"S - 40³0'02.0"W, 04/xi/2006, col. F.L. Mantelatto, $1 \widehat{\jmath}(\mathrm{CCDB} 2247)$ - Guarapari, 20³8'55.5"S - 40³0'02.0"W, 18/vi/2012, col. F.L. 
Carvalho et al., 10̄, 2q (CCDB 3975) - Marataízes, 2059'42.7"S - 4048'53.2"W, 20/vi/2012, col. F.L. Carvalho et al., $2 \widehat{\bigcirc}$ (CCDB 3970). Rio de Janeiro - Niterói, 2257'9.3"S

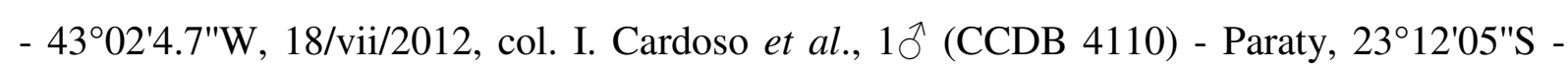
4443'22"W, 06/vii/2011, col. F.L. Mantelatto et al., 20̂, 2 (CCDB 3460). São Paulo -

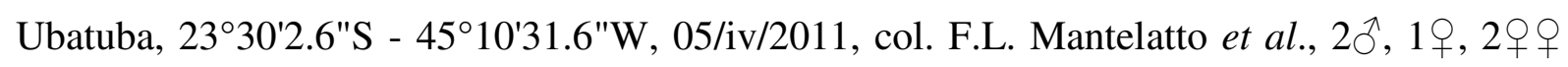

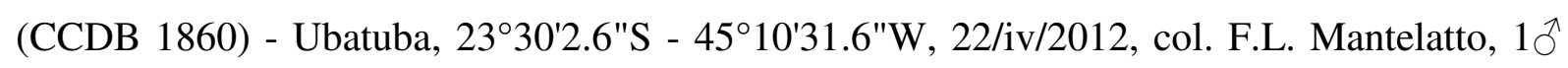
(CCDB 3913) - Ubatuba, 2330'2.6"S - 45²10'31.6"W, 23/iv/2012, col. F.L. Mantelatto et al.,

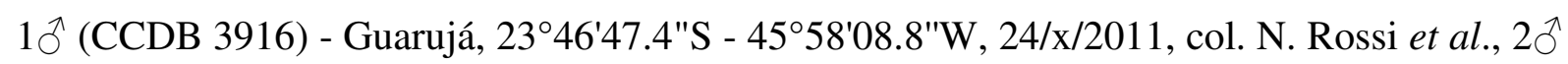
(CCDB 2962) - Bertioga, 2349'11.9"S - 4609'07.7"W, 13/iv/2014, col. R.C. Buranelli \& L.P. Cerantola, 10 (CCDB 4966) - Cubatão, 2354'24.7"S - 46²2'44.3"W, 30/xi/1996, col. R. Silva, 1ð̋ (MZUSP 12241) - Cananéia, 2459'45.1"S - 4754'16.9"W, 17/iv/2011, col. R. Costa et al., 1우 (CCDB 3217) - Cananéia, 2459'45.1"S - 4754'16.9"W, 30/viii/2011, col. R. Costa et al., 1今̂, 4 (CCDB 746) - Cananéia, 2459'45.1"S - 4754'16.9"W, 10/iii/2012, col. R. Robles \& F.L. Mantelatto, $1 \delta^{\Uparrow}$ (CCDB 3777) - Ilha Comprida, Praia da Balsa, 2501.2"S - 4755.0"'W, 30/viii/2011, col. F.L. Mantelatto et al., 1ð (CCDB 785) - Ilha

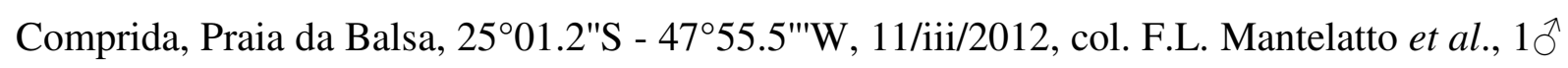
(CCDB 3778). Santa Catarina - Camboriú, 2700'16.4"S - 48³6'10.0"W, 05/xii/2012, col. F.L. Carvalho, $1 ð$ (CCDB 4399).

O tamanho dos animais analisados variou de 15.51 a $44.87 \mathrm{~mm}$ para CC e de 19.47 a $53.63 \mathrm{~mm}$ para LC em machos; de 18.37 a $42.85 \mathrm{~mm}$ para CC e de 21.89 a $51.66 \mathrm{~mm}$ para LC em fêmeas não ovígeras e de 21.49 a 39.09 mm para CC e de 26.68 a 47.98 para LC em fêmeas ovígeras.

Dentre as características morfológicas analisadas, foram observados, sem exceção: carapaça subquadrada com região branquial mais alta do que as demais, sofrendo um 
estufamento em sentido posterior; fronte tuberculada e com quatro lóbulos de igual tamanho, sendo o par mediano mais expandido em sentido anterior; margem da fronte retangular e com margem serrilhada; face externa da palma com única linha de tubérculos espiniformes na região dorsal; mero de todos os pereópodos com forte dente subterminal na margem anterior; carpo dos pereópodos com duas estrias horizontais; margens dos quelípodos tuberculadas.

Dentre os caracteres analisados que apresentaram maior variabilidade, estão: mero dos quelípodos ornamentados com carenas verticais ou, às vezes, estrias mais grossas do que aquelas presentes nos meros dos pereópodos; mero dos quelípodos com margem interna expandida em larga lâmina com margem espinhosa, com espinhos ou dentes que variam em número (de 5 a 13), forma e disposição; margem externa do mero dos quelípodos armada com espinhos ou dentes que variam em número (7 a 9), forma e disposição; ângulo interno do carpo do quelípodo armado com dentes ou espinho que variam em número (de 1 a 3); margem interna do ísquio do quelípodo armada com longos espinhos que variam em número (entre 2 e $3)$.

\section{Sesarma rectum}

Foram analisados 71 exemplares, sendo 37 machos, 29 fêmeas não ovígeras, três fêmeas ovígeras e 2 juvenis de $S$. rectum, provenientes de 14 localidades, ao longo de sua distribuição (Tabela 4).

\section{Material examinado}

Abreviações: CA: Academy of Natural Sciences of Drexel University, Filadélfia CCDB: Coleção de Crustáceos do Departamento de Biologia da Faculdade de Filosofia, Ciências e Letras de Ribeirão Preto da Universidade de São Paulo; MOUFPE: Museu de Oceanografia, Universidade Federal de Pernambuco; MZUSP: Museu de Zoologia da 
Universidade de São Paulo; USNM: United States National Museum do Smithsoniam Institution - National Museum of Natural History; UF: Florida Museum of Natural History, University of Florida. $\overbrace{}^{\Uparrow}$ : macho; $\bigcirc$ : fêmea; + + : fêmea ovígera; s/loc.: sem local de coleta; s/d.: sem data de coleta; s/col.: sem coletor.

TRINIDAD \& TOBAGO: Trinidad - Caroni Swamp, 10³5'29.6"N - 61²7'14.1"W, 22/v/1970, col. J.M. Stanley, 1ठ (USNM 139299), 1우 (USNM 1188936), 10 (USNM 1188937) - s/loc., 09/ii/2005, col. H.C. Liu, $1 \hat{\jmath}, 3 \bigcirc$ (UF 8817), $2 \hat{\jmath}, 1+q$ (UF 8827). Tobago

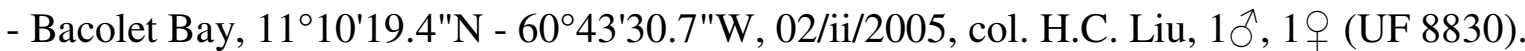

SURINAME: - s/loc., s/d., col. Hering, $1 ð$ (CA 3976) (material tipo)

BRASIL: Pará - Salinópolis, 0³6'49.24"S - 47²0'35.36"W, 16/xi/2012, col. F.L. Carvalho et al., 1 (CCDB 4440) - Bragança, 048'7.1"S - 46³6'57.0"W, 09/xi/2012, col. F. Abrunhosa, 2 ㅇ (CCDB 4469) - Bragança, 050'42.1"S - 46³8'39.0"W, 09/xi/2012, col. F. Abrunhosa, 1ð̄, 1 (CCDB 4613). Maranhão - São Luís, 2²9'35.1"S - 44²0'33.1"W, 1983, s/d., col. I. Schardijn, 1ô (MZUSP 29903), $1 q$ (MZUSP 29904). Ceará - Fortaleza, $3^{\circ} 46^{\prime} 34.0^{\prime \prime S}$ - 38²6'37.5"W, 22/i/2010, col. F.B. Ribeiro \& A.K. Araújo, 2へ, 2 (CCDB 4369). Rio Grande do Norte - Estuário do Rio das Conchas, 503'46.0"S - 36²46 $07.8^{\prime \prime} \mathrm{W}$, 25/xi/2009, col. M. Tavares et al., 19 (MZUSP 22926), 19 (MZUSP 29924), 19 (MZUSP 29925) - Natal, 545'53.8"S - 35²12'44.8"W, 09/vi/2011, col. R. Robles, 2 juvenis (CCDB 3477). Pernambuco - Rio Goiana, $7^{\circ} 33^{\prime} 57.7^{\prime \prime} \mathrm{S}$ - 3450'14.4"W, v/2003, s/col., 19 (MOUFPE

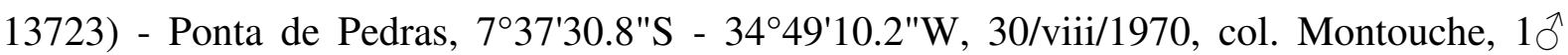

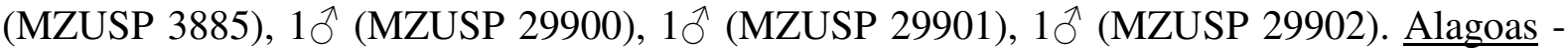
Estuário do Rio Camaragibe, Passo do Camaragibe, 9¹8'54.9"S - 35²5'11.9"W, 03/vi/2011, col. M. Cardoso \& A. Benetti, $1 ð$ (MZUSP 24878), 19 (MZUSP 29914), $1 q$ (MZUSP 29927). Bahia - Porto Seguro, 12²7'42.1"S - 3904'18.0"W, 13/vii/2011, col. F.L. Carvalho 
\& E.A. Souza-Carvalho, 2ð, $3 \propto$ (CCDB 700). Espírito Santo - Anchieta, 2047'8.3"S 40³8'44.3"W, 03/xi/2006, col. M. Tavares et al., $1 \overbrace{}^{\lambda}$ (MZUSP 29911), $10^{\Uparrow}$ (MZUSP 29912) Itapemirim, 2052'2.0"S - 4045'31.8"W, 04/xi/2006, col. M. Tavares et al., $10^{\Uparrow}$ (MZUSP

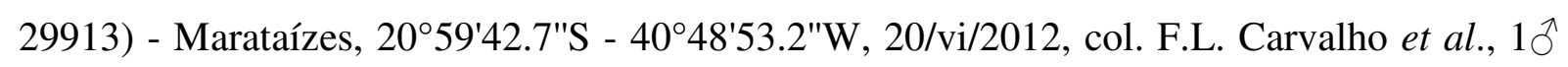

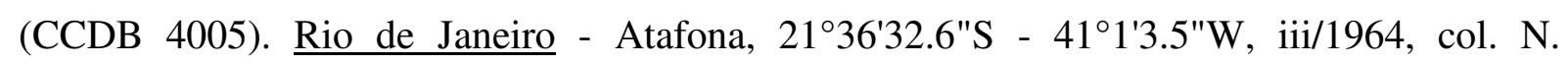
Menezes, 19 (MZUSP 1836) - Niterói, 2257.930’S - 4302.479’W, 06/i/1983, col. M.

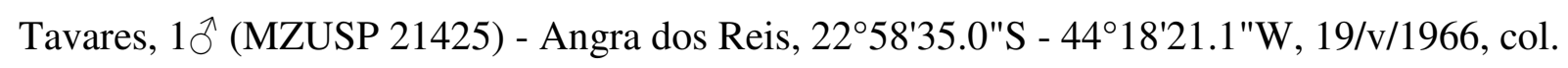

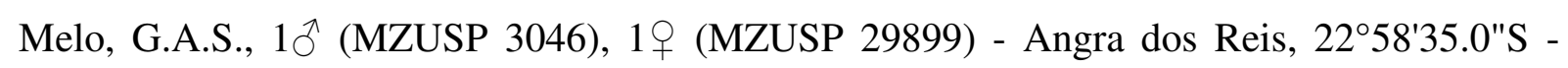

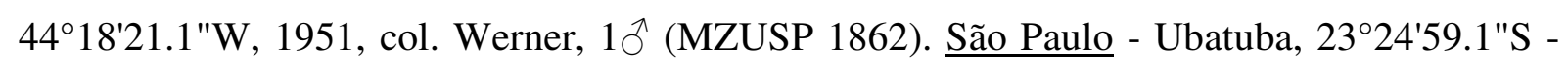
45³'15.7"W, 25/xi/2008, col. F.L. Mantelatto \& C. Tudge, 19 (CCDB 2539) - Ubatuba,

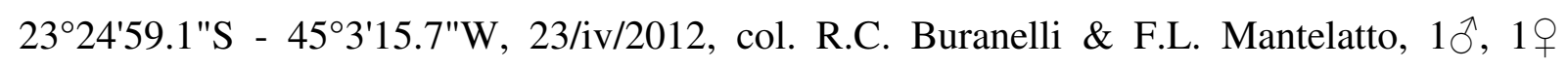

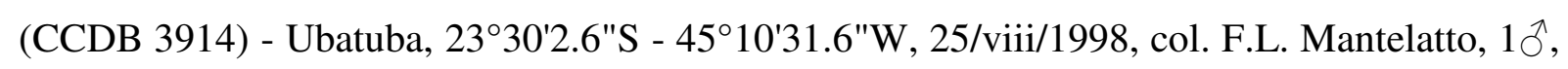

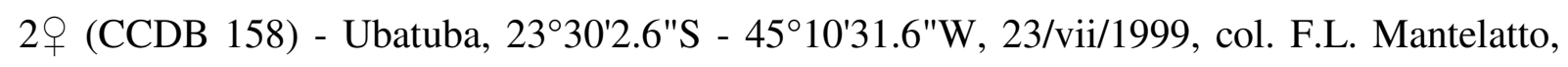
$1{ }^{\Uparrow}(\mathrm{CCDB} 159)$ - Bertioga, 2349'11.9"S - 4609'07.7"W, 13/iv/2014, col. R.C. Buranelli \&

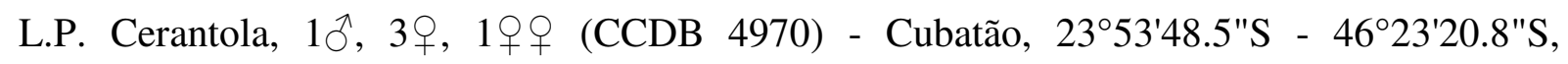
18/ii/1998, col. Silva \& Silva, 10 (MZUSP 12359), 10َ (MZUSP 29906) - Peruíbe, 242'ㄹ'3"S - 470'34.7"W, i/1968, col. D.L. Dall'oco \& R. Vezzani, $1{ }^{\Uparrow}$ (MZUSP 16213) Ilha Comprida, $25^{\circ} 01.2^{\prime \prime S}-47^{\circ} 55.5^{\prime \prime} \mathrm{W}, 09 / x i / 2011$, col. F.L. Carvalho et al., $4{ }^{\Uparrow}, 1$, (CCDB 3669). Santa Catarina - Florianópolis, 27³8'50.4"S - 48³2'9.2"N, 19/ii/1986, col. P.S.

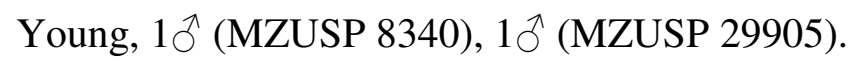

O tamanho dos animais analisados variou de 12.40 a $28.72 \mathrm{~mm}$ para CC e de 14.58 a $34.95 \mathrm{~mm}$ para LC em machos, de 11.03 a $28.37 \mathrm{~mm}$ para CC e de 12.71 a $33.53 \mathrm{~mm}$ para LC em fêmeas não ovígeras e de 16.77 a 21.94 mm para CC e de 19.71 a 26.19 mm para LC em fêmeas ovígeras. 
Dentre as características morfológicas analisadas, foram observados, sem exceção: carapaça significativamente mais larga do que longa $(\mathrm{t}=28.25 ; \mathrm{DF}=64 ; \mathrm{P}<0.05)$, com superfície irregular, tufos de cerdas e região anterior com pequenas carenas tuberculosas e preenchidas por cerdas; margem inferior da fronte cortada por um sinus mediano largo; mero dos pereópodos amplo, com comprimento menor que o dobro da largura; presença de dente subterminal nos meros dos pereópodos; mero e carpo dos pereópodos portando duas e uma estria transversal, respectivamente; fileira de cerdas na porção final da margem anterior do carpo, em toda a margem anterior do própodo e na margem em contato com o dátilo dos pereópodos; dátilo com seis fileiras de cerdas; mero e carpo do quelípodo com dentes subterminais em ambas as margens.

Dentre os caracteres analisados que apresentaram maior variabilidade, estão: carapaça com saliência posterior ao ângulo orbital interno que varia entre fraca e muito pronunciada; serrilhado da margem dorsal do dedo móvel que varia em extensão (de metade a dois terços do dedo móvel) e número de dentes (10 a 15); linhas transversais no mero dos pereópodos que variam quanto ao "pronunciamento", podendo ser mais fortes em PI e PII, mas também nos demais; face externa da palma que varia de raramente granulada à densamente granulada, com aparência áspera; face interna da palma com ornamentação variando de duas carenas oblíquas tuberculadas à ausência de carenas ou com tubérculos esparsos.

\section{Uca thayeri}

Foram analisados 112 exemplares, sendo 74 machos, 35 fêmeas não ovígeras e três fêmeas ovígeras de $U$. thayeri provenientes de 22 localidades, ao longo de sua distribuição (Tabela 5). 


\section{Material examinado}

Abreviações: AMS: Australian Museum; CCDB: Coleção de Crustáceos do Departamento de Biologia da Faculdade de Filosofia, Ciências e Letras de Ribeirão Preto da Universidade de São Paulo; CNCR: Colección Nacional de Crustaceos, Universidad Autonoma de México; MZUSP: Museu de Zoologia da Universidade de São Paulo; ULLZ: University of Louisiana at Lafayette Zoological Collection; USNM: United States National Museum do Smithsoniam Institution - National Museum of Natural History; UF: Florida Museum of Natural History, University of Florida. $\overbrace{}^{\lambda}$ : macho; $q$ : fêmea; $q$ + : fêmea ovígera; s/loc.: sem local de coleta; s/d.: sem data de coleta; s/col.: sem coletor.

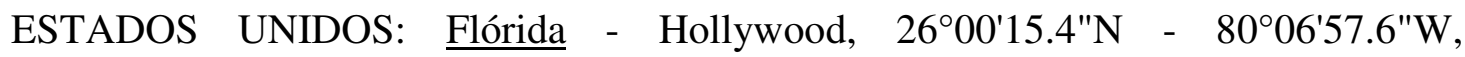

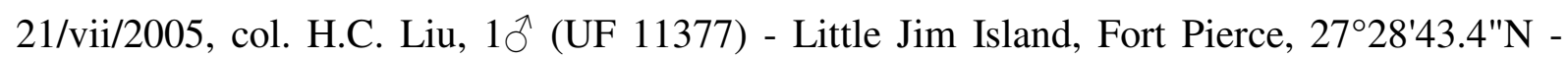
80¹8'43.5"W, 01/viii/2005, col. D.L. Felder, 2 우 (ULLZ 9501) - Little Jim Island, Fort Pierce, $27^{\circ} 28^{\prime} 43.4^{\prime \prime} \mathrm{N}-80^{\circ} 18^{\prime} 43.5^{\prime \prime} \mathrm{W}, 01 /$ viii/2005, col. D.L. Felder et al., $2 \bigcirc^{\Uparrow}$ (ULLZ 9541) Little Jim Island, Fort Pierce, $27^{\circ} 28^{\prime} 43.4^{\prime \prime} \mathrm{N}-80^{\circ} 18^{\prime} 43.5^{\prime \prime W}, 21 /$ vii/2008, col. D.L. Felder et al., $1 \bigcirc^{\Uparrow}$ (ULLZ 10115) - New Smyrna Beach County, Callalisa Park, 2901'45.5"N 8054'13.5"W, 08/v/2011, col. J. Moore \& J. Moore, 1 ( (UF 28616) - Egans Creek, Fernandina Beach, 3042'16.4"N - 81 ${ }^{\circ} 27^{\prime} 02.5^{\prime \prime}$ W, 14/vi/2014, col. D.L. Felder \& J. Felder, $1{ }^{\Uparrow}($ ULLZ 15310).

CUBA: Pinar del Río - Julían, 2200'29.0"N - 84³3'41.7"W, 08/iii/1952, col. R.P. Allen, $1^{\dagger} *(\mathrm{USNM} 93082)$. Matanzas - Cardenas, $23^{\circ} 02^{\prime} 21.9^{\prime \prime} \mathrm{N}-81^{\circ} 11^{\prime} 30.0 " \mathrm{~W}, 25 / \mathrm{xii} / 1953$, col. J.F. Hilera, 2今*, 1q* (USNM 96458) - Matanzas, $23^{\circ} 02^{\prime} 33.2^{\prime \prime} \mathrm{N}-81^{\circ} 30^{\prime} 54.1^{\prime \prime} \mathrm{W}$, iv/1927, col. M. Ward, 1ठ* (AM P.44529).

MÉXICO: Campeche - Campeche, 1950'12.4"N - 90³3'10.2"W, 21/viii/1987, col. M.D. Valle et al., 19 (CNCR 8602), 1ठ (CNCR 8621) - Champotón, 19²1'33.4"N - 
9043'21.2"W, 10/vii/1952, col. A.S.P., 10ึ (USNM 2204997) - Champotón, 19²1'33.4"N 9043'21.2"W, 01/ix/1976, col. C.L. Thurman, 10 (USNM 171531) - Champotón, 19²1'33.4"N - 9043'21.2"W, 19/i/1987, s/col., 1 ( (CNCR 20811). Quintana Roo - Felipe Carrillo Puerto, $19^{\circ} 45^{\prime} 56.4^{\prime \prime N}-87^{\circ} 35^{\prime} 53.6 " \mathrm{~W}, 21 / \mathrm{iv} / 1988$, s/col., 1 ( $(\mathrm{CNCR} 21365)$.

PORTO RICO: Palo Seco, Rio Bayamon, 18²7'10.3"N - 6609'28.4"W, 06/xi/1999, col. US Fish Commision Puerto Rico Expedition, 1 $\delta^{\Uparrow *}$ (USNM 24541), 1 $\delta^{\star *}$ (USNM 1188940), 1 우(USNM 1188941).

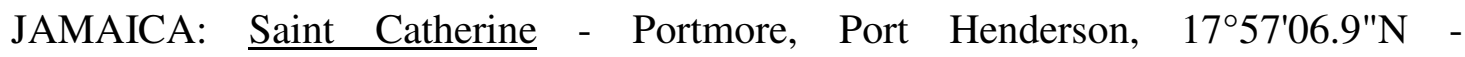
7652'22.1"W, 24/iii/1982, col. F.H. Barnwell, $1{ }^{\Uparrow}$ (USNM 210463), 1 (USNM 1188938), $19(\mathrm{USNM} 1188939)$.

TRINIDAD \& TOBAGO: $\underline{\text { Trinidad }}$ - Saint George, Cocorite, 1040'55.8"N 61³2'55.3"W, 17/vi/1970, col. J. Stanley, 3ð* (USNM 137752).

VENEZUELA: Aragua - Turiamo, 10²6'53.5"N - 6751'29.0"W, vii/1945, col. Ensley, 2万* (USNM 138127). Delta Amacuro - Pedernales, $10^{\circ} 02^{\prime} 35.8^{\prime \prime} \mathrm{N}-62^{\circ} 24^{\prime} 14.4^{\prime \prime} \mathrm{W}$, viii/1942, col. Ensley, 3 \%* (USNM 138128).

BRASIL: Amapá - Rio Amapá, 207'59.8"N - 5041'27.4"W, 01/vii/2010, col. C. Thurman et al., 1 ㅇ (MZUSP 23133), 1 q (MZUSP 33192). Pará - Salinópolis, 0³6'49.2"S 47²0'35.3"W, 15/xi/2012, col. F.L. Carvalho et al., 40ึ, 1 ( (CCDB 4441). Maranhão - Rio Munin, Itacu, $2^{\circ} 46^{\prime} 24.1^{\prime \prime S}-4^{\circ} 03^{\prime} 58.4^{\prime \prime} \mathrm{W}, 20 / v i i / 2010$, col. C. Thurman \& S. Faria, 1 q (MZUSP 33177), 19 (MZUSP 33178), 19 (MZUSP 33179). Ceará - Estuário do Rio Cocó, Fortaleza, $3^{\circ} 46^{\prime} 34.1^{\prime \prime S}-38^{\circ} 26^{\prime} 14.4^{\prime \prime} \mathrm{W}, 06 / v i / 2010$, col. C. Thurman \& S. Faria, 1 q (MZUSP 33187), 19 (MZUSP 33188), 1 웅 (MZUSP 33189), $1 q$ (MZUSP 33190), 19 (MZUSP 33191) - Estuário do Rio Pacoti, Fortaleza, 349'22.9"S - 38²4'46.7"W, 23/xii/2003, col. L.E.A. Bezerra, 2ð, 3q* (CCDB 4367). Paraíba - Rio Paraíba do Norte, Cabedelo,

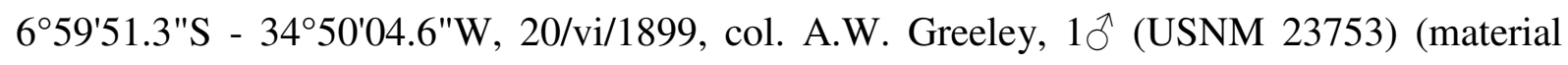


tipo). $\underline{\text { Pernambuco }}$ - Ilha de Tamaracá, Forte Orange, 747'14.6"S - 3451'10.4"W,

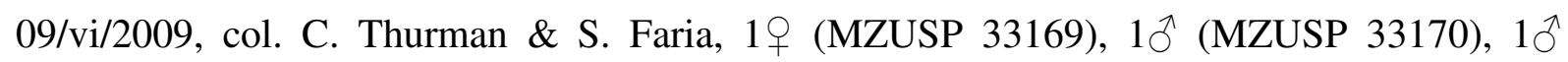
(MZUSP 33171) - Serinhaém, 0841.28'S - 350.611"W, 07/x/2010, col. F.L. Mantelatto \& D.S. Castiglioni, 1ð̂, $2 q$ (CCDB 2998). Alagoas - Estuário do Rio Camaragibe, Passo do Camaragibe, $9^{\circ} 18^{\prime} 45.7^{\prime \prime} \mathrm{S}-35^{\circ} 25^{\prime} 17.2^{\prime \prime} \mathrm{W}, 22 / \mathrm{x} / 2008$, col. M. Tavares et al., $19 q$ (MZUSP 33163 ) - Estuário do Rio Camaragibe, Passo do Camaragibe, 9¹8'45.7"S - 35²5'17.2"W, 29/iii/2010, col. W. Santana \& R. Bueno, $1 ð$ (MZUSP 33193), $1{ }^{\Uparrow}$ (MZUSP 33194). Bahia Porto do Sauípe, $12^{\circ} 24^{\prime} 12.2^{\prime \prime}$ - 3753'38.8"W, 02/i/2012, F.L. Carvalho \& E.A. SouzaCarvalho, 4ð (CCDB 4049) - Rio Cururupe, Rodovia BA 001, Ilhéus - Una, 1449'12.3"S 3901'50.2"W, 05/xi/2010, col. F.L. Mantelatto et al., 1ऽ* (CCDB 3028) - Porto Seguro, Ilha dos Aquários, $1^{\circ} 27^{\prime} 46.3^{\prime \prime} S$ - 3904'18.7"W, 14/viii/2011, col. F.L. Carvalho \& E.A. SouzaCarvalho, 1 $\overbrace{}^{\star *}$ (CCDB 4036) - Porto Seguro, Ilha dos Aquários, 16²7'46.3"S 3904'18.7"W, 07/i/2012, col. F.L. Carvalho \& E.A. Souza- Carvalho, 1ðْ* (CCDB 4088) Porto Seguro, Ilha dos Aquários, 16²7'46.3"S - 3904'18.7"W, 16/viii/2012, col. F.L. Carvalho \& E.A. Souza-Carvalho, $1 \delta^{\lambda}$ (CCDB 4263). Espírito Santo - Guarapari, 20³8'55.5"S - 40³0'02.0"W, 18/xi/2012, col. F.L. Carvalho et al., $1 \overbrace{}^{\star}$ (CCDB 4002) -

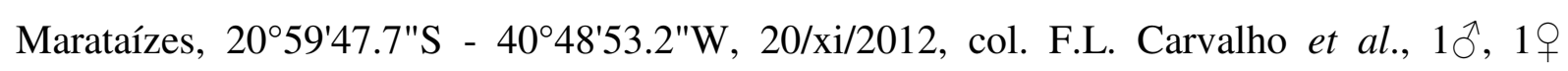
(CCDB 3996). io de Janeiro - Baía de Sepetiba, Barra da Guaratiba, 2303'47.0"S 433'ㄱ'57.'W, 07/vii/2009, col. C. Thurman \& S. Faria, 19 (MZUSP 33174), $1 q$ (MZUSP

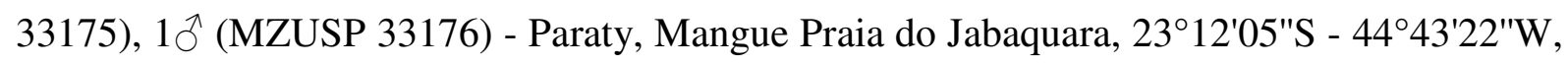
20/vii/2011, col. F.L. Mantelatto et al., $5 \bigcirc^{\lambda}$ (CCDB 3458), 1 $\overbrace{}^{\lambda *}$ (CCDB 3459). São Paulo -

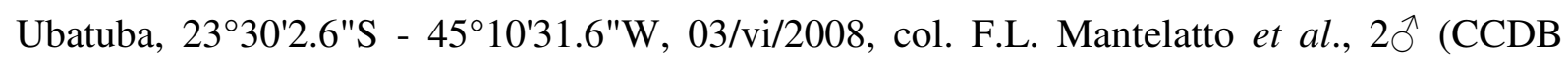
2364) - Ubatuba, $23^{\circ} 30^{\prime} 2.6^{\prime \prime} \mathrm{S}-45^{\circ} 10^{\prime} 31.6^{\prime \prime} \mathrm{W}, 25 / \mathrm{xi} / 2008$, col. F.L. Mantelatto \& C. Tudge, 1ठ* (CCDB 2540) - Ubatuba, 23³0'2.6"S - 45¹0'31.6"W, 15/v/2010, col. F.L. Mantelatto, 1ठ* (CCDB 2992) - Ubatuba, 23³0'2.6"S - 45¹0'31.6"W, 05/iv/2011, col. F.L. Mantelatto 


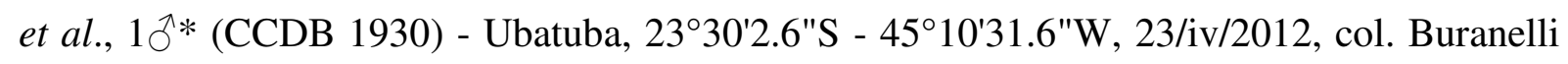

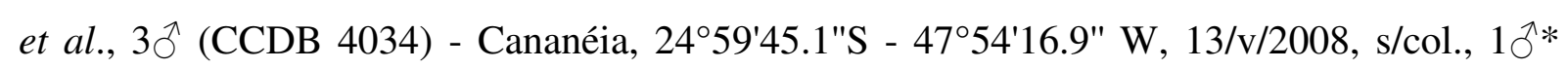
(CCDB 2987) - Cananéia, 2459'45.1"S - 4754'16.9" W, 30/viii/2011, col. R. Costa et al., 13*(CCDB 784) - Cananéia, 2459'45.1"S - 4754'16.9" W, 30/viii/2011, col. R. Costa et al., 5 § (CCDB 798) - Cananéia, 2459'45.1"S - 4754'16.9" W, 17/iv/2011, col. R. Costa et al., $\left.1 \delta^{\Uparrow *(C C D B} 3220\right)$ - Ilha Comprida, Praia da Balsa, 2501.232"S - 4755.075"'W, 09/xi/2011, col. F.L. Carvalho et al., 1ð* (CCDB 4027). Paraná - Baía de Guaratuba, Ilha Guaxuma, 2551'33.3"S - 4841'18.1"W, 19/ix/2009, col. C. Thurman \& S. Faria, $1{ }^{\curvearrowright}$ (MZUSP 33164),

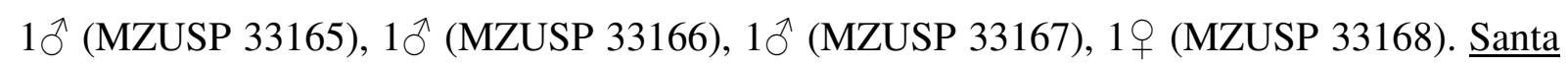

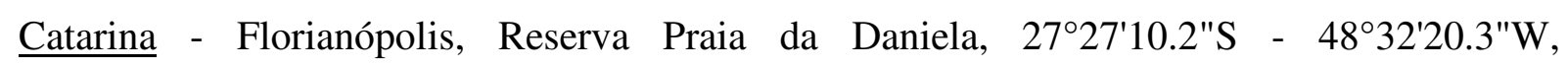
20/vii/2010, col. C. Thurman \& S. Faria, $1 \hat{\jmath}$ (MZUSP 33182), $1 \hat{\jmath}$ (MZUSP 33183), $1 \widehat{\jmath}$ (MZUSP 33184), $1 \overbrace{}^{\Uparrow}$ (MZUSP 33185), 1 ㅇ (MZUSP 33186).

O tamanho dos animais analisados variou de 8.15 a $17.99 \mathrm{~mm}$ para CC e de 12.74 a $29.69 \mathrm{~mm}$ para LC em machos, de 12.14 a $17.33 \mathrm{~mm}$ para CC e de 14.91 a $26.04 \mathrm{~mm}$ para LC em fêmeas não ovígeras e de 11.83 a 14.33 mm para CC e de 17.16 a 21.08 mm para LC em fêmeas ovígeras.

Dentre as características morfológicas analisadas, foram observados, sem exceção: margem dorsal da carapaça com pubescência em forma de H, não tão pronunciada em machos quanto em fêmeas; margem suborbicular estreita, com forma ondulada; depressão pósmargem suborbicular com forma ondulada, tal qual a própria margem; granulações suborbiculares formadas por tubérculos moderados que aumentam ligeiramente em tamanho em direção à margem externa, com uma linha de cerdas acima e abaixo das granulações; dedos dos quelípodos menores armados com serrilhado moderado na metade final de suas extensões; palma externa coberta por tubérculos pequenos, com aparência áspera e granulada; 
carena oblíqua tuberculada na palma interna, continuando para cima e não atingindo o meio da cavidade carpal; dedos fixo e móvel longos e delgados, sendo que o dedo móvel curva-se para baixo, ultrapassando o fixo.

Dentre os caracteres analisados que apresentaram maior variabilidade, estão: carapaça com estrias póstero-laterais superiores com tubérculos e com cerdas medianas ou penugens; pubescência aveludada na superfície dorsal de todos os artículos dos pereópodos ou, às vezes, somente no carpo e no própodo; margem interna dos dedos do quelípodo maior com tubérculos centrais no dedo móvel e dedo fixo que variam em números entre 2 e 2, 2 e 1 e 1 e 1, respectivamente; margem interna do carpo do quelípodo maior armada com tubérculos que variam em números de zero a seis.

\section{Ucides cordatus}

Foram analisados 79 exemplares, sendo 52 machos, 26 fêmeas não ovígeras e um juvenil de $U$. cordatus provenientes de 20 localidades, ao longo de sua distribuição (Tabela $6)$.

\section{Material examinado}

Abreviações: AMS: Australian Museum; CCDB: Coleção de Crustáceos do Departamento de Biologia da Faculdade de Filosofia, Ciências e Letras de Ribeirão Preto da Universidade de São Paulo; CNCR: Colección Nacional de Crustaceos, Universidad Autonoma de México; ULLZ: University of Louisiana at Lafayette Zoological Collection; USNM: United States National Museum do Smithsoniam Institution - National Museum of

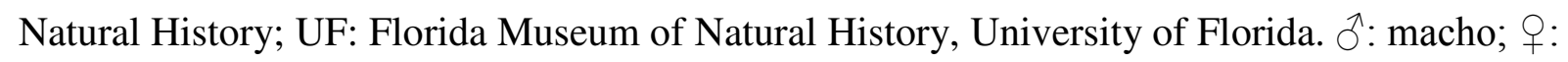


fêmea; 우: fêmea ovígera; s/loc.: sem local de coleta; s/d.: sem data de coleta; s/col.: sem coletor; s/n.: sem número.

ESTADOS UNIDOS: Flórida - Little Jim Island, Fort Pierce, 27²8’43.4"N 80¹8'43.5"W, 01/viii/2001, col. D.L. Felder, 1ð̋ (ULLZ 11988) - Dade County, Biscayne Bay National Park, Elliot Key, South Miami, 25²6'41.6"N - 80¹1'35.4"W, 15/ix/1960, col. R.B. Manning, 19 (USNM 105882) - Dade County, Biscayne Bay National Park, Elliot Key,

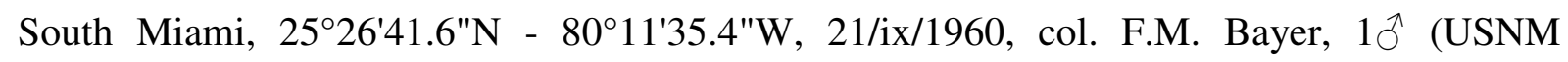
171615)

MÉXICO: Yucatán - Río Lagartos, 21³5'36.1"N - 8809'39.8"W, 5/xi/1985, s/col., $2 q$ (CNCR 21034). Veracruz - s/loc., ix/2013, col. J. Villalobos et al., $3 \hat{\jmath}, 1$ (CNCR s/n.) Tecolutla, 20²8'06.3"N - 9700'30.4"W, 17/ix/1961, s/col., 1ð̋ (CNCR 1199).

PORTO RICO: - Palo Seco, Rio Bayamon, 18²7'10.3"N - 6609'28.4"W, 16/i/1999, col. US Fish Commision Porto Rico Expedition, $1 q$ (USNM 240009), 1 ( (USNM 1188930), 1 ( $(\mathrm{USNM} 1188931)$

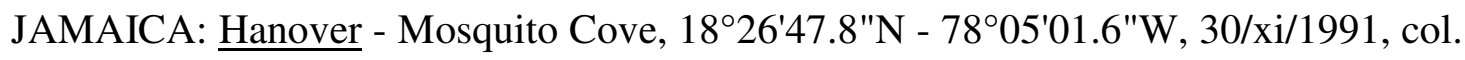
D.L. Felder \& J. Felder, $1 \delta^{\Uparrow}$ (ULLZ 11847) - Mosquito Cove, $18^{\circ} 26^{\prime} 47.8^{\prime \prime} \mathrm{N}-78^{\circ} 05^{\prime} 01.6^{\prime \prime} \mathrm{W}$,

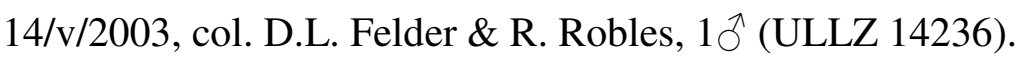

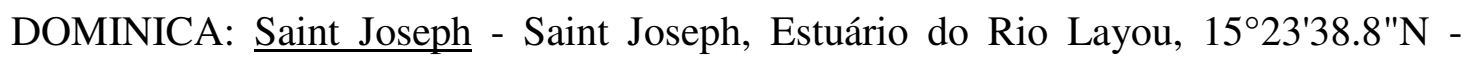
61²5'31.6"W, 12/ii/1966, col. H.H. Hobbes Jr, $1{ }^{\circledR}$ (USNM 126965), 1ठ (USNM 1188932),

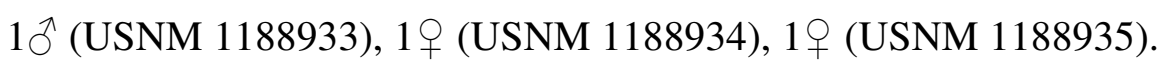

PANAMÁ: $\underline{\text { Bocas del Toro }}$ - Bocas del Toro, 9²1'03.5"N - 82²1 $24.7^{\prime \prime} \mathrm{W}$, 05/vii/2004, col. D.L. Felder, 1 (ULLZ 12263). 


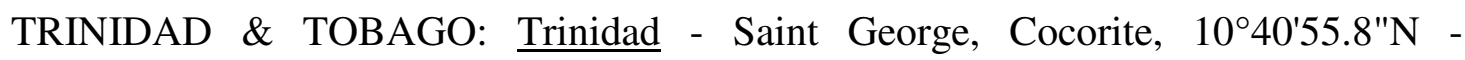

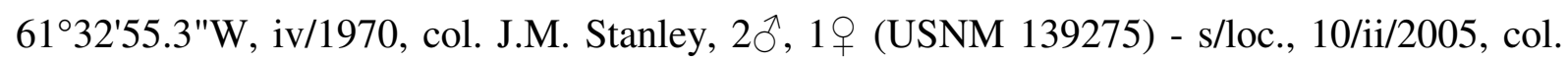
H.C. Liu, 2ð, 1J (UF 8815).

BRASIL: Amapá - Calçoene, Mangue Praia do Goiabal, 2³5'41.9"N - 5050'57.0"W, 02/ix/2014, col. M. Lopes \& A.B. Carvalho, $2 \widehat{\jmath}$ (CCDB 5411), $2 \widehat{O}$ (CCDB 5412). Pará Bragança, 048'7.1"S - 46³6'57.0"W, 09/xi/2012, col. F. Abrunhosa, $3{ }^{\Uparrow}$ (CCDB 4468) Belém, 1²4'12.0"S - 48³7'42.8"W, 11/xi/2012, col. R.C. Buranelli, $2{ }^{\circledR}$ (CCDB 4365). Ceará - Caucaia, Mangue Rio Ceará, 0344'48.9"S - 38³7'7.81"W, 12/ii/2013, col. F.L. Mantelatto

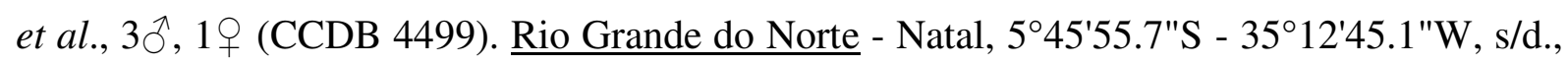
col. F.L. Mantelatto, 4ðิ (CCDB 5262). Pernambuco - Ipojuca, Manguezal de Serrambi, 08³3'30.58"S - 3501'36.18"W, 01/i/2103, col. F.L. Mantelatto, 5ð (CCDB 4467). Alagoas Estuário do Rio Camaragibe, Passo do Camaragibe, 9¹8'45.7"S - 35²5'17.2"W, 30/iii/2010, col. D. Peiró, $1 ð$ (CCDB 4146). Bahia - Ilhéus, Maria Jape, 14448'10.85"S - 3904'36.25"W, 09/iii/2013, col. F.L. Mantelatto \& A. Almeida, 2ð (CCDB 4520) - Porto Seguro, Ilha dos Aquários, 16²7'46.30"S - 3904'18.76"W, 07/i/2012, col. F.L. Carvalho \& E.A. SouzaCarvalho, $3 q$ (CCDB 3785). Espírito Santo - Marataízes, 2059'47.7"S - 4048'53.2"W, 20/vi/2012, col. F.L. Carvalho et al., $1 \overbrace{}^{\Uparrow}$ (CCDB 3976). Rio de Janeiro - Duque de Caxias, 2246'03"S - 43¹7'09"W, 22/ii/2014, col. P. Chaves, 4ð (CCDB 4951). São Paulo - Ubatuba, Mangue Praia Dura, $23^{\circ} 30^{\prime} 2.6^{\prime \prime} \mathrm{S}-4^{\circ} 10^{\prime} 31.6^{\prime \prime} \mathrm{W}, 03 / \mathrm{vi} / 2008$, col. F.L. Mantelatto et al., 3 q (CCDB 2372) - Ubatuba, 2330'2.6"S - 45¹0'31.6"W, 23/iv/2012, col. F.L. Mantelatto et al., 10̄, 2 (CCDB 3915) - Bertioga, 2349'11.9"S - 4609'07.7"W, 12/iv/2014, col. R.C. Buranelli \& L.P. Cerantola, 6ð (CCDB 4969) - Cananéia, Estuário do Rio Baguaçu,

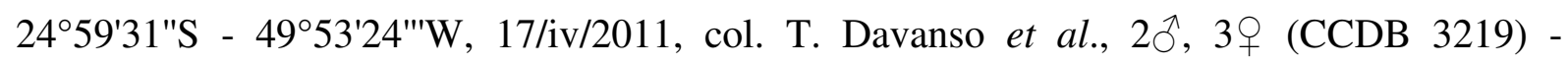
Cananéia, Estuário do Rio Baguaçu, 2459'31"S - 4953'24"'W, 30/viii/2011, col. R. Costa et

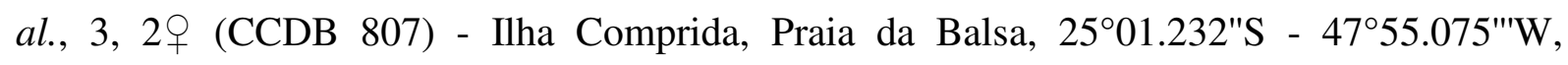


11/iii/2012, col. F.L. Mantelatto et al., 2 (CCDB 3780) - Cananéia, 2504'11.8"S -

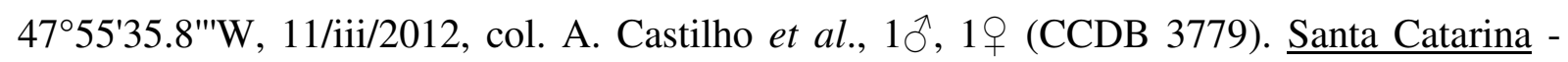
Camboriú, Estuário Rio Camboriú, 2700'17.09"S - 48³7'06.14"'W, 06/xii/2012, col. F.L. Carvalho, 1 우 (CCDB 4397).

O tamanho dos animais analisados variou de 26.55 a $74.97 \mathrm{~mm}$ para CC e de $32.72 \mathrm{a}$ $102.53 \mathrm{~mm}$ para LC em machos e de 18.01 a $56.10 \mathrm{~mm}$ para CC e de 23.99 a $73.68 \mathrm{~mm}$ para LC em fêmeas não ovígeras.

Dentre as características morfológicas analisadas, foram observados, sem exceção: carapaça transversal em formato subelíptico, levemente mais larga do que longa, com margens regularmente curvadas e convergendo posteriormente; largura fronto-orbital não atingindo mais do que dois terços da largura máxima da carapaça em machos e fronte estreitando em direção a base; córnea levemente inflada, ocupando menos da metade do comprimento do pedúnculo; tubérculos na margem suborbital e franja de cerdas presentes na região anterior.

Dentre os caracteres analisados que apresentaram maior variabilidade, estão: presença de uma longa franja de cerdas no própodo e, às vezes, no carpo dos pereópodos PII a PIV em machos; linha de tubérculos que desce até a porção final da margem suborbital e margeia o aparato bucal ou, às vezes, não margeia totalmente o aparato, ou, ainda, reduz levemente de tamanho em direção ao aparato bucal; mancha pubescente no carpo, própodo ou, as vezes, mero dos pereópodos presente ou, às vezes, ausente.

\subsubsection{Morfometria}

Para as análises morfométricas, foram utilizadas apenas as espécies que apresentaram elevada estruturação populacional (Aratus pisonii e Uca thayeri), na tentativa de se verificar 
variabilidade morfométrica entre os grupos evidenciados pelas análises moleculares. Foram adicionadas às análises somente as medidas obtidas para os indivíduos oriundos de localidades ou grupos de localidades abordadas nas análises moleculares.

No total, foram mensurados 117 indivíduos de Aratus pisonii, sendo 60 fêmeas (ovígeras e não ovígeras) e 57 machos e 78 indivíduos de Uca thayeri, sendo 25 fêmeas (ovígeras e não ovígeras) e 53 machos. Todo o material analisado encontra-se detalhado nas listas de material examinado constantes na seção "6.2.1. Variabilidade Morfológica Comparativa", para cada uma das espécies. O tamanho da largura da carapaça (LC), medida utilizada como padrão para o tamanho do animal e como variável independente, variou de 8.64 a $18 \mathrm{~mm}$ para Aratus pisonii e de 12.74 a $25.75 \mathrm{~mm}$ para Uca thayeri.

Para Aratus pisonii, os dados foram tratados de acordo com os três grupos geneticamente distintos [1) EUA + México, 2) Costa Rica + Panamá + Venezuela e 3) Trinidad \& Tobago + localidades brasileiras] observados nas análises moleculares, sendo a Análise Discriminante aplicada de forma a se verificar a existência de diferenças morfométricas entre seis amostras, conjuntamente: fêmeas pertencentes aos grupos geneticamente distintos 1, 2 e 3 [G1 $(n=19), G 3(n=10)$ e G5 $(n=31)$, respectivamente] e machos pertencentes aos mesmos grupos $[(\mathrm{G} 2(\mathrm{n}=17), \mathrm{G} 4(\mathrm{n}=7)$ e G6 $(\mathrm{n}=33)$, respectivamente]. Seis variáveis mensuradas foram consideradas discriminantes $(F>1)$ e significativas $(\mathrm{p}<0,05)$ na separação dos grupos pela análise de Wilks' Lambda: comprimento da carapaça (CC) e comprimento dos artículos carpo do pereópodo (Cp), própodo do pereópodo (Pp), dáctilo do pereópodo (Dp), carpo do quelípodo (C) e dedo móvel (Dm) (Tabela 14). A análise da estatística F da distância de Mahalanobis demonstrou diferenças significativas entre os grupos analisados $(\mathrm{p}<0,05)$ (Tabela 15). A análise de significância dos discriminantes canônicos pelo teste do $\chi^{2}$ apontou três variáveis canônicas (raízes) como significativas $(\mathrm{p}<0,05)$ (Tabela 16). O alto valor do coeficiente de correlação 
canônica, principalmente das duas primeiras raízes (89\% e 77\%, respectivamente), indica alto grau de associação entre essas funções discriminantes e os grupos, constituindo indicativos da influência dos caracteres na discriminação entre os grupos. No entanto, apesar da existência de algumas variáveis que discriminam os grupos e da significância na distância entre os mesmos, os gráficos de dispersão dos escores das variáveis canônicas significativas, embora indique uma tendência no posicionamento de alguns grupos, evidencia intersecção dos grupos formados, não sendo possível visualizar uma separação completa das categorias (Figs. 20 a 22). Assim, as raízes não podem ser consideradas suficientes para discriminar indivíduos dos grupos distintos. 
Tabela 14. Aratus pisonii. Poder de discriminação de cada variável mensurada, com seus respectivos valores de Wilks' Lamba, F e valor de significância (p). CC: comprimento da carapaça; Mp: comprimento do mero do pereópodo II; $\mathrm{Cp}$ : comprimento do carpo do pereópodo II; Pp: comprimento do própodo do pereópodo II; Dp: comprimento do dáctilo do pereópodo II; M: comprimento do mero do quelípodo; $\mathrm{C}$ : comprimento do carpo do quelípodo; P: comprimento da palma; Dm: comprimento do dedo móvel; Df: comprimento do dedo fixo. $){ }^{*}=$ valores significativos: $\mathrm{p}<0.05$.

\begin{tabular}{l|c|c|c}
\hline \multicolumn{1}{c|}{ Variáveis } & Wilks' Lambda & F & p \\
\hline CC & 0.153962 & 41.65138 & $0.000000^{*}$ \\
Mp & 0.052929 & 0.93180 & 0.463715 \\
Cp & 0.061535 & 4.40045 & $0.001141^{*}$ \\
Pp & 0.069343 & 7.54745 & $0.000005^{*}$ \\
Dp & 0.056677 & 2.44270 & $0.039092^{*}$ \\
M & 0.053619 & 1.21021 & 0.309749 \\
$\mathbf{C}$ & 0.056438 & 2.34637 & $0.046359^{*}$ \\
$\mathbf{P}$ & 0.051412 & 0.32063 & 0.899561 \\
Dm & 0.073739 & 9.31895 & $0.000000^{*}$ \\
Df & 0.054607 & 1.60830 & 0.164542 \\
\hline
\end{tabular}


Tabela 15. Aratus pisonii. Valores da estatística $\mathrm{F}$ da distância de Mahalanobis entre os grupos analisados. G1: fêmeas do grupo genético EUA + México; G2: machos do grupo genético EUA + México; G3: fêmeas do grupo genético Costa Rica + Panamá + Venezuela; G4: machos do grupo genético Costa Rica + Panamá + Venezuela; G5: fêmeas do grupo Trinidad \& Tobago + Brasil; G6: machos do grupo Trinidad \& Tobago + Brasil. * = valores significativos: $\mathrm{p}<0.05$.

\begin{tabular}{ccccccc}
\hline & G1 & G2 & G3 & G4 & G5 & G6 \\
\hline G1 & - & - & - & - & - & - \\
G2 & $6.51509^{*}$ & - & - & - & - & - \\
$\mathbf{G 3}$ & $32.19941^{*}$ & $30.18937^{*}$ & - & - & - & - \\
G4 & $35.76734^{*}$ & $25.15712^{*}$ & $7.05182^{*}$ & - & - & - \\
G5 & $11.05445^{*}$ & $8.95248^{*}$ & $12.59145^{*}$ & $10.54832^{*}$ & - & - \\
G6 & $12.12511^{*}$ & $4.41057^{*}$ & $37.5335^{*}$ & $27.29457^{*}$ & $8.38344^{*}$ & - \\
\hline
\end{tabular}


Tabela 16. Aratus pisonii. Análise de significância das variáveis canônicas (raízes), por meio do teste do $\chi^{2}$, com seus respectivos variância das variáveis canônicas (auto-valores), coeficientes de correlação canônica (R Canônico), valor de $\chi^{2}$, graus de liberdade (GL) e valor de significância $(\mathrm{p}) . *$ = valores significativos: $\mathrm{p}<0.05$.

\begin{tabular}{c|c|c|c|c|c}
\hline Raízes & Auto-valores & R Canônico & $\chi^{2}$ & GL & p \\
\hline $\mathbf{1}$ & 3.820984 & 0.890266 & 322.2155 & 50 & $0.000000^{*}$ \\
$\mathbf{2}$ & 1.462735 & 0.770680 & 152.3339 & 36 & $0.000000^{*}$ \\
$\mathbf{3}$ & 0.463995 & 0.562972 & 54.9964 & 24 & $0.000313^{*}$ \\
$\mathbf{4}$ & 0.091822 & 0.290000 & 13.8302 & 14 & 0.462437 \\
$\mathbf{5}$ & 0.041029 & 0.198523 & 4.3426 & 6 & 0.630420 \\
\hline
\end{tabular}




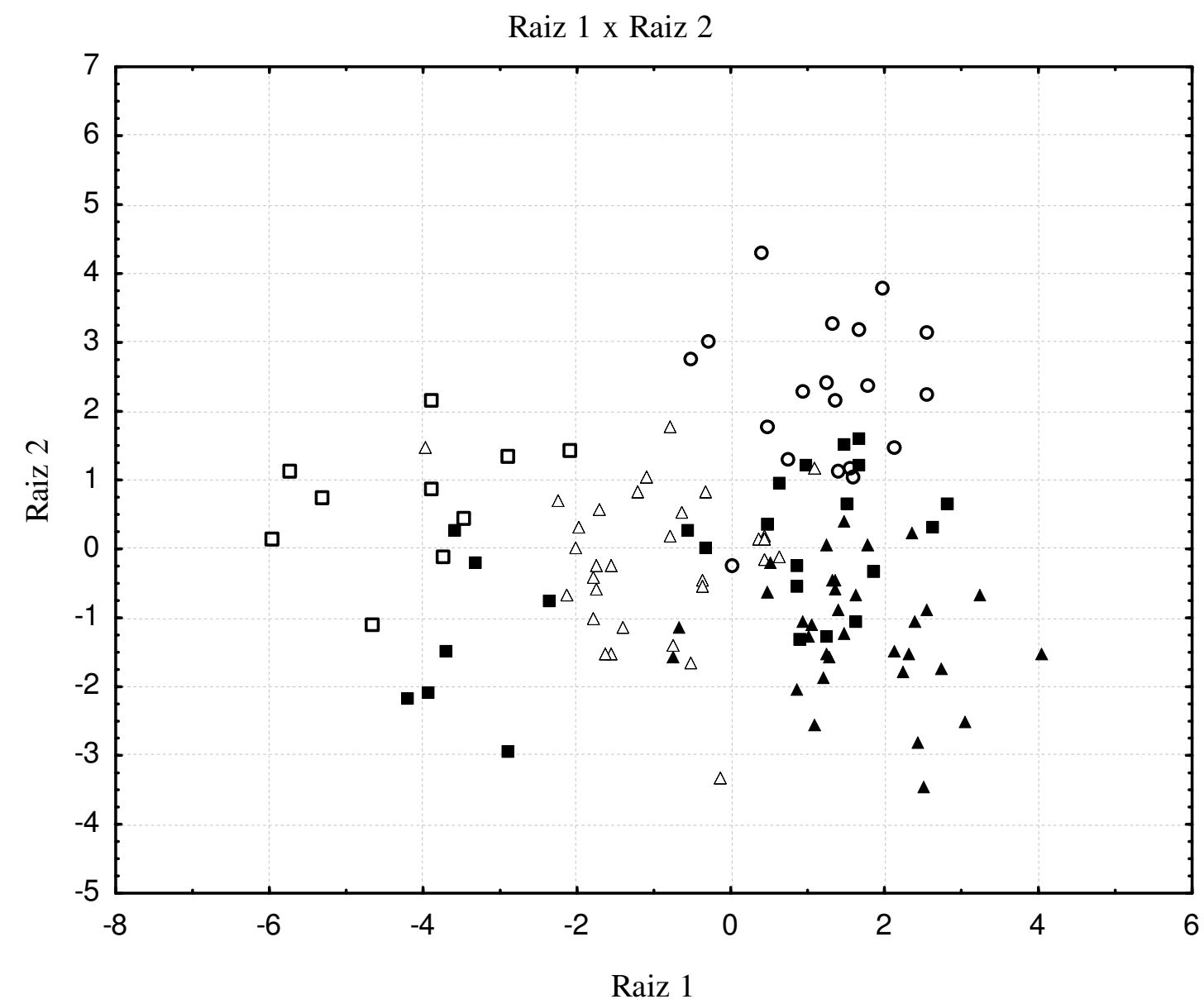

Figura 20. Aratus pisonii. Diagrama de dispersão para a Análise de Discriminantes Canônicos para as variáveis canônicas (raízes) 1 e 2. ○: G1 - fêmeas do grupo genético EUA + México; •: G2 - machos do grupo genético EUA + México; 口: G3 - fêmeas do grupo genético Costa Rica + Panamá + Venezuela; m: G4 - machos do grupo genético Costa Rica + Panamá + Venezuela; $\Delta$ : G5 - fêmeas do grupo Trinidad \& Tobago + Brasil; $\mathbf{~ : ~ G 6 ~ - ~ m a c h o s ~}$ do grupo Trinidad \& Tobago + Brasil. 


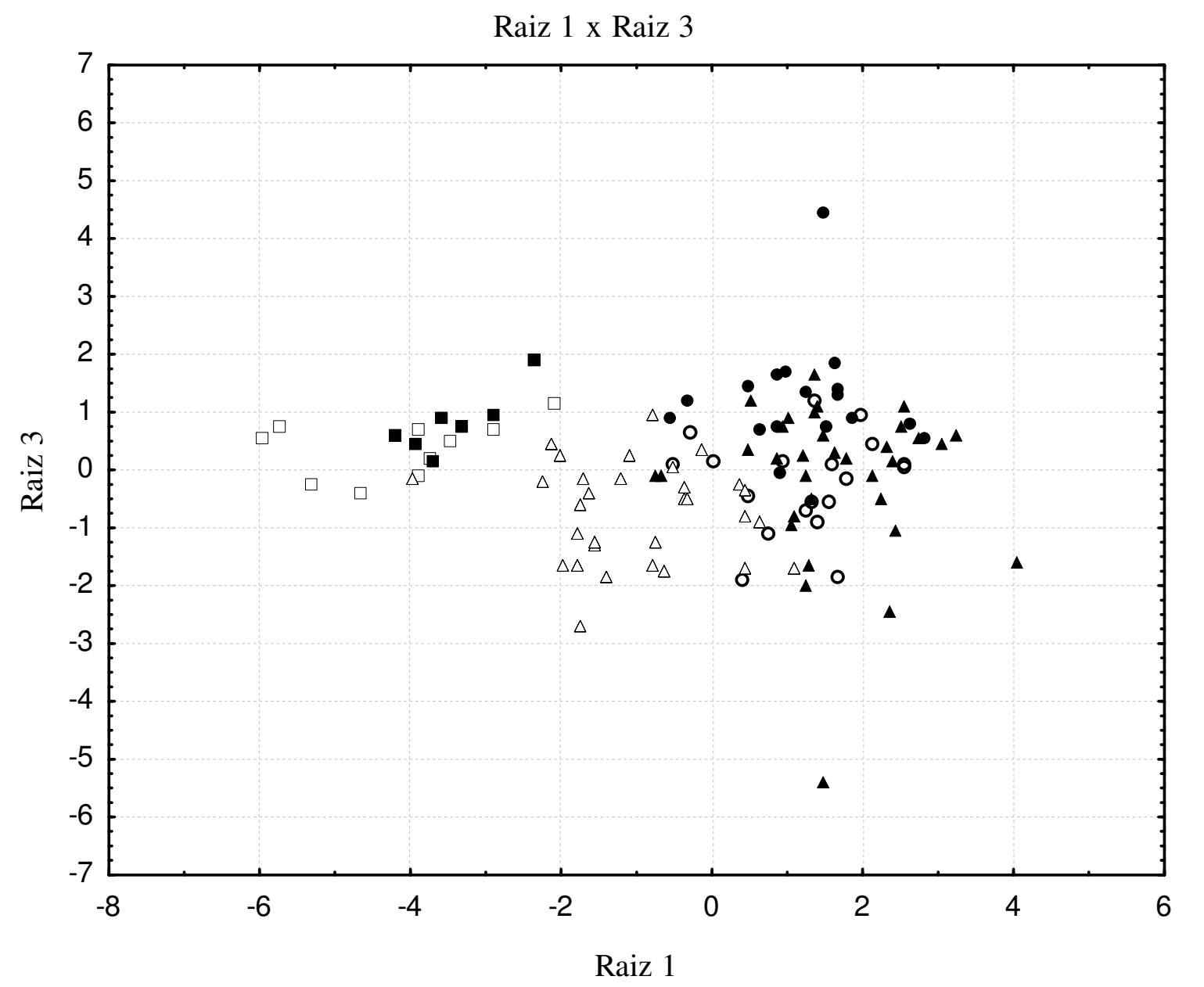

Figura 21. Aratus pisonii. Diagrama de dispersão para a Análise de Discriminantes Canônicos para as variáveis canônicas (raízes) 1 e 3. ○: G1 - fêmeas do grupo genético EUA + México; •: G2 - machos do grupo genético EUA + México; 口: G3 - fêmeas do grupo genético Costa Rica + Panamá + Venezuela; m: G4 - machos do grupo genético Costa Rica + Panamá + Venezuela; $\Delta$ : G5 - fêmeas do grupo Trinidad \& Tobago + Brasil; $\mathbf{\Delta}$ : G6 - machos do grupo Trinidad \& Tobago + Brasil. 
Raiz 2 x Raiz 3

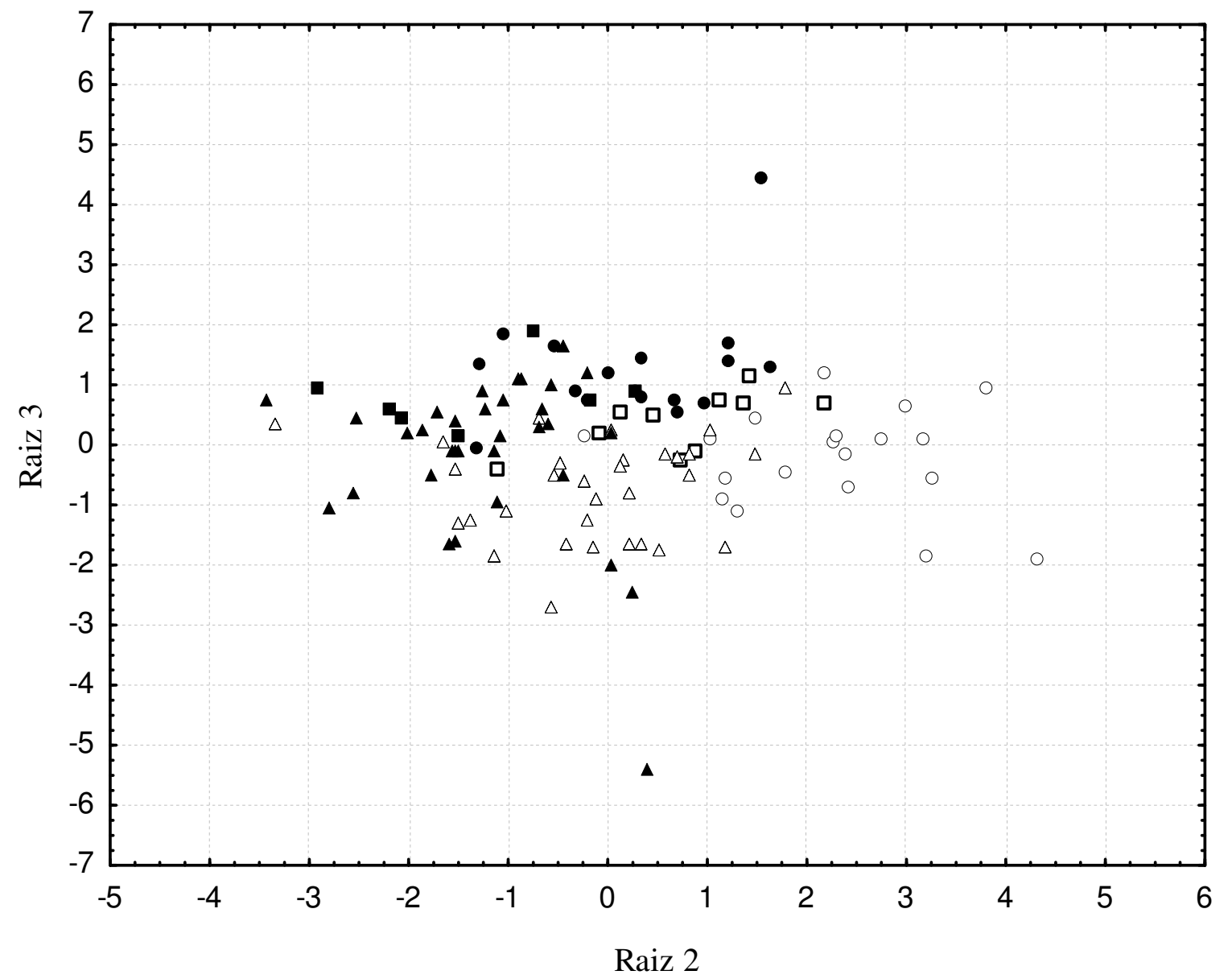

Figura 21. Aratus pisonii. Diagrama de dispersão para a Análise de Discriminantes Canônicos para as variáveis canônicas (raízes) 2 e 3. o: G1 - fêmeas do grupo genético EUA + México; •: G2 - machos do grupo genético EUA + México; $\square$ : G3 - fêmeas do grupo genético Costa Rica + Panamá + Venezuela; a: G4 - machos do grupo genético Costa Rica + Panamá + Venezuela; $\Delta$ : G5 - fêmeas do grupo Trinidad \& Tobago + Brasil; $\mathbf{\Delta}$ : G6 - machos do grupo Trinidad \& Tobago + Brasil. 
Da mesma forma que para Aratus pisonii, para Uca thayeri, os dados foram tratados de acordo com os dois grupos geneticamente distintos (EUA + México + Jamaica e Brasil) observados nas análises moleculares, sendo a Análise Discriminante aplicada de forma a se verificar a existência de diferenças morfométricas entre quatro amostras, conjuntamente: fêmeas pertencentes aos grupos genéticos 1 e 2 [G1 $(n=17)$ e G3 $(n=8)$, respectivamente] e machos pertencentes aos mesmos grupos [G2 $(n=44)$ e G4 $(n=9)$, respectivamente]. Apenas duas variáveis mensuradas foram consideradas discriminantes $(\mathrm{F}>1)$ e significativas $(\mathrm{p}<$ 0,05) na separação dos grupos pela análise de Wilks’ Lambda: comprimento da carapaça (CC) e comprimento do mero do pereópodo (Mp) (Tabela 17). A análise da estatística $\mathrm{F}$ da distância de Mahalanobis apontou diferenças significativas entre alguns dos grupos analisados $(\mathrm{p}<0,05)$ (Tabela 18). A análise de significância dos discriminantes canônicos pelo teste do $\chi^{2}$ apontou uma única variável (raiz) como significativa $(\mathrm{p}<0,05)$ (Tabela 19), portanto, o gráfico de dispersão dos escores das variáveis canônicas não pôde ser gerado. O alto valor do coeficiente de correlação canônica da raiz significativa (73\%) indica alto grau de associação entre essa função discriminante e os grupos, constituindo indicativos da influência dos caracteres na discriminação entre os grupos. 
Tabela 17. Uca thayeri. Poder de discriminação de cada variável mensurada, com seus respectivos valores de Wilks' Lamba, F e valor de significância (p). CC: comprimento da carapaça; Mp: comprimento do mero do pereópodo II; $\mathrm{Cp}$ : comprimento do carpo do pereópodo II; Pp: comprimento do própodo do pereópodo II; Dp: comprimento do dáctilo do pereópodo II; M: comprimento do mero do quelípodo; $\mathrm{C}$ : comprimento do carpo do quelípodo; P: comprimento da palma; Dm: comprimento do dedo móvel; Df: comprimento do dedo fixo. $*=$ valores significativos: $\mathrm{p}<0.05$.

\begin{tabular}{l|c|c|c}
\hline Variáveis & Wilks' Lambda & $\mathbf{F}$ & $\mathbf{p}$ \\
\hline $\mathbf{C C}$ & 0.457772 & 9.302762 & $0.000033^{*}$ \\
$\mathbf{M p}$ & 0.370344 & 3.388056 & $0.023172^{*}$ \\
$\mathbf{C p}$ & 0.335959 & 1.061833 & 0.371485 \\
$\mathbf{P p}$ & 0.344976 & 1.671852 & 0.181710 \\
$\mathbf{D p}$ & 0.324866 & 0.311331 & 0.817113 \\
$\mathbf{M}$ & 0.332589 & 0.833814 & 0.480152 \\
$\mathbf{C}$ & 0.339286 & 1.286909 & 0.286345 \\
$\mathbf{P}$ & 0.325470 & 0.352190 & 0.787687 \\
Dm & 0.336966 & 1.129963 & 0.343544 \\
Df & 0.329405 & 0.618414 & 0.605578 \\
\hline
\end{tabular}


Tabela 18. Uca thayeri. Valores da estatística F da distância de Mahalanobis entre os grupos analisados.. G1: fêmeas do grupo genético Brasil; G2: machos do grupo genético Brasil; G3: fêmeas do grupo genético EUA + Jamaica + México; G4: machos do grupo genético EUA + Jamaica + México. $*=$ valores significativos: $\mathrm{p}<0.05$.

\begin{tabular}{ccccc}
\hline & G1 & G2 & G3 & G4 \\
\hline G1 & - & - & - & - \\
G2 & $3.668216^{*}$ & - & - & - \\
G3 & 2.475970 & $5.387463 *$ & - & - \\
G4 & $4.057673^{*}$ & $8.292397 *$ & 3.098450 & - \\
\hline
\end{tabular}


Tabela 19. Uca thayeri. Análise de significância das variáveis canônicas (raízes), por meio do teste do $\chi^{2}$, com seus respectivos variância das variáveis canônicas (auto-valores), coeficientes de correlação canônica (R Canônico), valor de $\chi^{2}$, graus de liberdade (GL) e valor de significância $(\mathrm{p}) *=$ valores significativos: $\mathrm{p}<0.05$.

\begin{tabular}{c|c|c|c|c|c}
\hline Raízes & Auto-valores & R Canônico & $\chi^{2}$ & GL & p \\
\hline 1 & 1.182695 & 0.736105 & 79.70271 & 30 & $0.000002 *$ \\
2 & 0.252970 & 0.449329 & 25.06350 & 18 & 0.123177 \\
3 & 0.141717 & 0.352315 & 9.27733 & 8 & 0.319444 \\
\hline
\end{tabular}




\section{$\underline{\text { DISCUSSÃO }}$}




\section{DiscuSSÃo}

Considerando os resultados moleculares, foi possível constatar duas tendências para as espécies analisadas: elevada estruturação populacional ou ausência de estruturação com total compartilhamento de haplótipos. De forma específica, constatou-se uma nítida separação entre grupos geográficos para as localidades de Aratus pisonii e Uca thayeri. Situação oposta foi encontrada para as espécies Goniopsis cruentata, Sesarma rectum e Ucides cordatus, não corroborando nenhuma, ou apenas em partes, as hipóteses propostas inicialmente, já que as espécies escolhidas como modelo de estudo não apresentaram comportamento e padrão similares em relação à diferenciação genética e estruturação populacional e, para algumas delas, não foi possível observar elevada diferenciação genética e estruturação populacional. Este perfil indicaria, portanto, que cada espécie apresenta um padrão de estruturação populacional possivelmente ancorado pelas características de seu modo de vida e de reprodução, associadas a fatores ecológicos, ambientais e/ou eventos geológicos passados, conforme será discutido adiante.

Os resultados das análises morfológicas, no entanto, não acompanham os perfis moleculares obtidos, uma vez que não foi encontrada variabilidade morfológica para nenhuma das espécies e, principalmente, não foi encontrada variabilidade que possa definir padrões de variação para cada localidade ou grupo de localidades, não sendo possível identificar variação correspondente às regiões geográficas. Dessa forma, os caracteres morfólogicos analisados de forma compartiva não puderam estabelecer ou confirmar o padrão encontrado nas análises moleculares e nem a formação de grupos sugeridos para as espécies.

Da mesma forma, os dados morfométricos e a consequente Análise Discriminante e Análise de Discriminantes Canônicos para as espécies A. pisonii e U. thayeri, embora tenham apontado a existência de algumas estruturas e de variáveis canônicas que significativamente 
discriminassem os indivíduos pertencentes a grupos distintos, os gráficos de dispersão dos escores das variáveis canônicas para A. pisonii evidenciou intersecção entre os grupos, indicando que os dados não são suficientes para discriminar indivíduos dos grupos distintos. Assim, embora estruturas genéticas distintas possam estar relacionadas à existência de variabilidade morfométrica entre diferentes populações (Waldman et al., 1988) e espécimes com as mesmas características morfométricas possam constituir um estoque (Tzeng, 2004), os grupos geneticamente distintos encontrados na análise molecular não foram acompanhados por estoques morfométricos.

Possivelmente, o posicionamento específico de alguns grupos nos gráficos de dispersão e, inclusive, a significância de algumas medidas na discriminação dos grupos e na distância entre os mesmo se dê, em grande parte, devido ao baixo número amostral utilizado para alguns grupos. Os resultados significativos podem ter sido enviesados pelo número amostral, uma vez que a técnica discriminante é muito sensível à proporção do tamanho da amostra em relação ao número de variáveis preditoras (Hair et al., 2005). Assim, como regra geral, seriam necessárias, no mínimo, 20 observações para cada variável, considerando cada grupo separadamente (Hair et al., 2005).

No entanto, é possível prever que a ausência de padrões de variação exista devido à inexistência de uma barreira de isolamento suficientemente forte que permita o acúmulo de diferenciação morfológica entre os indivíduos das populações. Conforme discutido adiante, mesmo considerando o não compartilhamento de haplótipos entre indivíduos de algumas regiões para determinadas espécies, o conjunto dos dados moleculares ofereceram resultados que não embasam divergência genética elevada o suficiente para invalidar a identidades dos espécimes analisados, bem como indicam elevada congruência na formação de clados que incluem todos os indivíduos de cada espécie analisada. 


\subsection{OS DIFERENTES PADRÕES DE ESTRUTURACC̃̃O POPULACIONAL}

Retomando aos resultados moleculares, para Aratus pisonii, é evidente que não há compartilhamento de haplótipos entre as localidades dos três grupos 1) EUA + México, 2) Costa Rica + Panamá + Venezuela e 3) Trinidad \& Tobago + Brasil. A divisão entre esses três grupos foi sustentada pela AMOVA, já que os dados revelam que a maior parte da variação genética $(84.52 \%)$ encontra-se entre os dois grupos analisados. Ademais, os índices de fixação obtidos para todas as hierarquias e os altos valores associados $(\mathrm{FCT}=0.84521$; FSC $=$ 0.48357; FST = 0.92006) indicam elevada estruturação genética entre as populações (Wright, 1978). Esse índice está relacionado ao cálculo de distância genética entre os haplótipos e os valores de divergência podem ser classificados como: entre zero e 0.05: baixa estruturação populacional; entre 0.05 e 0.15 : moderada estruturação populacional; entre 0.15 e 0.25 : alta estruturação populacional e maior que 0.25: muito alta estruturação populacional (Wright, 1978). Assim, valores acima de 0.25 constituem indicativos de elevada estruturação genética das populações (Wright, 1978), sugerindo altos níveis de diferenciação genética e baixo fluxo gênico entre elas.

Ademais, a rede de haplótipos obtida constitui forte indicativo de que os indivíduos das localidades Trinidad \& Tobago, Brasil (AP) e Brasil (PA) não compartilham haplótipos com as demais populações brasileiras e as taxas de distância genética para o gene COI entre esses indivíduos e os das demais localidades brasileiras variou de 0 a $0.8 \%$, sendo que a distância entre todos os outros indivíduos, com exceção dos dessas localidades em específico, não atingiu valores superiores a $0.3 \%$. Resguardadas as devidas proporções quanto aos números amostrais utilizados e, apesar dos haplótipos dessas localidades encontrarem-se à, no máximo, três passos mutacionais de distância do haplótipo brasileiro principal, é possível que elas estejam iniciando um processo de restrição de fluxo gênico entre as demais localidades 
brasileiras, muito provavelmente atrelado à forte barreira imposta pelo Rio Amazonas. O mesmo pode ser observado no grupo EUA + México, no qual não há compartilhamento de haplótipos entre as localidades, embora a distância entre elas não passe de $0.3 \%$ e apenas um passo mutacional.

A mesma estruturação observada na rede de haplótipos e corroborada pelas análises de variação molecular foi claramente ressaltada na análise filogenética, com o agrupamento dos indivíduos pertencentes aos grupos 1) EUA + México, 2) Costa Rica + Panamá + Venezuela e 3) Trinidad \& Tobago + localidades brasileiras em clados bem suportados. Ademais, para a análise de distância genética para o gene COI, a presença de um pequeno gap entre as distâncias intra e intergrupos também constitui indicativos para a estruturação populacional dessa espécie.

No entanto, apesar da evidente separação entre grupos para Aratus pisonii, os valores de divergência genética para o gene 16S apontaram uma sobreposição entre as taxas das distâncias intra e intergrupos. Dado o caráter mais conservado desse gene, bem como do gene H3, que indicou divergência nula entre todos os espécimes, pode-se inferir que todos os grupos ainda pertençam à mesma identidade taxonômica.

Considerando as localidades analisadas da espécie Uca thayeri, a rede de haplótipos obtida indica uma evidente separação entre grupos EUA + Jamaica + México e todas as localidades brasileiras. Essa separação também pode ser visualizada no dendrograma obtido para a análise filogenética, com a formação de um clado bem suportado incluindo apenas os indivíduos pertencentes às localidades EUA, Jamaica e México. Para essa espécie, assim como observado para Aratus pisonii, não há compartilhamento de haplótipos entre as localidades México e EUA, embora a distância entre os haplótipos seja mínima e o número amostral para as localidades do México seja bastante reduzido. A divisão entre os dois principais grupos foi altamente sustentada pela AMOVA, já que os dados revelaram que a 
maior parte da variação genética $(85.93 \%)$ encontra-se entre os dois grupos analisados. Os altos valores significativos dos índices de fixação FST (0.86263) e FCT (0.85936) indicam forte estruturação genética entre as populações (Wright, 1978).

Considerando a análise de distância genética para o gene COI para essa espécie, da mesma forma que para Aratus pisonii, a presença de um pequeno gap entre as distâncias intra e intergrupos também constitui indicativos para a estruturação populacional dessa espécie. Também da mesma forma que para Aratus pisonii, a distância genética encontrada para os genes mais conservados $16 \mathrm{~S}$ e H3 poderia indicar que ambos os grupos ainda pertencem à mesma identidade taxonômica.

Considerando as demais espécies analisadas, as redes de haplótipos apresentadas evidenciam compartilhamento de haplótipos entre todas as localidades, não havendo diferenciação entre grupos. Os resultados da AMOVA revelaram que a maior parte da variação genética $(106.40 \%, 52.98 \%$ e $99.33 \%$ para Goniopsis cruentata, Sesarma rectum e Ucides cordatus, respectivamente) encontra-se dentro das localidades, indicando que a variabilidade entre indivíduos da mesma localidade é maior do que a variabilidade entre indivíduos de localidades diferentes. Para as espécies G. cruentata e U. cordatus, principalmente, os valores de FST (-0.06405 e 0.00662, respectivamente) e os valores de p a eles associados constituem indicativos da ausência de estruturação genética e restrição não significativa de fluxo gênico entre os indivíduos das localidades distintas. Especificamente para Ucides cordatus, os resultados aqui apresentados concordam com trabalhos prévios, nos quais não foram encontradas evidências significativas de estruturação geográfica entre algumas localidades brasileiras para essa espécie (Oliveira-Neto et al., 2007a e b).

Para Sesarma rectum, apesar da ausência de compartilhamento de haplótipos entre a localidade Brasil (CE) e as demais e os elevados valores dos índices de fixação (FCT = 0.14327; FSC $=0.38158 ; \mathrm{FST}=0.47018)$ para todas as hierarquias na aplicação da AMOVA 
com estruturação das populações, detectou-se que a maior parte da variação genética (52.98\%) encontra-se dentro das localidades e não entre os grupos sugeridos. Isso indica que, embora exista uma marcante estruturação genética, essa não é necessariamente congruente com as localidades geográficas.

Ainda, os dendrogramas obtidos para essas três espécies incluem todos os espécimes dentro de um único clado relativo a cada espécie, com a formação de subclados que incluem indivíduos de localidades distintas, não havendo padronização com relação às localidades geográficas. A formação desses subclados pode estar relacionada à elevada porcentagem de variação encontrada dentro das populações e à presença de muitos haplótipos individuais, principalmente para as espécies Goniopsis cruentata e Ucides cordatus, em comparação a Aratus pisonii e Uca thayeri.

Atentando-se às análises de distância genética para essas três espécies, a ausência de gaps dentro da variabilidade intraespecífica corrobora o compartilhamento de haplótipos e a ausência da formação de grupos genéticos distintos e ressalta o posicionamento dos espécimes como pertencentes a entidades taxonômicas únicas, assim como para os resultados dos genes $16 \mathrm{~S}$ e H3.

Considerando os dados das espécies Aratus pisonii e Uca thayeri, diferentemente das demais, a elevada estruturação populacional encontrada ao longo de toda a distribuição de ambas as espécies corrobora fortemente o modelo stepping-stones de fluxo gênico, segundo o qual o isolamento geográfico influencia consideravelmente o fluxo gênico e aumenta a diferenciação genética entre populações distantes (Kimura \& Weiss, 1964; Hellberg et al., 2002; Ituarte et al., 2012). A correlação com esse modelo torna-se ainda mais clara considerando-se o amplo limite de distribuição das espécies, além do ecossistema discreto habitado por elas, sendo inevitável que a distância geográfica e variações climáticas, ambientais e a presença de barreiras fisológicas ao longo de toda essa área geográfica tornem 
muito prováveis a redução do fluxo gênico entre áreas mais distantes (Keenan, 1994; Bilton et al., 2002; Gopurenko \& Hughes, 2002; Laurenzano et al., 2012). Ainda, esse modelo pôde ser confirmado, já que a distância genética foi significativamente correlacionada com a distância geográfica, conforme apontado pelo teste de Mantel para A. pisonii e U. thayeri e, inclusive, para Goniopsis cruentata, apesar da ausência de estruturação geográfica e populacional para essa espécie.

Dentre as espécies de Brachyura distribuídas ao longo dessa mesma área geográfica, no Atlântico Ocidental, e coabitantes do mesmo ecossistema de manguezais, ou sistemas muito similares, cujas variabilidades intraespecíficas foram analisadas, algumas estudadas anteriormente de forma isolada também apresentaram estruturação populacional, semelhante a Aratus pisonii e Uca thayeri. As espécies Uca rapax (Smith 1870) (Laurenzano et al., 2013), Neohelice granulata (Ituarte et al., 2012), Sesarma reticulatum (Say 1817) e Uca minax (LeConte 1855) (Felder \& Staton, 1994), por exemplo, apresentaram separação de grupos geográficos entre Caribe e Atlântico Sul, entre Brasil e Argentina e entre sudeste dos Estados Unidos e Golfo do México, respectivamente, dados que suportam nossos achados para algumas das espécies em estudo e o modelo de fluxo gênico aqui discutido.

Apesar da ausência de estruturação nas espécies Goniopsis cruentata, Sesarma rectum e Ucides cordatus, o compartilhamento de haplótipos encontrado entre as localidades brasileiras para todas as espécies, poderia, também, corroborar indiretamente o modelo stepping-stones, uma vez que não se encontrou restrição nos níveis de fluxo gênico, sugerindo alto potencial dispersivo entre algumas localidades, possivelmente conectadas por populações intermediárias, ou stepping-stones (Kimura \& Weiss, 1964; Hellberg et al., 2002; Ituarte et al., 2012; Laurenzano et al., 2013).

Essa proximidade genética, além de confirmar esse modelo, também indica que, obviamente, o limite aqui definido como sendo a geografia dos estados ou países para as 
populações não refletem os limites genéticos, uma vez que as espécies limitam-se a fatores geográficos ou fisiológicos e não políticos. É muito provável que as populações de todas as espécies se estendam por distâncias maiores, formando metapopulações, incluindo um número de populações distribuídas no espaço, conectadas por processos de fluxo gênico (Botsford et al., 1994; Fogarty \& Botsford, 2006), porém controladas por extinções e novas colonizações (Zucchi, 2002), além de outros fatores ambientais.

Além disso, possivelmente, o isolamento entre essas metapopulações não se dê apenas por distância geográfica, já que, por exemplo, as populações brasileiras constituintes de uma metapopulação encontram-se distantes umas das outras por distâncias superiores a 4000 km e dois tipos de estruturação populacional foram encontradas para espécies distribuídas ao longo dessa mesma área. Na realidade, espécies marinhas representam verdadeiros desafios à ideia de estruturação populacional e, consequentemente, especiação alopátrica, especialmente em táxons com alta capacidade de dispersão larval, a exemplo das espécies aqui analisadas, uma vez que a diferenciação genética nesses organismos pode ser altamente influenciada pelas capacidades dispersivas (Palumbi, 1994; Silva et al., 2010b; Gopurenko \& Hughes, 2002).

\subsection{FATORES BIÓTICOS E ABIÓTICOS ASSOCIADOS À ESTRUTURAČ̃̃O POPULACIONAL}

Considerando-se que a dispersão confere o intercâmbio de indivíduos e genes ao longo de uma extensão geográfica, histórias de vida com características de elevada capacidade de dispersão larval resultam em espécies que apresentem ampla distribuição geográfica, elevados tamanhos populacionais e altas taxas de fluxo gênico entre localidades distantes (Palumbi, 1994; Silva et al., 2010b). Assim, assumindo-se o transporte passivo, as espécies com larvas planctônicas com desenvolvimento longo apresentam maior potencial para serem carregadas por longas distâncias por meio das correntes oceânicas, em comparação com aquelas que 
apresentam desenvolvimento abreviado (Shanks, 2009). Dessa forma, esperar-se-ia que as espécies analisadas nesse estudo apresentariam o mesmo padrão de diferenciação genética, considerando-se que todas apresentam desenvolvimento larval estendido, com uma série prolongada de larvas planctônicas (Anger, 2001) e que poucas barreiras absolutas ao fluxo gênico ocorrem nos oceanos e, como resultado, mesmo regiões muito distantes podem estar conectadas geneticamente (Palumbi, 1994). No entanto, esse padrão esperado não foi detectado, demonstrando que cada espécie apresenta certas particularidades com relação à diferenciação genética, além das características atreladas ao tipo de desenvolvimento larval.

Ainda, algumas teorias sugerem que espécies com ampla capacidade dispersiva apresentam diferenciação genética reduzida e baixo potencial na resposta às pressões de seleção locais (Hedgecock, 1986; Palumbi, 1992; Palumbi, 2003) e muitos trabalhos demonstraram uma correlação positiva entre a duração da fase planctônica de uma determinada espécie e os níveis de fluxo gênico detectados entre alcances amostrados, sendo inversos à estruturação populacional (e.g., Waples, 1987; Williams \& Benzie, 1993; Doherty et al., 1995). Essa correlação constata-se, inclusive, em crustáceos decápodes, como, por exemplo, Cardisoma guanhumi (Oliveira-Neto et al., 2008) Uca annulipes (H. Milne Edwards 1837) (Silva et al., 2010b), Uca uruguayensis Nobili 1901 (Laurenzano et al., 2012), Macrobrachium olfersii (Wiegmann 1836) (Rossi \& Mantelatto, 2013), Uca maracoani (Latreille 1802) (Wieman et al., 2014), Artemesia longinaris Spence Bate 1888 (CarvalhoBatista et al., 2014), Scyllarides brasiliensis Rathbun 1906 (Rodríguez-Rey et al., 2014) e Farfantepenaeus paulensis (Pérez-Farfante 1967) (Teodoro et al., 2015).

No entanto, apesar da aparente elevada capacidade de dispersão, mesmo entre espécies com desenvolvimento larval pelágico, uma estruturação genética considerável tem sido encontrada em muitas espécies de crustáceos (Silva et al., 2010b; Burton \& Feldman, 1982), como, por exemplo, em Panulirus argus, (Latreille 1804) (Sarver et al., 1998), Panulirus 
interruptus (Randall 1840) (Perez-Enriquez et al., 2001), Palaemon elegans De Man 1892 (Reuchel \& Schubart, 2006), Hippolyte obliquimanus Dana 1852 (Terossi \& Mantelatto, 2012) e, inclusive, em muitas espécies de Brachyura, como Sesarma reticulatum (Felder \& Staton, 1994), Uca minax (Felder \& Staton, 1994), Uca pugilator (Bosc 1802) (Weese et al., 2009), Perisesarma guttatum (A. Milne-Edwards 1869) (Silva et al., 2010a), Neohelice granulata (Ituarte et al., 2012) e Uca rapax (Laurenzano et al., 2013). Mesmo entre espécies proximamente relacionadas, é possível encontrar graus drasticamente distintos de estruturação populacional e diversidade genética (e.g., Weber \& Levy, 2000; McMillen-Jackson \& Bert, 2003; McMillen-Jackson \& Bert, 2004; Pfeiler et al., 2005). Assim, essa aparente relação entre a duração larval dos estágios larvais e conectividade e fluxo gênico não pode ser considerada universal entre espécies habitantes dos ecossistemas marinhos e costeiros (Wieman et al., 2014), ainda mais considerando-se que se supõe a existência de barreiras ao menos fisiológicas ao longo de toda a distribuição das espécies (Gopurenko \& Hughes, 2002).

$\mathrm{Na}$ realidade, a relação inversa entre a capacidade de dispersão e diferenciação genética pode sim ser aplicada em alguns casos, como comprovado pelos dados aqui apresentados para as espécies Goniopsis cruentata, Sesarma rectum e Ucides cordatus, mas uma variedade de fatores pode influenciar o fluxo gênico na determinação da diferenciação genética que não somente história de vida e capacidade de dispersão, causando disparidades entre elevados potenciais de dispersão e fluxo gênico reduzido (Burton, 1983; Scheltema, 1986; Gopurenko \& Hughes, 2002). Esses fatores variam amplamente, dependendo da espécie, habitat, condições oceânicas locais, eventos geológicos passados e história recente e, apesar desses fatores raramente criarem barreiras efetivas e absolutas ao fluxo gênico, eles podem limitá-lo em algumas direções ou temporariamente, de forma que populações parcialmente isoladas ocorram comumente em sistemas marinhos (Palumbi, 1994). 
A restrição de fluxo gênico em espécies que aparentemente apresentam elevadas capacidades dispersivas pode ser o resultado de dois processos distintos, que poderiam justificar a diferença na estruturação populacional entre as espécies desse estudo: 1) a dispersão é reduzida devido à presença de uma barreira biótica ou abiótica; 2) se a dispersão é realizada com sucesso, os imigrantes falham em reproduzir-se no novo ambiente (Burton, 1983).

Considerando os fatores que podem constituir barreiras abióticas, as correntes marinhas apresentam efeitos óbvios na dispersão passiva das larvas planctônicas, já que muitos organismos com estágios de vida larvais pelágicos podem potencialmente conectar populações distantes via correntes (Taylor \& Hellberg, 2002; Burton, 1983; Hamasaki et al., 2015), mas a variação na estruturação genética encontrada entre espécies com estágios larvais extensos pode refletir diferenças no padrão de correntes oceânicas às quais as larvas estão expostas (Burton \& Feldman, 1982; Burton, 1983). No caso das espécies aqui utilizadas, o padrão de correntes, então, não poderia ser considerado como um fator que determinaria diferenças na estruturação populacional, uma vez que elas estão distribuídas ao longo da mesma área geográfica e são coabitantes de um mesmo ecossistema, estando, portanto, sujeitas à dispersão passiva por meio das mesmas correntes oceânicas. No entanto, uma vez que a dispersão, mesmo passiva, pode ser afetada pelo comportamento larval específico e pela interação das larvas com processos ecológicos e físicos (Burton, 1983; Barber et al., 2000; Hellberg et al., 2002; Palumbi, 2003; Shanks et al., 2003), padrões de correntes que supostamente agiriam no fluxo gênico podem ter efeitos distintos na estruturação genética de espécies marinhas codistribuídas, devido às características ecológicas e biológicas distintas entre as espécies (Rodríguez-Rey et al., 2014).

A circulação no Atlântico Sul, por exemplo, é bastante complexa e influencia fortemente o sistema de correntes no transporte das larvas de muitas espécies marinhas 
(Rodríguez-Rey et al., 2014). A Corrente Sul Equatorial sofre uma bifurcação no encontro com a costa brasileira, dividindo-se entre a Corrente Norte do Brasil, que flui em direção às Guianas e ao Mar do Caribe e a Corrente do Brasil, que, por sua vez, flui para o sul do país (Cirano et al., 2006). A intensidade e a bifurcação da Corrente Sul Equatorial pode ter um efeito na estruturação de muitas espécies marinhas vivendo nessa área, agindo como uma barreira ao fluxo gênico entre populações de cada lado dessa corrente (Rodríguez-Rey et al., 2014) (e.g., Puchnick-Legat \& Levy, 2006; Affonso \& Galetti Jr, 2007), o que poderia justificar, por exemplo, a estruturação populacional encontrada entre a região do Caribe (Costa Rica, Panamá e Venezuela) e o Brasil para Aratus pisonii, mas não afetaria a dispersão das demais espécies estudadas.

Ainda, a existência de muitas espécies que apresentam diferenciação geográfica significativa entre o Golfo do México e o Atlântico (e.g., Felder \& Staton, 1994; Young et al., 2002; Oliveira, 2014), ou que apresentam um hiato na distribuição correspondente a essa área, pode estar relacionada a uma complexa hidrodinâmica de correntes dentro do Golfo do México que atua como uma barreira geográfica à migração, impossibilitando o fluxo gênico entre essas áreas e isolando a região do Golfo (Weese et al., 2012; Oliveira, 2014). Aparentemente, a existência desse complexo hidrodinâmico não altera a troca de indivíduos e o fluxo gênico nas espécies aqui analisadas, uma vez que, mesmo nas espécies que apresentaram elevada estruturação populacional, não foi observado isolamento das localidades pertencentes ao Golfo do México. No entanto, o não compartilhamento de haplótipos entre as localidades dos EUA e do México para Aratus pisonii e Uca thayeri, embora a distância entre os haplótipos dessas localidades seja ínfima, em comparação com a distância entre grupos, indica, possivelmente, que essas localidades estejam iniciando um processo de restrição de fluxo gênico. 
Dentre outros fatores abióticos que influenciam a dispersão estão as temperaturas ou salinidades desfavoráveis presentes, por exemplo, em ambientes estuarinos. O ambiente estuarino pode ser um desafio ao processo de recrutamento, podendo constituir barreiras efetivas à dispersão larval, como mudanças drásticas de salinidade e temperatura que podem causar $100 \%$ de mortalidade das larvas que adentram essas massas (Burton \& Feldman, 1982; Burton, 1983).

Considerando a espécie Aratus pisonii, apesar do ciclo larval estendido e estimado em, aproximadamente, 30 dias (Warner, 1968), o contato das larvas com salinidades muito diferentes levaria a uma supressão de estágios larvais, consequentemente reduzindo o tempo de desenvolvimento (Diaz \& Bevilacqua, 1986, 1987). Além disso, as larvas que exibem um desenvolvimento mais curto podem ficar retidas próximas às populações parentais, reduzindo o fluxo gênico para outras áreas (Diaz \& Bevilacqua, 1987). No caso de Uca thayeri, da mesma forma que para Aratus pisonii, apesar do ciclo larval estendido e estimado em 40 dias (Anger et al., 1990), o desenvolvimento larval só se dá por completo em salinidades maiores de 20\%, com preferência por água do mar, indicando que áreas de estuários, por exemplo, podem atuar como barreiras, reduzindo o número de larvas que chegam a vida adulta e consequentemente reduzindo o fluxo genético para outras áreas (Anger et al., 1990).

Então, para essas duas espécies, a variação na salinidade pode estar conduzindo diferenças no desenvolvimento larval em algumas áreas, consequentemente retendo larvas próximas às populações de origem e agindo na estruturação genética. Esses pontos de variação de salinidade podem estar relacionados com a presença de ambientes estuarinos configurados pela foz de rios como o Amazonas ou o Orinoco, cujo volume de água doce que adentra as regiões costeiras altera drasticamente a salinidade, o que pode constituir uma grande barreira fisiológica à dispersão para muitos organismos, assim como postulado para outros táxons (Gilbert, 1972; Lessios et al., 2003; Boltovskoy et al., 1999; Terossi \& 
Mantelatto, 2012; Laurenzano et al., 2013). Ademais, considerando que os ecossistemas de manguezais e sistemas similares podem estar situados em diferentes tipos de corpos d'água, esses ecossistemas diferentes, distribuídos ao longo de uma ampla área geográfica, podem agir diferentemente no desenvolvimento larval.

Retomando aos fatores que podem constituir barreiras à dispersão, alguns fatores bióticos estão intimamente relacionados aos abióticos, tais como as respostas comportamentais das larvas à luz, salinidade, temperatura e pressão hidroestática, uma vez que as espécies apresentam capacidades comportamentais distintas ao longo do desenvolvimento pelágico (Burton \& Feldman, 1982; Burton, 1983). Outros fatores bióticos que influenciam na dispersão podem incluir disponibilidade de alimento e predação (Burton, 1983), que podem ser muito variados ao longo de uma ampla área geográfica.

Ainda, apesar do desenvolvimento larval planctônico de longa duração, algumas espécies apresentam mecanismos comportamentais que agem na prevenção da dispersão passiva, influenciando no fluxo gênico (Burton \& Feldman, 1982), o que também poderia justificar diferenças na estruturação populacional entre espécies com desenvolvimento larval estendido e habitantes de uma mesma área. Podem existir algumas vantagens evolutivas no controle comportamental sobre a dispersão passiva, já que isso pode previnir que as larvas sejam transportadas para um ambiente potencialmente hostil (Burton \& Feldman, 1982). Se persistir por muitas gerações, o mecanismo de retenção dos recrutas e o controle comportamental sobre a dispersão pode criar uma estrutura populacional em um nível no qual estratégias distintas de manejo ou conservação devam ser garantidas para diferentes populações (Taylor \& Hellberg, 2002; Burton \& Feldman, 1982). Além disso, a retenção persistente de larvas pode rapidamente permitir a evolução de caracteres de reconhecimento, como a cor, por exemplo, ou a especificidade de proteínas de fertilização, levando às populações a um isolamento reprodutivo (Taylor \& Hellberg, 2002). Assim, se as larvas são 
retidas próximas às populações parentais por comportamento (Burton \& Feldman, 1982) ou por mecanismos oceanográficos físicos (Cowen et al., 2000), então essas populações apresentam grandes probabilidades de diferenciação genética e adaptação local (Taylor \& Hellberg, 2002).

Com relação às espécies que apresentaram ausência de estruturação populacional, observa-se que a completa dispersão de suas larvas se dá de forma inerente à presença de barreiras geográficas ou fisiológicas, diferentemente do que foi postulado para Aratus pisonii e Uca thayeri. Principalmente para Goniopsis cruentata e Ucides cordatus constatou-se a inexistência de isolamento de regiões e o completo compartilhamento de haplótipos pertencentes a indivíduos oriundos de populações localizadas em regiões extremas ao longo da costa do Atlântico Ocidental, dos Estados Unidos ao estado de Santa Catarina, no Brasil. Uma vez que períodos de desenvolvimento longos podem ser interpretados como evidências de capacidade dispersiva relativamente alta (Waples, 1987; Laurenzano et al., 2012), esses padrões poderiam estar relacionados a desenvolvimentos larvais um pouco mais longos e menos sujeitos a fatores abióticos e comportamentais, embora todas as espécies adotadas nesse estudo apresentem desenvolvimento larval estendido.

Considerando o desenvolvimento larval para a espécie Ucides cordatus de, aproximadamente, 57 dias (Rodrigues \& Hebling, 1989), mais longo do que as demais espécies e sem restrições consideráveis para o desenvolvimento das larvas, mudanças bruscas na temperatura ou salinidade não impediriam a chegada dos indivíduos às outras regiões, antes que completem seu ciclo larval. Ademais, a baixa diferenciação genética ao longo de uma ampla área geográfica reflete uma estratégia de dispersão a longas distâncias e a falta de uma barreira geográfica ou fisiológica forte ou permanente ao fluxo genético na distribuição dessa espécie, favorecendo a formação de metapopulações (Waples, 1987; Laurenzano et al., 2012). 
A descrição do desenvolvimento larval completo para Goniopsis cruentata está ausente na literatura e apenas contempla os três primeiros estágios larvais que duram até 23 dias (Fransozo et al., 1998; Abrunhosa, 2007; Carvalho, 2010). No entanto, considerando que essa espécie apresenta alta fecundidade e que essa característica normalmente está associada a desenvolvimentos larvais mais longos (Waples, 1987; Moura \& Coelho, 2003), o desenvolvimento de G. cruentata poderia ser considerado maior do que, pelo menos, 30 dias, tempo suficiente para que longas distâncias sejam atingidas, independentemente de qualquer fator ambiental. Ademais, a proximidade genética encontrada ao longo de uma distância muito grande, sugere um alto poder de dispersão dessa espécie, assim como para Ucides cordatus (Waples, 1987; Laurenzano et al., 2012) e a estruturação genética dessas espécies pode ser considerada panmítica, devido a elevada quantidade de fluxo gênico ao longo de um amplo gradiente geográfico durante a fase larval planctônica (Silva et al., 2010b).

Com relação à espécie Sesarma rectum, o desenvolvimento larval mais curto (em torno de 20 dias) (Anger \& Moreira, 2004), em comparação a todas as demais espécies, inclusive aquelas que apresentaram estruturação populacional, justificaria o limite da distribuição geográfica da espécie e impossibilitaria uma comparação justa com as outras espécies. No entanto, a homogeneidade encontrada para essa espécie, com compartilhamento de haplótipos entre regiões muito distantes, pode estar associada à elevada capacidade dispersiva plantônica, ainda que por um tempo de duração reduzido (Waples, 1987; Laurenzano et al., 2012).

Assim, a importância de se compreender detalhes da ecologia larval na explicação da diferenciação genética entre as populações de crustáceos decápodes baseia-se no fato de que as larvas não devem ser consideradas partículas necessariamente passivas e a integração de dados comportamentais, fisiológicos e modelos oceanográficos com a duração dos estágios 
larvais torna possível o aumento do poder de explicação das histórias de vida larvais e diferenciação genética entre espécies (Kelly \& Palumbi, 2010).

\subsection{EVENTOS GEOLÓGICOS E HISTÓRIA DEMOGRÁFICA}

Retomando aos fatores que podem pode influenciar a determinação da diferenciação genética, além das questões já discutidas anteriormente, que englobam fatores bióticos e abióticos, existem alguns outros fatores, que não somente barreiras de fluxo gênico aparentes ou não, que podem auxiliar na identificação de agentes determinantes de estruturação populacional. Muitos fatores históricos, como eventos geológicos passados e história demográfica podem contribuir para a diferenciação genética populacional em organismos marinhos.

A descoberta de muitas espécies que apresentam diferenciação genética significante entre localidades ao longo do Oceano Atlântico Ocidental, principalmente entre Golfo do México, Caribe e Atlântico Norte, sugere que esses táxons têm vivenciado eventos de vicariância, nos quais as populações foram subdivididas e isoladas por barreiras geológicas ou ecológicas (Young et al., 2002). Esses complexos efeitos na biota podem constituir o resultado de perturbações ambientais associadas com a glaciação do hemisfério norte e a formação do Istmo do Panamá (Harrison, 2004).

A formação do Istmo do Panamá pode ser considerada como um processo bastante complexo que se estendeu pelos últimos 15 milhões de anos, com consequências na evolução de muitos organismos marinhos, não somente em linhagens que sofreram diferenciação Atlântico-Pacífico (Jones \& Hasson, 1985; Coates \& Obando, 1996). O fechamento do Istmo pode ter afetado fortemente a circulação oceânica, a distribuição de nutrientes, temperatura e salinidade do Atlântico Ocidental, afetando a evolução da fauna marinha nessa área (Allmon, 
2001; Coates \& Obando, 1996). Os efeitos nos organismos marinhos provavelmente têm ocorrido ao longo de milhões de anos e foram provavelmente distintos para diferentes táxons, de acordo com suas características ecológicas e de história de vida (Coates \& Obando, 1996).

Além do evento geológico do fechamento do Istmo do Panamá, cerca de 15 avanços e retrações glaciais ocorreram durante o Pleistoceno (2.6 a 10 mil anos atrás), principalmente nos últimos 3 milhões de anos, na América do Norte, modificando os padrões climáticos globais (Imbrie et al., 1992; Harrison, 2004; Rodríguez-Rey et al., 2014) e propiciando a existência de grandes áreas inabitáveis para muitas espécies. Ademais, cada um desses eventos produziu mudanças no nível do mar, no nível de nutrientes, nos padrões de temperatura de correntes, na intensidade de ressurgências e, consequentemente, na biogeografia, com modificações e consequências na distribuição e evolução de muitos organismos, propiciando o isolamento de populações do Atlântico e do Caribe, e promovendo o isolamento de estoques genéticos (Avise, 1992; Cronin, 1985,1991; Harrison, 2004).

Assim, alguns desses eventos passados e a combinação de alguns deles podem ter agido como fatores que propiciaram o isolamento e a consequente diferenciação genética de espécies que apresentam elevada estruturação populacional, ao longo do Oceano Atlântico Ocidental. Para as espécies Sesarma reticulatum e Uca minax, por exemplo, a elevada diferenciação genética encontrada entre as populações do Golfo do México e do sudeste dos Estados Unidos é compatível com modelos de períodos de contato e subsequente isolamento dos estoques genéticos das regiões do Golfo do México e do Atlântico durante os picos de avanços glaciais na América do Norte (Felder \& Staton, 1994).

Esse tipo de evento geológico também poderia propiciar o isolamento de populações da América do Norte e do Caribe, conforme visto para Aratus pisonii, já que avanços e recuos glaciais teriam promovido o isolamento de estoques genéticos dessas áreas (Harrison, 2004). Além disso, em períodos anteriores ao fechamento do Istmo do Panamá, correntes equatoriais 
fortes em direção ao oeste podem ter separado a América do Sul do Atlântico Norte/Golfo do México (Briggs, 1974), promovendo ou facilitando a divergência de grupos ao Norte e Sul da América (Harrison, 2004), o que poderia, possivelmente, explicar a separação dos grupos geográficos encontrados para áreas para A. pisonii e Uca thayeri. Ainda, apesar de os ciclos glaciais da América do Norte terem gerado menores impactos na região do Caribe tropical, com relação às flutuações e deslocamentos latitudinais (Felder \& Staton, 1994), populações habitando o nordeste da América do Sul e Trinidad \& Tobago, podem ter sido fortemente expostas a uma grande influência de sedimentos mistos, derivados de águas fluviais e marinhas e uma maior variabilidade na salinidade e turbidez da água, provocando o isolamento dessa região (Harrison, 2004).

Assim, os padrões de diferenciação genética observados para Aratus pisonii e Uca thayeri concordam com os cenários biogeográficos propostos para o Atlântico Ocidental e o Caribe, no qual mudanças e flutuações geológicas, climáticas e oceanográficas, resultantes do fechamento do Istmo do Panamá e de ciclos glaciais, promoveram divergência genética (Harrison, 2004). Ainda, de acordo com os dados de datação molecular obtidos para A. pisonii e $U$. thayeri, a separação entre os grupos geográficos de cada uma das espécies ocorreu durante os períodos Pleistoceno e Plioceno, respectivamente, consistentes com as mudanças e as flutuações climáticas e oceanográficas ocorridas anteriormente e após o fechamento do Istmo do Panamá e com os picos de glaciações.

Ainda, registros paleontológicos e dados biogeográficos sugerem que, durante as flutuações climáticas de ciclos interglaciais, a maioria das espécies marinhas sobreviveu às glaciações por meio de recuos em refúgios de baixa latitude, onde as condições climáticas eram menos extremas, isolando as populações (Bennet et al., 1991; Rodríguez-Rey et al., 2014). Posteriormente, essas populações teriam recolonizado outras áreas quando o clima tornou-se mais quente e favorável (Hewitt, 1999; Provan \& Bennett, 2008), de forma que as 
populações dos refúgios apresentem uma história demográfica com níveis mais elevados de diversidade do que as populações colonizadas a partir das áreas de refúgio (Maggs et al., 2008; Provan \& Bennett, 2008).

Esse cenário de áreas de refúgios pode ser claro para as espécies que apresentaram elevada estruturação populacional, como Aratus pisonii e Uca thayeri, dada a heterogeneidade genética observada ao longo da costa americana. Por outro lado, para as espécies com ausência de estruturação genética, a homogeneidade genética sugere que a expansão demográfica deve ter ocorrido simultaneamente ao longo da distribuição geográfica das espécies, estando associada a uma expansão geográfica (Rodríguez-Rey et al., 2014). A capacidade de dispersão a longas distâncias durante a expansão pode estar associada à manutenção dos níveis de diversidade de forma homogênea (Fayard et al., 2009).

Considerando as análises sobre diversidade haplotípica e nucleotíca, constatou-se que algumas populações das espécies estudadas retêm maiores valores para esses índices. Uma vez que esses índices revelam graus de divergência, seja entre nucleotídeos de um mesmo sítio, seja entre o conjunto de nucleotídeos que formam uma sequência, populações geneticamente distintas provavelmente apresentam diferentes valores de frequências haplotípicas e, consequentemente, diferentes índices de diversidade nucleotídica e haplotípica (Beaty et al., 2005). Os índices de diversidade haplotípica mais próximos a 1 estão relacionados a um grande número de indivíduos com haplótipos exclusivos, já que o cálculo desse índice baseia-se fundamentalmente na frequência dos diferentes haplótipos (Freeland, 2005). Assim, o elevado número de diferentes haplótipos para as espécies estudadas, principalmente Goniopsis cruentata, Uca thayeri e Ucides cordatus, bem como os elevados índices de diversidade haplotípica total, estão intimamente relacionados aos diferentes índices de diversidade detectados para as populações estudadas. Além disso, a diversidade de 
haplótipos para um dado conjunto de sequências pode refletir o tamanho da amostra e a estrutura populacional subadjacente da qual as amostras foram retiradas (Beaty et al., 2005).

Valores de diversidades nucleotídicas $(\pi)$ acima de 0.005 são considerados elevados e, combinados com elevados índices de divergência gênica (h), podem ser interpretados como dados resultantes de populações grandes e estáveis, com longa história evolutiva ou contato secundário entre diferentes linhagens (Grant \& Bowen, 1998), como pode ser o caso da grande maioria das localidades analisadas para as espécies Goniopsis cruentata e Ucides cordatus. Já valores de diversidades nucleotídicas $(\pi)$ reduzidos, abaixo de 0.005 , associados a altos valores divergência gênica (h), são indicativos de um acúmulo de mutações após um evento de retração populacional, seguido de um rápido crescimento populacional (Grant \& Bowen, 1998), o que, aparentemente, parece ocorrer com Aratus pisonii, Sesarma rectum e Uca thayeri, já que todas, ou senão a grande maioria, das localidades amostradas dessas espécies apresentaram valores reduzidos de $\pi$. Esses últimos dados podem estar de acordo com os cenários de retração populacional e refúgios ocorridos durante as mudanças e flutuações climáticas e oceanográficas no passado que possivelmente interferiram na diagramação da biota marinha, promovendo a diferenciação genética observada em A. pisonii e U. thayeri.

No entanto, embora esses índices possam estar associados aos eventos geológicos do passado que isolaram as populações de Aratus pisonii e Uca thayeri e possam explicar a variação encontrada para diferenciação genética entre as espécies abordadas nesse estudo, esses resultados não concordam com os índices obtidos para os testes de neutralidade Tajima $\mathrm{D}$ e $\mathrm{Fu} \mathrm{F}_{\mathrm{s}}$. Para Aratus pisonii, o teste de neutralidade não apontou valores significativamente diferentes de zero para todos os grupos, indicando que a hipótese nula de neutralidade das populações não pode ser rejeitada e a não ocorrência de eventos de expansão demográfica ou gargalo recente. Para todas as outras espécies, os testes apontaram resultados 
significativamente negativos, indicadores de expansão demográfica após evento de retração. Parte dos resultados para os testes de neutralidade pode ser corroborada pelo que foi encontrado nas redes de haplótipos para as espécies Goniopsis cruentata, Sesarma rectum e Ucides cordatus. Espécies que não apresentem divisões filogeográficas, podem exibir redes em formato de estrela, tipicamente formadas por haplótipos raros irradiando-se de um mais comum e mais compartilhado e distribuído (Ituarte et al., 2012; Hamasaki et al., 2015), como pode constatado para essas três espécies. Esse padrão é esperado em espécies que tenham sofrido expansão demográfica recente a partir de uma única fonte geográfica, sendo o haplótipo ancestral, o mais comum (Avise, 2009).

Retomando a questão de diversidade genética, apesar do reduzido número amostral para algumas populações, foi constatou-se que algumas apresentam elevados índices de diversidade, tais como Costa Rica para Aratus pisonii, EUA e Costa Rica para Goniopsis cruentata, Brasil (CE) para Sesarma rectum, Brasil (PE) para Uca thayeri e Brasil (PE) para Ucides cordatus, indicando que duas regiões, nordeste do Brasil e Costa Rica, sobressaem-se como portadoras de maiores índices de diversidade. Para essa comparação, é importante considerar as localidades com números amostrais mais elevados, uma vez que localidades com um amostral reduzido podem apresentar valores artificialmente reduzidos ou elevados, dependendo do número e frequência de haplótipos (Carvalho, 2011). Considerando a teoria dos refúgios glaciais acima discutida, essas regiões portadoras de maiores diversidades poderiam representar as populações dos refúgios, já que essas apresentam níveis mais elevados de diversidade do que as populações posteriormente colonizadas (Maggs et al., 2008; Provan \& Bennett, 2008). 


\subsection{A BIOLOGIA MOLECULAR NA GENÉTICA DA CONSERVACC̃̃o}

Considerando que as populações que abrigam maiores índices de diversidade, possivelmente, apresentam também maiores estoques genéticos, as populações pertencentes às regiões acima mencionadas devem, portanto, ser consideradas em análises futuras no estabelecimento de estratégias de manejo e preservação, caso as espécies aqui tratadas estejam, em algum momento, sujeitas à drástica redução de suas populações. Tratando-se especificamente de ambientes de manguezais, a ausência de diferenciação genética significativa entre populações habitantes de estuários tem implicações importantes em projetos de manejo, uma vez que o fluxo gênico considerável entre essas populações indica que elas são demograficamente interdependentes, com troca substancial de indivíduos entre estuários adjacentes (Oliveira-Neto et al., 2007a). Assim, no estabelecimento de estratégias de manejo, áreas de estuários bem preservadas e com elevados níveis de índices de diversidade podem atuar como fontes de larvas e novos indivíduos, permitindo a recolonização das áreas degradadas (Oliveira-Neto et al., 2007a).

A diversidade genética de uma população deve ser considerada quando na designação futura de centros de prioridade de conservação de espécies e no estabelecimento de estratégias de manejo (Schubart \& Huber, 2006), uma vez que o declínio da variação genética pode inibir, no futuro, a adaptação do organismo às mudanças ambientais e, consequentemente, limitar seu potencial evolutivo, podendo levar as populações a um possível risco de extinção (Schubart \& Huber, 2006; Frankham et al., 2008). Assim, qualquer fator que resulte na redução do tamanho da população abaixo de um nível crítico pode prejudicar a manutenção da variabilidade genética dentre uma população (Ryman et al., 1995) e muitos fatores, além dos naturais, tais como eventos geológicos ou desastres ambientais podem influenciar na 
redução severa do tamanho de uma população, caracterizando o efeito gargalo populacional (Spencer et al., 2000).

Um tema comum na genética de conservação tem sido o uso de variabilidade intraespecífica na identificação, principalmente, de populações que vivenciaram esses gargalos demográficos, com drásticas e temporárias reduções de tamanho que implicam em redução da diversidade (Spencer et al., 2000; Wright, 1931; Nei et al., 1975). Uma vez que esses efeitos podem influenciar a distribuição da variação genética entre e dentro da população, os efeitos genéticos da redução de populações em tamanho têm sido bastante estudados (Wright, 1931; Nei et al., 1975). Alguns estudos, inclusive, têm diagnosticado espécies exibindo elevada homogeneidade genética, caracterizando uma consequência do efeito gargalo populacional (e.g., Carvalho-Batista et al., 2014; Teodoro et al., 2015). Essa homogeneização genética combinada com uma distribuição restrita e limitada pode tornar as espécies mais sensíveis a mudanças consequentes de ações antrópicas (Teodoro et al., 2015).

A redução do tamanho populacional devido à ação antrópica pode também reduzir o número de migrantes e causar perda de variação genética entre as populações, reduzindo a capacidade de elas evoluírem no futuro (Ryman et al., 1995). Dentre as atividades antrópicas relacionadas à redução demográfica de populações naturais estão todas aquelas que causam degradação de habitat, sobrepesca e manipulação direta ou indireta de razões sexuais e taxas reprodutivas, como, por exemplo, atividades pesqueiras que selecionem tamanhos ou sexo (Ryman et al., 1995).

Embora os resultados desse estudo não indiquem reduções drásticas no número populacional ou na diversidade genética das espécies aqui abordadas, é necessária atenção às consequências futuras de efeitos gargalos nas populações, uma vez que a destruição de áreas de manguezais, a sobrepesca e a captura seletiva têm provocado alterações no tamanho de populações de caranguejos consumidos no Brasil, influenciando na distribuição da variação 
genética entre as populações das espécies (Spencer et al., 2000). Este pode ser o caso, por exemplo, de Ucides cordatus, uma vez que a perda de habitat, a sobrepesca e uma nova doença infecciosa (doença do caranguejo letárgico) causaram drásticas reduções nas populações nos últimos anos e estão reduzindo substancialmente os estoques dessa espécie (Boeger et al., 2005; Oliveira-Neto et al., 2007a e b), fazendo com que, atualmente, a espécie encontre-se classificada como "Quase Ameaçada (NT)", conforme últimas avaliações com utilização de critérios IUCN (International Union for Conservation of Nature and Natural Resources) ocorrida em três workshops em 2010 e 2013 (Fernando Mantelatto, comunicação pessoal; ICMBio, 2013).

Em suma, um complexo conjunto de fatores, incluindo ações antrópicas e eventos naturais, pode contribuir para a não recuperação dos estoques genéticos não somente de espécies de interesse econômico, mas também daquelas coabitantes, diretamente afetadas pela destruição dos hábitats (Amaral \& Jablonski, 2005), considerando-se a sensibilidade e a menor capacidade de recuperação dos ecossistemas de zonas costeiras (Almeida et al., 2001). Assim, a compreensão das mudanças genéticas e das respostas evolutivas em populações de espécies exploradas é determinante no estabelecimento de manejos e exploração sustentável dos recursos biológicos (Walsh et al., 2006; Teodoro et al., 2015). 
CONCLUSÕES 


\section{Conclusões}

Dados moleculares para os genes mitocondriais COI e $16 \mathrm{~S}$ revelaram dois padrões de diferenciação genética de espécies codistribuídas, indicando que esses genes constituem bons marcadores moleculares na avaliação de padrões de estruturação populacional. Encontrou-se elevada estruturação populacional para as espécies Aratus pisonii e Uca thayeri e ausência de estruturação para Goniopsis cruentata, Sesarma rectum e Ucides cordatus. A ausência de estruturação populacional pode estar relacionada às fases larvais planctônicas de maior duração e sem restrições consideráveis quanto às mudanças abióticas. Já as situações de elevada estruturação populacional podem ser explicadas por pequenas reduções na duração do estágio larval, comportamento das larvas e menores suportabilidade das larvas a diferentes salinidades. Assim, a variação na salinidade em alguns pontos ao longo da distribuição, como em áreas estuarinas, pode estar conduzindo diferenças no desenvolvimento larval, retendo larvas próximas às populações de origem e, consequentemente, agindo na estruturação genética. Além disso, os padrões de diferenciação genética observados para Aratus pisonii e Uca thayeri concordam com os cenários biogeográficos propostos para o Atlântico Ocidental, no qual mudanças e flutuações geológicas, climáticas e oceanográficas, resultantes do fechamento do Istmo do Panamá e de ciclos glaciais na América do Norte, promoveram divergência genética. 


\section{BIBLIOGRAFIA}




\section{Bibliografia}

Abele, L.G. 1992. A review of the Grapsid crab genus Sesarma (Crustacea: Decapoda: Grapsidae), with the description of a new genus. Smithsonian Contributions to Zoology Number 527. Smithsonian Institution Press, Washington, D.C., 60pp.

Abele, L.G. \& W. Kim. 1986. An illustrated guide to the marine decapod crustaceans of Florida. Florida Department of Enviromental Regulation, Technical Series, 8(1): $1-760$.

Abrunhosa, J.P. 2007. Aspectos morfofisiológicos de Goniopsis cruentata (Latreille, 1803) (Decapoda: Grapsidae), cultivado em laboratório. Programa de Pós-Graduação em Biologia Ambiental, Universidade Federal do Pará, Bragança (PA), 61 pp. Dissertação de Mestrado.

Affonso, P.R.A.M. \& P.M. Galetti Jr. 2007. Genetic diversity of three ornamental reef fishes (families Pomacanthidae and Chaetodontidae) from the Brazilian coast. Brazilian Journal of Biology, 67: 925-933.

Almeida, B.M.; Hamacher, C.; Alves, J.R.P; Pereira-Filho, O. \& R. Nehrer. 2001. Questões sócioambientais, pp. 19-34. In: J.R.P. Alves (ed), Manguezais: educar para proteger. FEMAR-SEMADS, Rio de Janeiro.

Allmon, W.D. 2001. Nutrients, temperature, disturbance, and evolution: a model for the late Cenozoic marine record of the western Atlantic. Palaeogeography Palaeoclimatology Palaeoecology, 166: 9-26.

Alongi, D.M. 2002. Present state and future of the world's mangrove forests. Environmental Conservation, 29(3): 331-349. 
Alongi, D.M. 2009. Paradigm shifts in mangrove biology, pp. 615-640. In: G.M.E. Perillo; E.Wolanski; D.R. Cahoon \& M.M. Brinkson (eds), Coastal Wetlands: an integrated ecosystem approach. Elsevier, Amsterdam.

Amaral, A.C. \& S. Jablonski. 2005. Conservação da biodiversidade marinha e costeira no Brasil. Megadiversidade, 1(1): 43-51.

Amaral, A.C.Z.; Migotto, A.E.; Turra, A. \& Y. Schaeffer-Novelli. 2010. Araçá: biodiversidade, impactos e ameaças. Biota Neotropica, 10(1): 219-264.

Anastasiadou, C.A. \& I.D. Leonardos. 2008. Morphological variation among populations of Atyaephyra desmarestii (Millet, 1831) (Decapoda: Caridea: Atyidae) from freshwater habitats of northwester Greece. Journal of Crustacean Biology, 28(2): 240-247.

Anger, K. 2001. The biology of Decapod crustacean larvae. Crustacean Issues, 14: 1-419.

Anger, K.; Montu, M.; Bakker, C. \& L.L. Loureiro-Fernandes. 1990. Larval development of Uca thayeri Rathbun, 1900 (Decapoda: Ocypodidae) reared in the laboratory. Meeresforschung, 32: 276-294.

Anger, K. \& G.S. Moreira. 2004. Biomass and elemental composition of eggs and larvae of a magrove crab, Sesarma rectum Randall (Decapoda: Sesarmidae) and comparison to a related species with abbreviated larval development. Scientia Marina, 68(1): 117126.

Avise, J.C. 1992. Molecular population structure and the biogeographic history of a regional fauna: a case history with lessons for conservation biology. Oikos, 63(1): 62-76.

Avise, J.C. 1994. Molecular markers, natural history and evolution. Chapmall \& Hall, New York, 511pp.

Avise, J.C. 1998. The history and purview of phylogeography: a personal reflection. Molecular Ecology, 7: 371-379. 
Avise, J.C. 2000. Phylogeography the history and formation of species. Harvard University Press, Cambridge, 447pp.

Avise, J.C. 2009. Phylogeography: retrospect and prospect. Journal of Biogeography, 36: 315.

Bandelt, H.J.; Forster, P. \& A. Röhl. 1999. Median-joining networks for inferring intraspecific phylogenies. Molecular Biology and Evolution, 16: 37-48.

Barber, P.H.; Palumbi, S.R.; Erdmann, M.V. \& M.K. Moosa. 2000. A marine Wallace’s line? Nature, 406: 692-693.

Beaty, T.H.; Fallin, M.D.; Hetmanski, J.B.; McIntosh, I.; Chong, S.S.; Ingersoll, R.; Sheng, X.; Chakraborty, R. \& A.F. Scott. 2005. Haplotype diversity in 11 candidate genes across four populations. Genetics, 171(1): 259-267.

Begg, G.A.; Friedland, K.D. \& J.B. Pearce. 1999. Stock identification and its role in stock assessment and fisheries management: an overview. Fisheries Research, 43: 1-8.

Bennett, K.D.; Tzedakis, P.C. \& K.J. Willis. 1991. Quaternary refugia of north European trees. Journal of Biogeography, 18: 103-115.

Benzie, J.A.H. 1998. Genetic structure of marine organisms and SE Asian biogeography, pp. 197-209. In: R. Hall \& J.D. Holloway (eds), Biogeography and geological evolution of SE Asia. Backhuys Publishers, Leiden.

Benzie, J.A.H. 2000. Population genetic structure in penaeid prawns. Aquaculture Research, 31: $95-119$.

Bezerra, L.E.A. 2012. The fiddler crabs (Crustacea: Brachyura: Ocypodidae: genus Uca) of the South Atlantic Ocean. Nauplius, 20(2): 203-246.

Bilodeau, A.L.; Felder, D.L. \& J.E. Neigel. 2005. Population structure at two geographic scales in the burrowing crustacean Callichirus islagrande (Decapoda, Thalassinidea): 
historical and contemporary barriers to planktonic dispersal. Evolution, 59(10): 21252138.

Bilton, D.T.; Paula, J. \& J.D.D. Bishop. 2002. Dispersal, genetic differentiation and speciation in estuarine organisms. Estuarine, Coastal and Shelf Science, 55: 937-952.

Boeger, W.A.; Pie, M.R.; Ostrensky, A. \& L. Patella. 2005. Lethargic crab disease: multidisciplinary evidence supports a mycotic etiology. Memórias do Instituto Oswaldo Cruz, 100: 161-167.

Bohonak, A.J. 1999. Dispersal, gene flow, and population structure. The Quarterly Review of Biology, 74(1): 21-45.

Boltovskoy, D.; M.J. Gibbons; L. Hutchings \& D. Binet. 1999. General biological features of the South Atlantic, pp. 1-42. In: D. Boltovskoy (ed), South Atlantic Zooplankton. Backhuys Publishers, Leiden.

Botsford, L.W.; Moloney, C.L.; Hastings, A.; Largier, J.L.; Powell, T.M; Higgins, K. \& J.F. Quinn. 1994. The influence and temporally varying oceanographic conditions on meroplanktonic metapopulations. Deep-Sea Research II, 41(1): 107-145.

Bowen, B.W.; Bass, A.L.; Muss, A.; Carlin, J. \& D.R. Robertson. 2006. Phylogeography of two Atlantic squirrelfishes (family Holocentridae): exploring links between pelagic larval duration and population connectivity. Marine Biology, 149: 899-913.

Bracken-Grissom, H.D.; Cannon, M.E.; Cabezas, P.; Feldmann, R.M.; Schweitzer, C.E.; Ahyong, S.T.; Felder, D.L.; Lemaitre, R. \& K.A. Crandall. 2013. A comprehensive and integrative reconstruction of evolutionary history for Anomura (Crustacea: Decapoda). BMC Evolutionary Biology, 13: 1-28.

Briggs, J.C. 1974. Marine Zoogeography. McGraw-Hill, New York, 475pp.

Burton, R.S. 1983. Protein polymorphisms and genetic differentiation of marine invertebrate populations. Marine Biology Letters, 4: 193-206. 
Burton, R.S. \& M.W. Feldman. 1982. Population genetics of coastal and estuarine invertebrates: does larval behavior influence population structure?, pp. 537-551. In: V.S. Kennedy (ed), Estuarine Comparisons. Academic Press, San Diego.

Calcagnotto, D. 2001. Taxas de evolução e o relógio molecular, pp. 52-63. In: S.R. Matioli (ed), Biologia Molecular e Evolução. Holos, Ribeirão Preto.

Carvalho, A.L. 2010. Avaliação do efeito da salinidade e alimentação no desenvolvimento inicial em larvas de três espécies de caranguejos de importância econômica em laboratório. Instituto de Zootecnia, Universidade Federal Rural do Rio de Janeiro, Seropédica (RJ), 61 pp. Dissertação de Mestrado.

Carvalho, P.H. 2011. Análises filogenéticas e filogeográficas do complexo de espécies Hypostomus ancistroides (Siluriformes: Loricariidae). Instituto de Biociências, Universidade de São Paulo, São Paulo (SP), 113 pp. Tese de Doutorado.

Carvalho-Batista, A.; Negri, M.; Pileggi, L.G.; Castilho, A.L.; Costa, R.C. \& F.L. Mantelatto. 2014. Inferring population connectivity across the range of distribution of the stiletto shrimp Artemesia longinaris Spence Bate, 1888 (Decapoda, Penaeidae) from DNA barcoding: implications for fishery management. ZooKeys, 457: 271-288.

Chace, F.A. \& H.H. Hobbs. 1969. The freshwater and terrestrial decapod crustaceans of the West Indies with special reference to Dominica. Smithsonian Institution Press, Washington D.C., 276pp.

Cintrón, G. \& Y. Schaeffer-Novelli. 1983. Introduccion a la ecologia del manglar. Rostlac, Montevideo, 109 pp.

Cirano, M.; Mata, M.M.; Campos, E.J.D. \& N.F.R. Deir. 2006. A circulação oceânica de larga-escala na região oeste do Atlântico Sul com base no modelo de circulação global OCCAM. Revista Brasileira de Geofísica, 24: 209-230. 
Clough, B.F. 1992. Primary productivity and growth of mangrove forests, pp. 225-249. In: A.I. Robertson \& D.M. Alongi (eds), Tropical Mangrove Ecosystems. American Geophysical Union, Washington.

Coates, A.G. \& J.A. Obando. 1996. The geologic evolution of the Central America Isthmus, pp. 21-57. In: J.B.C. Jackson; A.F. Budd \& A.G. Coates (eds), Evolution and Environment in Tropical America. University of Chicago Press, Chicago.

Coelho, P.A. 1965. Os crustáceos decápodos de alguns manguezais pernambucanos. Trabalhos do Instituto Oceanográfico, 7/8: 71-90.

Colgan, D.J.; McLauchlan, A.; Wilson, G.D.F.; Livingston, S.P.; Edgecombe, G.D.; Macaranas, J.; Cassis, G. \& M.R. Gray. 1998. Histone H3 and U2 snRNA sequences and arthropod molecular evolution. Australian Journal of Zoology, 46:419-437.

Cowen, R.K.; Kamazima, M.M.L.; Sponaugle, S.; Paris, C.B. \& D.B. Olson. 2000. Connectivity or marine populations: open or closed? Science, 287: 857-859.

Crane, J. 1975. Fiddler crabs of the world: Ocypodidae: genus $U \boldsymbol{c a}$. Princeton University Press, Princeton, 736pp.

Cronin, T.M. 1985. Speciation and stasis in marine Ostracoda: climatic modulation of evolution. Science, 227: 60-63.

Cronin, T.M. 1991. Pliocene shallow water palaeoceanography of the North Atlantic ocean based on marine ostracods. Quaternary Science Reviews, 10: 175-188.

Darriba, D.; Taboada, G.L.; Doallo, R. \& D. Posada. 2012. jModelTest 2: more models, new heuristics and parallel computing. Nature Methods, 9(8): 772.

Diaz, H. \& M. Bevilacqua. 1986. Larval development of Aratus pisonii (Milne Edwards) (Brachyura, Grapsidae) from marine and estuarine environments reared under different salinity conditions. Journal of Costal Research, 2(1): 43-49. 
Diaz, H. \& M. Bevilacqua. 1987. Early developmental sequences of Aratus pisonii (H. Milne Edwards) (Brachyura, Grapsidae) under laboratory conditions. Journal of Coastal Research, 3(1): 63-70.

Diele, K.; Koch, V. \& U. Saint-Paul. 2005. Population structure, catch composition and CPUE of the artisanally harvested mangrove crab Ucides cordatus (Ocypodidae) in the Caeté estuary, North Brazil: indications for overfishing? Aquatic Living Resources, 18: 169-178.

Dinerstein, E.; Olson, D.M.; Graham, D.; Webster, A.; Primm, S.; Bookbinder, M. \& G. Ledec. 1995. A conservation assessment of the terrestrial ecoregions of Latin America and the Caribbean. The World Bank in association with The World Wildlife Fund, Washington, D.C., 129pp.

Doherty, P.J.; Planes, S. \& P. Mather. 1995. Gene flow and larval duration in seven species of fish from the Great Barrier Reef. Ecology, 76(8): 2373-2391.

Duret, L. 2008. Neutral theory: The null hypothesis of molecular evolution. Nature Education, 1(1): 218.

Excoffier, L.; Laval, G. \& S. Schneider. 2005. Arlequin (version 3.0): an integrated software package for population genetics data analysis. Evolutionary Bioinformatics Online, 1: 47-50.

Excoffier, L.; Smouse, P.E. \& J.M. Quattro. 1992. Analysis of molecular variance inferred from metric distances among DNA haplotypes: application to human mitochondrial DNA restriction data. Genetics, 131: 479-491.

Fávero, L.P.; Belfiore, P.; Silva, F.L. \& B.L. Chan. 2009. Análise de dados: modelagem multivariada para tomada de decisões. Elsevier, Rio de Janeiro, 646pp.

Fayard, J.; Klein, E.K. \& F. Lefèvre. 2009. Long dispersal and the fate of a gene from the colonization front. Journal of Evolutionary Biology, 22: 2171-2182. 
Felder, D.L. \& J.L. Staton. 1994. Genetic differentiation in trans-floridian species complexes of Sesarma and Uca (Decapoda: Brachyura). Journal of Crustacean Biology, 14(2): 191:209.

Feliciano, C. 1962. Notes on the biology and economic importance of the land crab Cardisoma guanhumi Latreille of Puerto Rico. Special Contribution, Institute of Marine Biology, University of Porto Rico, Porto Rico, 13pp.

Felsenstein, J. 1973. Maximum likelihod and minimum-steps methods for estimating evolutionary trees from data on discrete characters. Systematic Biology, 22(3): 240249.

Felsenstein, J. 1981. Evolutionary trees from DNA sequences: a Maximum Likelihood approach. Journal of Molecular Evolution, 17: 368-376.

Fisher, R.A. 1930. The genetical theory of natural selection. Clarendon Press, Oxford, 265pp.

Fisher, R.A. 1936. The use of multiple measurements in taxonomic problems. Annals of Eugenics, 7: 179-188.

Foale, S. 1999. Local ecological knowledge and biology of the land crab Cardisoma hirtipes (Decapoda: Gecarcinidae) at West Nggela, Solomon Islands. Pacific Science, 53: $37-$ 49.

Fogarty, M.J. \& L.W. Botsford. 2006. Metapopulation dynamics of coastal decapods, pp. 371-320. In: J.P. Kritzer \& P.F. Sale (eds), Marine Metapopulations. Elsevier Academic Press, Burlington.

Folmer, O.; Black, M.; Hoeh, W.; Lutz, R. \& R. Vrijenhoek. 1994. DNA primers for amplification of mitochondrial cytochrome $c$ oxidase subunit I from diverse metazoan invertebrates. Molecular Marine Biology and Biotechnology, 3: 294-299. 
Frankham, R. 1995. Inbreeding and extinction: a threshold effect. Conservation Biology, 9: 792-799.

Frankham, R.; Ballou, J.D \& D.A. Briscoe. 2008. Genética da Conservação. Sociedade Brasileira de Genética, Ribeirão Preto, 262pp.

Fransozo, A.; Cuesta, J.A. \& M.L. Negreiros-Fransozo. 1998. The first zoeal stage of two species of Grapsidae (Decapoda, Brachyura) and a key to such larvae from the Brasilian coast. Crustaceana, 71(3): 331-343.

Freeland, J.R. 2005. Molecular Ecology. John Wiley \& Sons Ltd, Chichester, 388pp.

Fu, Y.X. 1997. Statistical tests of neutrality of mutations against population growth, hitchhiking and background selection. Genetics, 146: 915-925.

Gilbert, C.R. 1972. Characteristics of the western Atlantic reef-fish fauna. Quaterly Journal of the Florida Academy of Sciences, 35: 130-144.

Glaser, M. 2003. Interrelations between mangrove ecosystem, local economy and social sustainability in Caeté Estuary, North Brasil. Wetlands Ecology and Management, 11: $265-272$.

Gopurenko, D.G. 2002. Genetic structure within the distribution of the Indo-West Pacific mud crab Scylla serrata (Forskål, 1775). Australian School of Environmental Studies, Faculty of Environmental Sciences, Griffith University, Queensland, 131 pp. Tese de Doutorado.

Gopurenko, D. \& J.M. Hughes. 2002. Regional patterns of genetic structure among Australian populations of the mud crab, Scylla serrata (Crustacea: Decapoda): evidence from mitochondrial DNA. Marine Freshwater Research, 53: 849-857.

Grant, W.S. \& B.W. Bowen. 1998. Shallow population histories in deep evolutionary lineages of marine fishes: insights from sardines and anchovies and lessons for conservation. Journal of Heredity, 89(5): 415-426. 
Hair, J.F.; Anderson, R.E.; Tatham, R.L. \& W.C. Black. 2005. Análise multivariada de dados. Bookman, Porto Alegre, 593pp.

Hall, T.A. 1999. BioEdit: a user-friendly biological sequence alignment editor and analysis program for Windows 95/98/NT. Nucleic Acids Symposium Series, 41: 95-98.

Hamasaki, K.; Iizuka, C.; Ojima, A.; Sugizaki, M.; Sugimoto, A.; Shigeki, D. \& S. Kitada. 2015. Genetic diversity and demographic history of the terrestrial hermit crabs Birgus latro and Coenobita brevimanus in the north-western Pacific region. Journal of Crustacean Biology, 35(6): 793-803.

Harrison, J.S. 2004. Evolution, biogeography, and the utility of mitochondrial 16S and COI genes in phylogenetic analysis of the crab Austinixa. Molecular Phylogenetic and Evolution, 30: 743-754.

Hedgecock, D. 1986. Is gene flow from pelagic larval dispersal important in the adaptation and evolution of marine invertebrates? Bulletin of Marine Science, 39: 550-564.

Hellberg, M.E. 1994. Relationships between inferred levels of gene flow and geographic distance in a philopatric coral, Balanophyllia elegans. Evolution, 48(6): 1829-1854.

Hellberg, M.E.; Burton, R.S.; Neigel, J.E. \& S.R. Palumbi. 2002. Genetic assessment of connectivity among marine populations. Bulletin of Marine Science, 70(1): 273-290.

Hewitt, G.M. 1999. Post-glacial re-colonization of European biota. Biological Journal of the Linnean Society Linnean Society of London, 68: 87-112.

ICMBio. 2013. Lista das espécies avaliadas. http://www.icmbio.gov.br/portal/biodiversidade/fauna-brasileira/estado-deconservacao/2783-crustaceos. Acessado em 18 de Fevereiro de 2016.

Imbrie, J.; Boyle, E.A.; Clemens, S.C.; Duffy, A.; Howard, W.R.; Kukla, G.; Kutzbach, J.; Martinson, D.G.; McIntyre, A.; Mix, A.C.; Molfino, B.; Morley, J.J.; Peterson, L.C.; Pisias, N.G.; Prell, W.L.; Raytoo, M.E.; Shackletons, N.J. \& J.R. Toggweiler. 1992. 
On the structure and origin of major glaciation cycles. 1. Linear responses to Milankovitch forcing. Paleoceanography, 7: 701-738.

Ituarte, R.B.; D’Anatro, A.; Luppi, T.A.; Ribeiro, P.D.; Spivak, E.D.; Iribarne, O.O. \& E.P. Lessa. 2012. Population structure of the SW Atlantic estuarine crab Neohelice granulata throughout its range: a genetic and morphometric study. Estuarine and Coasts, 35: 1249-1260.

Jones, D.S. \& P.F. Hasson. 1985. History and development of the marine invertebrate faunas separated by the Central American Isthmus, pp 325-355. In: F.G. Stehli \& S. Webb (eds), The Great American Biotic Interchange. Plenum Press, New York.

Keenan, C.P. 1994. Recent evolution of population structure in australian barramundi, Lates calcarifer (Bloch): an example of isolation by distance in one dimension. Australian Journal of Marine and Freshwater Research, 45: 1123-1148.

Kelly, R.P. \& S.R. Palumbi. 2010. Genetic structure among 50 species of the northeastern Pacific rocky intertidal community. PLoS ONE, 5(1): e8594.

Khattree, R. \& D.N. Naik. 2000. Multivariate data reduction and discrimination with SAS software. SAS Institute Inc., Cary, 558pp.

Kimura, N. 1980. A simple method for estimating evolutionary rates of base substitutions through comparative studies of nucleotide sequences. Journal of Molecular Evolution, 16: 111-120.

Kimura, M. \& G.H. Weiss. 1964. The stepping stone model of population structure and the decrease of genetic correlation with distance. Genetics, 49: 561-576.

Kramer, R.; Van Schaik, C. \& J. Johnson. 1997. Last stand: protected areas and the defense of tropical biodiversity. Oxford University Press, Oxford, 242pp. 
Laurenzano, C.; Farías, N.E. \& C.D. Schubart. 2012. Mitochondrial genetic structure of two populations of Uca uruguayensis fails to reveal an impact of the Rio de la Plata on gene flow. Nauplius, 20(1): 15-25.

Laurenzano, C.; Mantelatto, F.L.M. \& C.D. Schubart. 2013. South American homogeneity versus Caribbean heterogeneity: population genetic structure of the western Atlantic fiddler crab Uca rapax (Brachyura, Ocypodidae). Journal of Experimental Marine Biology and Ecology, 449: 22-27.

Lee, S.Y. 1999. Ecology of tropical mangals: the need for a synthesis of physical and biotic influences on ecosystem structure and function. Australian Journal of Ecology, 24, 355-366.

Lessios, H.A.; Kane, J. \& D.R. Robertson. 2003. Phylogeography of the pantropical sea urchin Tripneustes: contrasting patterns of population structure between oceans. Evolution, 57: 2026-2036.

Lu, G. \& L. Bernatchez. 1999. Correlated trophic specialization and genetic divergence in sympatric lake whitefish ecotypes (Coregonus clupeaformis): support for the ecological speciation hypothesis. Evolution, 53(5): 1491-1505.

Maggs, C.A.; Castilho, R.; Foltz, D.; Henzler, C.; Jolly, M.T.; Kellt, J.; Olsen, J.; Perez, K.E.; Stam, W.; Väinölä, R.; Viard, F. \& J. Wares. 2008. Evaluating signatures of glacial refugia for north Atlantic benthic marine taxa. Ecology, 89: S108-S122.

Mantel, N. 1967. The detection of disease clustering and a generalized regression approach. Cancer Research, 27: 209-220.

Mantelatto, F.L.; Robles, R.; Biagi, R. \& D.L. Felder. 2006. Molecular analysis of the taxonomic and distributional status for the hermit crab genera Loxopagurus Forest, 1964 and Isocheles Stimpson, 1858 (Decapoda, Anomura, Diogenidae). Zoosystema, 28(2): 495-506. 
Mantelatto, F.L.; Robles, R. \& D.L. Felder. 2007. Molecular phylogeny of the western Atlantic species of the genus Portunus (Crustacea, Brachyura, Portunidae). Zoological Journal of the Linnean Society, 150(1): 211-220.

Mantelatto, F.L.; Pardo, L.M.; Pileggi, L.G. \& D.L. Felder. 2009a. Taxonomic re-examination of the hermit crab species Pagurus forceps and Pagurus comptus (Decapoda: Paguridae) by molecular analysis. Zootaxa, 2133: 20-32.

Mantelatto, F.L.; Robles, R.; Schubart, C.D. \& D.L. Felder. 2009b. Molecular phylogeny of the genus Cronius Stimpson, 1860, with reassignment of C. tumidulus and several American species of Portunus to the genus Achelous De Haan, 1833 (Brachyura: Portunidae), pp. 537-551. In: J.W. Martin; K.A. Crandall \& D.L. Felder (eds), Crustacean Issues: Decapod Crustacean Phylogenetics. Taylor \& Francis/CRC Press, Boca Raton.

Martin, J.W.; Crandall, K.A. \& D.L. Felder. 2009. Preface, pp. ix-xi. In: J.W. Martin, K.A. Crandall \& D.L. Felder (eds), Crustacean Issues Vol.18. CRC Press, New York.

Maxson, R.; Cohn, R. \& L. Kedes. 1983. Expression and organization of histone genes. Annual Review of Genetics, 17: 239-277.

Mayr, E. 1977. Populações, espécies e evolução. Nacional e EDUSP, São Paulo, 485pp.

McLaughlin, P.A. 1980. Comparative morphology of recent Crustacea. W.H. Freeman and Company, San Francisco, 177pp.

McLay, C.L.; Hinnendael, F.; Lavery, S. \& R. Riquelme-Bugueño. 2011. Morphological and molecular comparison of Hemigrapsus crenulatus (Milne Edwards, 1837) (Brachyura: Varunidae) from New Zealand and Chile: was miss Rathbun right? Journal of Crustacean Biology, 31(4): 582-589.

McMillen-Jackson, A.L. \& T.M. Bert. 2003. Disparate patterns of population genetic structure and population history in two sympatric penaeid shrimp species 
(Farfantepenaeus aztecus and Litopenaeus setiferus) in the eastern United States. Molecular Ecology, 12: 2895-2905.

McMillen-Jackson, A.L. \& T.M. Bert. 2004. Mitochondrial DNA variation and population genetic structure of the blue crab Callinectes sapidus in the eastern United States. Marine Biology, 145: 769-777.

Meirmans, P.G. \& P.W. Hedrick. 2011. Assessing population structure: $F_{\mathrm{ST}}$ and related measures. Molecular Ecology Resources, 11: 5-18.

Melo, G.A.S. 1996. Manual de identificação dos Brachyura (caranguejos e siris) do litoral brasileiro. Plêidae, São Paulo, 603pp.

Moritz, C.; Dowling, T.E. \& W.M. Brown. 1987. Evolution of animal mitochondrial DNA: relevance for population biology and systematics. Annual Review of Ecology and Systematics, 18(1): 269-292.

Morrison, D.F. 1976. Multivariate statistical methods. McGraw Hill, New York, 415pp.

Moura, N.F.O. \& P.A. Coelho. 2003. Fecundidade de Goniopsis cruentata (Latreille, 1803) (Crustacea, Brachyura, Grapsidae) no manguezal do Rio Paripe - Pernambuco Brasil. Tropical Oceanography, 31(2): 127-133.

Negri, M.; Pileggi, L.G. \& F.L. Mantelatto. 2012. Molecular barcode and morphological analyses reveal the taxonomic and biogeographic status of the striped-legged hermit crab species Clibanarius sclopetarius (Herbst, 1796) and Clibanarius vittatus (Bosc, 1802) (Decapoda: Diogenidae). Invertebrates Systematics, 26: 561-571.

Nei, M. 1987. Molecular Evolutionary Genetics. Columbia University Press, New York, 512pp.

Nei, M.; Marayuma, T. \& R. Chakraborty. 1975. The bottleneck effect and genetic variability in populations. Evolution, 29: 1-10. 
Ng, P.K.L.; Guinot, D. \& P.J.R. Davie. 2008. Systema Brachyuororum: Part I. An annotated checklist of extant brachyuran crabs of the world. Raffles Bulletin of Zoology, 17: 1286.

Niem, V.H. 1993. Phylogenetic e systematic position of Sesarma rubripes Rathbun, 1897 (Brachyura: Grapsidae). Zoologische Mededelingen, 67(12): 185-195.

Niem, V.H. 1996. Phylogenetic relationships among american species of Sesarma (Subgenus Armases) (Brachyura, Grapsidae). Crustaceana, 69(3): 330-348.

Oliveira, C.M.C.A. 2014. Variabilidade genética do camarão de água doce Atya scabra (Leach, 1816) ao longo de sua distribuição geográfica (Decapoda, Caridea, Atyidae). Faculdade de Filosofia, Ciências e Letras de Ribeirão Preto, Universidade de São Paulo, Ribeirão Preto (SP), 88 pp. Monografia de Bacharelado.

Oliveira-Neto, J.F.; Boeger, W.A.; Pie, M.R.; Ostrensky, A. \& D.B. Hungria. 2007a. Genetic structure of populations of the mangrove crab Ucides cordatus (Decapoda: Ocypodidae) at local and regional scales. Hydrobiologia, 583: 69-76.

Oliveira-Neto, J.F.; Pie, M.R.; Boeger, W.A.; Ostrensky, A. \& R.A. Baggio. 2007b. Population genetics and evolutionary demography of Ucides cordatus (Decapoda: Ocypodidae). Marine Ecology, 28(4): 460-469.

Oliveira-Neto, J.F.; Pie, M.R.; Chammas, M.A.; Ostrensky, A. \& W.A. Boeger. 2008. Phylogeography of the blue land crab, Cardisoma guanhumi (Decapoda: Gecarcinidae) along the Brazilian coast. Journal of the Marine Biological Association of the United Kingdom, 88(7): 1417-1423.

Olson, D.M.; Dinerstein, E.D.; Wikramanayake, E.D.; Burgess, N.D.; Powell, G.V.N.; Underwood, E.C.; D’Amico, J.A.; Itoua, I.; Strand, H.E.; Morrison, J.C.; Loucks, C.J.; Allnutt, T.F.; Ricketts, T.H.; Kura, Y.; Lamoreux, J.F.; Wettengel, W.W.; Hedao, P. \& 
K.R. Kassem. 2001. Terrestrial ecoregions of the world: a new map of life on Earth. BioScience, 51(11): 933-938.

Oshiro, L.M.Y; Silva, R. \& Z.S. Silva. 1998. Composição da fauna de braquiúros (Crustacae: Decapoda) da Baía de Sepetiba - RJ. Nauplius, 6: 31-40.

Palumbi, S.R. 1992. Marine speciation on a small planet. Tree, 7(4): 114-118.

Palumbi, S.R. 1994. Genetic divergence, reproductive isolation, and marine speciation. Annual Review of Ecology and Systematics, 25: 547-572.

Palumbi, S.R. 2003. Population genetics, demographic connectivity, and the design of marine reserves. Ecological Applications, 13(1): s146-s158.

Palumbi, S.R. \& J. Benzie. 1991. Large Mitochondrial DNA differences between morphologically similiar penaeid shrimp. Molecular Marine Biology and Biotechnology, 1(1): 27-34.

Pereira, S.L.; Miyaki, C.Y. \& C.A.M Russo. 2001. Reconstrução filogenética: Métodos probabilísticos, pp 117-129. In: S.R. Matioli (ed), Biologia Molecular e Evolução. Holos, Ribeirão Preto.

Perez-Enriquez, R.; Veja, A.; Avila, S. \& J.L. Sandoval. 2001. Population genetics of red spiny lobster (Panulirus interruptus) along the Baja California Peninsula, Mexico. Marine and Freshwater Research, 52: 1541-1549.

Pfeiler, E.; Hurtado, L.A.; Knowles, L.L.; Torre-Cosío, J.; Bourrillón-Moreno, L.; MárquezFarías, J.F. \& G. Montemayor-López. 2005. Population genetics of the swimming crab Callinectes bellicosus (Brachyura: Portunidae) from eastern Pacific Ocean. Marine Biology, 146: 559-569.

Pileggi, L.G. \& F.L. Mantelatto. 2010. Molecular phylogeny of the freshwater prawn genus Macrobrachium (Decapoda, Palaemonidae), with emphasis on the relationships among selected American species. Invertebrate Systematics, 24: 194-208. 
Pimentel, R.A. 1979. Morphometrics. Kendall/Hunt, Dubuque, 275pp.

Prado-Ratti, A. 2004. Taxonomia e biogeografia da superfamília Grapsoidea MacLeay (excl. Gecarcinidae) (Crustacea: Decapoda: Brachyura) do Atlântico Ocidental. Instituto de Biociências, Universidade de São Paulo, São Paulo (SP), 376 pp. Tese de Doutorado.

Provan, J. \& K.D. Bennett. 2008. Phylogeographic insights into cryptic glacial refugia. Trends in Ecology \& Evolution, 23: 564-571.

Puchnick-Legat, A. \& J.A. Levy. 2006. Genetic structure of Brazilian populations of white mouth croaker Micropogonias furnieri (Perciformes: Sciaenidae). Brazilian Archives of Biology and Technology, 49: 429-439.

Reuchel, S. \& D.C. Schubart. 2006. Phylogeny and geographic differentiation of AtlantoMediterranean species of the genus Xantho (Crustacea: Brachyura: Xanthidae) based on genetic and morphometric analyses. Marine Biology, 148: 853-866.

Ridd, P.V. 1996. Flow through animal burrows in mangrove creeks. Estuarine, Coastal and Shelf Science, 43: 617-625.

Robertson, A.I. 1986. Leaf-burying crabs: their influence on energy flow and export from mixed mangrove forests (Rhizophora spp.) in northeastern Australian Journal of Experimental Marine Biology and Ecology, 102: 237-248.

Robertson, A.I. \& S.J.M. Blaber. 1992. Plankton, epibenthos and fish communities, pp. 173224. In: A.I. Robertson \& D.M. Alongi (eds), Tropical Mangrove Ecosystems. American Geophysical Union, Washington.

Rodrigues, M.D. \& N.J. Hebling.1989. Ucides cordatus cordatus (Linnaeus, 1763) (Crustacea, Decapoda). Complete larval development under laboratory conditions and its systematic position. Revista Brasileira de Zoologia, 6(1): 147-166. 
Rodríguez-Rey, G.T.; Solé-Cava, A.M. \& C. Lazoski. 2014. Genetic homogeneity and historical expansions of the slipper lobster, Scyllarides brasiliensis, in the south-west Atlantic. Marine and Freshwater Research, 65: 59-69.

Ronquist, F.; Teslenko, M.; Van der Mark, P.; Ayres, D.; Darling, A.; Höhna, S.; Larget, B.; Lui, L.; Suchard, M.A. \& J.P. Huelsenbeck. 2012. MrBayes 3.2: efficient Bayesian phylogenetic inference and model choice across a large model space. Systematic Biology, 61: 539-542.

Rosenberg, M.S. 2001. The systematics and taxonomy of fiddler crabs: a phylogeny of the genus Uca. Journal of Crustacean Biology, 21(3): 839-869.

Rossi, N. \& F.L. Mantelatto. 2013. Molecular analysis of the freshwater prawn Macrobrachium olfersii (Decapoda, Palaemonidae) supports the existence of a single species throughout its distribution. PLoS ONE, 8: 1-12.

Rozas, J. \& R. Rozas. 1999. DnaSP version 3.0: an integrated program for molecular population genetics and molecular evolution analysis. Bioinformatics, 15(2): 174175.

Ryman, N.; Utter, F. \& L. Laikre. 1995. Protection of intraspecific biodiversity of exploited fishes. Reviews in Fish Biology and Fisheries, 5: 417-446.

Sambrook, J.; Fritsch, E.F. \& T. Maniatis. 1989. In vitro amplification of DNA by the Polymerase Chain Reaction, pp. 2-35. In: J. Sambrook; E.F. Fritsch \& T. Maniatis (eds), Molecular cloning: a laboratory manual. Cold Spring Harbor Laboratory Press, New York.

Santos, S.; Schneider, H. \& I. Sampaio. 2003. Genetic differentiation of Macrodon ancylodon (Sciaenidae, Perciformes) populations in Atlantic coastal waters of South America as revealed by mtDNA analysis. Genetics and Molecular Biology, 26(2): 151-161. 
Sarver, S.K.; Silberman, J.D. \& P.J. Walsh. 1998. Mitochondrial DNA sequence evidence supporting the recognition of two subspecies or species of the Florida spiny lobster Panulirus argus. Journal of Crustacean Biology, 18(1): 177-186.

Schaeffer-Novelli, Y. 1991. Manguezais brasileiros. Universidade de São Paulo, São Paulo (SP), 42pp. Tese de Livre Docência.

Scheltema, R.S. 1971. Larval dispersal as a means of genetic exchange between geographically separated populations of shallow-water benthic marine gastropods. Biological Bulletin, 140(2): 284-322.

Scheltema, R.S. 1975. Relationship of larval dispersal, gene-flow, and natural selection to geographic variation of benthic invertebrates in estuaries and along coastal regions, pp. 372-391. In: L.E. Cronin (ed), Estuarine Research. Academic Press, New York.

Scheltema, R.S. 1986. On dispersal and planktonic larvae of benthic invertebrates: an eclectic overview. Bulletin of Marine Science, 39(2): 290-322.

Schubart, C.D. 2011. Reconstruction of phylogenetic relationships within Grapsidae (Crustacea: Brachyura) and comparison of trans-isthmian versus amphi-atlantic gene flow based on mtDNA. Zoologischer Anzeiger, 250: 472-478.

Schubart, C.D.; Cuesta, J.A.; Diesel, R. \& D.L. Felder. 2000a. Molecular phylogeny, taxonomy and evolution of nonmarine lineages within the American grapsoid crabs (Crustacea: Brachyura). Molecular Phylogenetics and Evolution, 15(2): 179-190.

Schubart, C.D.; Neigel, J.E. \& D.L. Felder. 2000b. Use of the mitochondrial 16S rRNA gene for phylogenetic and population studies of Crustacea. Crustacean Issues, 12: 817830.

Schubart, C.D. \& M.G.J. Huber. 2006. Genetic comparisons of german populations of the stone crayfish, Austropotamobius torrentium (Crustacea: Astacidae). Bulletin Français de la Pêche et de la Pisciculture, 380-381: 1019-1028. 
Shanks, A.L. 2009. Pelagic larval duration and dispersal distance revisited. Biological Bulletin, 216: 373-385.

Shanks, A.L.; Grantham, B.A. \& M.H. Carr. 2003. Propagule dispersal distance and the size and spacing of marine reserves. Ecological Applications, 13: S159-S169.

Shih, H.T.; Naruse, T. \& P.K.L. Ng. 2010. Uca jocelynae sp. nov., a new species of fiddler crab (Crustacea: Brachyura: Ocypodidae) from the Western Pacific. Zootaxa, 2337 : $47-62$.

Shulman, M.J. \& E. Bermingham. 1995. Early life histories, ocean currents, and the population genetics of Caribbean Reef Fishes. Evolution, 49(5): 897-910.

Silva, I.C.; Mesquita, N \& J. Paula. 2010a. Genetic and morphological differentiation of the mangrove crab Perisesarma guttatum (Brachyura: Sesarmidae) along an East African latitudinal gradient. Biological Journal of the Linnean Society, 99(1): 28-46.

Silva, I.C.; Mesquita, N \& J. Paula. 2010b. Lack of population structure in the fiddler crab Uca annulipes along an East African latitudinal gradient: genetic and morphometric evidence. Marine Biology, 157: 1113-1126.

Slatkin, M. 1987. Gene flow and the geographic structure of natural populations. Science, 236: 787-792.

Spalding, M.; Blasco, F. \& C. Field. 1997. World Mangrove Atlas. The International Society for Mangrove Ecosystems, Okinawa, 178pp.

Spencer, C.C.; Neigel, J.E. \& P.L. Leberg. 2000. Experimental evaluation of the usefulness of microsatellite DNA for detecting demographic bottlenecks. Molecular Ecology, 9: $1517-1528$.

Stamatakis, A. 2006. RAxML-VI-HPC: maximum likelihood-based phylogenetic analyses with thousands of taxa and mixed models. Bioinformatics, 22(21): 2688-2690. 
Stamatakis, A.; Hoover, P. \& J. Rougemont. 2008. A rapid bootstrap algorithm for the RAxML web servers. Systematic Biology, 57(5): 758-771.

Taissoun, E. 1974. El cangrejo de tierra Cardisoma guanhumi (Latreille) en Venezuela. I. Métodos de captura, comercialización e industrializacion. II. Medidas e recomendaciones para la conservación de la espécie. Boletín del Centro de Investigaciones Biológicas (Universidad del Zulia), 10: 1-36.

Tajima, F. 1989. Statistical method for testing the neutral mutation hypothesis by DNA polymorphism. Genetics, 123: 585-595.

Tavaré, S. 1986. Some probabilistic and statistical problems in the analysis of DNA sequences, pp. 57-86. In: R.M. Miura (ed), Lectures on mathematics in the life sciences Vol. 17. American Mathematical Society, Providence.

Taylor, M.S. \& M.E. Hellberg. 2002. Genetic evidence for local retention of pelagic larvae in a Caribbean reef fish. Science, 299: 107-109.

Teodoro, S.S.A.; Terossi, M.; Costa, R.C. \& F.L. Mantelatto. 2015. Genetic homogeneity in the commercial pink shrimp Farfantepenaeus paulensis revealed by COI barcoding gene. Estuarine, Coastal and Shelf Science, 166: 1-7.

Terossi, M. \& F.L. Mantelatto. 2012. Morphological and genetic variability in Hippolyte obliquimanus Dana, 1852 (Decapoda, Caridea, Hippolytidae) from Brasil and the Caribbean Sea. Crustaceana, 85(6): 685-712.

Thiercelin, N. \& C.D. Schubart. 2014. Transisthmian differentiation in the tree-climbing mangrove crab Aratus H. Milne Edwards, 1853 (Crustacea, Brachyura, Sesarmidae), with description of a new species from the tropical eastern Pacific. Zootaxa, 3793(5): 545-560.

Thoma, B.P.; Guinot, D. \& D.L. Felder. 2014. Evolutionary relationships among American mud crabs (Crustacea: Decapoda: Brachyura: Xanthoidea) inferred from nuclear and 
mitochondrial markers, with comments on adult morphology. Zoological Journal of the Linnean Society, 170: 86-109.

Thompson, J.D.; Higging, D.G. \& T.J. Gibson. 1994. CLUSTALW: Improving the sensitivity of progressive multiple sequence alignment through sequence weighting specific gap penalties and weight matrix choice. Nucleic Acids Research, 22: 4673-4680.

Timm, L. \& H.D. Bracken-Grissom. 2015. The forest for the tress: evaluating molecular phylogenies with an emphasis on higher-level Decapoda. Journal of Crustacean Biology, 35(5): 577-592.

Tourinho, J.L.; Solé-Cava, A.M. \& C. Lazoski. 2012. Cryptic species within the commercially most important lobster in the tropical Atlantic, the spiny lobster Panulirus argus. Marine Biology, 159: 1897-1906.

Tsang, L.M.; Schubart, C.D.; Ahyong, S.T.; Lai, J.C.Y.; Au, E.Y.C.; Chan, T.Y.; Ng; P.K.L. \& K.H. Chu. 2014. Evolutionary history of the true crabs (Crustacea: Decapoda: Brachyura) and the origin of freshwater crabs. Molecular Biology and Evolution, 31(5): 1173-1187.

Türkay, M. 1983. The systematic position of an Australian mangrove crab Heloecius cordiformis (Crustacea: Decapoda: Brachyura). Australian Museum Memoir, 18 (Papers from the Conference on the biology and evolution of Crustacea): 107-111.

Tzeng, T.D. 2004. Stock identification of sword prawn Parapenaeopsis hardwickii in the East China Sea and Taiwan Strait inferred by morphometric variation. Fisheries Science, 70: 758-764.

Varjabedian, E. 1995. Impactos sobre os manguezais, pp. 49-52. In: Y. Schaefer-Novelli (ed), Manguezal: Ecossistema entre a terra e o mar. Caribbean Ecological Research, São Paulo. 
Vergamini, F.G.; Pileggi, L.G. \& F.L. Mantelatto. 2011. Genetic variability of the amazon river prawn Macrobrachium amazonicum (Decapoda, Caridea, Palaemonidae). Contributions to Zoology, 80(1): 67-83.

Von Sternberg, R. 1994. Systematic implications of color pattern polymorphism in Goniopsis pulchra (Decapoda: Brachyura: Grapsidae) from Ecuador. Proceedings of the Biological Society of Washington, 107(4): 721-728.

Waldman, J.R.; Grossfield, J. \& I. Wrigin. 1988. Review of stock discrimination techniques for striped bass. North-American Journal of Fisheries Management, 8: 410-425.

Walsh, M.R.; Munch, S.B.; Chiba, S. \& D.O. Conover. 2006. Maladaptive changes in multiple traits caused by fishing: impediments to population recovery. Ecology Letters, 9(2): 142-148.

Waples, R.S. 1987. A multispecies approach to the analysis of gene flow in marine shore fishes. Evolution, 41(2): 385-400.

Warner, G.F. 1967. The life history of the mangrove tree crab Aratus pisonii. Journal of Zoology, 153: 321-335.

Warner, G.F. 1968. The larval development of the mangrove tree crab Aratus pisonii (H. Milne Edwards), reared in the laboratory (Brachyura, Grapsidae). Crustaceana, 2: 249-258.

Weber, L.I. \& J.A. Levy. 2000. Genetic population structure of the swimming crab Callinectes danae (Crustacea: Decapoda) in southern Brazil. Hydrobiologia, 420: 203-210.

Weese, D.A.; Fujita, Y.; Hidaka, M. \& S.R. Santos. 2012. The long and short of it: genetic variation and population structure of the anchialine atyid shrimp Caridina rubella on Miyako-Jima, Japan. Journal of Crustacean Biology, 32(1): 109-117. 
Weese, D.A.; McLain, D.K.; Pratt, A.E. \& Q.Q. Fang. 2009. Population structure of the Atlantic sand fiddler crab Uca pugilator along the eastern cost of US revealed by molecular data. Current Zoology, 55(2): 150-157.

Wieman, A.C.; Berendzen, P.B; Hampton, K.R.; Jang, J.; Hopkins, M.J.; Jurgenson, J.; McNamara, J.C. \& C.L. Thurman. 2014. A panmictic fiddler crab from the coast of Brazil? Impact of divergent ocean currents and larval dispersal potential on genetic and morphological variation in Uca maracoani. Marine Biology, 161: 173-185.

Williams, A.B. 1984. Shrimps, lobsters and crabs of the Atlantic coast of the Eastern United States, Maine to Florida. Smithsonian Institution Press, Washington D.C., 550pp.

Williams, S.T. \& J.A.H Benzie. 1993. Genetic consequences of long larval life in the starfish Linckia laevigata (Echinodermata: Asteroidea) on the Great Barrier Reef. Marine Biology, 117: 71-77.

Wilson, E.O. 1988. The current state of biological diversity. In: E.O. Wilson \& F.M. Peter (eds), Biodiversity. National Academy Press, Washington.

Winkelmann, I.; Campos, P.F.; Strugnell, J.; Cherel, Y.; Smith, P.J.; Kubodera, T.; Allcock, L.; Kampmann, M.L.; Schroeder, H.; Guerra, A.; Norman, M.; Finn, J.; Ingao, D.; Clarke, M. \& M.T.P. Gilbert. 2013. Mitochondrial genome diversity and population structure of the giant squid Architeuthis: genetics sheds new light on one of the most enigmatic marine species. Procedings of the Royal Society B, 280: 20130273.

Wright, S. 1931. Evolution in Medelian populations. Genetics, 16: 97-159.

Wright, S. 1943. Isolation by distance. Genetics, 38: 114-138.

Wright, S. 1965. The interpretation of population structure by F-statistics with special regard to systems of mating. Evolution, 19(3): 395-420.

Wright, S. 1978. Evolution and the Genetics of Populations. Vol. 4. Variability Within 
and Among Natural Populations. University of Chicago Press, Chicago.

Young, A.M.; Torres, C.; Mack, J.E. \& C.W. Cunningham. 2002. Morphological and genetic evidence for vicariance and refugium in Atlantic and Gulf of Mexico populations of the hermit crab Pagurus longicarpus. Marine Biology, 140: 1059-1066.

Zucchi, M.I. 2002. Análise da estrutura genética de Eugenia dysenterica DC utilizando marcadores RAPD e SSR. Escola Superior de Agricultura "Luiz de Queiroz", Universidade de São Paulo, Piracicaba (SP), 130 pp. Tese de Doutorado. 